\title{
Nature and Reactivity of Oxygen and Hydroxide on Metal Surfaces
}

\author{
A Dissertation \\ Presented to \\ the faculty of the School of Engineering and Applied Science \\ University of Virginia
}

\author{
In Partial Fulfillment \\ of the requirements for the Degree \\ Doctor of Philosophy \\ in Chemical Engineering
}

by

David Douglas Hibbitts

August

2012 


\section{APPROVAL SHEET}

The dissertation

is submitted in partial fulfillment of the requirements

for the degree of

Doctor of Philosophy

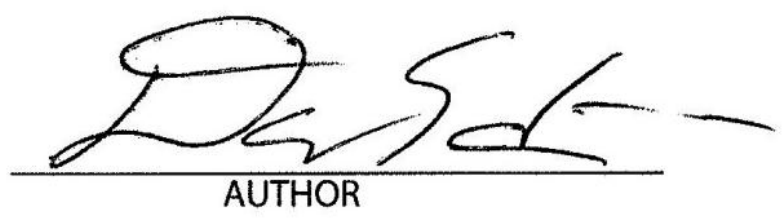

The dissertation has been read and approved by the examining committee:

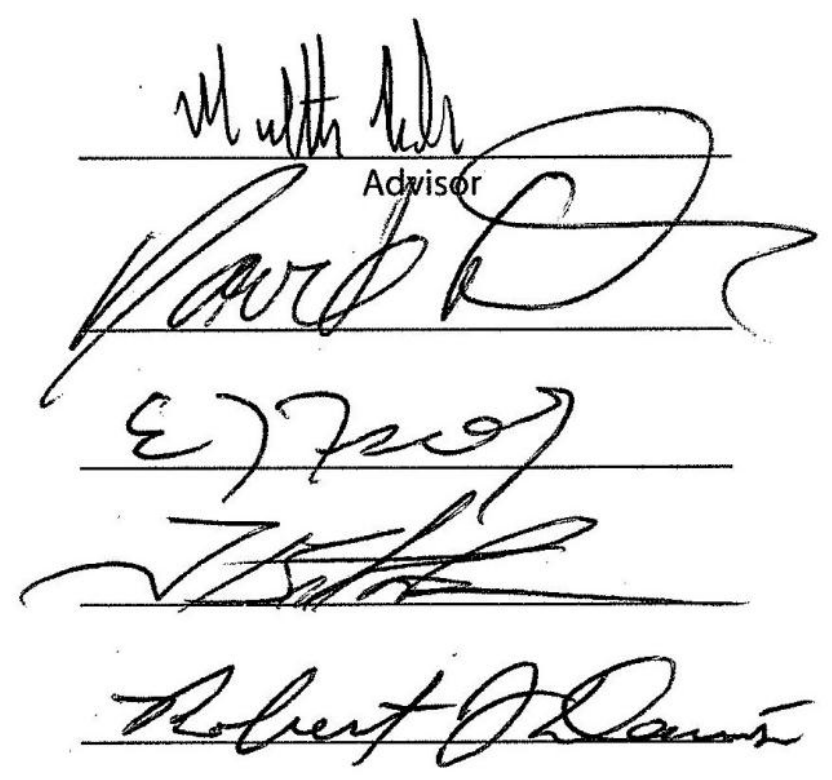

Accepted for the School of Engineering and Applied Science:

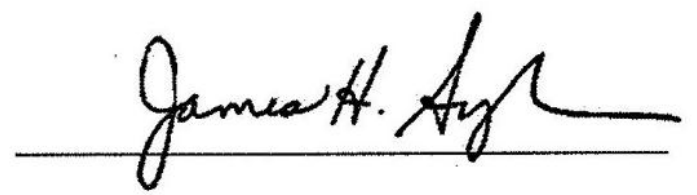

Dean, School of Engineering and Applied Science

August 


\section{Abstract}

The catalytic oxidation of hydrocarbons and oxygenates used in the conversion of petroleum and biomass to chemicals and fuels results in formation of surface oxygen intermediates, namely chemisorbed oxygen $\left(\mathrm{O}^{*}\right)$ and hydroxide $\left(\mathrm{OH}^{*}\right)$ that can alter the reaction mechanism and control the overall catalytic activity and selectivity. The role of these intermediates and their influence on bond activation depends upon the nature of the metal that is used to carry out catalytic transformations, the specific reaction and the coverage of the adsorbate on the surface. For instance, $\mathrm{O}^{*}$ or $\mathrm{OH}^{*}$ can act as a Brønsted base reducing the barrier for $\mathrm{O}-\mathrm{H}$ or $\mathrm{C}-\mathrm{H}$ activation of alkanes or alcohols through $\mathrm{H}$-abstraction mechanisms. Another example is when a bimetallic alloy is composed of a noble metal and an oxophilic metal, in which $\mathrm{OH}^{*}$ bound to the oxophilic metal can act as a Brønsted acid that can catalyze dehydration and hydrogenolysis reactions.

On coinage (group IB) metals, the binding energy of $\mathrm{O}^{*}$ or $\mathrm{OH}^{*}$ is very weak compared to the binding energy on platinum group metals. Furthermore, the charge on the oxygen atom is more negative when $\mathrm{O}^{*}$ or $\mathrm{OH}^{*}$ is bound to coinage metals than when it's bound to platinum group metals as there is significant charge transfer from the filled dband to the oxygen. The weak binding energy and increased charge on the oxygen enable $0^{*}$ or $\mathrm{OH}^{*}$ to act as a Brønsted base under a wide range of conditions, thus allowing for the $\mathrm{H}$ abstraction of mildly acidic $\mathrm{O}-\mathrm{H}$ bonds in alcohols and even non-acidic $\mathrm{C}-\mathrm{H}$ bonds, such as those found in alkanes.

On platinum group metals, $\mathrm{O}^{*}$ binds too strongly to the metal surface and is not basic enough, even at the bridge site, to help activate the $\mathrm{C}-\mathrm{H}$ bonds of alkanes or alcohols. At higher coverages, the $0^{*}$ binding energy decreases, which leads to a greater basicity on the $\mathrm{O}^{*}$ (reducing the barrier for $\mathrm{O}^{*}$-assisted $\mathrm{C}$ - $\mathrm{H}$ activation of methane). However, the $\mathrm{O}^{*}$ assisted activation does have a lower barrier for $\mathrm{O}-\mathrm{H}$ activations, such as the initial 
activation of alcohols. For $\mathrm{OH}^{*}$-assisted R-H activation, the activation barriers are lower than the $\mathrm{O}^{*}$-assisted barriers for all metals except $\mathrm{Cu}$ and $\mathrm{Ag}$.

During alcohol oxidation at high $\mathrm{pH}$, the presence of hydroxide, in solution and adsorbed on the surface, can act as a base to catalyze the initial deprotonation of the alcohol, the hydride elimination of the alkoxide (on the surface) and the nucleophilic addition to the aldehyde, leading to the acid product. As the $\mathrm{pH}$ of the system decreases, the rate decreases until a point when a change in the mechanism occurs, in which direct $\mathrm{C}-\mathrm{H}$ activation of the $\alpha \mathrm{C}-\mathrm{H}$ bond or $\mathrm{O}^{*}$-assisted $\mathrm{O}-\mathrm{H}$ activation of the hydroxyl group takes over (depending on the coverage of $0^{*}$ ).

During the hydrogenolysis of alcohols or cyclic ethers, noble metal catalysts (such as $\mathrm{Rh}$ or $\mathrm{Pt}$ ) are promoted with partially reduced oxides of oxophilic metals (such as $\mathrm{MoO}_{\mathrm{x}}$ or $\mathrm{ReO}_{\mathrm{x}}$ ). These partially reduced oxides hydroxylate in the presence of water, generating a $\mathrm{OH}^{*}$ intermediate strongly bound to the oxophilic metal center, thus resulting in a Brønsted acid site. The acidity of such sites was studied for a wide range of alloys, to determine which combinations might produce acidic $\mathrm{OH}^{*}$. Further investigations studied the effect of the position and form of the alloy as well as the relationship between the acidity and the binding energy of $\mathrm{O}^{*}$, the covalent strength of the $\mathrm{O}-\mathrm{H}$ bond and the binding energy of ammonia. The results indicate that as the binding energy of $0^{*}$ becomes stronger the strength of the $\mathrm{O}-\mathrm{H}$ bond decreases thus increasing the acidity of the $\mathrm{OH}^{*}$. The binding energy of ammonia increases with increasing acidity non-linearly.

Through these studies, a set of rules can be established to determine the conditions for $\mathrm{O}^{*}$ or $\mathrm{OH}^{*}$ to act as a base or $\mathrm{OH}^{*}$ as an acid when adsorbed on a metal surface (or alloy). 


\section{Contents}

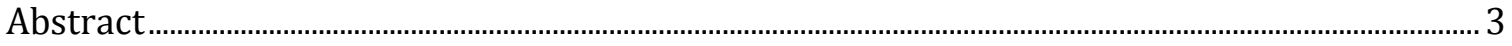

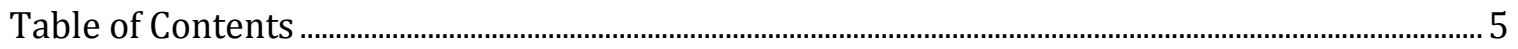

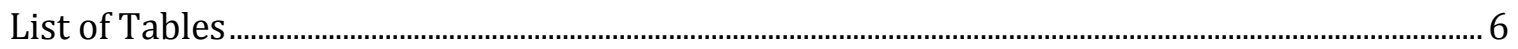

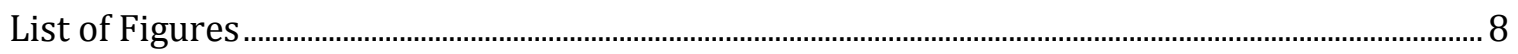

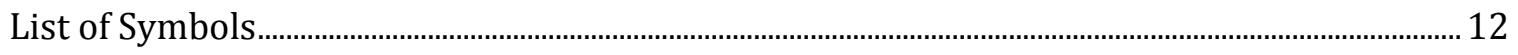

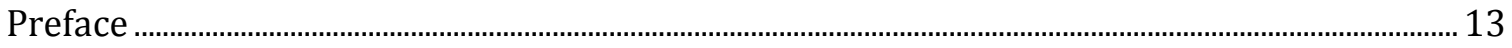

Chapter 1 - Nature of $\mathbf{0}^{*}$ and $\mathrm{OH}^{*}$ on Metal Surfaces at Various Coverages …………......... 16

Binding State of $\mathrm{O}^{*}$ and $\mathrm{OH}^{*}$ on Closed-Packed and (100) Transition Metal Surfaces .................................. 17

Hydrogen Bonding of $O^{*}$ on Closed-Packed Transition Metal Surfaces ............................................................. 34

Nature of $\mathrm{O}^{*}$ and $\mathrm{OH}^{*}$ at Higher Coverages on (111) Surfaces .................................................................... 46

Chapter 2 - Aqueous-Phase Oxidation of Alcohols over Au, Pt and Pd Catalysts ............. 53

Reactivity of the Gold/Water Interface during Selective Oxidation Catalysis................................................. 54

Influence of Oxygen and Alkalinity during Selective Oxidation of Ethanol over Pd Catalysts .................... 64

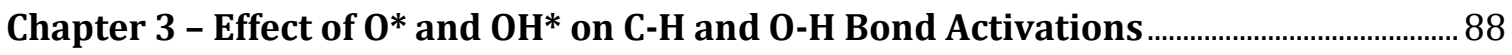

Methane Activation over Clean and Oxygen-Covered Transition Metal Surfaces............................................. 89

Evaluation of the Brønsted Basicity of $\mathrm{O}^{*}$ and $\mathrm{OH}^{*}$ on Transition Metal Surfaces ...................................... 107

Chapter 4 - Hydrogenolysis of Polyols and Cyclic Ethers over Bimetallic Alloys.......... 131

Selective Hydrogenolysis of Polyols and Cyclic Ethers over Bifunctional Surface Sites on Rhodium-

Rhenium Catalysts

Acidity of Hydroxides on Alloys of Noble Metals and Oxophilic Oxide Promoters such as Rh-ReOx ........ 138

Summary and Recommendations for Future Work ................................................................... 156

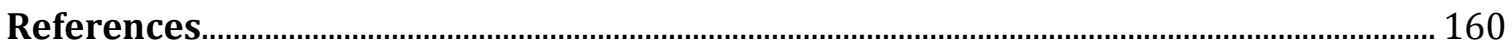




\section{List of Tables}

Table 1.1. Binding Energy of $0^{*}$ on Various Transition Metals and Unit Cell Sizes....................................19

Table 1.2. Charge Transfer to $0^{*}$ on Closed-Packed $3 \times 3$ Transition Metal Surfaces. ...............................21

Table 1.3. Binding Energy of $0 *$ on $3 \times 3$ Closed-Packed Surfaces of Various Transition Metals and Binding Modes.

Table 1.4. Charge Distribution of $0^{*}$ Bound on a $3 \times 3$ Closed-Packed Metal Surface of Various Metals and Binding Modes.

Table 1.5. Binding Energy of $O^{*}$ on $3 \times 3$ (100) Surfaces of Various Transition Metals and Binding Modes.

Table 1.6. Binding Energy of $\mathrm{OH}^{*}$ on $3 \times 3$ Closed-Packed Surfaces of Various Transition Metals and Binding Modes.

Table 1.7. Charge Distribution of $\mathrm{OH}^{*}$ Bound on Various Transition Metals and Binding Modes..........31

Table 1.8. Binding Energy of $\mathrm{OH}^{*}$ on (100) Surfaces of Various Transition Metals and Binding Modes.

Table 1.9. Average Hydrogen Bond Interactions between $\mathrm{H} 2 \mathrm{O}$ and $\mathrm{O}^{*}$ on All Studied Transition Metals. 38

Table 1.10. Average Hydrogen Bond Interactions between $\mathrm{H} 2 \mathrm{O}$ and $\mathrm{O}^{*}$ on Coinage Metals 39

Table 1.11. Average Hydrogen Bond Interactions between $\mathrm{H} 2 \mathrm{O}$ and $\mathrm{O}^{*}$ on fcc crystal structure PGMs (Rh, Pd, Ir, and Pt).

Table 1.12. Average Hydrogen Bond Interactions between $\mathrm{H} 2 \mathrm{O}$ and $\mathrm{O}^{*}$ on hcp crystal structure PGMs (Ru and Os).

Table 1.13. Average Hydrogen Bond Interactions between $\mathrm{H} 2 \mathrm{O}$ and $\mathrm{O}^{*}$ on oxophilic metals (Tc and $\mathrm{Re})$.

Table 1.14. Binding and Hydrogen Binding Energies (HBE) of $\mathrm{OH}^{*}$ on a $3 \times 3 \mathrm{Pt}(111)$ Surface. . .51

Table 2.1: Glycerol Oxidation over $\mathrm{Au} / \mathrm{C}, \mathrm{Au} / \mathrm{TiO} 2, \mathrm{Pt} / \mathrm{C}$ and $\mathrm{Pd} / \mathrm{C}$ in Liquid Water. . .56

Table 2.2: Ethanol Oxidation over $\mathrm{Au} / \mathrm{C}, \mathrm{Au} / \mathrm{TiO} 2$ and $\mathrm{Pt} / \mathrm{C}$ in Liquid Water. . .56

Table 2.3: Selected reaction energies $(\mathrm{kJ} / \mathrm{mol})$ and activation barriers $(\mathrm{kJ} / \mathrm{mol})$ for the oxidation of ethanol to acetic acid over Pt(111) and Au(111).

Table 2.4. Three-step scheme for surface DFT calculations. . .71

Table 2.5. Complete Summary of Modeled Oxidation Reactions. 80 
Table 2.6. Complete Summary of Modeled ORR Reactions.

Table 3.1. The 0 adsorption energies, methane activation barriers and bond distances associated with each TS geometry on $10^{*}(0.11 \mathrm{ML})$ on metal surfaces.

Table 3.2. The activation barriers and bond distances for each TS geometry with oxygen coverage on a Pt(111) surface, as illustrated in Figure 3.5.... 101

Table 3.3. The barriers and bond distances for each TS geometry with oxygen on a $\operatorname{Ag}(111)$ surface, as illustrated in Figure 3.7. 103

Table 4.1. Hydrogenolysis of HMTHF and MTHF over Rh-ReOx/C (1:0.5).

Table 4.2. Selected results from surface monoalloy sites. 144

Table 4.3. Regression Data for Figure 4.11... . .151 


\section{List of Figures}

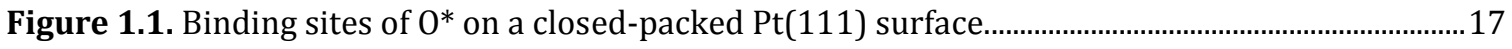

Figure 1.2. Binding energy of $0^{*}$ on $3 \times 3$ closed-packed metal surfaces.

Figure 1.3. A comparison of the binding energy of $0^{*}$ computed with two different sets of potentials and density functionals..

Figure 1.4. Charge of $0^{*}$ on $3 \times 3$ closed-packed metal surfaces.

Figure 1.5. Correlation between the diffusion barrier and binding energy on various transition metal surfaces. Parity plot between the diffusion barrier estimated from binding energies of the bridge site compared to fully modeled diffusion barriers from Section 1.2.

Figure 1.6. Binding sites of $\mathrm{O}^{*}$ on a $\mathrm{Pt}(100)$ surface

Figure 1.7. Binding energy profile from bridge to hollow sites for $0^{*}$ on (100) surfaces of fcc metals.

Figure 1.8. Periodic trend for the difference between bridge and hollow sites for $0^{*}$ adsorption on (100) surfaces of fcc metals.

Figure 1.9. Binding energy of $\mathrm{OH}^{*}$ on closed-packed metal surfaces.

Figure 1.10. Correlation between the binding energy of $\mathrm{O}^{*}$ and $\mathrm{OH}^{*}$ on closed-packed metal surfaces.

Figure 1.11. Positions of water around $\mathrm{O}^{*}$ in 3 -fold and bridge sites, shown for $\mathrm{Cu}$

Figure 1.12. Reaction path and charge transfer diagrams for the diffusion of $0^{*}$ from the fcc site to the hcp site.

Figure 1.13. Reaction path and charge transfer diagrams for the diffusion of 0 * from the fcc site to the hcp site with water present.

Figure 1.14. Potential energy surface (PES) calculations for the adsorption of $\mathrm{O}^{*}$ on a $3 \times 3 \mathrm{Pd}(111)$ surface with increasing $0^{*}$ coverage.

Figure 1.15. Differential binding energy of $O^{*}$ from $1 / 9$ to $1 \mathrm{ML}$ on selected fcc metals.

Figure 1.16. Binding energy of different amounts of $\mathrm{OH}^{*}$ on a $3 \times 3 \mathrm{Pt}(111)$ surface. 50

Figure 1.17. The interaction of one $\mathrm{OH}^{*}$ with two others. 51

Figure 1.18. Parity plots for the total binding energy (left) and hydrogen bond energy (right) as predicted by Equation 1.1 
Figure 2.1. Selected reaction energies $(\mathrm{kJ} / \mathrm{mol})$ and activation barriers $(\mathrm{kJ} / \mathrm{mol})$ for the oxidation of ethanol to acetic acid on $\mathrm{Au}$ and $\mathrm{Pt}(111)$ surfaces in the presence of liquid water

Figure 2.2. Reaction profile for the oxidation of glycerol over $\mathrm{Au} / \mathrm{C}$ in liquid water.

Figure 2.3. Reaction scheme for the oxidation of alcohols to acids over a gold surface in water at high $\mathrm{pH}$.

Figure 2.4. Reaction network for the oxidation of ethanol to acetic acid or acetate products... . .72

Figure 2.5. Dehydrogenation reactions from ethanol to acetaldehyde. . .74

Figure 2.6. Base-catalyzed oxidation of acetaldehyde in the aqueous phase. The change in energy along the reaction coordinate shows a barrier of $45 \mathrm{~kJ} / \mathrm{mol}$ due to the restructuring of the water network.

Figure 2.7. Oxidation reactions of acetaldehyde over $\mathrm{Pd}(111)$ in the presence an aqueous media.....78

Figure 2.8. Brønsted-Evans-Polyani (BEP) correlation for the activation of $\mathrm{C}-\mathrm{H}$ and $\mathrm{O}-\mathrm{H}$ bonds, metal-catalyzed, over the Pd(111) surface.

Figure 2.9. Binding energy of $\mathrm{O}^{*}$ and $\mathrm{OH}^{*}$ in various modes over a $\mathrm{Pd}(111)$ surface.

Figure 3.1. Activation energy of methane with a single oxygen bound to various transition metal surfaces.

Figure 3.2. The thermochemical cycle for the transition state of Ag-10*, this type of cycle was used to determine the controlling factors of the activation barrier. .95

Figure 3.3. The activation barrier is strongly dependent upon the stabilization of hydrogen in the transition state by the metal and oxygen.

Figure 3.4. The activation energy variations with increasing the oxygen coverage.

Figure 3.5. The TS geometries on Pt(111) surface at high oxygen coverage.

Figure 3.6. Overall activation energy of methane activation over $\mathrm{Rh}$ at $1-60 *$ coverage plotted alongside $\mathrm{O}-\mathrm{H}$ and $\mathrm{M}-\mathrm{H}$ stabilization energies.

Figure 3.7. The TS geometries on $\mathrm{Ag}(111)$ at high oxygen coverage. 103

Figure 3.8. Overall activation energy of methane activation over $\mathrm{Ag}$ at $10^{*}, 40^{*}$ and $60^{*}$ coverage plotted alongside $\mathrm{O}-\mathrm{H}$ and $\mathrm{M}-\mathrm{H}$ stabilization energies.

Figure 3.9. Transition state geometries for the activation of methane through direct, $0 *$-assisted and $\mathrm{OH}^{*}$-assisted $\mathrm{C}-\mathrm{H}$ activations. 106

Figure 3.10. Reaction energetics for methane dissociation on closed-packed transition metal surfaces. 
Figure 3.11. Activation barriers and reaction energies for the activation of methane on closedpacked metal surfaces.

Figure 3.12. Difference between $0^{*}$-assisted and bare-metal methane activation barriers and the difference between $\mathrm{OH}^{*}$-assisted and bare-metal methane activation.

Figure 3.13. Binding energies referenced to radicals in vacuum and molecular species of alkyl species on different transition metal surfaces.

Figure 3.14. Binding modes of alkyl species in atop positions on $\mathrm{Pd}(111)$.

Figure 3.15. The reaction energy and activation barrier of the primary $\mathrm{C}-\mathrm{H}$ activation of methane, ethane and propane as well as the secondary $\mathrm{C}-\mathrm{H}$ activation of propane across coinage and platinumgroup metals.

Figure 3.16. The activation of primary $\mathrm{C}-\mathrm{H}$ bonds of methane, ethane and propane via metal-atominsertion, $\mathrm{O}^{*}$-assisted and $\mathrm{OH}^{*}$-assisted routes for coinage and platinum-group metals.

Figure 3.17. Transition state geometries for the $\mathrm{C}$ - $\mathrm{H}$ activation of methyl through direct, $\mathrm{O}^{*}$-assisted and $\mathrm{OH}^{*}$-assisted reactions on $\mathrm{Pd}$.

Figure 3.18. A comparison of the activation barriers of methane and methyl on platinum-group and coinage metals.

Figure 3.19. BEP plot of the $\mathrm{C}-\mathrm{H}$ activation of methyl to form methylene on platinum-group and coinage metals.

Figure 3.20. A comparison of the activation barriers for the $\mathrm{C}-\mathrm{H}$ activation of methyl through direct, $\mathrm{O}^{*}$-assisted and $\mathrm{OH}^{*}$-assisted reactions on platinum-group and coinage metals. 120

Figure 3.21. A comparison of the effect of $\mathrm{O}^{*}$ - and $\mathrm{OH}^{*}$-assistance on the activation barriers of methyl and methane..

Figure 3.22. A comparison of the activation barriers of methane and methyl through direct, $0^{*}$ assisted and $\mathrm{OH}^{*}$-assisted reactions on platinum-group and coinage metals.

Figure 3.23. Reaction pathway for the activation of the $\mathrm{O}-\mathrm{H}$ bond of methanol, on a clean metal surface and through $\mathrm{O}^{*}$ - and $\mathrm{OH}^{*}$-abstraction mechanisms, shown in the pictures below.

Figure 3.24. BEP relationship for the $\mathrm{O}-\mathrm{H}$ activation of methanol on bare surfaces of platinum-group and coinage metals.

Figure 3.25. Comparison between the $\mathrm{C}-\mathrm{H}$ activation of methane and the $\mathrm{O}-\mathrm{H}$ activation of methanol on bare surfaces of platinum-group and coinage metals.

Figure 3.26. Activation barrier (referenced to methanol in the gas phase) for the $\mathrm{O}-\mathrm{H}$ activation of methanol through direct, $\mathrm{O}^{*}$-assisted and $\mathrm{OH}^{*}$-assisted mechanisms for platinum-group and coinage metals. 
Figure 4.1. DFT-calculated carbenium and oxocarbenium ion formation or reaction energies for 2,3butanediol, 2,4-pentanediol, and MTHF.

Figure 4.2. Comparison of the ratio between specific reaction rate ( $\mu \mathrm{mol} g-1 \mathrm{~min}-1)$ and initial reactant concentration ( $\mu \mathrm{mol} \mathrm{mL-1)}$ (on a logarithmic scale) and DFT-calculated carbenium and oxocarbenium ion energies.

Figure 4.3. Acidity of hydroxide bound to nanoparticles of bimetallic alloys.

Figure 4.4. DFT-calculated reactant and transition state structures for the concerted protonation, hydride transfer and ring-opening of the water-stabilized HMTHF over a model Rh(111) surface with well dispersed Re-OH sites. 135

Figure 4.5. Reaction network of glycerol hydrogenolysis.

Figure 4.6. Commonly studied ring ethers for ring-opening hydrogenolysis. 138

Figure 4.7. Heatmaps of the dehydrogenation energies (DHEs) and ammonia binding energies (NH3 BEs) of hydroxide bound atop on a survey of bimetallic metal alloys.

Figure 4.8. Hydroxylated (111) terrace surface monoalloy site. Dotted atoms represent the (100) terrace, edge11, edge10 and corner sites.................................................................................................. 145

Figure 4.9. Relationship between DPE, DHE and the eAff of the bulk metal. ........................................ 145

Figure 4.10. DHE shown as the relationship between the binding energy of $\mathrm{O}^{*}$ and $\mathrm{OH}^{*} \ldots \ldots \ldots \ldots \ldots \ldots . . . . . . .146$

Figure 4.11. Relationship between DPE and ammonia binding energy .................................................150

Figure 4.12. Proton-ammonia and proton-oxygen bond lengths of ammonia bound to a variety of $\mathrm{MOH}$ surface alloys as well as a variety of adsorbates bound to HPA systems. . .151

Figure 4.13. The point of deprotonation as seen through the $\mathrm{N}--\mathrm{H}$ bond length at varying DPE. 4 gth at varying DPE. . .152 


\section{List of Symbols}

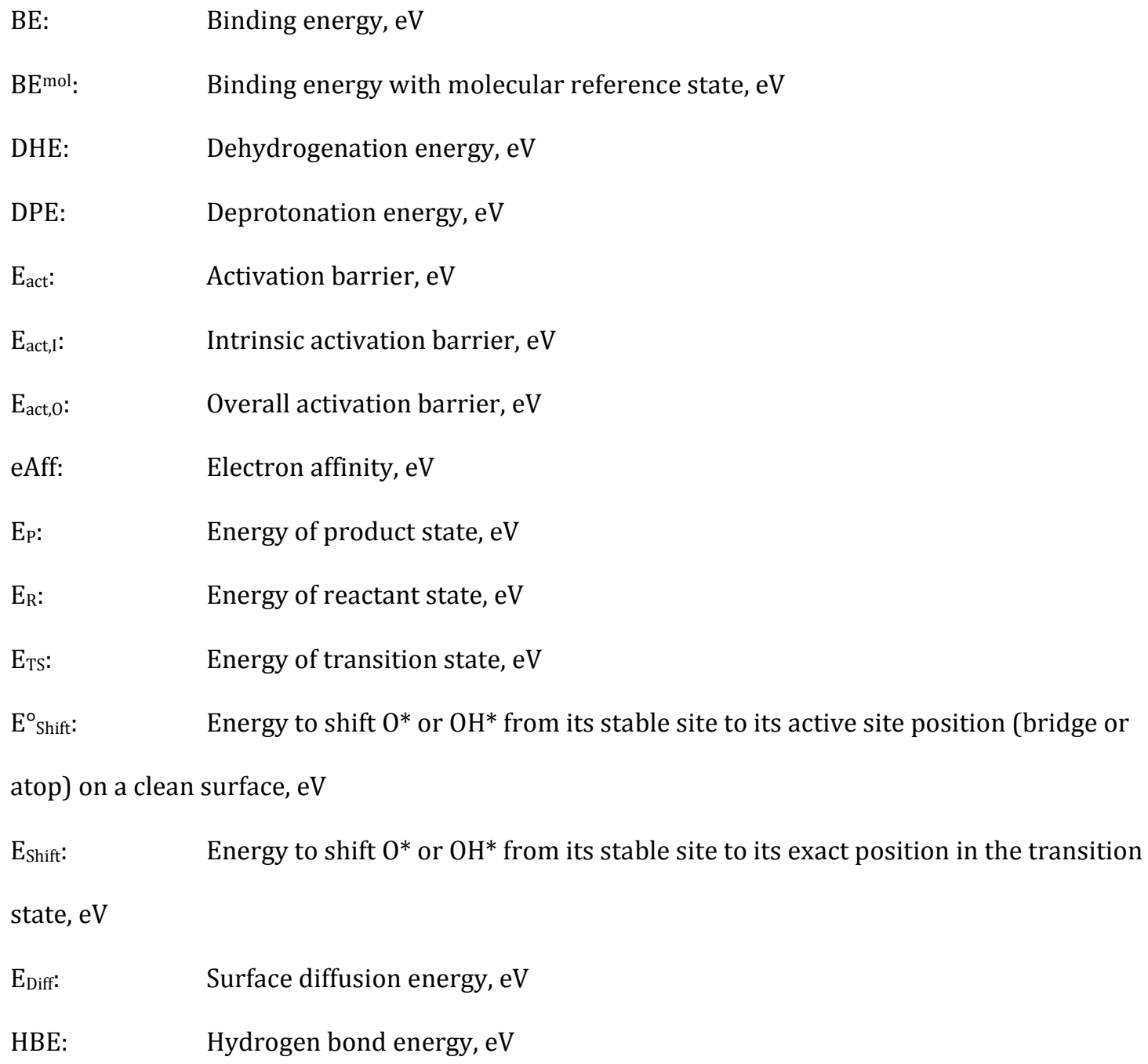




\section{Preface}

Biomass-derived chemicals, in contrast to petroleum-derived chemicals, have high oxygen content present in a variety of functional groups, such as alcohols, ethers, carbonyls and carboxylates. One branch of biomass conversion research has been focused on creating fuels or fueladditives, in which a high $\mathrm{H} / \mathrm{C}$ ratio is desired. Unfortunately, the high oxygen content limits the ability of these biomass-derived feedstocks as fuels so developing catalysts which remove oxygen functional groups is a priority in the area. Some approaches are drastic, such as pyrolysis, in which the chemicals are rapidly heated, causing thermal decomposition to a variety of light gases, including $\mathrm{H}_{2}, \mathrm{CO}, \mathrm{CO}_{2}$ and $\mathrm{CH}_{4}$ as well as char. After pyrolysis, the syngas and $\mathrm{CH}_{4}$ can be further upgraded by a combination of Fischer-Tropsch, steam reforming and water gas shift chemistry to create longer chain alkanes. A similar approach, known as aqueous phase reforming, can be performed in the presence of water solvent over a variety of (often) supported-metal catalysts. Once again, the goal here is to break down the molecule into its most stable components, creating $\mathrm{H}_{2} / \mathrm{CO}_{2}$ for the goal of hydrogen production. Other methods involve the selective de-functionalization of these feedstocks to create appropriate fuels or value-added chemicals. The reactions of interest include: dehydration, hydrogenolysis, which requires $\mathrm{H}_{2}$ : decarbonylation, the removal of $\mathrm{CO}$ or decarboxylation, the removal of $\mathrm{CO}_{2}$. An alternative approach has been to utilize the functionality of the feedstocks and add additional functionality, rather than removing it, to form value-added chemicals. A common reaction of interest for this approach is the oxidation of alcohols to aldehydes and organic alcohols.

All of these aqueous phase reactions present new challenges to the area of catalysis, both at the fundamental and practical levels. The mere presence of water rules out many possible catalysts and supports due to leaching and sintering in these harsh environments. Beyond the issues of catalyst stability, the aqueous phase introduces the possibility of solvent-phase reactions and altered reaction mechanisms due to differences in solvation energies of various intermediates. In order to develop catalysts for this area, a fundamental understanding of the roles of: 1) any co-adsorbates 2) the aqueous solvent and 3) the metal is necessary. 
The following chapters build an understanding of how those three factors affect binding energies of chemical adsorbates, activation barriers of elementary steps, and ultimately how a reaction proceeds in this catalytic environment.

Chapter 1 will present some very fundamental calculations, meant to provide an understanding of the chemical nature of $\mathrm{O}^{*}$ and $\mathrm{OH}^{*}$ on metal surfaces which will be useful during the application-based studies to follow. This includes the calculation of binding energies and charge analysis of adsorbed $\mathrm{O}^{*}$ and $\mathrm{OH}^{*}$ as well as a description of the interactions between $\mathrm{O}^{*}$ and a water solvent and the effect of increasing the coverage of these adsorbates.

Chapter 2 discusses the selective oxidation of alcohols, in which ethanol is used as a model compound. Experimental research has demonstrated that during heterogeneous alcohol oxidation, the activity is strongly dependent upon the $\mathrm{pH}$ of the reaction medium (typically through adding varying concentrations of $\mathrm{NaOH}$ ). Furthermore, the reaction requires $\mathrm{O}_{2}$ to be present (at moderate pressures). The roles of these two species have been explored and it was demonstrated that surfacebound $\mathrm{OH}^{*}$ can act as both a Brønsted base and a nucleophile which plays a very important role during the oxidation chemistry.

Chapter 3 follows up on the previous chapter, by examining the ability of $\mathrm{O}^{*}$ and $\mathrm{OH}^{*}$ to abstract hydrogen from various $\mathrm{O}-\mathrm{H}$ and $\mathrm{C}-\mathrm{H}$ bonds on a variety of closed-packed metal surfaces. The goal of this work isn't to directly understand any particular reaction system or mechanism, but to develop general rules for understanding when these $\mathrm{O}^{*}$ and $\mathrm{OH}^{*}$-assisted $\mathrm{C}-\mathrm{H}$ and $\mathrm{O}-\mathrm{H}$ activations will be favorable compared to the bare metal case. For instance, the ability of $0^{*}$ to act as a Brønsted base during the activation of methane was examined over a variety of closed-packed metal surfaces and at varying degrees of $0^{*}$ coverage, since it has been previously determined that increasing $0^{*}$ coverage increases its ability to behave as a Brønsted base.

Chapter 4 studies a very different system, one in which bio-derived oxygenates are being selectively reduced through hydrogenolysis in the presence of $\mathrm{H}_{2}$ and water. Recent experimental work has demonstrated that bi-metallic alloys, in which one metal (such as Rh, Pt, or Ir) has been promoted with an oxophilic metal oxide (such as $\mathrm{ReO}_{\mathrm{x}}, \mathrm{MoO}_{\mathrm{x}}$ and $\mathrm{WO}_{\mathrm{x}}$ ), show increased selectivity 
during hydrogenolysis of polyols and ring ether compounds. In these systems, the increased selectivity suggests an acid-catalyzed mechanism, and ammonia adsorption experiments have confirmed the presence of acid sites on these catalysts. While characterization of these catalysts has demonstrated that the oxidic promoter is partially reduced in situ, the exact nature of the acid site is unknown. We have suggested that the oxophilic metal will activate water in situ, generating M-OH sites at the metal-water interface. Model sites have been shown to be moderately acidic and to catalyze ring-opening reactions of cyclic ethers, yielding the same products observed experimentally. However, the hydrogenolysis of polyols in these systems has not yet been studied through DFT calculations, and experimentally, the selectivity patterns for polyol hydrogenolysis is much more complex than for the ring-opening of cyclic ethers. It is proposed to examine glycerol hydrogenolysis over Pt-ReO $\mathrm{x}_{\mathrm{x}}$ and $\mathrm{Rh}-\mathrm{ReO}_{\mathrm{x}}$ as well as a fundamental survey to determine the Brønsted acidity of various bimetallic alloys which may suggest candidates for experimental studies, such as $\mathrm{Au}-\mathrm{Re} \mathrm{O}_{\mathrm{x}}$. 


\section{1... Chemical Nature of $\mathrm{O}^{*}$ and $\mathrm{OH}^{*}$ on Metal Surfaces at Various Coverages}

1.1: Chemical Nature of $O^{*}$ and $\mathrm{OH}^{*}$ on (111) and (100) Transition Metal Surfaces.

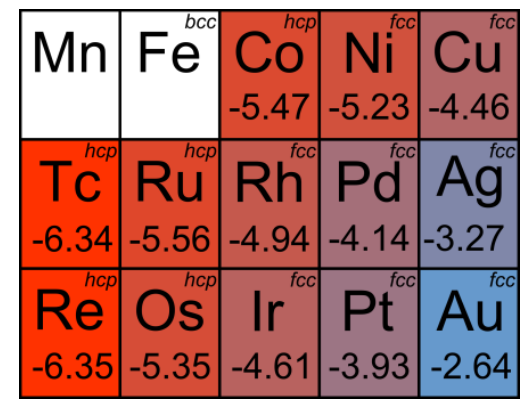

This section examines binding energy, charge transfer and bond analysis of $\mathrm{O}^{*}, \mathrm{OH}^{*}$ and $\mathrm{MeO}^{*}$ bound to a range of low-index transition metal surfaces. Periodic trends like the one on the left for the binding energy of $0^{*}$ are described.

\section{2: Hydrogen bonding of $O^{*}$ on Closed-Packed Transition Metal Surfaces.}

An examination of the strengthened interaction between $0^{*}$ and water as $0^{*}$ shifts to the bridge binding mode, hinting at Brønsted basicity when $0^{*}$ resides in the bridge site, as shown on the right.
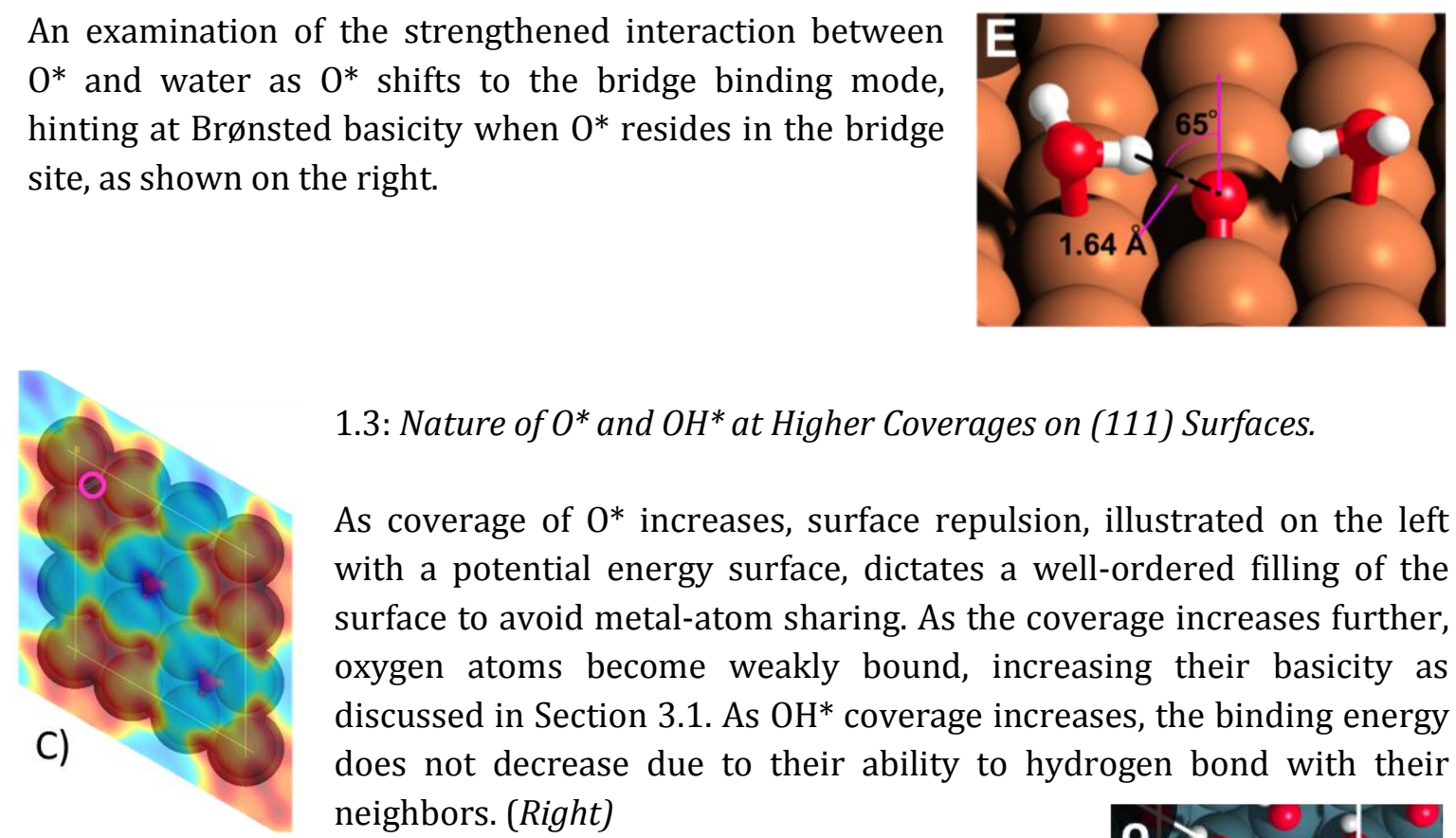

1.3: Nature of $\mathrm{O}^{*}$ and $\mathrm{OH}^{*}$ at Higher Coverages on (111) Surfaces.

As coverage of $0^{*}$ increases, surface repulsion, illustrated on the left with a potential energy surface, dictates a well-ordered filling of the surface to avoid metal-atom sharing. As the coverage increases further, oxygen atoms become weakly bound, increasing their basicity as discussed in Section 3.1. As $\mathrm{OH}^{*}$ coverage increases, the binding energy does not decrease due to their ability to hydrogen bond with their neighbors. (Right)

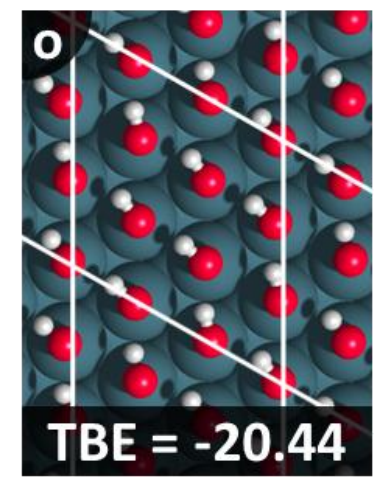




\section{1: Chemical Nature of $O^{*}$ and $\mathrm{OH}^{*}$ on Closed-Packed and (100) Transition Metal}

\section{Surfaces}

Prior to describing how oxygen and hydroxide can influence chemistry at metal surfaces, it's important to describe the nature of these adsorbates on surfaces and how that is altered by the electronic nature of the metal surface, the surface density (coverage) of the adsorbate and the presence of an aqueous solvent. Some of these calculations have been presented in literature in many different forms, such as the binding state of $0^{*}$ on a closed-packed metal surface. However, the method of the calculations presented throughout literature greatly vary between different publications, so many calculations were performed here in order to provide a consistent comparison between these fundamental examinations and the more novel mechanistic studies presented in later chapters.

On a closed-packed (111) fcc or (0001) hcp surface (shown in Figure 1.1), oxygen binds to three metal atoms in either a 3-fold-fcc (3ff) or 3-fold-hcp (3fh) site for fcc and hcp metals, respectively. In order to determine how the nature of adsorbed oxygen changes depending on the metal surface it is bound to, a series of calculations were run on the closed-packed surfaces of commonly studied transition metal surfaces: $3 d: \mathrm{Co}, \mathrm{Ni}, \mathrm{Cu}, 4 d$ : Tc, Ru, Rh, Pd, Ag, 5d: Re, Os, Ir, Pt and $\mathrm{Au}$.

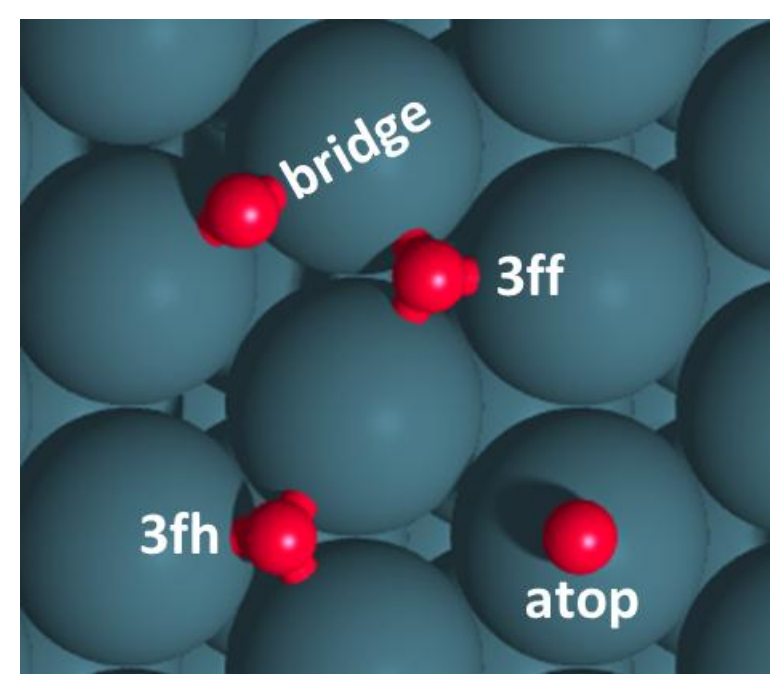

Figure 1.1. Binding sites of $O^{*}$ on a closed-packed metal surface. 
Density functional theory (DFT) Calculations were carried out using periodic, planewavebased methods as implemented in VASP.1-4 The planewaves were constructed with an energy cutoff of $396 \mathrm{eV}$ using projector augmented-wave (PAW) potentials.5,6 To determine corrections for the exchange and correlation energies, the RPBE form of the generalized gradient approximation (GGA) was used..$^{7-9}$ Closed-packed surface calculations were run using a $2 \times 2-4 \times 4$ unit cell with four atomic layers and at least $10 \AA ̊$ of vacuum in between slabs in the z-direction. To prevent the metal layers of the slab from relaxing in both the $z$ and $-z$ directions, the bottom two layers were fixed in their bulk positions. During relaxation, the force on unconstrained atoms was converged to $<0.01 \mathrm{eV} / \AA \AA$. In order to ensure accurate forces, the wavefunctions were converged to within $10^{-6} \mathrm{eV}$ and the forces were computed using an FFT grid with a cutoff of twice the planewave cutoff. The first Brillouin zone was sampled using a Monkhorst-pack ${ }^{10}$ scheme, the size of the k-point mesh was dependent upon the size of the unit cell: $6 \times 6 \times 1$ for a $2 \times 2$ unit cell, $4 \times 4 \times 1$ for a $3 \times 3$ unit cell and $3 \times 3 \times 1$ for a $4 \times 4$ unit cell. Once geometric convergence was reached, a single-point calculation with a k-point sampling twice as large (in the $\mathrm{x}$ and $\mathrm{y}$ direction) was performed.

The results, shown in Table 1.1, show that at low coverage, the unit cell size has an effect of $10-15 \mathrm{~kJ} / \mathrm{mol}$ on the binding energy. In comparing different metals, the binding energy of oxygen decreases from right to left and from top to bottom on the periodic table, which is well-known in this field, and is shown in Figure 1.2. Some calculations presented later were performed with using Vanderbilt ultra-soft pseudopotentials (USPP) ${ }^{11,12}$ and the Perdew-Wang 91 (PW91) ${ }^{13}$ density functional in which the forces on atoms were converged to $<0.05 \mathrm{eV} / \AA ̊$. In Figure 1.3, we present a comparison of the binding energies of $0^{*}$ between this convergence scheme and the one described above, showing differences in binding energy between -14 and $16 \mathrm{~kJ} / \mathrm{mol}$. 
Table 1.1. Binding Energy of $0^{*}$ on Various Transition Metals with different Unit Cell Sizes ${ }^{\mathrm{a}}$

\begin{tabular}{lcccc}
\hline & \multicolumn{4}{c}{ Unit Cell Size } \\
& $2 \times 2$ & $3 \times 3$ & $4 \times 4$ & Site \\
\hline $\operatorname{Co}(0001)$ & -5.55 & -5.47 & -5.56 & $3 f h$ \\
$\operatorname{Ni}(111)$ & -5.27 & -5.23 & -5.24 & $3 f f$ \\
$\operatorname{Cu}(111)$ & -4.51 & -4.46 & -4.53 & $3 f f$ \\
$\operatorname{Tc}(0001)$ & -6.44 & -6.34 & -6.39 & $3 f h$ \\
$\operatorname{Ru}(0001)$ & -5.53 & -5.56 & -5.57 & $3 f h$ \\
$\operatorname{Rh}(111)$ & -4.89 & -4.94 & -4.92 & $3 f f$ \\
$\operatorname{Pd}(111)$ & -4.12 & -4.14 & -4.15 & $3 f f$ \\
$\operatorname{Ag}(111)$ & -3.28 & -3.27 & -3.24 & $3 f f$ \\
$\operatorname{Re}(0001)$ & -6.35 & -6.35 & -6.22 & $3 f h$ \\
$\operatorname{Os}(0001)$ & -5.31 & -5.35 & -5.35 & $3 f h$ \\
$\operatorname{Ir}(111)$ & -4.58 & -4.61 & -4.62 & $3 f f$ \\
$\operatorname{Pt}(111)$ & -3.97 & -3.93 & -3.98 & $3 f f$ \\
$\operatorname{Au}(111)$ & -2.71 & -2.64 & -2.75 & $3 f f$
\end{tabular}

aThese optimizations fully relaxed the top two metal layers as well as the $0^{*}$.

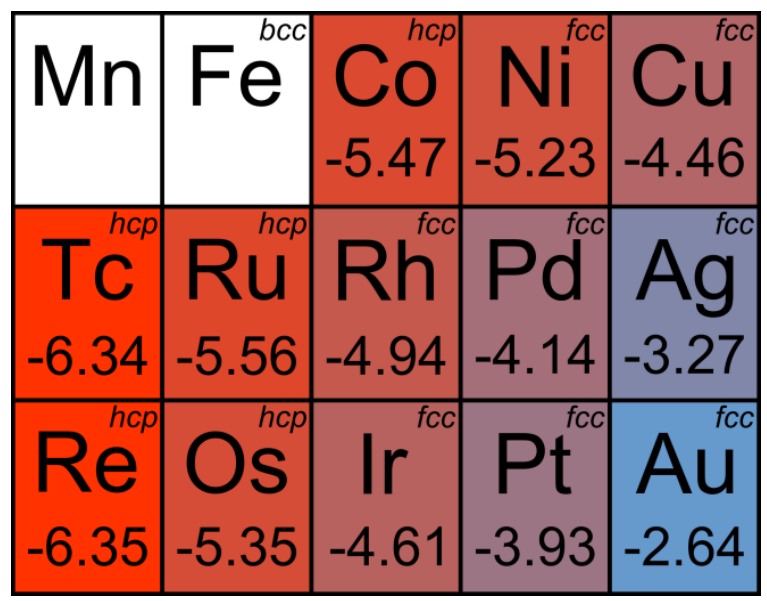

Figure 1.2. Binding energy of $0^{*}$ on $3 \times 3$ closed-packed metal surfaces. 


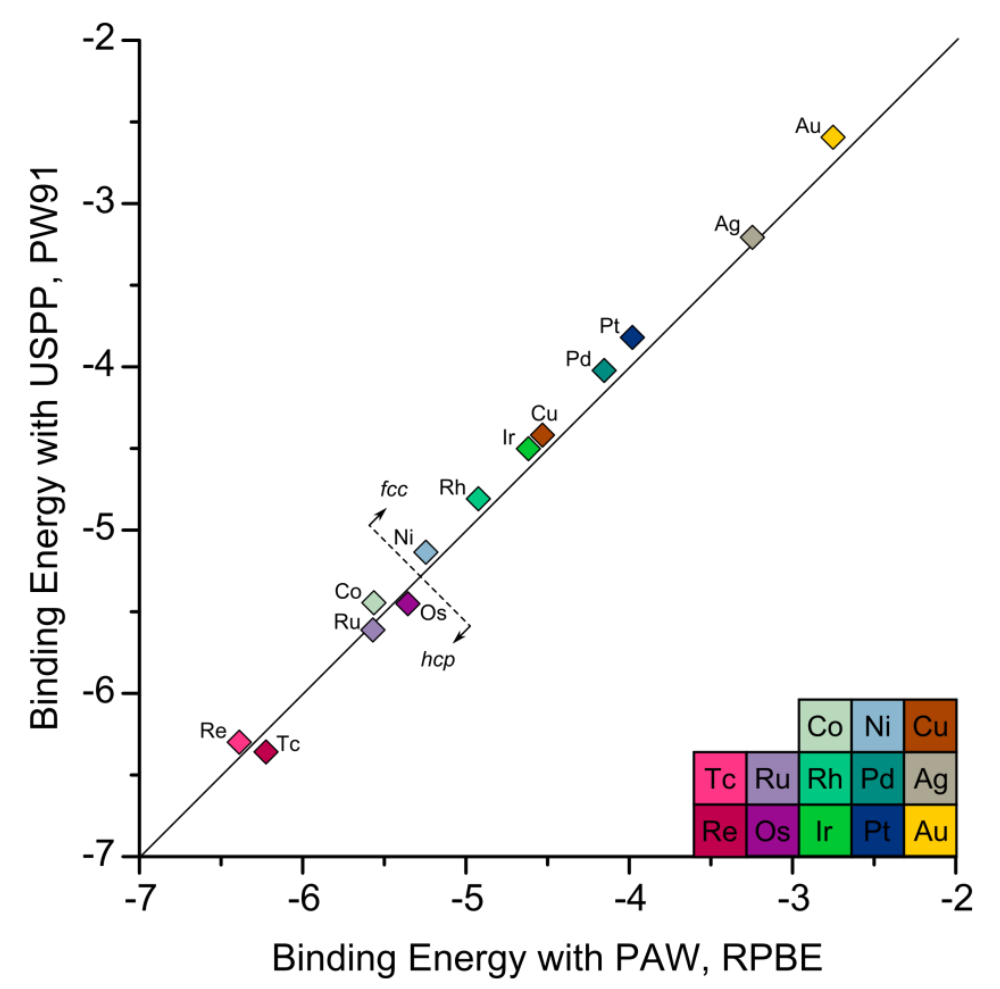

Figure 1.3. A comparison of the binding energy of $0^{*}$ computed with two different sets of potentials and density functionals.

After calculation, the wavefunctions were transformed into a set of localized quasiatomic orbitals (QUAMBOs) ${ }^{14-17}$. From these quasiatomic orbitals, a Löwdin population analysis ${ }^{18,19}$ was performed and the results are shown in Table 1.2. On the platinum-group metals (Pt, Pd, Ir, Rh, Os, and $\mathrm{Ru}$ ) (PGMs) as well as Re and Tc, oxygen withdraws $0.5-0.7 \mathrm{e}^{-}$from the metal surface. A comparison of the results over this sequence of metals shows that the charge on the oxygen is very similar from group 7-10 decreasing by 0.01 from Tc to Pd and decreasing by 0.05 from Re to Pt. Oxygen adsorbed on period 4 metals is less charged than those on period 5 metals. The ferromagnetic metals ( $\mathrm{Co}$ and $\mathrm{Ni}$ ) have greater charge transfer $\left(\sim 0.8 \mathrm{e}^{-}\right)$. However, as shown in Figure 1.4, the coinage metals $(\mathrm{Cu}, \mathrm{Ag}$ and $\mathrm{Au})(\mathrm{CMs})$ donate significantly more electrons to the oxygen $\left(\sim 1 \mathrm{e}^{-}\right)$than other metals due to the filled d-band of coinage metals. 
Table 1.2. Charge Transfer to $0^{*}$ on Closed-

Packed 3x3 Transition Metal Surfaces.

\begin{tabular}{lcccc}
\hline & $\mathrm{O}^{* \mathrm{a}}$ & $\mathrm{M}_{1} \mathrm{~b}$ & $\mathrm{M}_{2+} \mathrm{c}$ & Site \\
\hline $\mathrm{Co}(0001)$ & -0.84 & +0.63 & -0.21 & $3 f h$ \\
$\mathrm{Ni}(111)$ & -0.81 & +0.70 & -0.10 & $3 f f$ \\
$\mathrm{Cu}(111)$ & -1.05 & +1.05 & -0.003 & $3 f f$ \\
$\mathrm{Tc}(0001)$ & -0.56 & +0.48 & -0.08 & $3 f h$ \\
$\operatorname{Ru}(0001)$ & -0.58 & +0.45 & -0.13 & $3 f h$ \\
$\operatorname{Rh}(111)$ & -0.56 & +0.49 & -0.07 & $3 f f$ \\
$\operatorname{Pd}(111)$ & -0.55 & +0.70 & +0.15 & $3 f f$ \\
$\mathrm{Ag}(111)$ & -1.03 & +0.83 & -0.20 & $3 f f$ \\
$\operatorname{Re}(0001)$ & -0.63 & +0.33 & -0.30 & $3 f h$ \\
$\mathrm{Os}(0001)$ & -0.64 & +0.37 & -0.27 & $3 f h$ \\
$\operatorname{Ir}(111)$ & -0.65 & +0.44 & -0.21 & $3 f f$ \\
$\operatorname{Pt}(111)$ & -0.61 & +0.62 & +0.01 & $3 f f$ \\
$\operatorname{Au}(111)$ & -0.95 & +0.65 & -0.30 & $3 f f$ \\
\hline
\end{tabular}

aThe charge on the $0^{*}$ adsorbate. ${ }^{\mathrm{b}} \mathrm{The}$ total charge on the metal atoms which the $0^{*}$ adsorbate is bound directly to (the ensemble metal atoms). cThe total charge on all other metals in the system (non-ensemble).

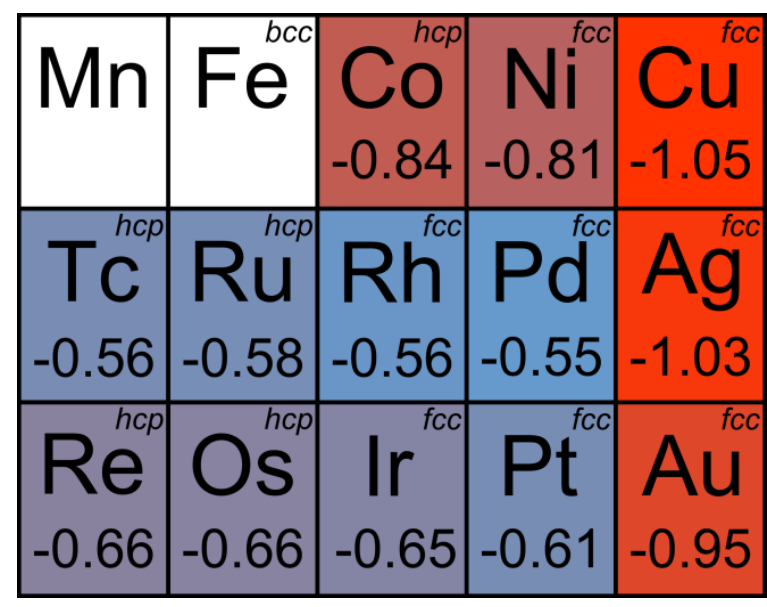

Figure 1.4. Charge of $0^{*}$ on $3 \times 3$ closed-packed metal surfaces.

The mobility of $\mathrm{O}^{*}$ species on a metal surface depends upon the degree in which the binding energy changes as you move the adsorbate from one site to another. For closed-packed surfaces, the 
diffusion of $0^{*}$ species occurs through bridge sites between the $3 \mathrm{ff}$ and $3 \mathrm{fh}$ binding modes. As will be discussed later, when $\mathrm{O}^{*}$ is in that bridge site it can take on certain unique chemical properties (such as the ability to form strong hydrogen bonds or abstract $\mathrm{H}$ from $\mathrm{O}-\mathrm{H}$ and $\mathrm{C}-\mathrm{H}$ bonds on certain metals) which may aid in activating bonds from vicinal adsorbates. For this reason, the difficulty in shifting $\mathrm{O}^{*}$ from one binding mode to the other becomes important to reactivity as well as diffusion. Table 1.3 reports the binding energy of $0^{*}$ at different sites on a $3 \times 3$ closed-packed surface of various transition metals. As shown in Figure 1.5, the estimated diffusive barrier correlates loosely with the binding energy of $0^{*}$, with $\mathrm{Au}(111)$ having the lowest barrier and $\mathrm{Tc}(0001)$ having the highest and these estimated barriers are very similar to the diffusion barriers computed in Section 1.2. 
Table 1.3. Binding Energy of $O^{*}$ on $3 \times 3$ Closed-Packed Surfaces of Various Transition Metals in Various Binding Modes

\begin{tabular}{cccccc}
\hline & atop $^{a}$ & bridge $^{b}$ & Sfhc $^{c}$ & 3ff $^{c}$ & barrier $^{d}$ \\
\hline $\operatorname{Co}(0001)$ & -4.16 & -5.16 & -5.47 & -5.42 & 0.31 \\
$\mathrm{Ni}(111)$ & -3.54 & -4.72 & -5.08 & -5.23 & 0.51 \\
$\mathrm{Cu}(111)$ & -2.88 & -4.09 & -4.33 & -4.46 & 0.37 \\
$\mathrm{Tc}(0001)$ & -5.00 & -5.59 & -6.34 & -5.72 & 0.75 \\
$\operatorname{Ru}(0001)$ & -4.48 & -5.08 & -5.56 & -5.41 & 0.49 \\
$\operatorname{Rh}(111)$ & -3.58 & -4.45 & -4.78 & -4.94 & 0.49 \\
$\operatorname{Pd}(111)$ & -2.62 & -3.65 & -3.93 & -4.14 & 0.49 \\
$\operatorname{Ag}(111)$ & -2.04 & -2.98 & -3.16 & -3.27 & 0.29 \\
$\operatorname{Re}(0001)$ & -5.65 & -5.72 & -6.35 & -5.93 & 0.63 \\
$\operatorname{Os}(0001)$ & -4.63 & -4.78 & -5.35 & -5.19 & 0.57 \\
$\operatorname{Ir}(111)$ & -3.71 & -4.08 & -4.38 & -4.61 & 0.53 \\
$\operatorname{Pt}(111)$ & -2.65 & -3.35 & -3.48 & -3.93 & 0.58 \\
$\operatorname{Au}(111)$ & -1.61 & -2.35 & -2.36 & -2.64 & 0.29
\end{tabular}

${ }^{\mathrm{a}}$ Only the z-axis was relaxed to maintain the atop binding site. ${ }^{b}$ Only the $y, z$-axes were relaxed to maintain the bridge binding site. cFully relaxed the top two metal layers and the $0^{*}$. dDifference in energy between the bridge site and the minimum binding site (3fh or $3 \mathrm{ff}$ ).
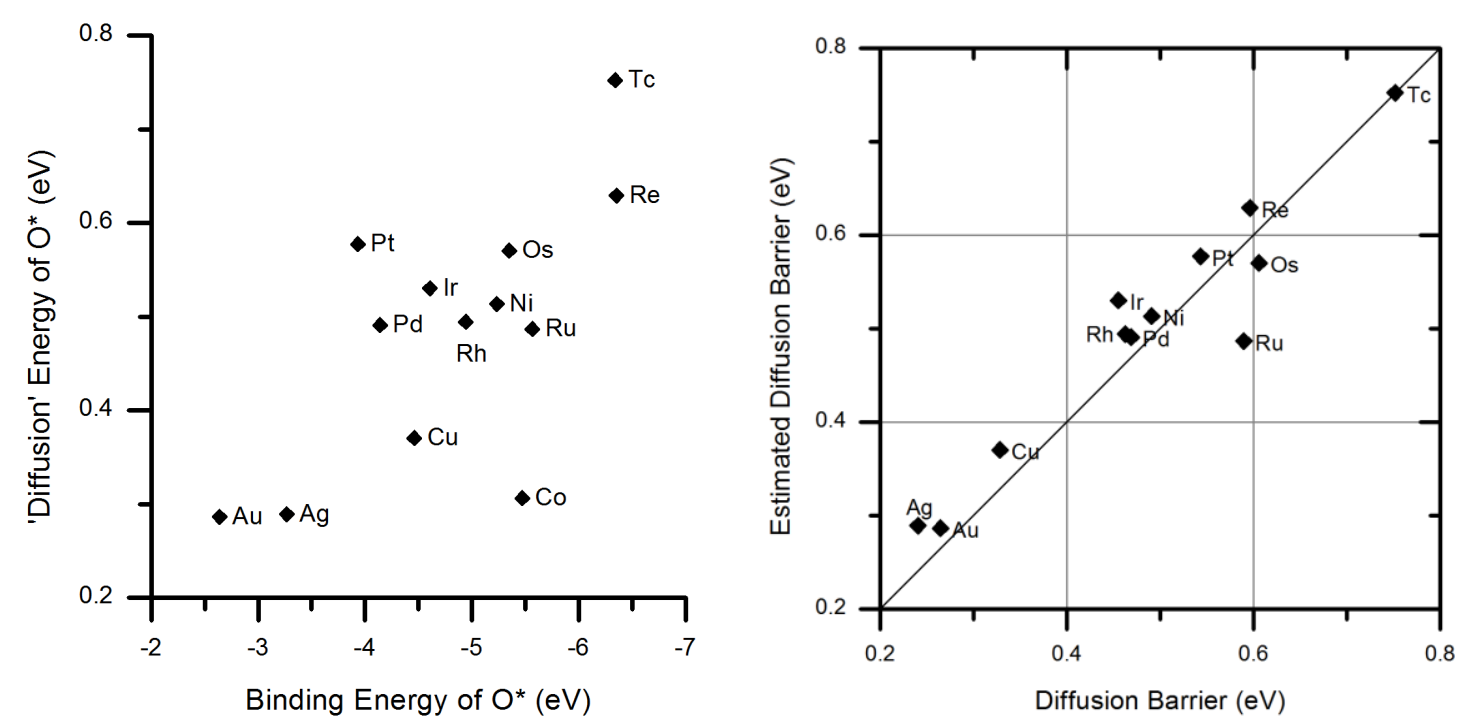

Figure 1.5. (Left) Correlation between the estimated diffusion barrier and binding energy of $0^{*}$ on various transition metal surfaces. (Right) Parity plot between the diffusion barrier estimated from binding energies of the bridge site compared to fully modeled diffusion barriers from Section 1.2. 
As shown in Table 1.4 , the charge of the $0^{*}$ adsorbate does not significantly vary between binding modes. Although there is a slight increase in the charge from the atop site (average of -0.64) to the bridge position (average of -0.74), the subsequent shift to the $3 \mathrm{ff}$ and $3 \mathrm{fh}$ sites (averages of -0.75 and -0.76 , respectively) shows a very small increase in the charge on the $0^{*}$ atom. If we examine the charges on the metal atoms which bind directly to the $0^{*}$ (referred to as ensemble metals), we can see that in the atop position, the metal atom has a charge between 0.32 and 0.49 , and as you increase the coordination of the $0^{*}$ with the metal, the charge on each metal atom of the ensemble decreases, but the increase in coordination results in greater total charge from the ensemble metals. The charge on the rest of the metal atoms follows the opposite trend, with atop and bridge sites donating significant amounts of charge from non-ensemble metals while in $3 \mathrm{ff}$ and $3 \mathrm{fh}$ the non-ensemble metals donate very little. Ultimately, when $0^{*}$ is placed on a metal surface it will withdraw 0.5 to 0.8 electrons from a non-coinage metal and $\sim 1$ electron from a coinage metal. A comparison of the binding modes reveal that as oxygen shifts from highly stable $3 \mathrm{ff}$ and $3 \mathrm{fh}$ sites to less-coordinated bridge and atop sites, it maintains most of its negative charge, withdrawing more electrons from its ensemble metals and making up for the rest by depleting charge from vicinal nonensemble metals through the M-M interactions with the ensemble metals. The relative invariance of the charge of $0^{*}$ in various binding sites indicates that the site-specific ability of $0^{*}$ to act as a Brønsted base observed are not due to a shift in charge. It indicates that a closer examination of the electronic structure is necessary. 
Table 1.4. Charge Distribution of $O^{*}$ Bound on a $3 \times 3$ Closed-Packed Metal Surface of Various Metals in Various Binding Modes

\begin{tabular}{|c|c|c|c|c|}
\hline $\begin{array}{l}O^{* a} \\
M_{1}{ }^{b} \\
M_{2+}{ }^{c} \\
\end{array}$ & atop & bridge & $3 f h$ & $3 f f$ \\
\hline $\operatorname{Co}(0001)$ & $\begin{array}{r}-0.65 \\
+0.31 \\
-0.34\end{array}$ & $\begin{array}{r}-0.82 \\
+0.34 \\
-0.48\end{array}$ & $\begin{array}{r}-0.84 \\
+0.63 \\
-0.21\end{array}$ & $\begin{array}{r}-0.85 \\
+0.66 \\
-0.19\end{array}$ \\
\hline $\mathrm{Ni}(111)$ & $\begin{array}{r}-0.67 \\
+0.35 \\
-0.32\end{array}$ & $\begin{array}{r}-0.80 \\
+0.37 \\
-0.43\end{array}$ & $\begin{array}{r}-0.81 \\
+0.69 \\
-0.12\end{array}$ & $\begin{array}{r}-0.81 \\
+0.71 \\
-0.10\end{array}$ \\
\hline $\mathrm{Cu}(111)$ & $\begin{array}{r}-0.95 \\
+0.30 \\
-0.65\end{array}$ & $\begin{array}{r}-1.05 \\
+0.51 \\
-0.54\end{array}$ & $\begin{array}{r}-1.05 \\
+0.92 \\
-0.13\end{array}$ & $\begin{array}{r}-1.05 \\
+1.05 \\
-0.003\end{array}$ \\
\hline $\mathrm{Tc}(0001)$ & $\begin{array}{r}-0.42 \\
+0.33 \\
-0.09\end{array}$ & $\begin{array}{r}-0.58 \\
+0.20 \\
-0.38\end{array}$ & $\begin{array}{r}-0.56 \\
+0.48 \\
-0.08\end{array}$ & $\begin{array}{r}-0.61 \\
+0.47 \\
-0.14\end{array}$ \\
\hline $\mathrm{Ru}(0001)$ & $\begin{array}{r}-0.44 \\
+0.33 \\
-0.11\end{array}$ & $\begin{array}{r}-0.59 \\
+0.22 \\
-0.37\end{array}$ & $\begin{array}{r}-0.58 \\
+0.45 \\
-0.13\end{array}$ & $\begin{array}{r}-0.60 \\
+0.48 \\
-0.13\end{array}$ \\
\hline $\operatorname{Rh}(111)$ & $\begin{array}{r}-0.50 \\
+0.36 \\
-0.14\end{array}$ & $\begin{array}{r}-0.56 \\
+0.23 \\
-0.33\end{array}$ & $\begin{array}{r}-0.55 \\
+0.49 \\
-0.06\end{array}$ & $\begin{array}{r}-0.56 \\
+0.49 \\
-0.06\end{array}$ \\
\hline $\operatorname{Pd}(111)$ & $\begin{array}{r}-0.54 \\
+0.38 \\
-0.16\end{array}$ & $\begin{array}{r}-0.56 \\
+0.33 \\
-0.23\end{array}$ & $\begin{array}{r}-0.54 \\
+0.67 \\
+0.13\end{array}$ & $\begin{array}{r}-0.55 \\
+0.70 \\
+0.15\end{array}$ \\
\hline $\operatorname{Ag}(111)$ & $\begin{array}{r}-0.92 \\
+0.31 \\
-0.61\end{array}$ & $\begin{array}{r}-1.02 \\
+0.46 \\
-0.56\end{array}$ & $\begin{array}{r}-1.01 \\
+0.80 \\
-0.21\end{array}$ & $\begin{array}{r}-1.03 \\
+0.83 \\
-0.20\end{array}$ \\
\hline $\operatorname{Re}(0001)$ & $\begin{array}{r}-0.47 \\
+0.34 \\
-0.14\end{array}$ & $\begin{array}{r}-0.64 \\
+0.10 \\
-0.55\end{array}$ & $\begin{array}{r}-0.63 \\
+0.33 \\
-0.30\end{array}$ & $\begin{array}{r}-0.66 \\
+0.29 \\
-0.37\end{array}$ \\
\hline Os(0001) & $\begin{array}{r}-0.45 \\
+0.36 \\
-0.09\end{array}$ & $\begin{array}{r}-0.65 \\
+0.18 \\
-0.47\end{array}$ & $\begin{array}{r}-0.64 \\
+0.37 \\
-0.26\end{array}$ & $\begin{array}{r}-0.66 \\
+0.40 \\
-0.26\end{array}$ \\
\hline $\operatorname{Ir}(111)$ & $\begin{array}{r}-0.49 \\
0.42 \\
-0.07\end{array}$ & $\begin{array}{r}-0.63 \\
+0.20 \\
-0.43\end{array}$ & $\begin{array}{r}-0.63 \\
0.45 \\
-0.18\end{array}$ & $\begin{array}{r}-0.65 \\
0.44 \\
-0.21\end{array}$ \\
\hline $\operatorname{Pt}(111)$ & $\begin{array}{r}-0.54 \\
0.46 \\
-0.08\end{array}$ & $\begin{array}{r}-0.61 \\
+0.27 \\
-0.34\end{array}$ & $\begin{array}{r}-0.59 \\
+0.61 \\
+0.03\end{array}$ & $\begin{array}{r}-0.61 \\
+0.62 \\
-0.01\end{array}$ \\
\hline $\mathrm{Au}(111)$ & $\begin{array}{r}-0.80 \\
0.40 \\
-0.40\end{array}$ & $\begin{array}{r}-0.91 \\
+0.35 \\
-0.57\end{array}$ & $\begin{array}{r}-0.92 \\
0.68 \\
-0.24\end{array}$ & $\begin{array}{r}-0.95 \\
+0.65 \\
-0.30\end{array}$ \\
\hline
\end{tabular}

aCharge on the $0^{*}$ adsorbate. ${ }^{b}$ Total charge on the metal atoms which the $0^{*}$ adsorbate is bound directly to (the ensemble metal atoms). cTotal charge on all other metals in the system. 
For fcc metals, another surface of interest is the (100) surface, shown in Figure 1.6, which is a more open surface and has three possible binding sites, the atop, bridge and hollow. As shown in Table 1.5, the most stable binding mode for $0^{*}$ on the (100) surface is the hollow site for all studied metals with the exception of Ir and Pt, where bridge sites are much more stable. This result is very intriguing and a more in-depth analysis of the binding should be performed to understand why these two metals behave so differently. This could have major impacts on single crystal studies and on the nature of adsorbate binding to (100) and edge vertices of metal nanoparticles. As shown in Figure 1.7, certain metals have a much 'flatter' profile as $0^{*}$ diffuses from stable sites through hollow or bridge intermediates. The energy difference between the hollow and bridge sites decreases, favoring the bridge sites as you move from right to left or from top to bottom metals in the periodic table as is shown in Figure 1.8. Another interesting feature is that the $5 \mathrm{~d}$ metals show a significant amount of relaxation between the partially relaxed and fully relaxed calculations (average of $0.13 \mathrm{eV}$ compared to $0.04 \mathrm{eV}$ for the other metals).

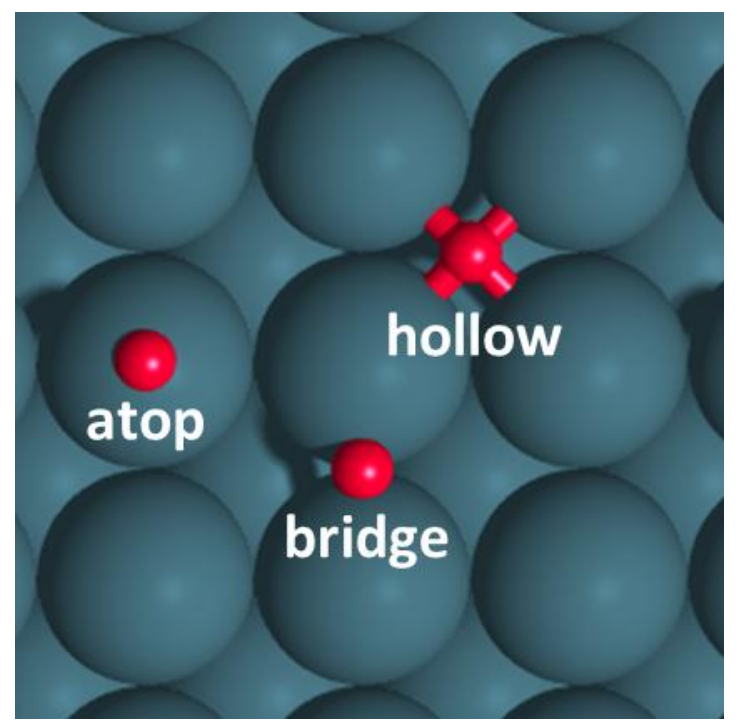

Figure 1.6. Binding sites of $0^{*}$ on a $\operatorname{Pt}(100)$ surface. 
Table 1.5. Binding Energy of $0^{*}$ on $3 \times 3$ (100) Surfaces of Various Transition Metals in Various Binding Modes ${ }^{\mathrm{a}}$

\begin{tabular}{ccccc}
\hline & & & & diff. \\
& atop & bridge & hollow & barrier $^{b}$ \\
\hline $\mathrm{Ni}(100)$ & -3.62 & -4.83 & $\mathbf{- 5 . 4 6}$ & 0.63 \\
$\mathrm{Cu}(100)$ & -2.96 & -4.14 & $\mathbf{- 4 . 9 0}$ & 0.76 \\
$\operatorname{Rh}(100)$ & -3.73 & -4.78 & $\mathbf{- 4 . 9 5}$ & 0.17 \\
$\operatorname{Pd}(100)$ & -2.62 & -3.75 & $\mathbf{- 4 . 0 2}$ & 0.28 \\
$\operatorname{Ag}(100)$ & -1.94 & -2.94 & $\mathbf{- 3 . 6 7}$ & 0.73 \\
$\operatorname{Ir}(100)$ & -3.99 & $\mathbf{- 4 . 9 0}$ & -4.46 & 0.43 \\
$\operatorname{Pt}(100)$ & -2.85 & $\mathbf{- 4 . 0 0}$ & -3.55 & 0.45 \\
$\operatorname{Au}(100)$ & -1.67 & -2.67 & $\mathbf{- 2 . 7 2}$ & 0.05
\end{tabular}

aThese calculations run with USPP and PW91, converged to $-0.05 \mathrm{eV} / \AA ̊$. bDifference in energy (absolute) between the hollow and bridge sites.

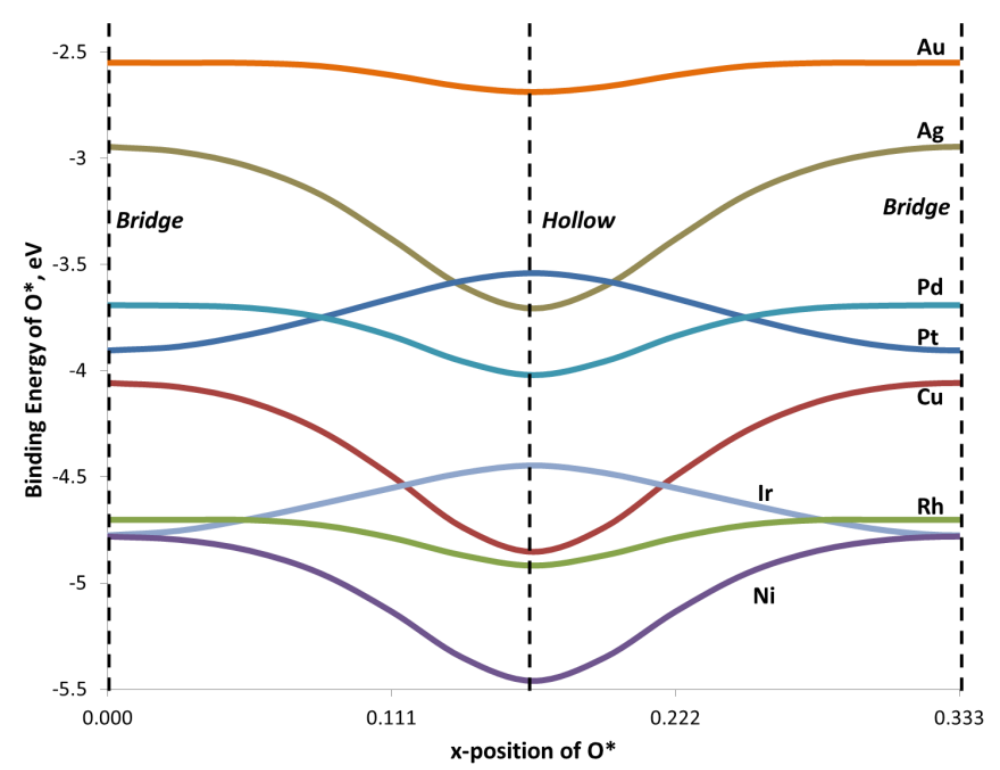

Figure 1.7. Binding energy profile from bridge to hollow sites for $0^{*}$ on (100) surfaces of fcc metals. 


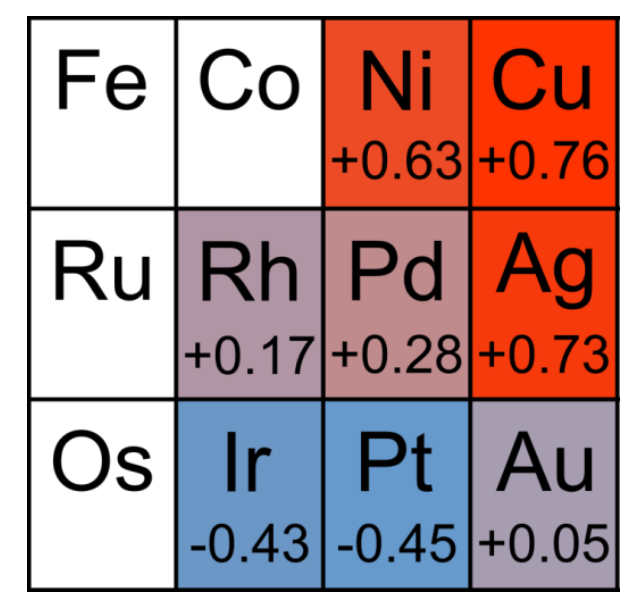

Figure 1.8. Periodic trends for the 0 * binding energy difference between bridge and hollow sites for on (100) surfaces of fcc metals. Red indicates surfaces where the hollow site is more favorable, blue indicates surfaces where the bridge site is more favorable.

\section{Chemical Nature of $\mathrm{OH}^{*}$ on Low-Index Transition Metal Surfaces}

The binding energy of $\mathrm{OH}^{*}$ on a $3 \times 3$ surface at different binding modes on various closedpacked metal surfaces is shown in Table 1.6. Once again, the binding energy of $\mathrm{OH}^{*}$ decreases as you move from left to right and from $3 \mathrm{~d}$ to $5 \mathrm{~d}$ metals across the periodic table as shown in Figure 1.9. The $\mathrm{OH}^{*}$ binding energy also correlates strongly to the binding energy of $\mathrm{O}^{*}$ as shown in Figure 1.10. This linear relationship, between the binding energy of $\mathrm{O}^{*}$ and $\mathrm{OH}^{*}$ can be derived from an application of bond-order conservation (BOC) relationships. ${ }^{20,21}$ Unlike $0^{*}$, which was always most stable in a 3-fold binding site, $\mathrm{OH}^{*}$ shows a much 'flatter' binding energy profile, with multiple binding modes of similar energies for most metals, resulting in small diffusion barriers between stable and meta-stable intermediate states. As you move from the upper left to the lower right of the table, hydroxide prefers to bind in lower coordinated bridge and atop positions than the highly coordinated 3-fold sites. (This is similar to the periodic trend observed for $0^{*}$ on a (100) surface.) As previously discussed, the comparison of these binding energies tells us the mobility of the species on the catalyst surface. Furthermore, certain reactions will occur with $\mathrm{OH}^{*}$ at bridge or atop sites to allow for interaction between the lone pair on the oxygen and the co-reactants. These active sites, unlike $0^{*}$, are often the preferred binding mode for $\mathrm{OH}^{*}$ on closed-packed surfaces and in the cases in which 
they're not preferred, the energy required to shift $\mathrm{OH}^{*}$ to those active sites is small $(0.11-0.17 \mathrm{eV})$ compared to similar shifts with $0^{*}(0.29-0.75 \mathrm{eV})$.

Table 1.6. Binding Energy of $\mathrm{OH}^{*}$ on $3 \times 3$ Closed-Packed Surfaces of Various Transition Metals and Binding Modes

\begin{tabular}{cccccc}
\hline & & & & & diff. \\
& atop & bridge & $3 f h$ & $3 f f$ & barrier \\
\hline $\mathrm{Ni}(111)$ & -2.55 & -3.01 & -3.02 & $\mathbf{- 3 . 1 5}$ & $0.14^{\mathrm{a}}$ \\
$\mathrm{Cu}(111)$ & -2.30 & -2.77 & -2.89 & $\mathbf{- 2 . 9 3}$ & $0.17^{\mathrm{a}}$ \\
$\operatorname{Ru}(0001)$ & -2.86 & -3.22 & $\mathbf{- 3 . 2 7}$ & $\mathbf{- 3 . 2 7}$ & $0.05^{\mathrm{a}}$ \\
$\operatorname{Rh}(111)$ & -2.52 & $\mathbf{- 2 . 7 9}$ & -2.64 & -2.77 & $0.02^{\mathrm{a}}$ \\
$\operatorname{Pd}(111)$ & -2.08 & $\mathbf{- 2 . 3 0}$ & -2.11 & -2.24 & $0.06^{\mathrm{a}}$ \\
$\operatorname{Ag}(111)$ & -1.87 & -2.26 & -2.35 & $\mathbf{- 2 . 3 7}$ & $0.11^{\mathrm{a}}$ \\
$\operatorname{Re}(0001)$ & -3.17 & -3.40 & $\mathbf{- 3 . 5 7}$ & -3.37 & $0.17^{\mathrm{a}}$ \\
$\operatorname{Os}(0001)$ & -2.89 & $\mathbf{- 3 . 0 6}$ & -2.94 & -2.97 & $0.09^{\mathrm{a}}$ \\
$\operatorname{Ir}(111)$ & -2.49 & $\mathbf{- 2 . 5 2}$ & -2.09 & -2.31 & $0.03^{\mathrm{b}}$ \\
$\operatorname{Pt}(111)$ & $\mathbf{- 2 . 1 0}$ & -2.09 & -1.57 & -1.82 & $0.01^{\mathrm{b}}$ \\
$\operatorname{Au}(111)$ & -1.55 & $\mathbf{- 1 . 6 7}$ & -1.53 & -1.58 & $0.09^{\mathrm{a}}$ \\
\hline
\end{tabular}

${ }^{a}$ Absolute difference in energy between the bridge site and the minimum 3-fold binding site ( $3 \mathrm{fh}$ or $3 \mathrm{ff}$ ). ${ }^{\mathrm{b}} \mathrm{Absolute}$ difference in energy between the atop and bridge sites.

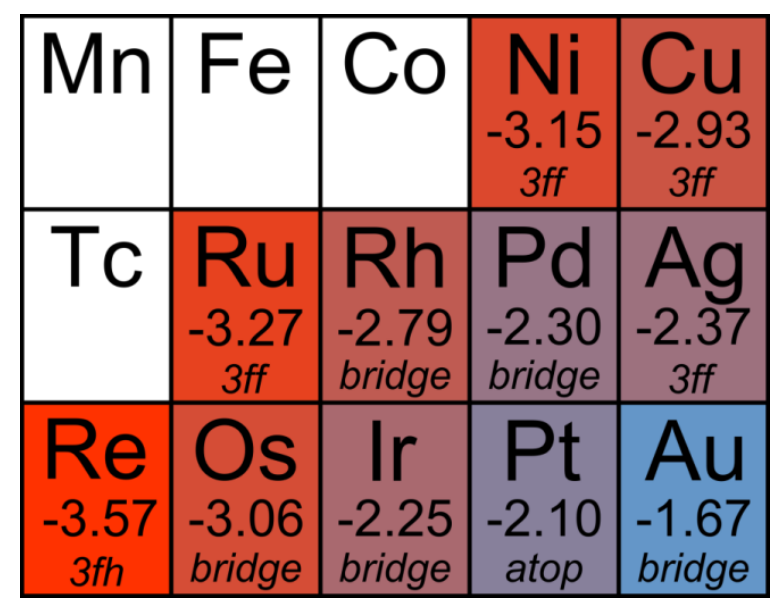

Figure 1.9. Binding energy of $\mathrm{OH}^{*}$ on closed-packed metal surfaces. 


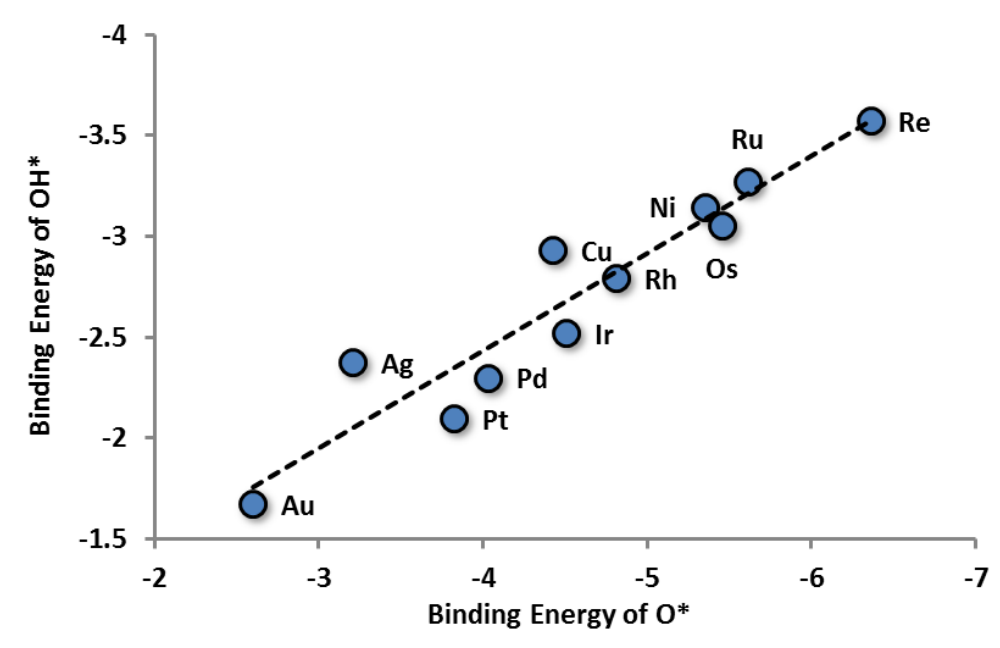

Figure 1.10. Correlation between the binding energy of $\mathrm{O}^{*}$ and $\mathrm{OH}^{*}$ on closed-packed metal surfaces.

Table 1.7 displays the charge distribution of $\mathrm{OH}^{*}$ bound on a various closed-packed metal surfaces in the binding modes previously shown. Across all metals, the charge on the hydrogen atom remains between 0.4 and 0.46 e-, slightly more positive in the 3 -fold binding modes. The oxygen atom has very similar charges to the charges presented in Tables 1.4 for the adsorption of $0^{*}$, with the charges shifted down 0.1 e- for non-coinage metals. On coinage metals, the charge on the oxygen remains the same in the $\mathrm{OH}^{*}$ case as it does in the $\mathrm{O}^{*}$ case. One significant area of difference is in the positive charge on the metal atoms. As the oxygen on $\mathrm{OH}^{*}$ withdraws $0.4-0.46 \mathrm{e}$ - from the hydrogen atom, the metal is less affected than in the $\mathrm{O}^{*}$ case. For $\mathrm{OH}^{*}$ bound atop of the metal, the ligand metal takes on a $0.2-0.3$ charge with non-ligand metals contributing 0.04-0.17 electrons for non-coinage metals and 0.26-0.34 electrons for the coinage metals. For $\mathrm{OH}^{*}$ at the bridge and 3-fold sites, the total charge on the ligand metals increases while the charge on each metal ligand atom decreases and the non-ligand atoms are slightly negative or slightly positive in charge. The charge analysis indicates that the site-specific properties of $\mathrm{OH}^{*}$ that are observed during reactions are not due to a change in charge between the binding states, similar to $0^{*}$ above. 
Table 1.7. Charge Distribution of $\mathrm{OH}^{*}$ Bound on Various Transition Metals and Binding Modes

\begin{tabular}{|c|c|c|c|c|}
\hline $\begin{array}{c}H^{*} \\
O^{*} \\
M_{1}{ }^{a} \\
M_{2+}{ }^{b}\end{array}$ & atop & bridge & $3 f h$ & $3 f f$ \\
\hline $\mathrm{Ni}(111)$ & $\begin{array}{c}0.40 \\
-0.84 \\
0.29 \\
0.15\end{array}$ & $\begin{array}{c}0.41 \\
-0.84 \\
0.44 \\
-0.01\end{array}$ & $\begin{array}{c}0.45 \\
-0.89 \\
0.50 \\
-0.07\end{array}$ & $\begin{array}{c}0.45 \\
-0.88 \\
0.50 \\
-0.07\end{array}$ \\
\hline $\mathrm{Cu}(111)$ & $\begin{array}{c}0.40 \\
-0.99 \\
0.31 \\
0.29\end{array}$ & $\begin{array}{c}0.42 \\
-1.02 \\
0.55 \\
0.05\end{array}$ & $\begin{array}{c}0.44 \\
-1.05 \\
0.64 \\
-0.03\end{array}$ & $\begin{array}{c}0.44 \\
-1.05 \\
0.62 \\
-0.02\end{array}$ \\
\hline $\mathrm{Ru}(0001)$ & $\begin{array}{c}0.40 \\
-0.74 \\
0.2 \\
0.13\end{array}$ & $\begin{array}{c}0.41 \\
-0.73 \\
0.25 \\
0.07\end{array}$ & $\begin{array}{c}0.44 \\
-0.74 \\
0.26 \\
0.03\end{array}$ & $\begin{array}{c}0.44 \\
-0.76 \\
0.29 \\
0.02\end{array}$ \\
\hline $\mathrm{Rh}(111)$ & $\begin{array}{c}0.40 \\
-0.73 \\
0.22 \\
0.11\end{array}$ & $\begin{array}{c}0.41 \\
-0.73 \\
0.28 \\
0.04\end{array}$ & $\begin{array}{c}0.44 \\
-0.77 \\
0.32 \\
0.01\end{array}$ & $\begin{array}{c}0.44 \\
-0.76 \\
0.32 \\
0.00\end{array}$ \\
\hline $\operatorname{Pd}(111)$ & $\begin{array}{c}0.40 \\
-0.75 \\
0.29 \\
0.07\end{array}$ & $\begin{array}{c}0.41 \\
-0.75 \\
0.39 \\
-0.05\end{array}$ & $\begin{array}{c}0.44 \\
-0.81 \\
0.45 \\
-0.08\end{array}$ & $\begin{array}{c}0.44 \\
-0.80 \\
0.48 \\
-0.12\end{array}$ \\
\hline $\operatorname{Ag}(111)$ & $\begin{array}{c}0.40 \\
-1.01 \\
0.28 \\
0.33\end{array}$ & $\begin{array}{c}0.41 \\
-1.04 \\
0.47 \\
0.16\end{array}$ & $\begin{array}{c}0.43 \\
-1.07 \\
0.57 \\
0.07\end{array}$ & $\begin{array}{c}0.43 \\
-1.07 \\
0.57 \\
0.07\end{array}$ \\
\hline $\operatorname{Re}(0001)$ & $\begin{array}{c}0.42 \\
-0.74 \\
0.21 \\
0.11\end{array}$ & $\begin{array}{c}0.41 \\
-0.77 \\
0.17 \\
0.19\end{array}$ & $\begin{array}{r}0.46 \\
-0.75 \\
0.14 \\
0.15\end{array}$ & $\begin{array}{c}0.46 \\
-0.79 \\
0.11 \\
0.23\end{array}$ \\
\hline Os(0001) & $\begin{array}{c}0.40 \\
-0.76 \\
0.19 \\
0.17\end{array}$ & $\begin{array}{c}0.41 \\
-0.77 \\
0.21 \\
0.16\end{array}$ & $\begin{array}{c}0.46 \\
-0.80 \\
0.18 \\
0.16\end{array}$ & $\begin{array}{c}0.45 \\
-0.82 \\
0.20 \\
0.16\end{array}$ \\
\hline $\operatorname{Ir}(111)$ & $\begin{array}{c}0.40 \\
-0.76 \\
0.24 \\
0.12\end{array}$ & $\begin{array}{c}0.41 \\
-0.75 \\
0.26 \\
0.08\end{array}$ & $\begin{array}{c}0.45 \\
-0.83 \\
0.27 \\
0.11\end{array}$ & $\begin{array}{c}0.46 \\
-0.82 \\
0.25 \\
0.11\end{array}$ \\
\hline $\operatorname{Pt}(111)$ & $\begin{array}{c}0.41 \\
-0.77 \\
0.31 \\
0.05\end{array}$ & $\begin{array}{c}0.41 \\
-0.76 \\
0.37 \\
-0.02\end{array}$ & $\begin{array}{c}0.45 \\
-0.87 \\
0.37 \\
0.05\end{array}$ & $\begin{array}{c}0.46 \\
-0.85 \\
0.40 \\
0.00\end{array}$ \\
\hline $\mathrm{Au}(111)$ & $\begin{array}{c}0.40 \\
-0.93 \\
0.30 \\
0.23\end{array}$ & $\begin{array}{c}0.40 \\
-0.96 \\
0.38 \\
0.17\end{array}$ & $\begin{array}{c}0.44 \\
-1.04 \\
0.43 \\
0.18\end{array}$ & $\begin{array}{c}0.44 \\
-1.04 \\
0.44 \\
0.17\end{array}$ \\
\hline
\end{tabular}


aThe total charge on the metal atoms which the $\mathrm{OH}^{*}$ adsorbate is bound directly to. ${ }^{\mathrm{b}}$ The total charge on all other metals in the system.

The adsorption of $\mathrm{OH}^{*}$ on the (100) surfaces of all of the studied $3 \mathrm{~d}-5 \mathrm{~d}$ transition metals is more favored at the bridge site rather than the hollow site, with the exception of $\mathrm{Cu}(100)$ and $\mathrm{Ag}(100)$, as is shown in Table 1.8. Comparing the binding energy preferences between $\mathrm{O}^{*}$ and $\mathrm{OH}^{*}$ on a (100) surface, there is a shift from the high-coordinated sites (in this case: hollow) for $0^{*}$ to the less coordinatively saturated bridge sites for $\mathrm{OH}^{*}$ in a similar manner to the results on the (111) surface. Among the metals, the binding energy difference between the hollow and bridge site range from 0.19 to $0.71 \mathrm{eV}$ with positive values preferring the bridge sites. This is an increase (towards more stable bridge sites) of $0.4-0.5 \mathrm{eV}$ compared to the $0^{*}$ case. This significantly lowers the diffusion barrier for all of the metals with the exception of Ir and Pt (because bridge was already preferred), where the barriers are increased $\sim 0.3 \mathrm{eV}$. Similar to the results for $0^{*}$ on (100) surfaces, the binding energies increase as you move from right-to-left along a particular row in the periodic table, where the more-coordinated hollow site is preferred and moving from $3 \mathrm{~d}$ to $5 \mathrm{~d}$ metals where the lesscoordinated bridge site is preferred.

Table 1.8. Binding Energy of $\mathrm{OH}^{*}$ on (100) Surfaces of Various Transition Metals and Binding Modes

\begin{tabular}{|c|c|c|c|c|}
\hline & atop & bridge & hollow & $\begin{array}{c}\text { diff. } \\
\text { barrier }^{a}\end{array}$ \\
\hline $\mathrm{Ni}(111)$ & -2.73 & -3.38 & -3.34 & 0.04 \\
\hline $\mathrm{Cu}(111)$ & -2.53 & -3.12 & -3.18 & 0.07 \\
\hline $\mathrm{Rh}(111)$ & -2.64 & -3.21 & -3.02 & 0.19 \\
\hline $\operatorname{Pd}(111)$ & -2.18 & -2.66 & -2.59 & 0.07 \\
\hline $\operatorname{Ag}(111)$ & -2.02 & -2.54 & -2.72 & 0.19 \\
\hline $\operatorname{Ir}(111)$ & -2.73 & -3.26 & -2.55 & 0.71 \\
\hline $\operatorname{Pt}(111)$ & -2.28 & -2.78 & -2.10 & 0.68 \\
\hline $\mathrm{Au}(111)$ & -1.69 & -2.12 & -1.91 & 0.21 \\
\hline
\end{tabular}

aifference in energy (absolute) between the hollow and bridge sites. 


\section{Conclusions}

In summary, $0^{*}$ prefers to sit in highly-coordinated 3fold sites on closed-packed surfaces. For fcc metals, it prefers $3 \mathrm{ff}$ sites and on hcp metals it prefers $3 \mathrm{fh}$ sites. These tendencies are wellestablished throughout literature and hold from a surface size of $2 \times 2$ up to $6 \times 6$ (in fact, surface size plays very little role in the binding energy, as expected). On the more open (100) surface, $0^{*}$ prefers to bind in a hollow site for all metals with the exception of Ir and $\operatorname{Pt}(100)$. Adding $\mathrm{H}^{*}$ to the $\mathrm{O}^{*}$ will weaken the interaction with the metal surface as predicted by bond-order-conservation (BOC) theory. The weakening has a larger impact upon the high-coordinated binding sites: the binding energy decreases by an average of $1.92 \mathrm{eV}$ in the 3 fold sites, $1.34 \mathrm{eV}$ for the bridge sites and $0.79 \mathrm{eV}$ for the atop sites. This uneven shift has two main impacts: 1) the most stable binding site changes from highly-coordinated 3-fold or hollow sites to low-coordinated bridge or atop sites for many metal surfaces; 2) the difference between binding energies of different sites is greatly decreased, resulting in increased mobility of $\mathrm{OH}^{*}$ compared to $0^{*}$ on metal surfaces (with the exceptions being (100) Ir and Pt).

QUAMBO-enabled Löwdin analysis of the charge reveals shows that coinage metals donate more electrons into the oxygen atom for both $\mathrm{O}^{*}$ and $\mathrm{OH}^{*}$ adsorptions. Adding $\mathrm{H}$ to the system (comparing $\mathrm{O}^{*}$ and $\mathrm{OH}^{*}$ ) increases the charge on the oxygen for non-coinage metals by $\sim 0.1$ electrons. It also results in less electron transfer from the metal to oxygen of $\mathrm{OH}^{*}$ as the $\mathrm{H}$ donates 0.4-0.46 electrons instead. There are, however, no significant changes in the charge on $0^{*}$ or $\mathrm{OH}^{*}$ between different binding sites, despite the observed differences in the chemical reactivity of these species as described subsequent chapters. To understand these differences a more in-depth understanding of the atomic orbitals and the nature of the lone pairs of oxygen is required, this work is being carried out by Craig Plaisance. 


\section{2: Hydrogen Bonding of $\mathrm{O}^{*}$ with $\mathrm{H}_{2} \mathrm{O}$ on Closed-Packed Metal Surfaces}

Atomically-bound oxygen is an important adsorbate in many catalytic reactions, including CO oxidation, ${ }^{22-24}$ methane partial oxidation and reforming ${ }^{25-31}$ as well as reactions that typically run in protic solvents such as alcohol oxidation ${ }^{32-37}$ and the oxygen reduction reaction (ORR). ${ }^{36-42}$ These reactions are often carried out on low-index transition metal surfaces, or supported nanoparticles of transition metals, which are mainly composed of closely packed terraces. Recently published work has demonstrated that oxygen on low-index surfaces can facilitate activation of $\mathrm{O}-\mathrm{H}$ bonds through a proton-transfer like mechanism on Pd, Pt and Au closed-packed surfaces. The transition state in these reactions involve the shift of oxygen from a neighboring three-fold site to the bridging site and the simultaneous activation of the $\mathrm{O}-\mathrm{H}$ bond..$^{36,37}$ Subsequent studies ${ }^{28,29}$ indicate that oxygen must shift from its stable, three-fold site on Pt and Rh to bridge sites in order to become active for the activation of the $\mathrm{C}-\mathrm{H}$ bonds of methane. Furthermore, the energy penalty required to shift oxygen to the bridge site depends upon the oxophilicity of the transition metal and the surface coverage of oxygen. ${ }^{28,29,31}$ (At higher coverages, the binding energy of oxygen decreases and it becomes easier to shift into a bridge site.) Therefore, if hydrogen bonding can preferentially stabilize oxygen in the bridge site, as compared to the stable three-fold site, the presence of a protic solvent may reduce the activation barrier for oxygen-assisted $\mathrm{O}-\mathrm{H}$ and $\mathrm{C}-\mathrm{H}$ activation. In addition to $\mathrm{O}-\mathrm{H}$ and $\mathrm{C}-\mathrm{H}$ bond activations, reduction of molecularly adsorbed oxygen also proceeds through the bridge binding mode, with one of the oxygen atoms shifting from the atop to the bridge position prior to $0-0$ cleavage. $^{36,41}$ Therefore, the ability of oxygen to hydrogen bond in the bridge site with co-adsorbates or a protic solvent can have a major impact upon the understanding of mechanisms in these catalytic systems. Furthermore, the transition state of oxygen diffusion across a closed packed surface is the bridge binding mode, indicating that if oxygen can interact with a protic solvent in this state, the surface diffusivity can be enhanced.

Herein we describe a computational study characterizing the ability of atomic oxygen bound to a range of metal surfaces in various binding modes to hydrogen bond with water. The metals studied include $3 d$ metals: $\mathrm{Co}, \mathrm{Ni}, \mathrm{Cu}$; $4 d$ : Tc, $\mathrm{Ru}, \mathrm{Rh}, \mathrm{Pd}, \mathrm{Ag}$; and $5 d$ : Re, Os, Ir, Pt and $\mathrm{Au}$. These 
calculations demonstrate that while atomic oxygen in its most stable 3-fold site interacts weakly with nearby water, oxygen in bridge sites form strong, orientation-dependent hydrogen bonds with up to two water molecules. Additionally, calculations were carried out to determine the impact of hydrogen bonding during surface diffusion of oxygen across the same set of transition metal surfaces. Furthermore, as you move across the periodic table from left to right, the hydrogen bond interactions become stronger as the binding energy of oxygen becomes weaker.

\section{Methods}

All of the calculations reported herein were carried out using periodic, planewave-based density functional theory (DFT) as implemented in VASP. ${ }^{1-4}$ The planewaves were constructed with an energy cutoff of $396 \mathrm{eV}$ using projector augmented-wave (PAW) potentials.5,6 To determine corrections to the exchange and correlation energies, the RPBE form of the generalized gradient approximation was used. $7^{7-9}$ Closed-packed surface calculations were run using a $3 \times 3$ unit cell with

four atomic layers and $10 \AA$ of vacuum in between slabs in the z-direction. To prevent the metal layers of the slab from relaxing in both directions, the bottom two layers were fixed in their bulk positions. During relaxation, the forces on unconstrained atoms were converged to $<0.01 \mathrm{eV} / \AA \AA$. In order to ensure accurate forces, the wavefunctions were converged to within $10^{-6} \mathrm{eV}$ with a $4 \times 4 \times 1$ Monkhorst-Pack ${ }^{10} \mathrm{k}$-point sampling of the first Brillouin zone and the forces were computed using an FFT grid with a cutoff of twice the planewave cutoff. Once geometric convergence was reached, a single-point calculation with an increased k-point sampling of $8 \times 8 \times 1$ was performed.

In order to separate the electrostatic and covalent-like interactions, water was placed in various positions around oxygen in a binding mode preserved by freezing the $0^{*}$ in the xy-plane. The metal atoms were allowed to fully optimized in the case of $0^{*}$ bound to 3 -fold sites and were optimized in the $y, z$-directions in the case of $0^{*}$ bound to bridge sites. This enabled the metal surface to relax while still constraining the binding mode of the $0^{*}$ adsorbate. The interaction energy was then computed by running two additional calculations to obtain the energy of the metal + $0^{*}$ system 
$\left(\mathrm{M}+\mathrm{O}^{*}\right)$, as well as the metal + water system $(\mathrm{M}+\mathrm{W})$ system, in which the species $\left(\mathrm{O}^{*}\right.$ or $\left.\mathrm{H}_{2} \mathrm{O}\right)$ were fixed in the positions they held during the interacting calculation. (Eqn 1).

$$
E_{H B}=E_{M+0+W}-E_{M+0}-E_{M+W}+E_{M}
$$

In addition to this interaction energy, electronic analysis was performed using the QUAMBO method, ${ }^{17}$ which transforms the wavefunctions of the VASP calculation into spatially localized nonorthogonal quasiatomic orbitals (QUAMBOs). This transformation provides information about the atomic orbitals of the system, and permits a Löwdin charge and bond order analysis. ${ }^{18,19}$ Unlike a Mulliken analysis, ${ }^{43}$ Löwdin's method does not produce orbital populations less than zero or greater than two, due to the an orthogonalization of the atomic orbitals which forms this restriction. ${ }^{18,19}$

In order to determine diffusive barriers, a two-stage approach was adopted to locate the transition state along the minimum energy path. First, the minimum energy path was estimated using a nudged elastic band (NEB) ${ }^{44}$ calculation with 16 intermediates converged until the force

normal to the reaction path was less than $0.3 \mathrm{eV} / \mathrm{A}$. Second, the results of the NEB were used to initiate a Dimer calculation, ${ }^{45}$ which uses a pair of closely-spaced structures to search for a saddle point on the potential energy surface. The Dimer calculation was converged until the normal force was less than $0.05 \mathrm{eV} / \AA ̊$ with a $4 \times 4 \times 1$ k-point mesh followed by a single-point energy calculation using an 8x8x1 k-point mesh (similar to the optimizations described above). The mode of the dimer method was checked to confirm that it belonged to the diffusion of $0^{*}$ across the bridge site.

\section{Results and Discussion}

The positions used to probe hydrogen bonding interactions between $\mathrm{H}_{2} \mathrm{O}$ and $\mathrm{O}^{*}$ are shown in Figure 1.11. As seen in Table 1.9, when $\mathrm{H}_{2} \mathrm{O}$ is oriented directly above $0^{*}$ (Figure 1.11A,C), forming a linear hydrogen bond which is normal to the surface, the average hydrogen bond is $\sim 10 \mathrm{~kJ} / \mathrm{mol}$, regardless of whether the $0^{*}$ is sitting in a bridge or 3-fold site. When $\mathrm{H}_{2} \mathrm{O}$ binds atop of a nearest neighbor metal atom via its oxygen at an angle $112-120^{\circ}$ (Figure 1.11B), the strength of the interaction between the bound water and the $0^{*}$ increases for most transition metals, resulting in an average increase in hydrogen bond energy of $\sim 9 \mathrm{~kJ} / \mathrm{mol}$ for the 3 -fold positions. This is somewhat 
unexpected, since the average $0^{*}-\mathrm{H}_{2} \mathrm{O}$ distance is $\sim 0.2 \AA$ longer than in the case where it is bound directly above. This is consistent with a decrease in the bond order and resonance integral observed by QUAMBO analysis. When $0^{*}$ is sitting in the bridge position, as shown in Figure 1C-E, the increase in hydrogen bond strength is $\sim 12 \mathrm{~kJ} / \mathrm{mol}$ when the water is shifted from directly above to interacting at an offset angle $105-115^{\circ}$, when a second water is present (Fig 1E), the overall increase in hydrogen bond strength is $66 \mathrm{~kJ} / \mathrm{mol}$, resulting in an average of $45 \mathrm{~kJ} / \mathrm{mol}$ per $\mathrm{H}_{2} \mathrm{O}$ molecule. This indicates that $\mathrm{O}^{*}$, sitting in a bridge site, can form strong hydrogen bond interactions with water and co-adsorbates, and that these interactions are stronger when water is interacting at an angle of $105-120^{\circ}$ to the oxygen atom. This result is consistent with $\mathrm{OH}^{*}$ in the bridge site, which prefers by $7-39 \mathrm{~kJ} / \mathrm{mol}$ to bind at an angle of $50-70^{\circ}$ to the surface normal vector depending on the metal surface. These results demonstrate that bridge-bound oxygen can be stabilized, relative to the 3 -fold state, through hydrogen bonding interactions. This is consistent earlier reports which suggest that oxygen sits in a bridge site during $\mathrm{H}$-transfer reactions. Furthermore, it suggests that water may assist during $\mathrm{O}^{*}$ diffusion, which will be discussed later. It is important to note that the increased hydrogen bonding ability does not make up for the weakened stability of the bridge site, shifting $0^{*}$ to the bridge site is still an endothermic process.

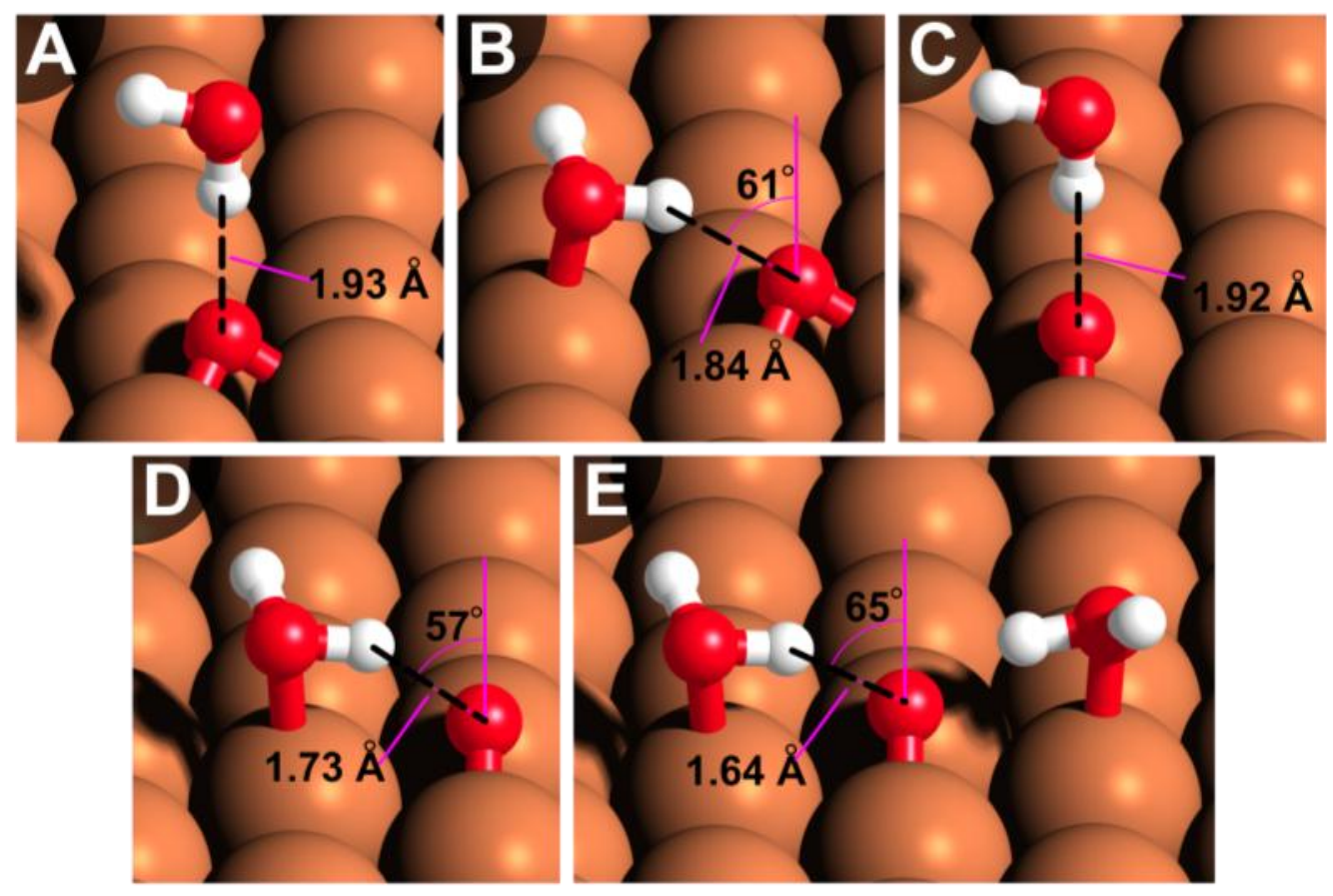


Figure 1.11. Positions of water around $0^{*}$ in 3 -fold and bridge sites, shown for $\mathrm{Cu}$. A) Above 3 -fold fcc site. B) Offset towards 3-fold fcc site. C) Above bridge site. D) Offset towards bridge site. E) Two waters offset towards a single bridge site.

Table 1.9. Average Hydrogen Bond Interactions between $\mathrm{H}_{2} \mathrm{O}$ and $\mathrm{O}^{*}$ on All Studied Transition Metals.

\begin{tabular}{ccccccccc}
\hline & & $\begin{array}{c}\mathrm{E}_{\mathrm{HB}} \\
(\mathrm{kJ} / \mathrm{mol})\end{array}$ & $\begin{array}{c}\mathrm{O}^{*} \\
\text { Chg. }\end{array}$ & $\begin{array}{c}\mathrm{M}-\mathrm{O} \\
(\AA)\end{array}$ & $\begin{array}{c}\mathrm{O}-\mathrm{H} \\
(\AA)\end{array}$ & $\begin{array}{c}\text { Bond } \\
\text { Order }\end{array}$ & $\begin{array}{c}\text { Charge } \\
\text { Transfer }\end{array}$ & $\begin{array}{c}\text { Resonance } \\
\text { Integral }\end{array}$ \\
\hline $\begin{array}{c}\text { 3-fold } \\
\text { fcc }\end{array}$ & above & -9.6 & -0.73 & 2.06 & 1.97 & 0.25 & 0.03 & -2.71 \\
& offset & -18.6 & -0.75 & 2.07 & 2.19 & 0.21 & 0.03 & -1.98 \\
3-fold & above & -8.4 & -0.71 & 2.05 & 1.98 & 0.24 & 0.03 & -2.66 \\
hcp & offset & -16.2 & -0.74 & 2.06 & 2.25 & 0.19 & 0.02 & -1.83 \\
& & & & & & & & \\
\multirow{2}{*}{ bridge } & above & -11.6 & -0.72 & 1.99 & 2.01 & 0.24 & 0.03 & -2.61 \\
& offset & -24.4 & -0.75 & 2.01 & 1.73 & 0.35 & 0.06 & -3.79 \\
& offset(2) & -45.2 & -0.78 & 2.08 & 1.54 & 0.45 & 0.09 & -5.17 \\
\hline
\end{tabular}

aThese values are averaged between the two waters, not totals.

Across the series of $3 \mathrm{~d}-5 \mathrm{~d}$ transition metals studied, the coinage metals $(\mathrm{Cu}, \mathrm{Ag}$ and $\mathrm{Au})$, behave quite differently from other metals as a result of their nearly filled d-band. For these metals, water directly above the $0^{*}$ still forms a moderately strong hydrogen bond of $\sim 20 \mathrm{~kJ} / \mathrm{mol}$ and $\sim 1.91$ $\AA$ An length, regardless of whether the $0^{*}$ is sitting in a 3-fold fcc, hcp or bridge site. QUAMBO analysis gives a bond order of 0.28 and a charge transfer between water and the adsorbed oxygen of 0.04 for all three cases. When water is shifted to an offset position, the hydrogen bond becomes stronger and shorter: an average of - $34 \mathrm{~kJ} / \mathrm{mol}$ and $1.83 \AA \AA$ when $0^{*}$ is sitting in the 3-fold sites. An increased bond order and charge transfer is also observed, to 0.33 and 0.06 . With $0^{*}$ in a bridge site, the hydrogen bond distance becomes slightly shorter $(1.72 \AA)$ and a very slight increase in strength is observed ($37 \mathrm{~kJ} / \mathrm{mol}, \mathrm{BO}=0.37, \mathrm{q}=0.07$ ). With the addition of a second water to interact with the bridge-bound $0^{*}$, the hydrogen bond strengths become shorter (1.63 $\AA$ ), stronger $(-46 \mathrm{~kJ} / \mathrm{mol}, \mathrm{BO}=0.41, \mathrm{q}=0.09)$ and the $0^{*}$ atom moves farther from the surface $(\mathrm{M}-0$ distances of $2.10 \AA \AA$ compared to $2.05 \AA$ with a single water interacting). These results are shown in Table 1.10 and the trends are consistent with 
the overall averages across all transition metals reported in Table 1.9, however the hydrogen bond is much stronger in the case of coinage metals.

Table 1.10. Average Hydrogen Bond Interactions between $\mathrm{H}_{2} \mathrm{O}$ and $\mathrm{O}^{*}$ on Coinage Metals

\begin{tabular}{|c|c|c|c|c|c|c|c|c|}
\hline & & $\begin{array}{c}\text { H-Bond } \\
\text { Energy } \\
E_{H B} \\
(\mathrm{~kJ} / \mathrm{mol}) \\
\end{array}$ & $\begin{array}{c}0^{*} \\
\text { Chg. } \\
z_{O}\end{array}$ & $\begin{array}{c}M-0 \\
d_{M O} \\
(\AA)\end{array}$ & $\begin{array}{l}\mathrm{O}-\mathrm{H} \\
d_{O H} \\
(\AA) \\
\end{array}$ & $\begin{array}{c}\text { Bond } \\
\text { Order } \\
\text { BO }\end{array}$ & $\begin{array}{c}\text { Charge } \\
\text { Transfer } \\
q\end{array}$ & $\begin{array}{c}\text { Resonance } \\
\text { Integral }\end{array}$ \\
\hline \multirow{2}{*}{$\begin{array}{l}\text { 3-fold } \\
\text { fcc }\end{array}$} & above & -18.8 & -1.01 & 2.09 & 1.91 & 0.28 & 0.04 & -3.05 \\
\hline & offset & -33.2 & -1.03 & 2.11 & 1.84 & 0.32 & 0.06 & -3.33 \\
\hline \multirow{2}{*}{$\begin{array}{l}\text { 3-fold } \\
\text { hcp }\end{array}$} & above & -19.3 & -1.01 & 2.10 & 1.93 & 0.28 & 0.04 & -2.98 \\
\hline & offset & -34.3 & -1.03 & 2.12 & 1.82 & 0.33 & 0.06 & -3.43 \\
\hline \multirow{3}{*}{ bridge } & above & -20.4 & -1.00 & 2.04 & 1.90 & 0.28 & 0.04 & -3.13 \\
\hline & offset & -36.7 & -1.01 & 2.05 & 1.72 & 0.37 & 0.07 & -3.97 \\
\hline & offset (2) ${ }^{a}$ & -46.4 & -1.00 & 2.10 & 1.63 & 0.41 & 0.09 & -4.52 \\
\hline
\end{tabular}

aThese values are averaged between the two waters, not totals.

As reported elsewhere, ${ }^{46}$ atomic oxygen adsorption on coinage metals results in greater charge transfer to the $0^{*}$ than on other noble transition metals despite the relatively low binding energy of oxygen to these surfaces (Au: $-2.6 \mathrm{eV}, \mathrm{Ag}:-3.3 \mathrm{eV}, \mathrm{Cu}:-4.5 \mathrm{eV}$ ). The QUAMBO-enabled Mulliken analysis performed here assigns a charge of -1.01 to the oxygen atom (averaged across all studied binding modes), compared to -0.70 for other transition metals. The increased charge on $0^{*}$ results in a hydrogen bond which is an average of $15 \mathrm{~kJ} / \mathrm{mol}$ stronger on coinage metals than on other transition metals through increased dipole interactions. Furthermore, due to the decreased oxygen binding energy on these surfaces, it is easier to shift $0^{*}$ from the 3 -fold to bridge sites. ${ }^{31}$ All of this indicates that atomic $0^{*}$ on coinage metals can be a very active chemical intermediate, capable of forming strong hydrogen bonds with $\mathrm{H}_{2} \mathrm{O}$ and co-adsorbates, as well as facilitate H-transfer reactions. ${ }^{47-52}$ Unfortunately, the decreased binding energy of $0^{*}$ also contributes to the difficulty of forming $\mathrm{O}^{*}$ on coinage metal surfaces, as $\mathrm{O}_{2}$ dissociation has been shown to be difficult over $\mathrm{Au}$ and Ag closed-packed surfaces $(\mathrm{Cu}$ is more oxophilic than $\mathrm{Au}$ or $\mathrm{Ag}$ and thus has a lower barrier for dissociation). 
During diffusion of $0^{*}$ from a 3 -fold fcc to a 3-fold hcp site, the $0^{*}$ adsorbate proceeds through a bridge intermediate as shown in Figure 1.11. In the absence of water, the average surface diffusion barrier is $27 \mathrm{~kJ} / \mathrm{mol}$ for coinage metals as shown in Figure 1.12. During the reaction, five metal atoms are principally involved, the two which are always bound to the $0^{*}\left(\mathrm{M}_{\mathrm{br}}\right)$, one metal atom which is losing its $\mathrm{M}-\mathrm{O}$ bond $\left(\mathrm{M}_{\mathrm{fcc}}\right)$, another metal atom which is forming a M-O bond $\left(\mathrm{M}_{\mathrm{hcp}}\right)$, and a sub-surface metal atom which forms a weak M-O bond when $\mathrm{O}^{*}$ sits in the 3-fold hcp site ( $\left.\mathrm{M}_{\text {sub }}\right)$. Examining the charge transfer during this reaction, Figure $1.12 \mathrm{~b}$ shows the change in charge through the course of the reaction on the $0^{*}$ and the five metal atoms involved, averaged across the three coinage metals. The charge on the $0^{*}$ slightly decreases during diffusion, peaking at +0.019 when at the bridge position, and in the final hcp position, the charge is 0.006 less than in the initial fcc position. The largest charge transfer occurs between $\mathrm{M}_{\mathrm{fcc}}$ and $\mathrm{M}_{\mathrm{hcp}}$ as expected, as the $\mathrm{O}-\mathrm{M}_{\mathrm{fcc}}$ bond breaks, the charge on $\mathrm{M}_{\mathrm{fcc}}$ decreases monotonically by 0.245 . In a similar manner, the charge on $\mathrm{M}_{\mathrm{hcp}}$ increases 0.238 due to the electron-withdrawing effect of the $0^{*}$ adsorbate. During the diffusion, the bridging metal atoms $\left(\mathrm{M}_{\mathrm{br}}\right)$ also see an increase in charge, a combined shift of 0.03 slightly before the bridging transition state.
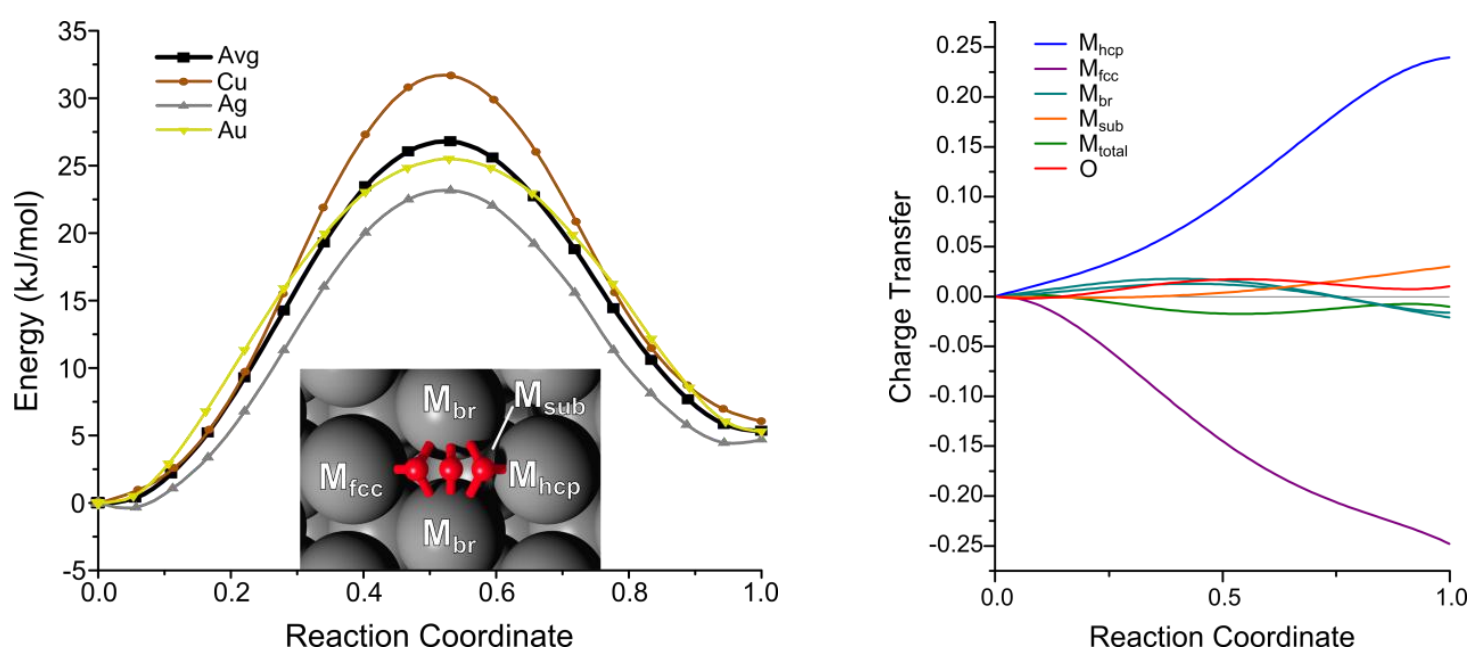

Figure 1.12. (Left) Reaction path diagrams for the diffusion of $O^{*}$ from the fcc site to the hcp site, through a bridging transition state. (Right) Charge transfer during the diffusion. 
With two water molecules present, the surface diffusion barriers on coinage metals decrease by an average of $11 \mathrm{~kJ} / \mathrm{mol}$ as shown in Figure 1.13, due to the increased ability of oxygen to hydrogen bond when in its bridge site as previously described. Charge analysis of the diffusion provides further insight into the role of water which is shown in Figure 1.13b. As before, the largest charge transfer is between $\mathrm{M}_{\mathrm{fcc}}$ and $\mathrm{M}_{\mathrm{hcp}}$, however in this case the magnitude of charge transfer is significantly decreased ( 0.11 e- compared to $0.24 \mathrm{e}-$ ) due to the ability of water to compensate charged (and partially charged) species. During the diffusion, the charge on water varies between 0.08 and -0.107 with the minimum charge occurring when oxygen is in the bridging position. The charge of oxygen varies between -1.032 and -1.009 , with the maximum charge occurring in the bridging position, mirroring the charge of water. These charge analysis results confirm that water can act as a charge accepting species during the formation of strong hydrogen bonds as the oxygen diffuses, preferentially stabilizing the bridge position, lowering the diffusion barrier. Due to the weak binding energy of $\mathrm{O}^{*}$ on a coinage metal surface, especially $\mathrm{Au}$ or $\mathrm{Ag}$, it is clear that in the presence of solution, very little energy is required for $0^{*}$ to diffuse on the surface or promote it to a bridge site, where it will become more active in surface chemistry, as described later.
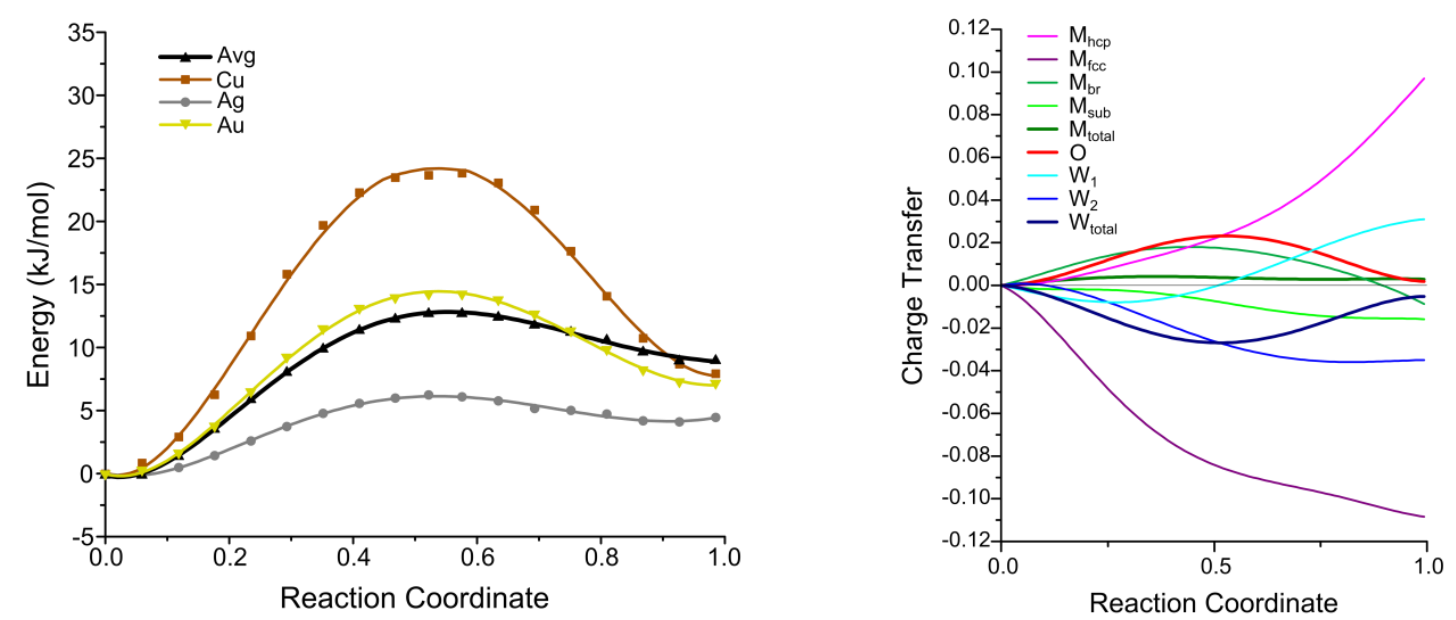

Figure 1.13. (Left) Reaction path diagrams for the diffusion of $0^{*}$ from the fcc site to the hcp site, through a bridging transition state with water present. (Right) Charge transfer during the diffusion. 
Pt-group metals (PGMs) with fcc crystal structures (Pt, Ir, Pd, and Rh), on the other hand, show decreased hydrogen bonding between $\mathrm{O}^{*}$ and $\mathrm{H}_{2} \mathrm{O}$, compared to other metals. On these surfaces, when $0^{*}$ is bound to a 3 -fold site and water is directly oriented above forming a linear HOH---O* interaction, the hydrogen bond is very weak $(\sim 5 \mathrm{~kJ} / \mathrm{mol})$ with an average distance of $1.97 \AA$ as shown in Table 1.11. QUAMBO analysis shows a bond order of 0.24 with a charge transfer between the water and $0^{*}$ of 0.03 , indicating a weaker H-bonding interaction when $\mathrm{O}^{*}$ is bound to fcc PGMs than to coinage metals. When the water is in an offset position, the interaction energy is calculated to be slightly stronger than when it is directly above, $\sim 9 \mathrm{~kJ} / \mathrm{mol}$. However, the hydrogen bond distance is much longer (2.39 $\AA$ ) and QUAMBO analysis shows a significantly smaller bond order (0.15) and charge transfer along the hydrogen bond (0.01). This indicates that the direct-through space interaction between water and $0^{*}$ is significantly weaker when the water is co-adsorbed next to $0^{*}$ in a 3-fold site, the observed interaction energy occurs predominantly through-surface interactions.

Table 1.11. Average Hydrogen Bond Interactions between $\mathrm{H}_{2} \mathrm{O}$ and $\mathrm{O}^{*}$ on fcc crystal structure PGMs (Rh, Pd, Ir, and Pt)

\begin{tabular}{|c|c|c|c|c|c|c|c|c|}
\hline & & $\begin{array}{c}E_{\mathrm{HB}} \\
(\mathrm{kJ} / \mathrm{mol})\end{array}$ & $\begin{array}{c}0^{*} \\
\text { Chg. }\end{array}$ & $\begin{array}{c}\mathrm{M}-0 \\
(\AA)\end{array}$ & $\begin{array}{c}\mathrm{O}-\mathrm{H} \\
(\AA)\end{array}$ & $\begin{array}{l}\text { Bond } \\
\text { Order }\end{array}$ & $\begin{array}{l}\text { Charge } \\
\text { Transfer }\end{array}$ & $\begin{array}{c}\text { Resonance } \\
\text { Integral }\end{array}$ \\
\hline \multirow{2}{*}{$\begin{array}{l}\text { 3-fold } \\
\text { fcc }\end{array}$} & above & -5.0 & -0.61 & 2.05 & 1.98 & 0.24 & 0.03 & -2.63 \\
\hline & offset & -8.9 & -0.63 & 2.06 & 2.39 & 0.15 & 0.01 & -1.30 \\
\hline \multirow{3}{*}{$\begin{array}{c}\text { 3-fold } \\
\text { hcp }\end{array}$} & above & -3.9 & -0.60 & 2.05 & 1.96 & 0.24 & 0.03 & -2.68 \\
\hline & offset & -8.0 & -0.62 & 2.06 & 2.39 & 0.15 & 0.01 & -1.29 \\
\hline & above & -8.1 & -0.61 & 1.98 & 2.07 & 0.22 & 0.02 & -2.36 \\
\hline \multirow[t]{2}{*}{ bridge } & offset & -18.1 & -0.64 & 2.00 & 1.79 & 0.32 & 0.06 & -3.48 \\
\hline & offset $(2)^{a}$ & -34.4 & -0.68 & 2.06 & 1.61 & 0.41 & 0.09 & -4.69 \\
\hline
\end{tabular}

aThese values are averaged between the two waters, not totals.

When $0^{*}$ is sitting in a bridge site, the results are much more consistent with the results over coinage metals, although the hydrogen bonds are weaker. When water is directly above a bridgebound $\mathrm{O}^{*}$, the average hydrogen bond interaction energy is $8 \mathrm{~kJ} / \mathrm{mol}$, approximately $3 \mathrm{~kJ} / \mathrm{mol}$ stronger than when $0^{*}$ is sitting in a 3 -fold site. The average bond order and charge transfer are slightly smaller ( 0.22 and 0.02 , respectively), which is consistent with the longer hydrogen bond distance (2.07 ̊̊ compared to $1.97 \AA$ ). When the water is shifted to an offset position, the hydrogen 
bond is stronger $(18 \mathrm{~kJ} / \mathrm{mol}, \mathrm{BO}=0.32, \mathrm{q}=0.06)$ and shorter $(1.79 \AA ̊)$, consistent with the results over coinage metals. With a second water present, the interactions become much stronger (34 $\mathrm{kJ} / \mathrm{mol}, \mathrm{BO}=0.41, \mathrm{q}=0.09 \mathrm{each})$, which is consistent with a shorter bond distance $(1.61 \AA)$. As the hydrogen bonds become stronger between the above, offset and 2-offset orientations, the $0^{*}$ is moving farther away from the surface, the $\mathrm{M}-0^{*}$ bonds increase from $1.98 \AA$ to $2.00 \AA$ to $2.06 \AA$ and the charge on the $0^{*}$ increases from -0.61 to -0.64 to -0.69 , most of which is from charge transfer directly between the $0^{*}$ and the water, rather than increased charged transfer from the metal.

Unlike $0^{*}$ bound to a 3 -fold fcc site, $0^{*}$ bound to a hcp crystal structure platinum group metals (Ru or Os) shows very different behavior. When $0^{*}$ is bound to the more stable hcp site, the interaction with water is similar to $0^{*}$ bound to the fcc-PGM, as shown in Table 1.12. However, when $0^{*}$ is bound to an fcc site, the interaction with water is nearly $2 \mathrm{x}$ as strong, regardless of whether water is directly above or co-adsorbed next to the $0^{*}$ adsorbate. When $0^{*}$ is in the bridge site and interacting with two water molecules simultaneously, the hydrogen bond interactions are very strong $(-59 \mathrm{~kJ} / \mathrm{mol})$ with very high bond orders and charge transfer predicted by QUAMBO analysis $(0.53$ and 0.15$)$ which is consistent with very short $0-\mathrm{H}$ distances $(1.38 \AA$ ) .

Table 1.12. Average Hydrogen Bond Interactions between $\mathrm{H}_{2} \mathrm{O}$ and $\mathrm{O}^{*}$ on hcp crystal structure PGMs (Ru and Os)

\begin{tabular}{|c|c|c|c|c|c|c|c|c|}
\hline & & $\begin{array}{c}\mathrm{E}_{\mathrm{HB}} \\
(\mathrm{kJ} / \mathrm{mol})\end{array}$ & $\begin{array}{c}0^{*} \\
\text { Chg }\end{array}$ & $\begin{array}{c}\mathrm{M-O} \\
(\AA)\end{array}$ & $\begin{array}{c}\mathrm{O}-\mathrm{H} \\
(\AA)\end{array}$ & $\begin{array}{l}\text { Bond } \\
\text { Order }\end{array}$ & $\begin{array}{l}\text { Charge } \\
\text { Transfer }\end{array}$ & $\begin{array}{c}\text { Resonance } \\
\text { Integral }\end{array}$ \\
\hline \multirow{2}{*}{$\begin{array}{l}\text { 3-fold } \\
\text { fcc }\end{array}$} & above & -7.2 & -0.65 & 2.08 & 2.03 & 0.23 & 0.03 & -2.46 \\
\hline & offset & -16.8 & -0.69 & 2.10 & 2.18 & 0.20 & 0.02 & -1.77 \\
\hline \multirow{3}{*}{$\begin{array}{l}\text { 3-fold } \\
\text { hcp }\end{array}$} & above & -4.3 & -0.62 & 2.04 & 2.09 & 0.20 & 0.02 & -2.20 \\
\hline & offset & -7.7 & -0.65 & 2.06 & 2.47 & 0.13 & 0.01 & -1.07 \\
\hline & above & -7.9 & -0.64 & 1.99 & 2.03 & 0.22 & 0.03 & -2.47 \\
\hline \multirow[t]{2}{*}{ bridge } & offset & -21.0 & -0.68 & 2.02 & 1.67 & 0.36 & 0.07 & -4.05 \\
\hline & offset $(2)^{a}$ & -59.8 & -0.72 & 2.14 & 1.38 & 0.53 & 0.15 & -6.51 \\
\hline
\end{tabular}

aThese values are averaged between the two waters, not totals.

When $0^{*}$ is bound to a more oxophilic metal such as Re or Tc studied here, , the hydrogen bonding interactions are very weak, regardless of the binding mode of $\mathrm{O}^{*}$ or the location of the water. This is consistent with bond-order conservation principles, as the $\mathrm{O}-\mathrm{M}$ interaction strengthens, the 
$0^{*}$ is less likely to interact with water (or anything else). These results indicate that on these surfaces, it is very unlikely that $\mathrm{O}^{*}$ will act as a Brønsted base, assisting in abstraction of acidic $\mathrm{H}$.

Table 1.13. Average Hydrogen Bond Interactions between $\mathrm{H}_{2} \mathrm{O}$ and $\mathrm{O}^{*}$ on oxophilic metals (Tc and Re)

\begin{tabular}{ccccccccc}
\hline \multicolumn{1}{c}{} & & $\begin{array}{c}\mathrm{E}_{\mathrm{HB}} \\
(\mathrm{kJ} / \mathrm{mol})\end{array}$ & $\begin{array}{c}\mathrm{O}^{*} \\
\mathrm{Chg}\end{array}$ & $\begin{array}{c}\mathrm{M}-\mathrm{O} \\
(\AA)\end{array}$ & $\begin{array}{c}\mathrm{O}-\mathrm{H} \\
(\AA)\end{array}$ & $\begin{array}{c}\text { Bond } \\
\text { Order }\end{array}$ & $\begin{array}{c}\text { Charge } \\
\text { Transfer }\end{array}$ & $\begin{array}{c}\text { Resonance } \\
\text { Integral }\end{array}$ \\
\hline $\begin{array}{c}\text { 3-fold } \\
\text { fcc }\end{array}$ & above & -6.6 & -0.65 & 2.08 & 1.95 & 0.25 & 0.03 & -2.73 \\
& offset & -15.3 & -0.66 & 2.09 & 2.27 & 0.22 & 0.02 & -1.93 \\
3-fold & above & -7.1 & -0.61 & 2.04 & 2.06 & 0.22 & 0.02 & -2.25 \\
hcp & offset & -9.4 & -0.63 & 2.05 & 2.51 & 0.13 & 0.01 & -0.98 \\
& & & & & & & & \\
& above & -8.2 & -0.63 & 1.98 & 2.03 & 0.23 & 0.03 & -2.45 \\
bridge & offset & -10.1 & -0.66 & 1.99 & 1.90 & 0.26 & 0.04 & -2.72 \\
& offset(2) & -14.2 & -0.70 & 2.02 & 1.84 & 0.31 & 0.05 & -3.22 \\
\hline
\end{tabular}

aThese values are averaged between the two waters, not totals.

\section{Conclusions}

In summary, the ability of $0^{*}$ to hydrogen bond with water strongly depends upon the binding mode as well as the nature and the structure of the metal surface structure. These interactions can be quantified through frozen-structure DFT calculations as well as through constructions of orthogonal quasiatomic orbitals which enables Löwdin charge and bond order analysis. The results indicate that $0^{*}$ bound to coinage metals interact the most with nearby water molecules due to a combination of factors, including the weaker binding energies and the increased charge of $0^{*}$ when adsorbed to those metals. The interactions are strongest when $0^{*}$ is bound to a bridge site and the waters are in an 'offset' position, where they can partially interact with the surface while hydrogen bonding with $0^{*}$. The preferential hydrogen bonding to $0^{*}$ in the bridge site significantly lowers the surface diffusion barrier for $0^{*}$ on coinage metals with water present. This is established through a charge compensation mechanism, as evidenced by a Löwdin analysis. This site dependence also supports previous results which has shown that $0^{*}$ shifts to a bridge position when assisting in $\mathrm{C}-\mathrm{H}$ or $\mathrm{O}-\mathrm{H}$ activations. On PGMs, the $\mathrm{O}^{*}$ adsorbate binds stronger to the surface than on $\mathrm{Au}$ or Ag (although $\mathrm{O}^{*}$ binds stronger to $\mathrm{Cu}$ than to $\mathrm{Pt}$ or $\mathrm{Pd}$ ). Furthermore, there is much less charge transfer to the $0^{*}$ adsorbate when bound to PGMs compared to coinage metals. This results in 
weaker interactions between $0^{*}$ and water when $0^{*}$ is bound to these PGMs compared to coinage metals, although in the bridge position, it still forms strong hydrogen bonds with water, especially when $\mathrm{O}^{*}$ is bound to hcp-PGMs ( $\mathrm{Ru}$ and $\mathrm{Os}$ ). When $\mathrm{O}^{*}$ is bound to more oxophilic metals, on the other hand, the interactions between $0^{*}$ and water are very weak, regardless of the binding position of $0^{*}$ or the position of water. This is consistent with work, presented later in the dissertation, that show that $\mathrm{O}^{*}$ can assist in $\mathrm{O}-\mathrm{H}$ or $\mathrm{C}-\mathrm{H}$ bond activation reactions (i.e. to act as a Brønsted base, abstracting a $\mathrm{H}$ ). The role of $\mathrm{O}^{*}$ is strongly dependent upon its binding energy to the metal, with more weakly bound $0^{* \prime}$ s being more active. Continued work is necessary to analyze the diffusion of $0^{*}$ (with and without the presence of water) on oxophilic and PGMs. 


\section{3: Nature of $\mathrm{O}^{*}$ and $\mathrm{OH}^{*}$ at Higher Coverages on Closed-Packed Metal Surfaces}

As shown in Table 1.3, the preferred binding mode of oxygen on an fcc surface is the $3 \mathrm{ff}$ site, followed closely by the $3 \mathrm{fh}$ site (which is weaker by an average of $0.16 \mathrm{eV}$ ), then bridge (weaker by an average of $0.53 \mathrm{eV}$ ), and finally atop (weaker by an average of $1.47 \mathrm{eV}$ ). On a $3 \times 3$ surface, this can be visualized as potential energy surface (PES) as shown in Figure 1.14a for a Pd(111) surface, where red represents strong binding sites and blue represents weak binding sites. ${ }^{i}$ When a second oxygen atom binds, it binds most strongly to a 3-fold-fcc site as far away from the first oxygen atom as possible, as shown in Figure 1.14b; this is repeated with the binding of a third oxygen atom, as shown in Figure 1.14c. However, once three oxygen atoms are present on the $3 \times 3$ surface, binding the fourth oxygen will result in metal-atom-sharing between oxygen adsorbates, which results in a significant decrease in the binding energy and the remaining six 3-fold fcc sites are all symmetrically equivalent as shown in Figure 1.14d. Figure 1.14d also shows that the site above a bound oxygen atom, which would create a vertically bound dioxygen, starts to become somewhat competitive with binding of $0^{*}$ to a vacant 3 -fold-fcc site, this trend will continue and at a coverage of $6 / 9 \mathrm{ML}$ the binding of dioxygen in a 3-fold-fcc site is more favored than binding two oxygen atoms in 3-fold-fcc sites. Overall, as you increase the coverage of oxygen atoms from 1/9 to $9 / 9 \mathrm{ML}$, the binding energy decreases from $-4.17 \mathrm{eV}$ to $-1.54 \mathrm{eV}$ in an almost linear fashion (though the decreases are somewhat step-wise, with the largest decreases in binding energy coming at the binding of the $4^{\text {th }}$ and $7^{\text {th }}$ oxygen atom, because metal-atom-sharing increases at these points, due to the size of the unit cell studied).

\footnotetext{
${ }^{\mathrm{i}}$ This potential energy surface (PES) is obtained by taking a relaxing a $3 \times 3$ Pd metal surface with a set number of oxygen atoms present. After relaxation, a series of calculations are run in which an additional oxygen atom is added at various $\mathrm{x}, \mathrm{y}$ positions of the unit cell, allowing only the z-direction to relax. For these calculations, the grid size of the surface was 9x9, which allows for sampling at the atop, bridge and 3 fold positions of the metal surface. The energies found are run through a surface-construction algorithm in order to create the heat-maps seen here.
} 
This trend is consistent across a variety of metals as shown in Figure 1.15, while the initial binding energies varying due to changes in the valency and d-band center, the pattern of decrease in binding energy is similar (although on $\mathrm{Cu}$ the increase is more dramatic than other metals).

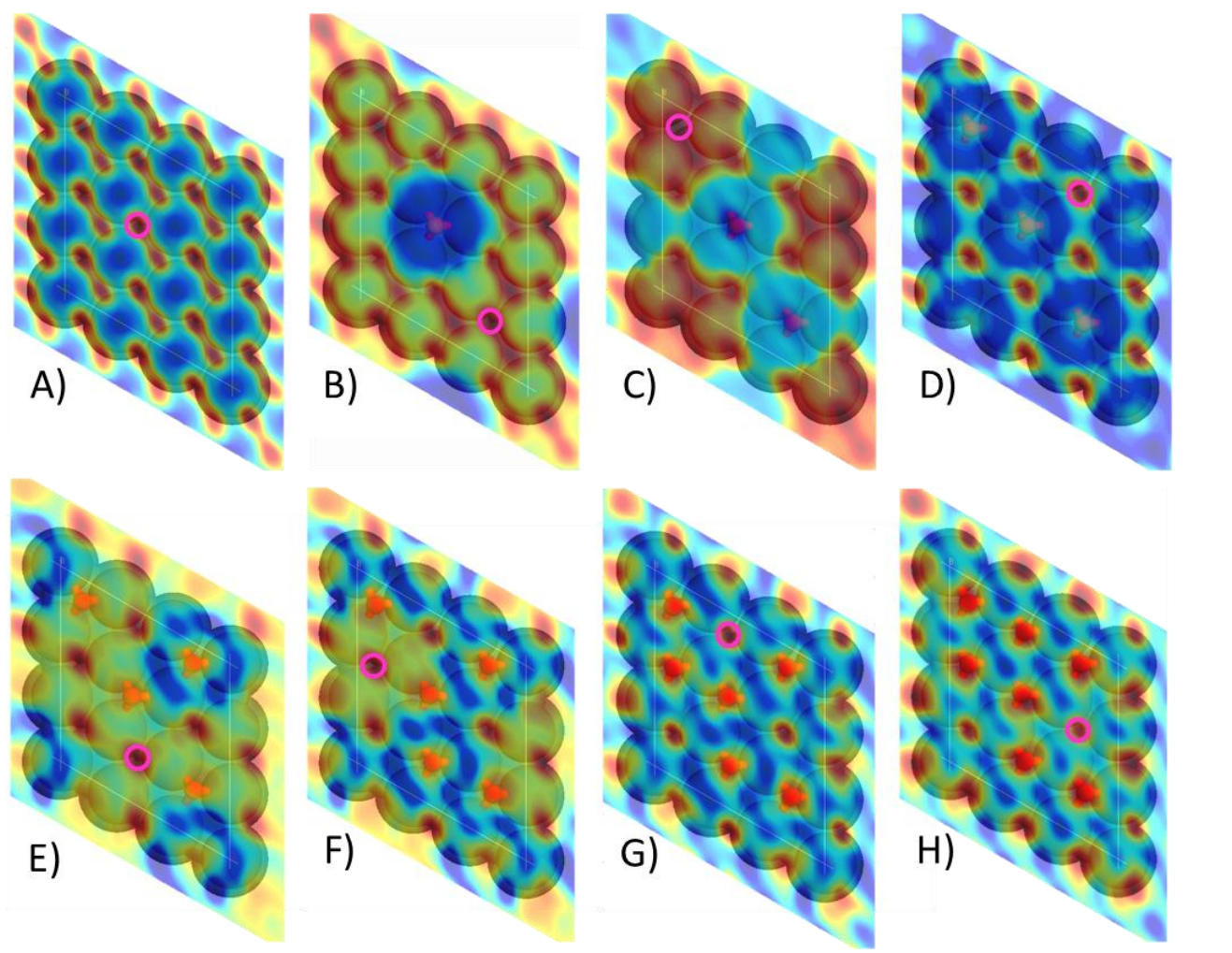

Figure 1.14. Potential energy surface (PES) calculations for the adsorption of $0^{*}$ on a $3 \times 3 \mathrm{Pd}(111)$ surface with increasing $0^{*}$ coverage. 


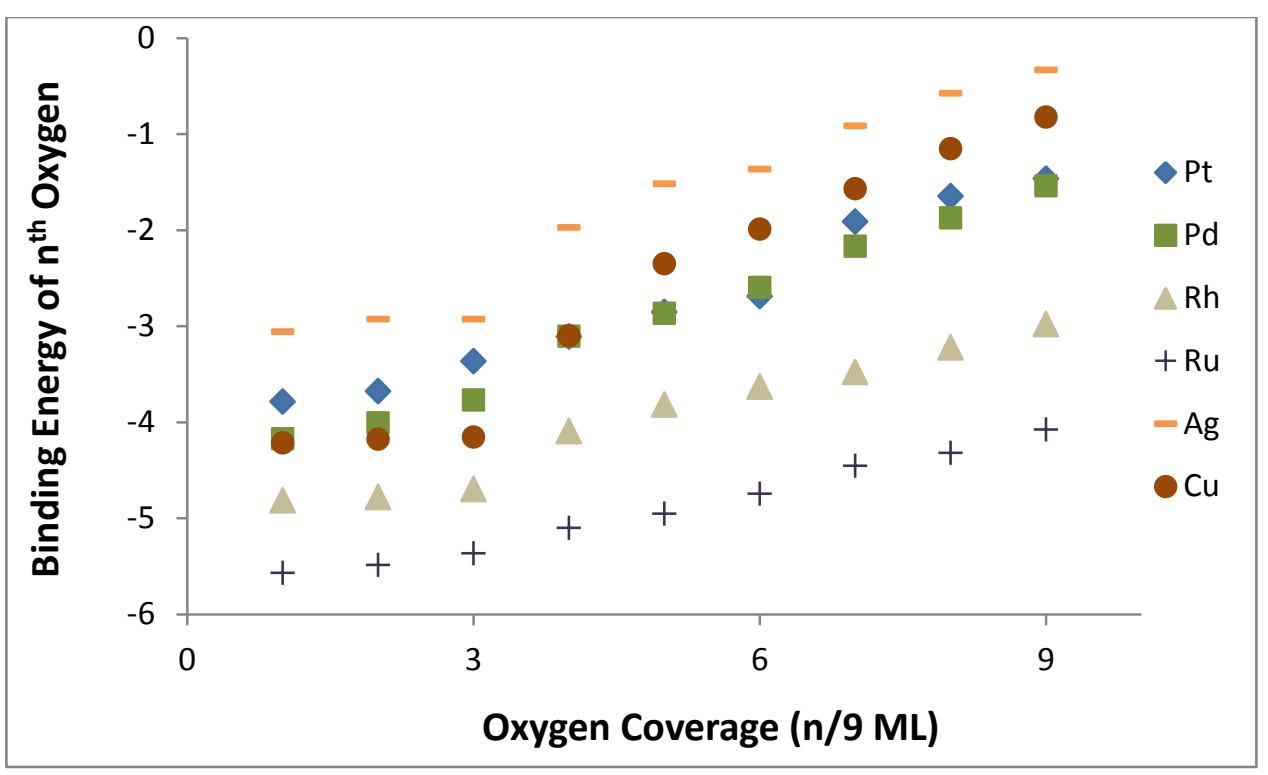

Figure 1.15. Differential binding energy (defined in Section 3.1) of $O^{*}$ from $1 / 9$ to 1 ML on selected fcc metals. Calculations performed by Corneliu Buda. Figure adopted from manuscript discussed in "The Study of Methane Activation over Clean and Oxygen-Covered Transition Metals" of Chapter 3.

Hydroxide, on the other hand, shows very different behavior at high coverages on noble metal catalysts. Due to the ability to hydrogen bond with other hydroxyl species on the surface, and the high mobility of these species as was described in the previous section, the hydroxyl groups will move along the catalyst surface until they find another hydroxyl to interact with. To model the impact of these observations, calculations were carried out on a 3x3 and 4x4 Pt(111) surface, varying coverage from 1/16 - $1 \mathrm{ML}$. Table 1.14 demonstrates that with $2 \mathrm{OH}^{*}$ on the surface, they prefer to occupy adjacent atop positions and hydrogen bond with an angle of 120 degrees between the two $\mathrm{OH}$ groups as shown in Figure 1.16c. This bent configuration of the hydrogen bond is slightly lower in energy (stronger) than a linear orientation $(\sim 0.02 \mathrm{eV}$ lower). When we examine the likely possibilities of orienting three hydroxyls on a surface (Figure 1.16d-h) the $3 \mathrm{x} 3$ size of the unit cell means that hydroxide can arrange themselves linearly in a periodic manner as shown in Figure 1.16d, resulting in a total BE of -6.92 and an HBE of $-0.74 \mathrm{eV}$, or $-0.25 \mathrm{eV}$ per hydrogen bond. When arranged at an angle towards each other (Figure 1.16e), the total HBE is $-0.55 \mathrm{eV}$ or $-0.27 \mathrm{eV}$ per 
hydrogen bond. Examining other configurations, Figures $1.16 \mathrm{f}$ and $1.16 \mathrm{~g}$ show that there is a significant penalty in two hydroxyls hydrogen bonding to the oxygen of a third and that this penalty is greater when the cluster is crowded across adjacent metal atoms (Figure 1.16f) as opposed to the more symmetrical and spread out orientation pictured in Figure 1.16g. Figure 1.16h shows a different type of hydrogen bonding interaction, in which one hydroxide is interacting with two others at the same time. This arrangement is further examined in Figure 1.17, which shows that in this type of configuration, $\mathrm{OH}^{*}$ slightly prefers to orient towards the center of the two other $\mathrm{OH}^{*}$ on the surface to interact with both. This angular study also demonstrates that the total interaction energy between the hydroxides can vary by up to $0.33 \mathrm{eV}$. At higher coverages, additional $\mathrm{OH}^{*}$ species add to the surface in a manner to reduce oxygen-atom-sharing among hydrogen bonds and there's some preference towards bent rather than linear hydrogen bonds. Figure 1.16p, once again shows an interaction in which each hydroxide interacts with two others at the same time, at full coverage, this configuration has been reported as the most favorable, ${ }^{53}$ however that was not the result we observed. 

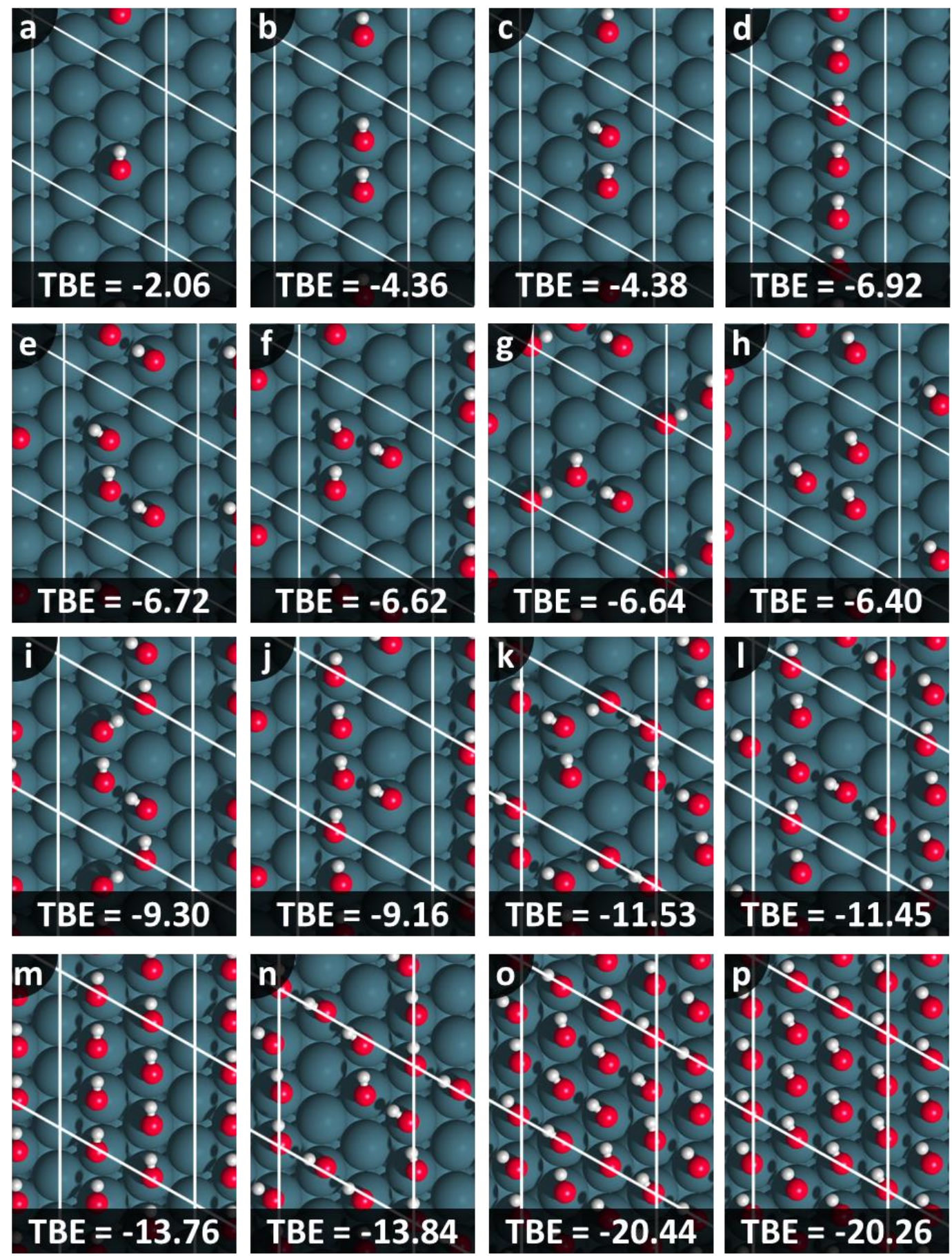

Figure 1.16. Total binding energy (TBE) of different amounts of $\mathrm{OH}^{*}$ on a $3 \times 3 \mathrm{Pt}(111)$ surface. 
Table 1.14. Binding and Hydrogen Binding Energies (HBE) of $\mathrm{OH}^{*}$ on a $3 \times 3$ Pt(111) Surface.

\begin{tabular}{lcccccc}
\hline & & Total & Avg. & Hyd. & Total & Avg. \\
& $n$ OH & BE & BE & Bonds & HBE & HBE \\
\hline Figure 1.16(a) & 1 & -2.06 & -2.06 & & & \\
Figure 1.16(b) & 2 & -4.36 & -2.18 & 1 & -0.25 & -0.25 \\
Figure 1.16(c) & 2 & -4.38 & -2.19 & 1 & -0.27 & -0.27 \\
Figure 1.16(d) & 3 & -6.92 & -2.31 & 3 & -0.74 & -0.25 \\
Figure 1.16(e) & 3 & -6.72 & -2.24 & 2 & -0.55 & -0.27 \\
Figure 1.16(g) & 3 & -6.64 & -2.21 & 2 & -0.46 & -0.23 \\
Figure 1.16(f) & 3 & -6.62 & -2.21 & 2 & -0.44 & -0.22 \\
Figure 1.16(h) & 3 & -6.40 & -2.13 & 1 & -0.22 & -0.22 \\
Figure 1.16(i) & 4 & -9.30 & -2.32 & 4 & -1.06 & -0.26 \\
Figure 1.16(j) & 4 & -9.16 & -2.29 & 4 & -0.92 & -0.23 \\
Figure 1.16(k) & 5 & -11.53 & -2.31 & 5 & -1.24 & -0.25 \\
Figure 1.16(l) & 5 & -11.45 & -2.29 & 5 & -1.16 & -0.23 \\
Figure 1.16(m) & 6 & -13.84 & -2.31 & 6 & -1.49 & -0.25 \\
Figure 1.16(n) & 6 & -13.76 & -2.29 & 6 & -1.41 & -0.24 \\
Figure 1.16(o) & 9 & -20.44 & -2.27 & 9 & -1.91 & -0.21 \\
Figure 1.16(p) & 9 & -20.26 & -2.25 & 9 & -1.73 & -0.19 \\
\hline
\end{tabular}

${ }^{\mathrm{a}} \mathrm{HBE}=\mathrm{BE}-(\mathrm{n} \mathrm{OH}) * \mathrm{BE}_{\mathrm{OH} 1}$

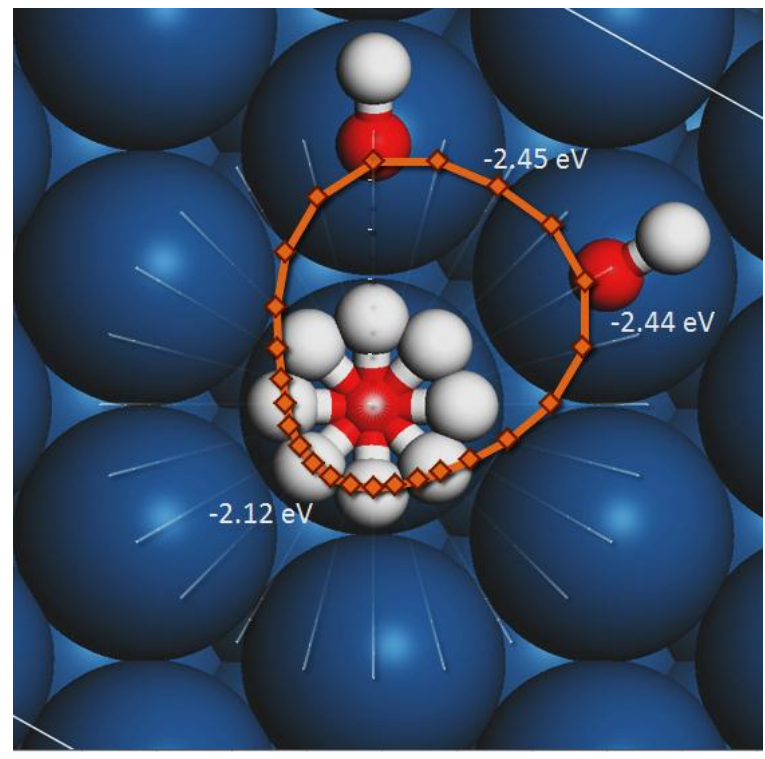

Figure 1.17. The interaction of one $\mathrm{OH}^{*}$ with two others, the peak is oriented in between the two others with a differential binding energy of $-2.45 \mathrm{eV}$. Oriented directly at a different $\mathrm{OH}^{*}$ yields -2.44 $\mathrm{eV}$. Oriented away from both results in $-2.12 \mathrm{eV}$. 
On a $4 \times 4$ surface, more configurations are possible due to the increased unit cell size. If we consider the different types of interactions between a number of $\mathrm{OH}^{*}$ on a surface $(\mathrm{OH})$, the bent $(B H)$ hydrogen bond, the linear $(L H)$ hydrogen bond, coupled with the penalties from sharing an oxygen atom in a tight or wide configuration $(\mathrm{Ot}, \mathrm{Ow})$, each type affects the total binding energy of the configuration. Through modeling of a large number of configurations, we are able generate a correlation (Eq. 1.1) to predict the total binding energy of $\mathrm{OH}^{*}$ on a $\operatorname{Pt}(111)$ surface within $1 \%$ as shown in this parity plot (Figure 1.18) and the hydrogen binding energy within $12 \%$. This can be used in a variety of ways, including kinetic Monte Carlo (KMC) simulations in which multiple configurations of $\mathrm{OH}^{*}$ can exist.

$$
\mathrm{BE}(\mathrm{eV})=-2.0854^{*} O H-0.209^{*} L H-0.231^{*} B H+9.2 \times 10^{-5 *} O H^{3}+0.051^{*} O t
$$

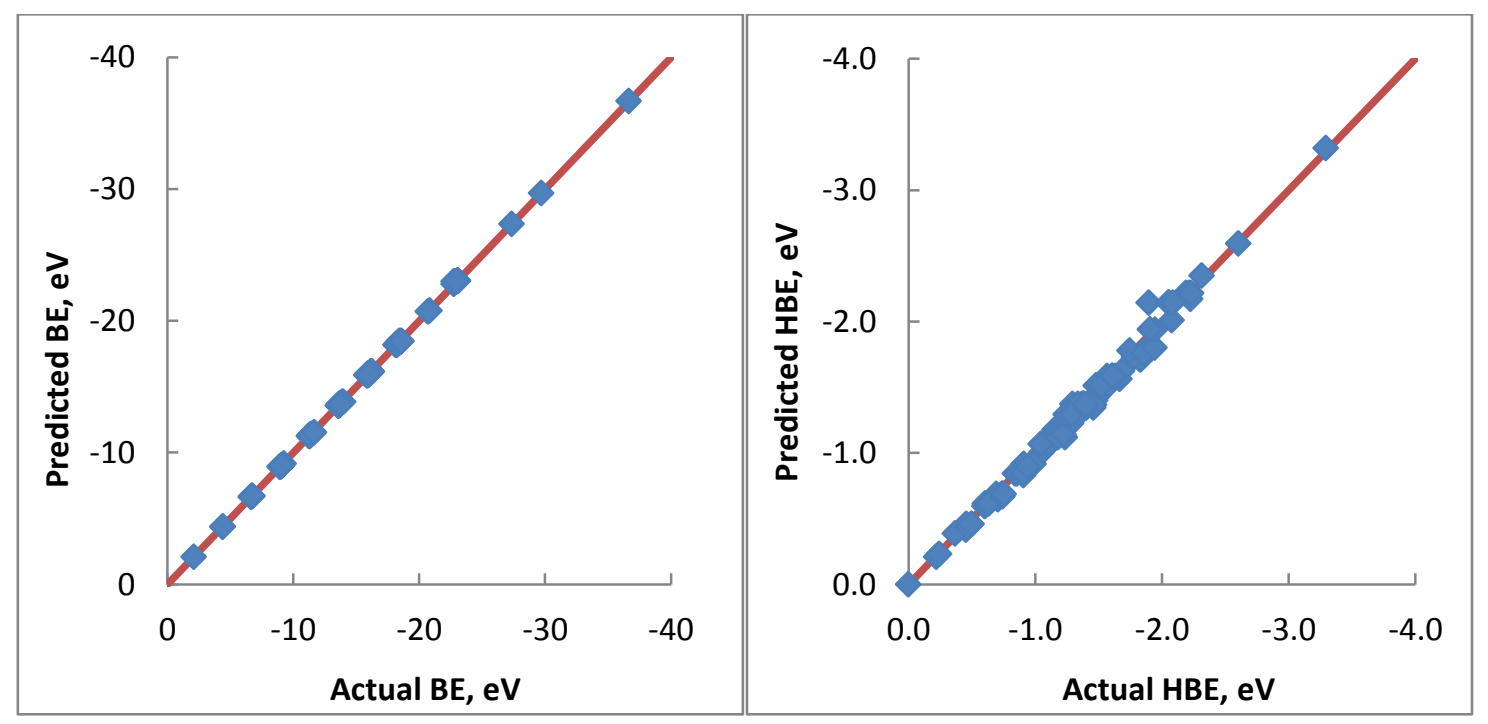

Figure 1.18. Parity plots for the total binding energy (left) and hydrogen bond energy (right) as predicted by Equation 1.1. 


\section{2...Aqueous-Phase Oxidation of Alcohols over Au, Pt and Pd Catalysts}

\section{1: Reactivity of the Gold/Water Interface during Selective Oxidation Catalysis.}

Gold catalysts show very high activity during the oxidation of alcohols at high $\mathrm{pH}$. This collaborative study examines the role of $\mathrm{pH}$ and $\mathrm{O}_{2}$ during this process.

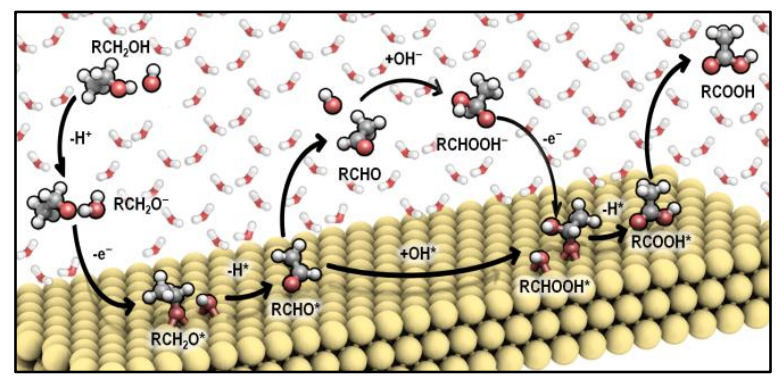

2.2: Influence of Oxygen and $p H$ during Selective Oxidation of Ethanol over Pd Catalysts

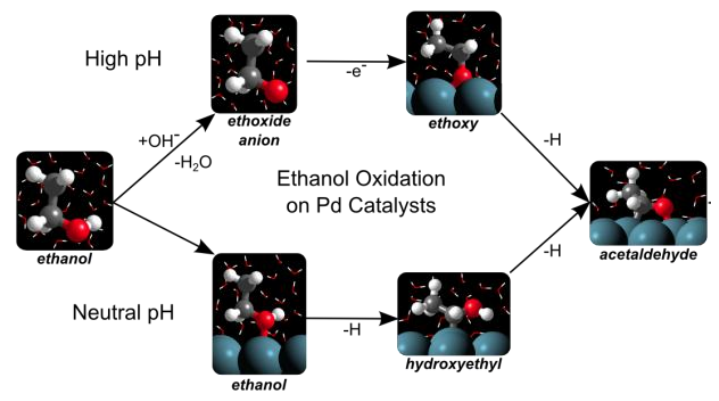

In a follow-up paper, a more comprehensive examination of the mechanism was performed on Pd catalysts. This work demonstrated the likely shift in mechanism as $\mathrm{pH}$ is reduced from basic, to neutral and acidic conditions. 


\section{Reactivity of the Gold/Water Interface during Selective Oxidation Catalysis}

[Adopted from: B. N. Zope, D. D. Hibbitts, M. Neurock, R. J. Davis, Science 330, 74 (2010).]

The selective oxidation of alcohols with molecular oxygen over gold catalysts in liquid water offers a sustainable, environmentally-benign alternative to traditional processes that utilize expensive inorganic oxidants and harmful organic solvents. ${ }^{54,55}$ These catalytic transformations are important to the rapidly-developing industry based on the conversion of biorenewable feedstocks to higher-valued chemicals ${ }^{32,56}$ as well as the current production of petrochemicals. Although gold is the noblest of metals, ${ }^{57}$ the water-gold interface provides a unique reaction environment that substantially enhances its catalytic performance. We provide here direct evidence for the predominant reaction path during alcohol oxidation at high $\mathrm{pH}$ that includes the coupling of both solution-mediated and metal-catalyzed elementary steps.

Alcohol oxidation catalyzed by Pt-group metals has been studied extensively, although the precise reaction path and extent of oxygen contribution are still under debate. ${ }^{32-34,58}$ The mechanism for the selective oxidation of alcohols in liquid water over the Au catalysts remains largely unknown $^{33,59}$ despite a few recent studies with organic solvents. ${ }^{60-62}$ In general, supported gold nanoparticles are exceptionally good catalysts for aerobic oxidation of diverse reagents ranging from simple molecules such as $\mathrm{CO}$ and $\mathrm{H}_{2}$ to more complex substrates such as hydrocarbons and alcohols. ${ }^{63,64}$ Gold catalysts are also substrate specific, highly selective, stable against metal leaching and resistant to over oxidation by oxygen. ${ }^{33,65,66}$ The unique catalytic properties of gold nanoparticles are the subject of many speculations and have been attributed to anionic Au species, ${ }^{67}$ cationic $\mathrm{Au}$ species, ${ }^{68,69}$ and neutral Au metal particles. ${ }^{70}$ Moreover, the size and structure of Au nanoparticles ${ }^{71,72}$ as well as the interface of these particles with the support ${ }^{73}$ have also been claimed to be important for catalytic activity. For the well-studied CO oxidation reaction, the presence of water vapor is known to increase the observed rate of the reaction. ${ }^{74-76}$ Large metallic gold particles and Au metal powder, which are usually considered to be catalytically inert, have demonstrated significant oxidation activity under aqueous conditions at high $\mathrm{pH} .77,78$ Herein we provide insights into the active intermediates and the mechanism for alcohol oxidation in aqueous media derived from experimental 
kinetic studies on the oxidation of glycerol and ethanol with isotopically-labeled $\mathrm{O}_{2}$ and $\mathrm{H}_{2} \mathrm{O}$ over supported $\mathrm{Au}$ and Pt catalysts as well as ab initio density functional theory calculations on ethanol oxidation over metal surfaces. Previous studies indicate that alcohol oxidation over supported metal catalysts ( $\mathrm{Au}, \mathrm{Pt}$ and $\mathrm{Pd}$ ) proceeds by dehydrogenation to an aldehyde or ketone intermediate, followed by oxidation to the acid product as shown in Eq. 2.1.

$$
\mathrm{RCH}_{2} \mathrm{OH} \stackrel{\mathrm{O}_{2}, \text { catalyst }}{\longrightarrow} \mathrm{RCH}=\mathrm{O} \stackrel{\mathrm{O}_{2}, \text { catalyst }}{\longrightarrow} \mathrm{RCOOH}
$$

Hydroxide ions play an important role during oxidation wherein the product distribution depends significantly on the $\mathrm{pH}$ of the system and little or no activity is seen over Au catalysts without added base. In this work, gold particles of various sizes (average diameter ranging from 3.5 to $10 \mathrm{~nm}$ ) on different supports (titania and carbon) were evaluated as catalysts for alcohol oxidation and compared to Pt and Pd particles supported on carbon. The oxidation of glycerol to glyceric and glycolic acids occurs at a turnover frequency (TOF) of 6.1 and $4.9 \mathrm{~s}^{-1}$ on $\mathrm{Au} / \mathrm{C}$ and $\mathrm{Au} / \mathrm{TiO}_{2}$, respectively, at high pH whereas the TOF on supported Pt and Pd (1.6 and $2.2 \mathrm{~s}^{-1}$, respectively) is slightly lower at otherwise identical conditions (see Table 2.1). For the gold catalysts used in this study, there did not appear to be a significant influence of particle size or support composition on the rate or selectivity. In the absence of base, the glycerol oxidation rate is significantly lower over the Pt and Pd catalysts and no conversion is observed over the Au catalysts (Table 2.1). Moreover, the products detected over Pt and Pd in the absence of base are primarily the intermediate aldehyde and ketone rather than acids. The effect of initial base concentration on the activity of glycerol oxidation on the supported Pt catalyst was further studied by varying the initial $\mathrm{NaOH}$ concentration from 0 to 0.6M. The TOF for glycerol oxidation over Pt was proportional to the initial hydroxide concentration and thus the initial glycerolate concentration formed by the deprotonation of glycerol (Table 1), which is consistent with prior work in our lab with a supported Au catalyst. ${ }^{79}$ Although the turnover frequencies for ethanol oxidation to acetic acid over the above-mentioned Au and Pt catalysts are an order of magnitude lower than those observed for glycerol oxidation at identical conditions, $\mathrm{Au}$ is still more active than Pt for ethanol oxidation at high $\mathrm{pH}$ (Table 2.2). 
Table 2.1: Glycerol Oxidation over $\mathrm{Au} / \mathrm{C}, \mathrm{Au} / \mathrm{TiO}_{2}, \mathrm{Pt} / \mathrm{C}$ and $\mathrm{Pd} / \mathrm{C}$ in Liquid Water.

\begin{tabular}{ccccccccc}
\hline & $\begin{array}{c}\text { NaOH: } \\
\text { glycerol }\end{array}$ & $\begin{array}{c}\text { TOF } \\
\text { Catalyst }\end{array}$ & $\begin{array}{c}\text { Conv. } \\
(\text { mol:mol })\end{array}$ & $\begin{array}{c}\text { Glyceric } \\
(\%)\end{array}$ & $\begin{array}{c}\text { Glycolic } \\
\text { Acid }\end{array}$ & $\begin{array}{c}\text { Tcid } \\
\text { Tartronity } \\
\text { c Acid }\end{array}$ & $\begin{array}{c}\text { Glycer- } \\
\text { aldehyde }\end{array}$ & $\begin{array}{c}\text { Dihydroxy } \\
\text {-acetone }\end{array}$ \\
\hline $\mathrm{Au} / \mathrm{C}^{*}$ & 2.0 & 6.1 & 6.8 & 67 & 33 & 0.0 & 0.0 & 0.0 \\
$\mathrm{Au} / \mathrm{TiO}_{2}{ }^{*}$ & 2.0 & 4.9 & 33 & 64 & 24 & 2.0 & 0.0 & 0.0 \\
$\mathrm{Pd} / \mathrm{C}^{*}$ & 2.0 & 2.2 & 29 & 83 & 6.0 & 5.0 & 0.0 & 0.0 \\
$\mathrm{Pt} / \mathrm{C}^{*}$ & 2.0 & 1.6 & 16 & 70 & 21 & 7.0 & 0.0 & 0.0 \\
$\mathrm{Pt} / \mathrm{C}^{*}$ & 1.0 & 0.76 & 7.1 & 78 & 14 & 7.0 & 0.0 & 0.0 \\
$\mathrm{Pt} / \mathrm{C}^{*}$ & 0.5 & 0.48 & 4.7 & 72 & 28 & 0.0 & 0.0 & 0.0 \\
$\mathrm{Pt} / \mathrm{C}^{\dagger}$ & $3 \times 10^{-4}$ & 0.05 & 8.0 & 29 & 0.0 & 0.0 & 50 & 21 \\
$\mathrm{Pt} / \mathrm{C}^{\dagger}$ & 0.0 & 0.06 & 9.0 & 25 & 0.0 & 0.0 & 54 & 21 \\
$\mathrm{Pd} / \mathrm{C}^{\dagger}$ & 0.0 & 0.004 & 1.3 & 25 & 0.0 & 0.0 & 50 & 25 \\
$\mathrm{Au} / \mathrm{C}^{\dagger}$ & 0.0 & 0.0 & 0.0 & 0.0 & 0.0 & 0.0 & 0.0 & 0.0 \\
$\mathrm{Au} / \mathrm{TiO}_{2}{ }^{\dagger}$ & 0.0 & 0.0 & 0.0 & 0.0 & 0.0 & 0.0 & 0.0 & 0.0 \\
\hline
\end{tabular}

${ }^{*}$ Reaction conditions: $0.3 \mathrm{M}$ Glycerol $(\mathrm{G}), 0.6 \mathrm{M} \mathrm{NaOH}, 30 \mathrm{~mL}, 333 \mathrm{~K}, \mathrm{pO}_{2} 150 \mathrm{psig}, \mathrm{G}: \mathrm{Au}=$ $\mathrm{G}: \mathrm{Pt}=8000$ (mol:mol), G:Pd $=2500$ (mol:mol), $\mathrm{t}=0.5 \mathrm{~h} ;{ }^{\dagger}$ Reaction conditions: $0.3 \mathrm{M}$ glycerol (G), 5mL, $333 \mathrm{~K}, \mathrm{pO}_{2} 150$ psig, G:Au = G:Pt $=5000$ (mol:mol), G:Pd $=2000$ (mol:mol), $\mathrm{t}=5 \mathrm{~h}$; Gold particle sizes: $\mathrm{Au} / \mathrm{C}=10.5 \mathrm{~nm}, \mathrm{Au} / \mathrm{TiO}_{2}=3.5 \mathrm{~nm}$; Dispersion: $\mathrm{Au} / \mathrm{C}$ $=0.05, \mathrm{Au} / \mathrm{TiO}_{2}=0.29, \mathrm{Pt} / \mathrm{C}=0.43, \mathrm{Pd} / \mathrm{C}=0.33$.

Table 2.2: Ethanol Oxidation over $\mathrm{Au} / \mathrm{C}, \mathrm{Au} / \mathrm{TiO}_{2}$ and $\mathrm{Pt} / \mathrm{C}$ in Liquid Water

\begin{tabular}{|c|c|c|c|c|}
\hline \multicolumn{3}{|c|}{ NaOH: ethanol } & \multicolumn{2}{|c|}{ \% Selectivity } \\
\hline Catalyst & (mol:mol) & $\operatorname{TOF}\left(s^{-1}\right)$ & Acetic Acid & Acetaldehyde \\
\hline $\mathrm{Au} / \mathrm{C}$ & 2.0 & 0.30 & 100 & 0.0 \\
\hline $\mathrm{Au} / \mathrm{TiO}_{2}$ & 2.0 & 0.46 & 100 & 0.0 \\
\hline $\mathrm{Pt} / \mathrm{C}$ & 2.0 & 0.04 & 100 & 0.0 \\
\hline $\mathrm{Au} / \mathrm{C}^{\mathrm{a}}$ & 0.0 & 0.0 & - & - \\
\hline $\mathrm{Au} / \mathrm{TiO}_{2}{ }^{\mathrm{a}}$ & 0.0 & 0.0 & - & - \\
\hline $\mathrm{Pt} / \mathrm{C}^{\mathrm{a}}$ & 0.0 & 0.01 & 67 & 33 \\
\hline
\end{tabular}

Reaction conditions: $0.3 \mathrm{M}$ ethanol (E), $0.6 \mathrm{M} \mathrm{NaOH}, 5 \mathrm{~mL}, 333 \mathrm{~K}, \mathrm{pO}_{2} 150$ psig, $\mathrm{E}: \mathrm{Au}=\mathrm{E}: \mathrm{Pt}=5000$ (mol:mol), $\mathrm{t}=2 \mathrm{~h} ;{ }^{\mathrm{a}} \mathrm{t}=5 \mathrm{~h}$; Dispersion: $\mathrm{Au} / \mathrm{C}=0.05$, $\mathrm{Au} / \mathrm{TiO}_{2}=0.29, \mathrm{Pt} / \mathrm{C}=0.43 .{ }^{*}$ The trace amount of $\mathrm{CO}_{2}$ observed is not included in selectivity calculations.

In an aqueous environment, the initial deprotonation of the alcohol to form an alkoxy intermediate occurs in basic solution and the extent of the reaction is related to the system $\mathrm{pH}$ (the pKa of alcohols is approximately 16)..$^{30}$ The initial activation of the alcohol can also occur on the 
catalyst surface. The calculated activation barriers for the dissociative adsorption of ethanol (see Figure 2.1A) over the $\mathrm{Au}(111)$ and $\mathrm{Pt}(111)$ surfaces in liquid water are calculated to be very high at 204 and $116 \mathrm{~kJ} \mathrm{~mol}^{-1}$, and thus $\mathrm{O}-\mathrm{H}$ bond activation by the metal alone is unlikely. The presence of surface-bound hydroxide intermediates however can facilitate $\mathrm{O}-\mathrm{H}$ bond activation via proton transfer in much the same way that it occurs in solution. This lowers the activation barrier to less than $25 \mathrm{~kJ} \mathrm{~mol}^{-1}$ for either metal, as summarized in Figure 2.1B. The presence of adsorbed hydroxide intermediates also significantly lowers the barrier for the subsequent activation of the $\mathrm{C}-\mathrm{H}$ bond of the ensuing alkoxide intermediate to form the aldehyde over Au. (For Pt, this step already has a very low barrier over the metal without the assistance of adsorbed $\mathrm{OH}$ ). The ability of adsorbed hydroxide to activate both the $\mathrm{C}-\mathrm{H}$ and $\mathrm{O}-\mathrm{H}$ bonds so effectively on $\mathrm{Au}(111)$ helps to explain the overall increase in catalytic activity of the noble metal at high $\mathrm{pH}$.

It is unclear whether or not oxygen atoms derived from molecular oxygen or from hydroxide ions are involved in carboxylate formation from the intermediate aldehyde or ketone. To determine the role of $\mathrm{O}_{2}$ in the mechanism, the oxidation of aqueous phase glycerol and ethanol was performed in a batch autoclave reactor using ${ }^{18} \mathrm{O}_{2}$ in the presence of base $(0.3 \mathrm{M}$ glycerol or $0.3 \mathrm{M}$ ethanol, $0.6 \mathrm{M}$ $\mathrm{NaOH})$ together with either $\mathrm{Au} / \mathrm{C}$ or $\mathrm{Au} / \mathrm{TiO}_{2}(0.8 \%$ and $1.6 \%$ respectively, World Gold Council, WGC) as a catalyst. The isotopomer distribution in the product was evaluated by mass spectrometry. Glyceric acid was the major product of glycerol oxidation for all catalysts evaluated at high pH (Table 2.1). However, no discernable amount of labeled oxygen was observed in the glyceric acid product. Figure 2.2 shows a representative reaction profile for the oxidation of glycerol as well as the mass spectrum of the product glyceric acid. For the reaction performed with ${ }^{18} \mathrm{O}_{2}$, only one peak in the mass spectrum of glyceric acid corresponding to unlabeled product was observed, analogous experiments with ethanol oxidation confirmed a lack of ${ }^{18} \mathrm{O}$ incorporation into the product acetic acid. The Au particle size, the composition of the support and the structure of the alcohol do not affect the overall reaction path for the oxidation reaction.

One might be tempted to attribute the lack of ${ }^{18} \mathrm{O}$ incorporation in the acid products to the inability of gold nanoparticles to dissociatively adsorb $\mathrm{O}_{2} \cdot 64,80,81$ Thus, glycerol oxidation over carbon- 
supported Pt (1\%, Sigma-Aldrich) and Pd (3\%, Sigma-Aldrich) was also performed with ${ }^{18} \mathrm{O}_{2}$ at high $\mathrm{pH}$ since they are transition metals that are known to dissociate $\mathrm{O}_{2}{ }^{82}$ Again, no labeled oxygen was observed in the glyceric acid product. In summary, the results from the labeling experiments indicate that the alcohol oxidation mechanism over Au is similar to that over Pt and Pd when carried out in liquid water. It should be emphasized that no glycerol oxidation was observed in the absence of $\mathrm{O}_{2}$.

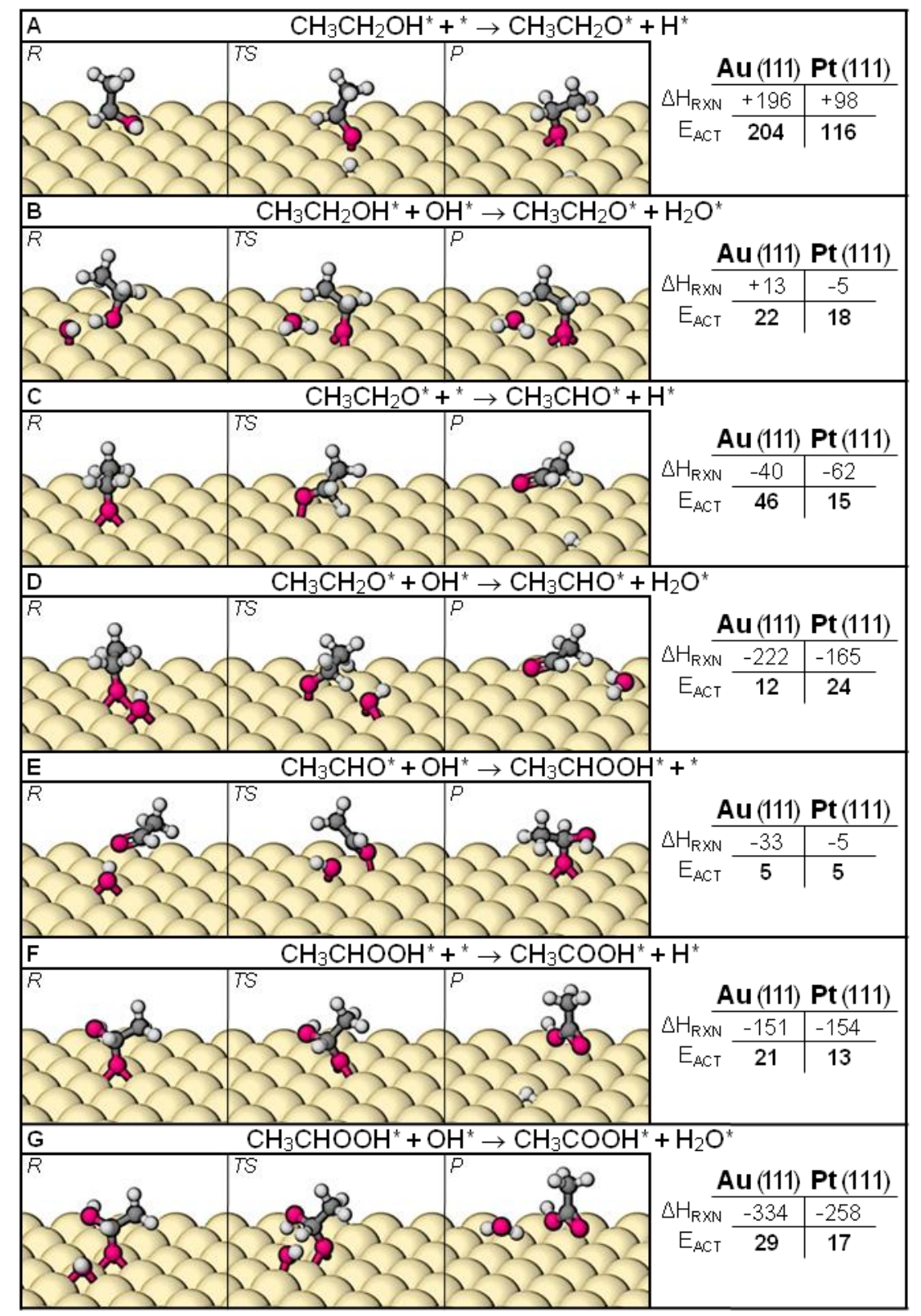

Figure 2.1. Selected reaction energies $(\mathrm{kJ} / \mathrm{mol})$ and activation barriers $(\mathrm{kJ} / \mathrm{mol})$ for the oxidation of ethanol to acetic acid on $\mathrm{Au}$ and Pt(111) surfaces in the presence of liquid water. The reactant (R), 
transition state (TS) and product (P) on the surfaces were computed with density functional theory.

The solution phase water was omitted for clarity.

Table 2.3: Selected reaction energies $\left(\mathrm{kJ} \mathrm{mol}^{-1}\right)$ and activation barriers $\left(\mathrm{kJ} \mathrm{mol}^{-1}\right)$ for the oxidation of ethanol to acetic acid over Pt(111) and $\mathrm{Au}(111)$.

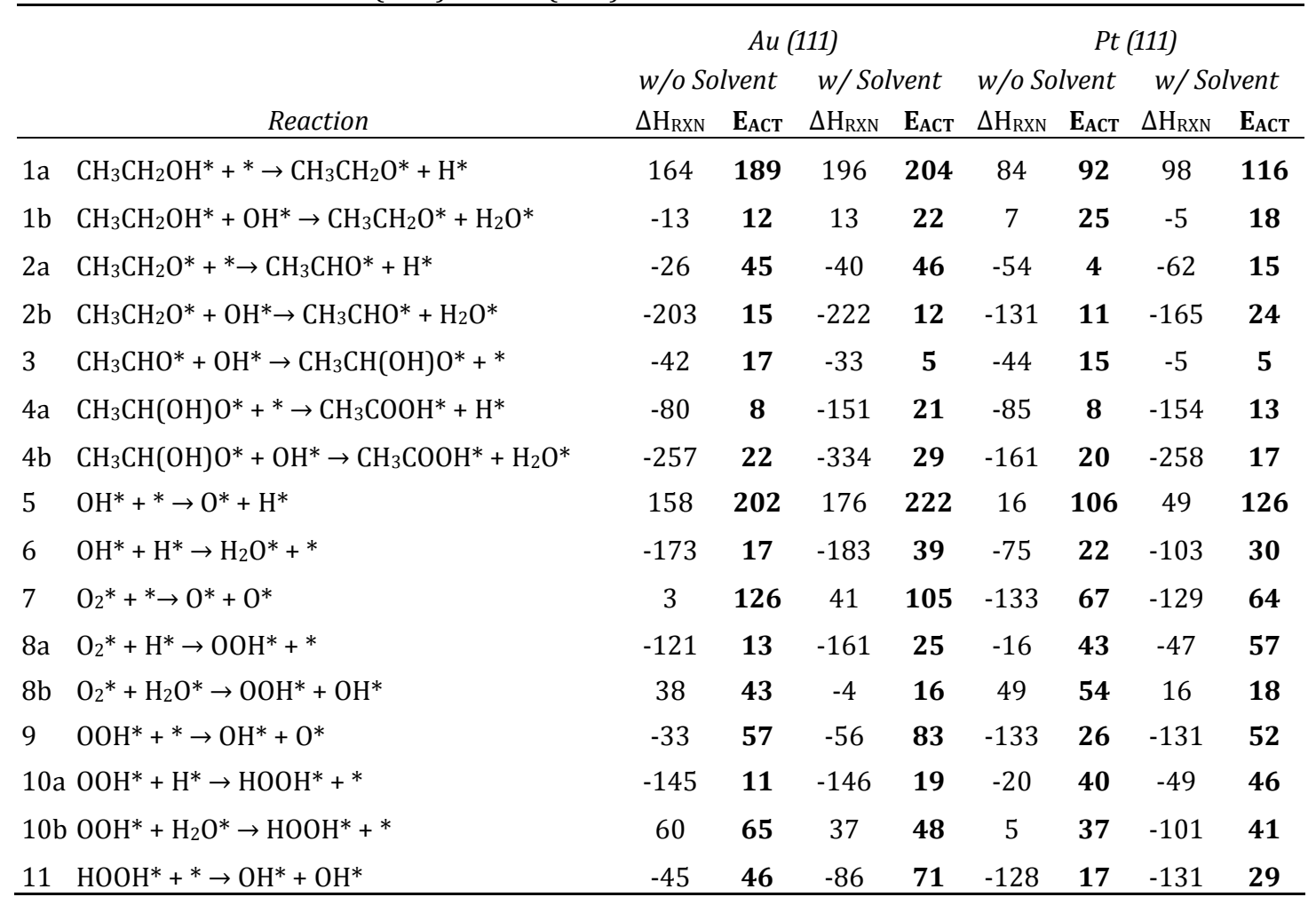

To explore the role of hydroxide in Au-catalyzed oxidation, glycerol and ethanol oxidation were oxidized over $\mathrm{Au} / \mathrm{C}$ and $\mathrm{Au} / \mathrm{TiO}_{2}$ with labeled water $\left(\mathrm{H}_{2}{ }^{18} \mathrm{O}\right)$ at high $\mathrm{pH}(0.3 \mathrm{M}$ glycerol or $0.3 \mathrm{M}$ ethanol, $0.6 \mathrm{M} \mathrm{NaOH}$ ) and ${ }^{16} \mathrm{O}_{2}$ as the gas phase oxidant. The mass spectrum for glyceric acid produced during glycerol oxidation (Figure 2.2) shows a range from one to four ${ }^{18} 0$ atoms was incorporated into the glyceric acid product. Incorporation of multiple labeled oxygen $\left({ }^{18} 0\right)$ atoms into the acetic acid product of ethanol oxidation over $\mathrm{Au} / \mathrm{C}$ and $\mathrm{Au} / \mathrm{TiO}_{2}$ and into the minor oxidation products of glycerol was also observed. Since the reaction products do not exchange oxygen with water at the timescale of the reaction, the appearance of ${ }^{18} \mathrm{O}$ in the product during reactions performed in $\mathrm{H}_{2}{ }^{18} \mathrm{O}$ suggests that aqueous phase alcohol oxidation proceeds through an alkoxy intermediate of the geminal diol that was formed by the reaction of the aldehyde intermediate with hydroxide, as shown in Figure 2.3. Rapid exchange of the diols with ${ }^{18} \mathrm{OH}^{-}$accounts for the two ${ }^{18} \mathrm{O}$ 
atoms found in the acetic acid product from ethanol oxidation. During glycerol oxidation, glyceraldehyde is the reaction intermediate produced by the initial dehydrogenation of the terminal alcohol of glycerol. The base-catalyzed rapid interconversion of glyceraldehyde to dihydroxyacetone (DHA) during the oxidation reaction could account for more than two ${ }^{18} 0$ atoms appearing in the product.83 Indeed, a control experiment with glyceraldehyde $(0.05 \mathrm{M})$ in presence of $\mathrm{Au} / \mathrm{C}$ and a small amount of base $\left(0.01 \mathrm{M} \mathrm{NaOH}\right.$ - to avoid degradation of glyceraldehyde) in $\mathrm{H}_{2}{ }^{18} \mathrm{O}$ resulted in ${ }^{18} \mathrm{O}$ incorporation in dihydroxyacetone (DHA) that was formed during the experiment.

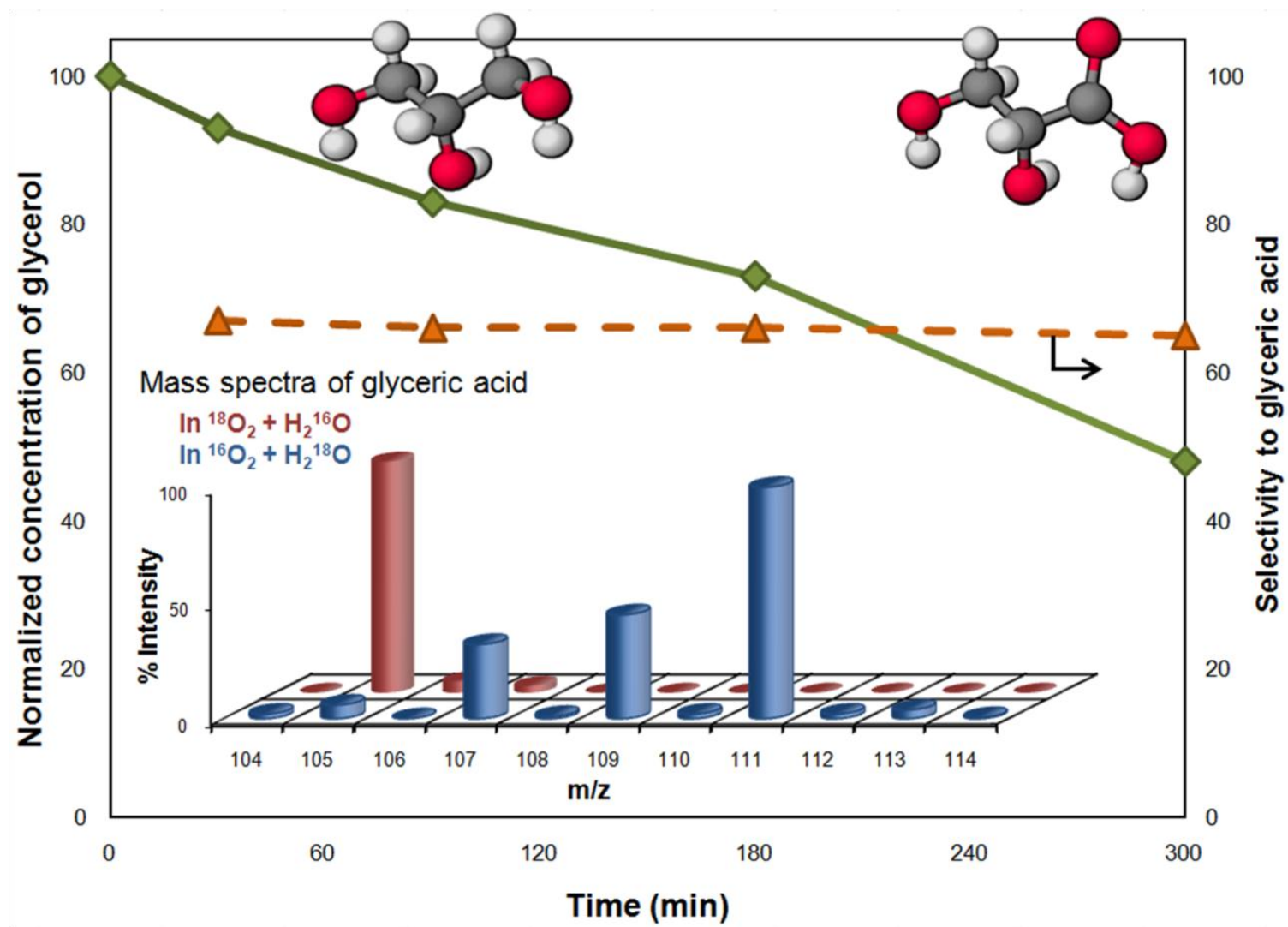

Figure 2.2. Reaction profile for the oxidation of glycerol over $\mathrm{Au} / \mathrm{C}$ in liquid water. (Reaction conditions: 0.3M glycerol, $\mathrm{NaOH}$ : glycerol $=2.0(\mathrm{~mol}: \mathrm{mol})$, glycerol: $\mathrm{Au}=8000: 1(\mathrm{~mol}: \mathrm{mol}), 333 \mathrm{~K}$, $\mathrm{pO}_{2}=150$ psig.) Inset: LC mass spectrum (electronegative ion mode) of glyceric acid (M.W. 106) formed during glycerol oxidation over $\mathrm{Au} / \mathrm{C}$ in ${ }^{18} \mathrm{O}_{2}+\mathrm{H}_{2}{ }^{16} \mathrm{O}$ or ${ }^{16} \mathrm{O}_{2}+\mathrm{H}_{2}{ }^{18} \mathrm{O}$. Glycerol oxidation in ${ }^{16} \mathrm{O}_{2}$ $+\mathrm{H}_{2}{ }^{18} \mathrm{O}$ results in the incorporation of multiple ${ }^{18} \mathrm{O}$ atoms in the product glyceric acid. 
Theory was used to examine the base-catalyzed, aqueous phase oxidation of acetaldehyde in solution, as shown in Equation 2.2, and to explore the role of hydroxide ion as the oxygen source.

$$
\mathrm{CH}_{3} \mathrm{CHO}+\mathrm{HO}^{-} \rightarrow \mathrm{CH}_{3} \mathrm{CHOOH}^{-}
$$

The activation barrier for this reaction in solution was calculated to be $45 \mathrm{~kJ} \mathrm{~mol}^{-1}$. The barrier is largely due to the energy required to restructure the hydrogen-bonding water network around the solvated hydroxide anion and the aldehyde to allow them to react together. The same reaction was also examined on the $\mathrm{Au}(111)$ and $\mathrm{Pt}(111)$ surfaces in the presence of solvent, which resulted in activation barriers of $5 \mathrm{~kJ} \mathrm{~mol}^{-1}$ for both metals (Figure 2.1E). These results describe the feasibility of $\mathrm{HO}^{-}$addition either in solution or at the solution-metal interface as shown in Figure 2.3. The subsequent $\mathrm{C}-\mathrm{H}$ activation of $\mathrm{CH}_{3} \mathrm{CHOOH}^{-}$intermediate to form acetic acid occurs quite readily over Pt as well as $\mathrm{Au}$, with barriers of only $10-20 \mathrm{~kJ} \mathrm{~mol}^{-1}$ as shown in Figure 2.1F.

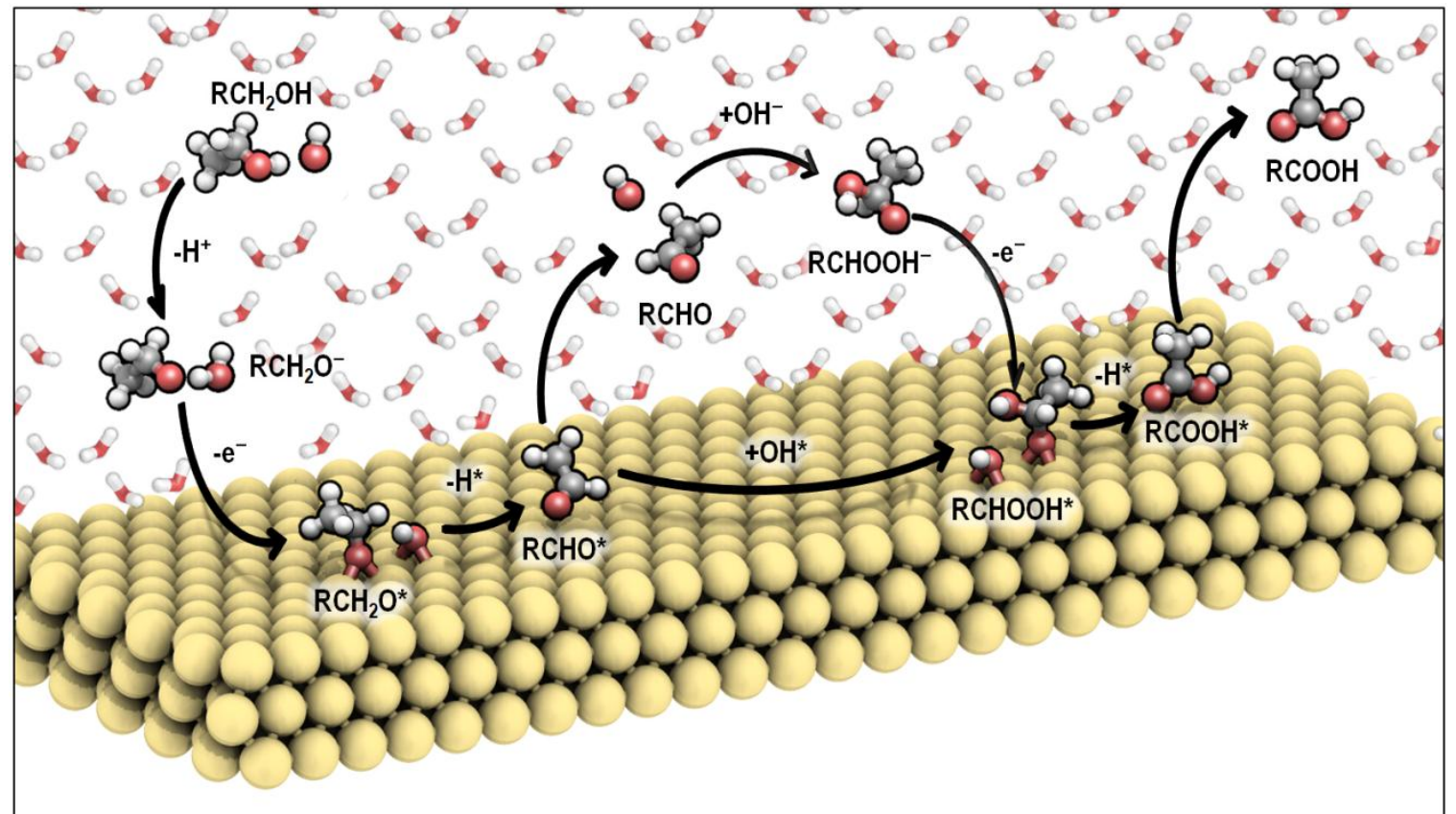

Figure 2.3. Reaction scheme for the oxidation of alcohols to acids over a gold surface in water at high pH. Hydroxide facilitates elementary steps in alcohol oxidation in both the solution phase and the metal-solution interface.

The important role of hydroxide in Au-catalyzed oxidation of alcohols might be more general in nature. For example, Kung et al. outline a compelling case for the role of adventitious hydroxide on 
$\mathrm{Au}$ nanoparticles used for $\mathrm{CO}$ oxidation. ${ }^{75}$ Prior work in our lab has shown that the $\mathrm{Au} / \mathrm{C}$ catalyst is not active for vapor phase $\mathrm{CO}$ oxidation but the reaction occurs at a high rate in aqueous solution at high $\mathrm{pH}$ indicating the importance of the hydroxide ions for $\mathrm{CO}$ oxidation. ${ }^{79}$ Attempts to elucidate the reaction mechanism for $\mathrm{CO}$ oxidation in liquid water using ${ }^{18}$ O-labeled reagents were inconclusive because of rapid scrambling of the oxygen atoms in the carbonate product with water.

The need for molecular oxygen during the oxidation reactions in water at high $\mathrm{pH}$ has been a consistent source of debate. The reported roles of oxygen include: the direct participation of atomic oxygen during dehydrogenation reactions, the reduction of atomic oxygen to water through hydrogen atoms adsorbed on the surface, the direct oxidation of the intermediate aldehyde with atomic oxygen to form the 0 -insertion product acids, and the removal of strongly bound organic adsorbates such as CO through oxidation. ${ }^{33}$ All of these speculations involve the dissociation of molecular oxygen on the catalyst surface; however, dissociation of $\mathrm{O}_{2}$ is not favored on $\mathrm{Au}$ catalysts $64,80,81$ and may be inhibited by water or hydroxides that adsorb on Pt-group catalysts. The activation barriers for $\mathrm{O}_{2}$ dissociation on $\mathrm{Au}(111)$ and $\mathrm{Pt}(111)$ were calculated to be 105 and $64 \mathrm{~kJ}$ mol- $^{-1}$, respectively, confirming the noble nature of Au compared to Pt-group metals (Table 2.3, reaction 7).

Prior work by us and others has reported the production of peroxide during oxidation reactions over $\mathrm{Au}^{78,79}$ indicating an important role of oxygen reduction during these reactions since the dissociation of molecular oxygen does not occur directly over bulk Au metal. (For the case of Pt, $\mathrm{O}_{2}$ dissociation is also difficult due to the high surface coverages of hydroxide intermediates. $)^{34}$ Oxygen reduction instead is thought to occur through the formation and dissociation of peroxide $\left(\mathrm{OOH}^{*}\right)$ and hydrogen peroxide $\left(\mathrm{HOOH}^{*}\right)$ intermediates (Eqs. 2.3-5) analogous to that formed electrocatalytically under alkaline conditions via 4 electron or 2 electron processes. ${ }^{84}$

$$
\begin{aligned}
& \mathrm{O}_{2}{ }^{*}+\mathrm{H}_{2} \mathrm{O}^{*} \rightarrow \mathrm{OOH}^{*}+\mathrm{HO}^{*} \\
& \mathrm{OOH}^{*}+\mathrm{H}_{2} \mathrm{O}^{*} \rightarrow \mathrm{H}_{2} \mathrm{O}_{2}{ }^{*}+\mathrm{HO}^{*} \\
& \mathrm{HO}^{*}+\mathrm{e}^{-} \leftrightarrow \mathrm{HO}^{-}+
\end{aligned}
$$


where * represents a site on the metal surface. This sequence accounts for the removal of electrons added to the surface during the adsorption of hydroxide ions and the regeneration of $\mathrm{HO}^{-}$species via oxygen reduction with water, thus closing the catalytic cycle. The steady state coverage of hydroxide on the surface is likely limited by the ability of the metal to accommodate the excess negative charge. To test the feasibility of this reduction sequence, DFT calculations were carried out over both Au and Pt surfaces. Reduction of $\mathrm{O}_{2}$ by water was calculated to have a low barrier of $16 \mathrm{~kJ} \mathrm{~mol}^{-1}$ on $\mathrm{Au}(111)$. The peroxide that forms can subsequently dissociate on Au to form atomic oxygen and hydroxide, with a barrier of $83 \mathrm{~kJ} \mathrm{~mol}^{-1}$; however, the more likely step is the further reduction of $\mathrm{OOH}^{*}$ to $\mathrm{H}_{2} \mathrm{O}_{2}$, with a barrier of only $48 \mathrm{~kJ} \mathrm{~mol}^{-1}$ (Table 2.3). The decomposition of $\mathrm{H}_{2} \mathrm{O}_{2}{ }^{*}$ to hydroxide has an activation barrier of $71 \mathrm{~kJ} \mathrm{~mol}^{-1}$. Interestingly, the decomposition of hydrogen peroxide over Pt and Pd has a barrier of only 29 and $5 \mathrm{~kJ} \mathrm{~mol}^{-1}$, respectively. The low calculated barrier for peroxide decomposition on Pd compared to Au explains why Ketchie et al. observed significant levels of peroxide in the product mixture formed during glycerol oxidation over $\mathrm{Au} / \mathrm{C}$ whereas trace amounts of peroxide were detected when $\mathrm{Pd} / \mathrm{C}$ was used as a catalyst at identical reaction conditions. ${ }^{85}$ Our computational results, coupled with the isotopic labeling studies, demonstrate that the role of $\mathrm{O}_{2}$ during alcohol oxidation is an indirect one that does not involve incorporation into the acid products but instead regenerates hydroxide ions.

In conclusion, the aqueous/Au interface provides a unique reaction environment that promotes $\mathrm{O}-\mathrm{H}$ and $\mathrm{C}-\mathrm{H}$ bond activation of the alcohol and subsequent oxygenate intermediates, hydroxyl addition to aldehyde as well as oxygen reduction and prevents poisoning or loss of the metal surface sites. The general understanding the catalytic phenomena at metal-liquid interface is essential for the development of new materials for the conversion of bioavailable and sustainable polyols to chemical intermediates in a future biorefinery. 


\section{2 - Influence of Oxygen and $p H$ during Selective Oxidation of Ethanol over Pd}

\section{Catalysts}

[Adopted from: D. D. Hibbitts and M. Neurock, Journal of Catalysis (Submitted).]

\section{Introduction}

Biomass-derived feedstocks provide an environmentally-friendly alternative to petroleum for the production of chemicals due to their sustainability and ability to be grown across large portions of the United States. ${ }^{86}$ These feedstocks are typically carbohydrates that are rich in oxygen content. Due to their thermal instability and their high solubility in water, biomass-derived feedstocks are typically reacted at lower temperatures and in the aqueous phase, which can have major impacts on the catalyst stability and reaction mechanisms. Many of the studies reported in the literature have focused on reducing the oxygen content of these feedstocks through reforming or selective hydrogenolysis in an effort to produce fuels. ${ }^{87}$ However, selective catalytic processes can offer routes to value-added chemicals, creating an additional offset for petroleum resources. Among these processes, the selective oxidation of alcohols in aqueous media provides an attractive route to produce organic acids from biorenewable feedstocks. For example, glycerol, a byproduct of biodiesel production ${ }^{86}$ that can also be produced through the hydrogenolysis of bio-mass derived sugars, ${ }^{88} \mathrm{can}$ be oxidized to form glyceric and tartronic acids used in pharmaceutical and cosmetics industries. ${ }^{89}$ Similarly, hydroxymethylfurfural (HMF), produced from the dehydration of fructose, ${ }^{90}$ can be oxidized to produce 2,5-furandicarboxylic acid (FDCA), which can be used to create PET plastics, offsetting the demand for oil-based terephthalic acid. ${ }^{91}$

The aerobic oxidation of alcohols is typically carried out on supported noble metal catalysts, including $\mathrm{Pt}, \mathrm{Pd}$ and $\mathrm{Au},{ }^{32,33}$ which are most active in their reduced state. ${ }^{92,93}$ Results reported in the literature suggest that the mechanism proceeds via the formation of an aldehyde intermediate and that activity and selectivity to the acid product increase significantly when the reactions are carried out at high $\mathrm{pH} .{ }^{33}$ While Pt and Pd show some activity at neutral and slightly acidic $\mathrm{pH}$, there is no reported activity over $\mathrm{Au}$ at neutral $\mathrm{pH}$ for the activation of various alcohols. ${ }^{36,55,65,79,94}$ 
Recent work by Zope, et al. ${ }^{36}$ used rigorous isotopic labeling along with density functional theory (DFT) calculations to determine the roles of both molecular oxygen and hydroxide in the mechanisms of glycerol and ethanol oxidation over supported Au catalysts. The results from this work suggest that the metal-solvent interface provides a unique active environment that promotes the oxidation of the alcohol via the hydroxide present on the on the surface as well as in solution. Molecular oxygen, which is necessary to carry out this reaction, is an indirect reagent that removes electrons from the metal catalyst produced during oxidation. This occurs through reduction with water as summarized in Scheme 1. The oxidation mechanism on supported Au is very similar to the mechanism of electrooxidation on supported Au electrodes (with the exception of the applied potential). In those direct alcohol fuel cells, the rate of oxidation that occurs at the anode is balanced by the rate of oxygen reduction at the cathode..$^{95-98}$

$$
\begin{gathered}
\mathrm{CH}_{3} \mathrm{CH}_{2} \mathrm{OH}+4 \mathrm{OH}-\rightarrow \mathrm{CH}_{3} \mathrm{COOH}+3 \mathrm{H}_{2} \mathrm{O}+4 \mathrm{e}- \\
\mathrm{O}_{2}+2 \mathrm{H}_{2} \mathrm{O}+4 \mathrm{e}-\rightarrow \mathrm{H}_{2} \mathrm{O}_{2} \rightarrow 4 \mathrm{OH}-
\end{gathered}
$$

However, other investigators have suggested that molecular oxygen first dissociates to form atomic oxygen on the surface, which subsequently behaves as a Brønsted base on the surface to carry out the oxidation chemistry, similar to the role of hydroxide above. ${ }^{99}$ Oxygen is known to dissociate over Pt and Pd surfaces ${ }^{100,101}$ and although oxygen dissociation is much more difficult over Au, there is the possibility that low-coordinated sites or defect sites on Au nanoparticles can dissociate oxygen, and any presence of oxygen atoms can increase the rate of oxygen dissociation ${ }^{81}$ leading to a partial coverage of atomic oxygen on Au. Furthermore, over Pt and Pd catalysts, there is some activity reported at neutral or slightly acidic $\mathrm{pH},{ }^{34,102}$ suggesting that there are pathways available which do not require large amounts of hydroxide to be present. The mechanisms, as discussed in the next section, vary significantly across the literature and a thorough examination of the reaction network has not yet been presented.

The work examined herein will focus on ethanol, which follows similar kinetics and mechanisms as glycerol and other polyols but is more computationally tractable. We examine Pd, as it is known that it can readily dissociate oxygen and reduce the $\mathrm{O}^{*}$ and $\mathrm{OH}^{*}$ intermediates that result 
to water. ${ }^{100,103} \mathrm{Pd}$, however, has a much lower tendency to completely oxidize the alcohol to $\mathrm{CO}_{2}$ and $\mathrm{H}_{2} \mathrm{O}$ as a result of the difficulty in activating $\mathrm{C}-\mathrm{C}$ bonds compared to that of $\mathrm{Pt}^{33}$

\section{Proposed Mechanisms}

\section{Ethanol Dehydrogenation}

The dehydrogenation of ethanol to acetaldehyde can proceed by the initial activation of either the $\mathrm{C}-\mathrm{H}$ (hydroxyethyl route) or $\mathrm{O}-\mathrm{H}$ bond (ethoxy route) as shown in Scheme 2. Studies of ethanol oxidation over Pt and Pd electrocatalysts suggest that dehydrogenation proceeds by the oxidative insertion of the metal into the $\mathrm{C}-\mathrm{H}$ bond to form hydroxyethyl and hydride surface intermediates $96,97,104$ as shown in Scheme 2a. Alternatively, studies in the heterogeneous catalysis literature report that alcohol oxidation proceeds via the initial activation of the $\mathrm{O}-\mathrm{H}$ bond to form an alkoxide intermediate on the surface ${ }^{32-34}$ as shown in Scheme $2 \mathrm{~b}$. In solution, equilibrium exists between ethanol and the ethoxide ion through base-catalyzed deprotonation as shown in Scheme 2c.

$$
\begin{array}{r}
\mathrm{CH}_{3} \mathrm{CH}_{2} \mathrm{OH}^{*} \rightarrow \mathrm{CH}_{3} \mathrm{CHOH}^{*}+\mathrm{H}^{*} \rightarrow \mathrm{CH}_{3} \mathrm{CH}=\mathrm{O}^{*}+2 \mathrm{H}^{*} \\
\mathrm{CH}_{3} \mathrm{CH}_{2} \mathrm{OH}^{*} \rightarrow \mathrm{CH}_{3} \mathrm{CH}_{2} \mathrm{O}^{*}+\mathrm{H}^{*} \rightarrow \mathrm{CH}_{3} \mathrm{CH}=\mathrm{O}^{*}+2 \mathrm{H}^{*} \\
\mathrm{CH}_{3} \mathrm{CH}_{2} \mathrm{OH}+\mathrm{OH}-\leftrightarrow \mathrm{CH}_{3} \mathrm{CH}_{2} \mathrm{O}-+\mathrm{H}_{2} \mathrm{O} \rightarrow \mathrm{CH}_{3} \mathrm{CH}_{2} \mathrm{O}^{*}+\mathrm{e}-+\mathrm{H}_{2} \mathrm{O}
\end{array}
$$

Adsorbed oxygen or hydroxide can also act as a Brønsted base to partially reduce the hydrocarbon as shown below in Scheme 3. This mechanism is supported by kinetic studies which suggest a Langmuir-Hinshelwood mechanism ${ }^{105,106}$ where the rate-limiting step involves the reaction between surface oxygen and an ethanol intermediate. ${ }^{99}$ We recently demonstrated that hydroxide behaves as a Brønsted base on $\mathrm{Au}$ and $\mathrm{Pt}(111)$ surfaces where it abstracts the more acidic proton of the alcohol. ${ }^{36}$

$$
\begin{aligned}
& \mathrm{CH}_{3} \mathrm{CH}_{2} \mathrm{OH}^{*}+2 \mathrm{O}^{*} \rightarrow \mathrm{CH}_{3} \mathrm{CH}_{2} \mathrm{O}^{*}+\mathrm{OH}^{*}+\mathrm{O}^{*} \rightarrow \mathrm{CH}_{3} \mathrm{CHO}^{*}+2 \mathrm{OH}^{*} \\
& \mathrm{CH}_{3} \mathrm{CH}_{2} \mathrm{OH}^{*}+2 \mathrm{OH}^{*} \rightarrow \mathrm{CH}_{3} \mathrm{CH}_{2} \mathrm{O}^{*}+\mathrm{H}_{2} \mathrm{O}^{*}+\mathrm{OH}^{*} \rightarrow \mathrm{CH}_{3} \mathrm{CHO}^{*}+2 \mathrm{H}_{2} \mathrm{O}^{*}
\end{aligned}
$$

Previous theoretical results indicate that the high alkalinity in this reaction would result in a high coverage of hydroxide groups on the metal surface which would facilitate the $\mathrm{C}-\mathrm{H}$ activation of ethanol through the hydroxyethyl $\left(\mathrm{CH}_{3} \mathrm{C} * \mathrm{HOH}\right)$ radical on the Pd surface as shown in Scheme $4 .{ }^{97}$ 
This work however was carried out using small Pd clusters (14-20 atoms) and does not consider the ethoxy route or the possibility of aqueous-phase deprotonation. They also did not report on any of the possible effects of hydroxide groups upon the subsequent oxidation of acetaldehyde to acetic acid.

$$
\mathrm{CH}_{3} \mathrm{CH}_{2} \mathrm{OH}^{*}+\mathrm{OH}^{*}+* \rightarrow \mathrm{CH}_{3} \mathrm{CHOH}^{*}+\mathrm{H}_{2} \mathrm{O}^{*}+* \rightarrow \mathrm{CH}_{3} \mathrm{CH}=\mathrm{O}^{*}+\mathrm{H}^{*}+\mathrm{H}_{2} \mathrm{O}^{*}
$$

\section{Acetaldehyde Oxidation}

Following acetaldehyde formation, the oxidation may proceed via two competing intermediates (Scheme 5): the acetyl radical $\left(\mathrm{CH}_{3} \mathrm{CO}\right)$, which is the more commonly proposed route in the literature ${ }^{33,34,96,98}$ and ethoxy-ethane-diol $\left(\mathrm{CH}_{3} \mathrm{CH}(\mathrm{OH}) 0\right)$, which can be formed on the surface as well as in solution. ${ }^{32,34,36}$ Each of these steps are considered in Scheme 5. Other routes, however, may also exist.

$$
\begin{aligned}
& \mathrm{CH}_{3} \mathrm{CHO}^{*}+\mathrm{OH}^{*}+* \rightarrow \mathrm{CH}_{3} \mathrm{CO}^{*}+\mathrm{H}^{*}+\mathrm{OH}^{*} \rightarrow \mathrm{CH}_{3} \mathrm{COOH}^{*}+2^{*} \\
& \mathrm{CH}_{3} \mathrm{CHO}^{*}+\mathrm{OH}^{*} \rightarrow \mathrm{CH}_{3} \mathrm{CH}(\mathrm{OH}) \mathrm{O}^{*}+* \rightarrow \mathrm{CH}_{3} \mathrm{COOH}^{*}+\mathrm{H}^{*} \\
& \mathrm{CH}_{3} \mathrm{CHO}+\mathrm{OH}-+2^{*} \rightarrow \mathrm{CH}_{3} \mathrm{CH}(\mathrm{OH}) \mathrm{O}-+2^{*} \rightarrow \mathrm{CH}_{3} \mathrm{CH}(\mathrm{OH}) \mathrm{O}^{*}+\mathrm{e}^{-} \rightarrow \mathrm{CH}_{3} \mathrm{COOH}^{*}+\mathrm{H}^{*}
\end{aligned}
$$

These pathways alone, for example, do not explain isotopic labeling studies performed by multiple investigators which show that the oxidation of ethanol ${ }^{36,107}$ and glycerol ${ }^{36}$ and other alcohols ${ }^{91}$ with $\mathrm{H}_{2}{ }^{18} \mathrm{O}$ labeled water in alkaline media result in the formation of the acetate product which contains multiple ${ }^{18} \mathrm{O}$ groups. This suggests that at some point within the mechanism an intermediate with an equivalence between the ${ }^{16} \mathrm{O}$ on the alcohol intermediate and the ${ }^{18} \mathrm{O}$ in solution is formed. One possibility for this equivalence is the aqueous phase hydration of the aldehyde to form a geminal diol occurs as shown in Scheme 6. If this process is equilibrated, the aldehyde can exchange its oxygen with that of the labeled oxygen in water, which can lead to two ${ }^{18} 0$ being observed in the acid product.

$$
\mathrm{RCHO}+\mathrm{OH}-+\mathrm{H}_{2} \mathrm{O} \leftrightarrow \mathrm{RCH}(\mathrm{OH}) \mathrm{O}-+\mathrm{H}_{2} \mathrm{O} \leftrightarrow \mathrm{RCH}(\mathrm{OH})_{2}+\mathrm{OH}-
$$

The gem-diol intermediate, once formed, can subsequently dehydrogenate to form the corresponding acid product, which subsequently deprotonates in basic media to form acetate.

\section{Role of Oxygen}


During aerobic alcohol oxidation, oxygen is reduced to form water, thus removing electrons from the catalyst surface. This reduction can occur in a variety of ways: Oxygen can dissociate to form atomic oxygen on the surface, which can react with adsorbed atomic hydrogen formed from oxidation reactions as shown in Scheme $7 \mathrm{a}^{108-110}$ In this case, oxygen is merely a hydrogen acceptor, removing electrons from the metal and adsorbed hydrogen from the surface. If that is its only purpose, then another hydrogen-acceptor, such as an olefin, may be substituted for $\mathrm{O}_{2}$ as shown in Scheme 7b. Hayashi, et al. ${ }^{111}$ has shown that for the selective oxidation of alcohols to aldehydes, the reaction is active in the absence of oxygen under an ethylene atmosphere. They did not report any further oxidation to acid products. Alternatively, atomic oxygen can act as a Brønsted base as previously discussed, directly abstracting hydrogen from the alcohol as shown in Scheme 3a. A third possibility is that $\mathrm{O}_{2}$ dissociates on the surface to form atomic oxygen which readily oxidizes strongly-bound $\mathrm{CO}$ intermediates to $\mathrm{CO}_{2} \cdot{ }^{112}$

$$
\begin{aligned}
& \mathrm{O}_{2}+4 \mathrm{H}^{*} \rightarrow 2 \mathrm{O}^{*}+4 \mathrm{H}^{*} \rightarrow 2 \mathrm{OH}^{*}+2 \mathrm{H}^{*} \rightarrow 2 \mathrm{H}_{2} \mathrm{O}^{*} \\
& \mathrm{RCH}_{2} \mathrm{OH}^{*}+\mathrm{CH}_{2}=\mathrm{CH}_{2}{ }^{*} \rightarrow \mathrm{CH}_{3} \mathrm{CH}=\mathrm{O}^{*}+\mathrm{CH}_{3} \mathrm{CH}_{3} * \\
& 1 / 2 \mathrm{O}_{2}+\mathrm{CO}^{*} \rightarrow \mathrm{CO}_{2}{ }^{*}
\end{aligned}
$$

In this work we examined the role of adsorbed oxygen and hydroxide intermediates for various possible pathways of ethanol oxidation over a model Pd(111) surface. Pd was chosen due to its ability to dissociate $\mathrm{O}_{2}$, creating active $\mathrm{O}^{*}$ species on the surface (unlike Au), while maintaining high selectivity (unlike Pt which frequently over-oxidizes the alcohol to $\mathrm{CO}_{2}$ ). All of the calculations reported, unless otherwise noted, were carried out on $\operatorname{Pd}(111)$ in an aqueous media in order to capture the effect of the solvent phase. The computed activation barriers and reaction energies indicate that the dehydrogenation of ethanol to acetald ehyde occurs via ethoxy, both in the aqueous phase and directly on the catalyst surface. Under high $\mathrm{pH}$, hydroxide groups on the surface facilitate dehydrogenation through direct interaction of hydroxide with the hydrocarbon intermediates as previously suggested. ${ }^{36}$ Furthermore, the role of atomic oxygen formed via the dissociation of $\mathrm{O}_{2}$ over 
Pd was determined. The findings suggest that the role of oxygen is primarily to close the catalytic cycle through removal of electrons from the catalyst surface through reduction and subsequent hydroxide regeneration. However, the activation barriers for certain $\mathrm{C}-\mathrm{H}$ or $\mathrm{O}-\mathrm{H}$ activation steps are reduced if atomic oxygen is present to act as a Brønsted base, similar to Scheme 3a above. This can explain the observed activity over Pt and Pd catalysts in absence of base, although, across all reactions, hydroxide behaves as a much better Brønsted base than atomic oxygen.

\section{Computational Methods}

First-principle DFT calculations were carried out using the Vienna ab initio simulation package (VASP). ${ }^{1-4}$ The planewaves were constructed with an energy cutoff of $396 \mathrm{eV}$ and Vanderbilt ultrasoft pseudopotentials ${ }^{11,12}$ with real space projection operators defining the features of the core region. The correlation and exchange energies were obtained using the Perdew-Wang 91 (PW91) form of the generalized gradient approximation (GGA) functional. ${ }^{13}$ The binding energy of each adsorbate was calculated as:

$$
E_{\mathrm{BE}}=E_{\text {surfads }}-E_{\text {surf }}-E_{a d s}
$$

where $E_{\text {surftads }}, E_{\text {surf }}$ and $E_{\text {ads }}$ are the energies of the surface-adsorbate complex, the surface and the adsorbate in vacuum, respectively. It is important to note that this formal definition of binding energy is not as kinetically relevant as a definition in which the reference state takes into account solvation of the adsorbate and solvent exchange on the surface. For this reason, binding energies will be over-predicted by this definition and phenomena such as desorption should be more facile in real systems. Furthermore, the free energy of adsorption would have to take into account the entropic effects of reorganizing the solution as well as the changes in entropy of the adsorbate between the aqueous and adsorbed phases.

The vacuum-cell calculations $\left(E_{a d s}\right)$ were performed spin-polarized with the species in an $18 \times 18 \times 18 \AA$ unit cell using the $\gamma$-point version of VASP. A relaxation was performed until the maximum force upon any atom (maximum force, as it will be referred to) was less than $0.05 \mathrm{eV} / \mathrm{A}$; 
the forces were obtained using a fast Fourier transform (FFT) grid with a cutoff of twice the planewave cutoff; the wavefunctions were converged to within $10^{-6} \mathrm{eV}$.

All calculations upon metal surfaces were carried out non-spin-polarized. A lattice of $3 \times 3$ was chosen in order to accommodate the reacting species with minimal interaction between supercells. The $\operatorname{Pd}(111)$ surface was modeled with four metal layers and a vacuum size of $18 \AA$ separating the periodic structure in the z-direction. The top two layers of the metal were allowed to relax while the lower two layers were fixed in their bulk lattice positions. When present, the aqueous solvent was modeled using a hexagonal bi-layer structure similar to previously published work ${ }^{36,113-}$ 115. On the $3 \times 3$ metal lattice, there are six water molecules per solvent bi-layer and four bi-layers were included in the z-direction with one or more water vacancies at the surface to accommodate reacting species. While this model allows us to assess the effects of local solvent molecules and captures some of the longer-range effects, such as the solvent-induced dipole effect, it does not accurately capture liquid water solvent, which would require millions of statistical configurations and dynamics along the reaction trajectories which are not possible at the quantum mechanical level.

The structures were optimized across two steps with the energy computed in a third step at a higher k-point mesh as shown in Table 1. To test this three-step system, a sample of intermediates were optimized using a 6x6x1 k-point mesh and an FFT grid size $2 \mathrm{x}$ the planewave cutoff to a force below $0.05 \mathrm{eV} / \mathrm{Ang}$. The results reveal a difference of binding energies less than $0.02 \mathrm{eV}$. To test the force convergence criteria of $0.05 \mathrm{eV} / \AA ̊$, a selection of intermediates were converged to forces less than $0.01 \mathrm{eV} / \AA$ in the second step. The differences in these two methods resulted in changes in binding energy $<0.02 \mathrm{eV}$.

For reactions, the activation barriers were obtained as:

$$
\begin{gathered}
A+B \rightarrow T S \rightarrow C+D \\
E_{A C T}=E_{T S}+\delta E_{\text {surf }}-E_{\text {surf }+A}-E_{\text {surf }+B}
\end{gathered}
$$

where $E_{\text {surfads }}, E_{\text {surf }}$ and $E_{\text {TS }}$ are the energy of the surface-adsorbate complex (A or B), the surface and the transition state respectively and $\delta$ refers the surface stoichiometric factor which for this example is equal to one. 
The structures of the transition states were determined using a combination of the nudged elastic band $(\mathrm{NEB})^{44}$ and dimer ${ }^{45}$ methods. The NEB method creates a chain of intermediate structures (referred to as images) along a pathway between the reactant and product states. For this work, it establishes an estimate of the transition state structure which was subsequently refined by using the dimer method 45 which uses two images with a very small distance between them (a 'dimer') together with an algorithm which allows the dimer to move up along the potential energy surface to a saddle point with a single negative eigenmode. In order to ensure that the saddle point reached is the correct one, a rough NEB calculation is first performed, providing the dimer algorithm with an initial guess for the transition state, as well as a reaction mode. The NEB was done using 16 images with using a $3 \times 3 \times 1$ k-point mesh and an FFT grid size $2 \times$ the planewave cutoff; the wavefunctions were converged to within $10^{-6} \mathrm{eV}$. The max atom force was converged to $0.20-0.50$ $\mathrm{eV} / \AA ̊$ depending on the quality of the initial path and ability of the algorithms. As stated, the NEB calculations were performed only to provide an initial guess to the dimer algorithm, so forces lower than $0.50 \mathrm{eV} / \AA ̊$ are not necessary.

The dimer algorithm was then performed using a 3x3x1 k-point mesh and an FFT grid size $2 \mathrm{x}$ the planewave cutoff; the wavefunctions were converged to within $10^{-6} \mathrm{eV}$. The distance between the dimers was set to $0.01 \AA$, the dimer was allowed to rotate four times or until the rotational force fell beneath $1 \mathrm{eV} /$ Ang. The max atom force was converged to $0.05 \mathrm{eV} / \mathrm{A}$. As with the binding energy calculations, the energy of the transition state was then determined using a $6 \times 6 \times 1 \mathrm{k}$-point mesh with the same parameters specified in Step 3 of Table 2.4.

Table 2.4. Three-step scheme for surface DFT calculations

\begin{tabular}{lccc}
\hline & Step 1 & Step 2 & Step 3 \\
\hline wavefunction & $10^{-4}$ & $10^{-6}$ & $10^{-3}$ \\
convergence & $1.5 \mathrm{x}$ & $2.0 \mathrm{x}$ & $1.5 \mathrm{x}$ \\
FFT grid size & $3 \times 3 \times 1$ & $3 \times 3 \times 1$ & $6 \times 6 \times 1$ \\
\hline
\end{tabular}




\section{Results and Discussion}

The results for the all of the elementary reaction steps studied on the $\operatorname{Pd}(111)$ surface in the presence of aqueous media are summarized in Figure 2.4. For all $\mathrm{C}-\mathrm{H}$ and $\mathrm{O}-\mathrm{H}$ activations, we examined the reaction on a bare Pd surface, and with surface oxygen $\left(\mathrm{O}^{*}\right)$ or surface hydroxyl $\left(\mathrm{OH}^{*}\right)$ intermediates to act as Brønsted bases. For oxygen-addition steps, $\mathrm{O}^{*}$-addition and $\mathrm{OH}^{*}$-addition were considered. In general, many of the $\mathrm{OH}^{*}$-assisted $\mathrm{C}-\mathrm{H}$ and $\mathrm{O}-\mathrm{H}$ activations have lower barriers than $\mathrm{O}^{*}$-assisted or direct metal atom insertion reactions. All of the barriers for steps involving $\mathrm{C}-\mathrm{H}$ activation by $0^{*}$ have barriers that are over $100 \mathrm{~kJ} / \mathrm{mol}$ and are significantly higher than those on the metal or via $\mathrm{OH}^{*}$.

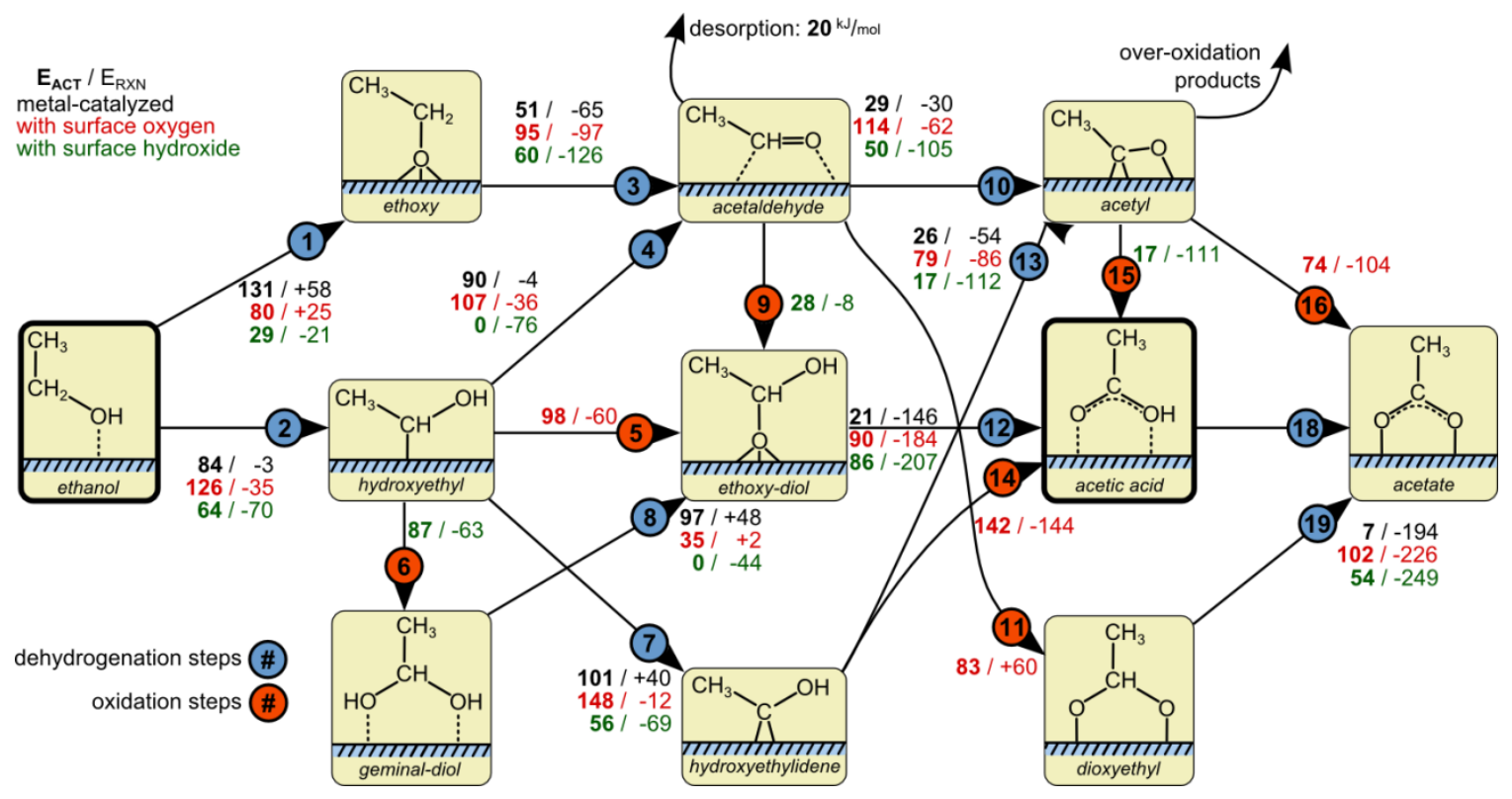

Figure 2.4. Reaction network for the oxidation of ethanol to acetic acid or acetate products. DFTcalculated activation barriers over Pd(111) with solvent present are shown in bold. Reaction 18, the conversion of acetic acid to acetate, was not modeled.

\section{Ethanol Dehydrogenation}

Ethanol in solution can deprotonate, forming an ethoxide anion, in an equilibrium-controlled reaction. Thus, the ethanol can deprotonate in solution followed by adsorption of the ethoxide anion 
$\left(\mathrm{CH}_{3} \mathrm{CH}_{2} \mathrm{O}-\right)$ onto the catalyst surface. Ethanol can also adsorb on the Pd surface and subsequently react with bound ${ }^{*} \mathrm{OH}$ to form an ethoxy $\left(\mathrm{CH}_{3} \mathrm{CH}_{2} \mathrm{O}^{*}\right)$ intermediate. The barrier for this reaction (Rxn 1c) is only $29 \mathrm{~kJ} / \mathrm{mol}$ and is largely due to due to the energy required to break the hydrogen-bonds that form between the hydroxyl group of the ethanol and the surrounding water molecules, as shown in Figure 2.5. Since ethanol, the ethoxide anion and hydroxide are also in equilibrium with their adsorbed species (Scheme 8), it's clear that increasing the $\mathrm{pH}$ of the system leads to an increase in coverage of the ethoxy group. The bound ethoxy group can then dehydrogenate via hydride elimination onto the metal surface to form acetaldehyde with a barrier of $51 \mathrm{~kJ} / \mathrm{mol}$ (Rxn 3a).

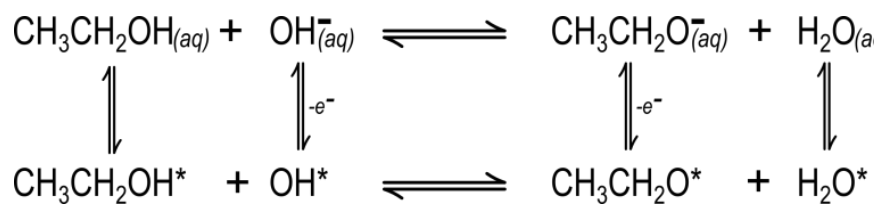

However, for systems at neutral or slightly acidic conditions, hydroxide may not be present at high enough concentrations to carry out these reactions. If $0^{*}$ is present at high coverages (due to $\mathrm{O}_{2}$ or $\mathrm{OOH}$ dissociation), it can also carry out initial $\mathrm{O}-\mathrm{H}$ activation via proton abstraction of the hydroxyl group which has a barrier of $80 \mathrm{~kJ} / \mathrm{mol}(\mathrm{Rxn} 1 \mathrm{~b})$. However, if the $0^{*}$ coverage is low, it is more likely that the exposed metal surface sites carry out the initial activation of ethanol through oxidative insertion into the $\alpha-\mathrm{C}-\mathrm{H}$ bond, as shown in Rxn $2 \mathrm{a}$, has an activation barrier of $84 \mathrm{~kJ} / \mathrm{mol}$ versus the barrier of $131 \mathrm{~kJ} / \mathrm{mol}$ to activate the $\mathrm{O}-\mathrm{H}$ bond of ethanol over Pd to form the ethoxy intermediate $\left(\mathrm{CH}_{3} \mathrm{CH}_{2} \mathrm{O}\right.$ in Rxn 1a). 


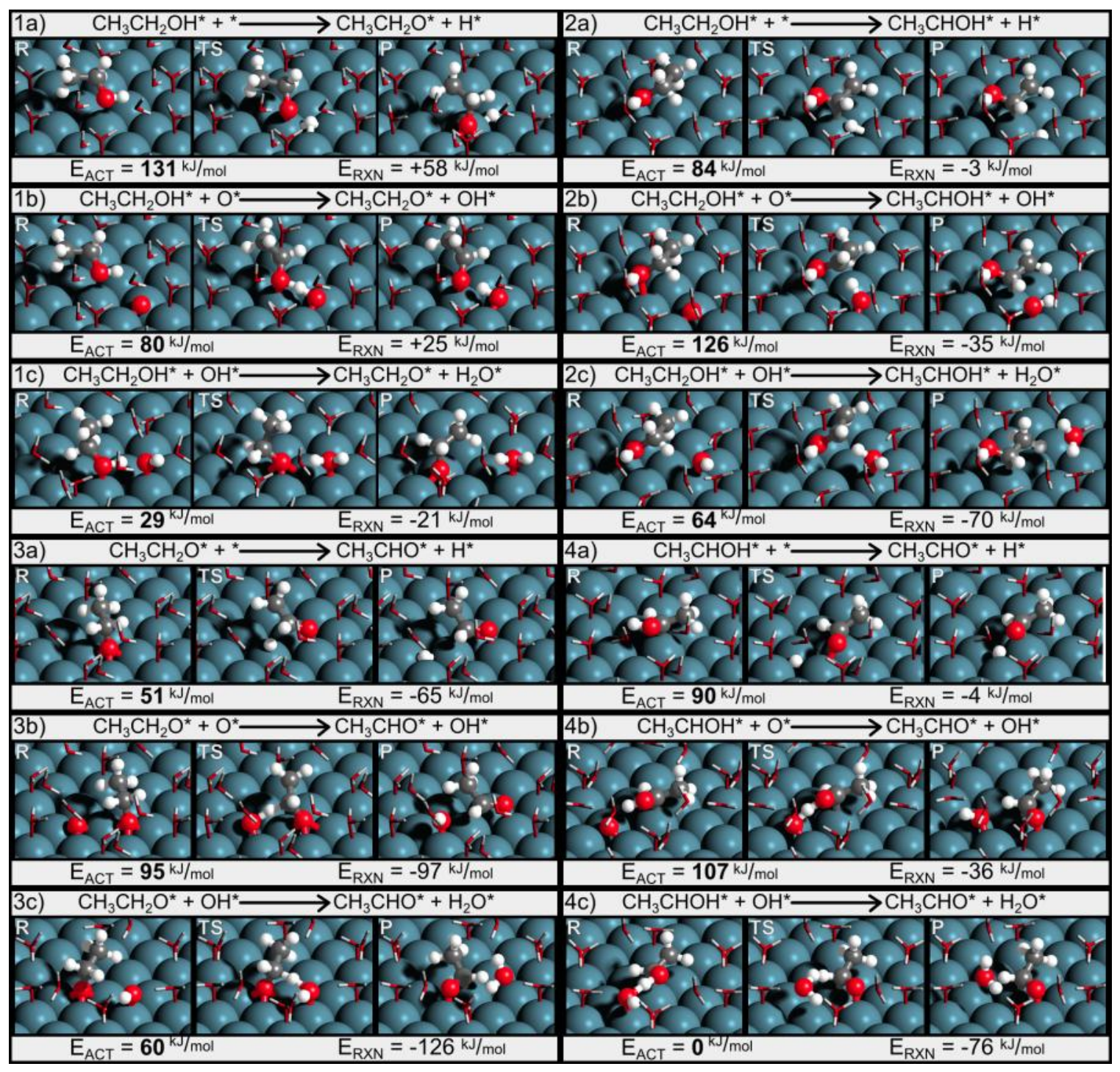

Figure 2.5. Dehydrogenation reactions from ethanol to acetaldehyde. The DFT-calculated reactant, transition and product states along with their activation barriers $\left(\mathrm{E}_{\mathrm{ACT}}\right)$ and energies of reaction $\left(\mathrm{E}_{\mathrm{RXN}}\right)$ are shown for both the hydroxyethyl and ethoxy routes. Each C-H or O-H activation step was modeled over a bare surface, with $\mathrm{O}^{*}$ and with $\mathrm{OH}^{*}$ acting to abstract the hydrogen. Only the lowest layer of solvent (out of the four layers that were modeled) which is in direct contact with the $\operatorname{Pd}(111)$ surface is shown.

As shown by the reaction network sketched in Figure 2.4, if the initial activation occurs at the $\alpha$-carbon, forming hydroxylethyl (Rxn 2), multiple routes exist towards the acid product which 
do not produce the observed aldehyde intermediate. Although these alternative intermediates are not observed, it is important to establish whether the aldehyde is a primary intermediate or just an observed by-product. Therefore, we examined each of the various paths that can occur which include: oxidation via $\mathrm{OH}^{*}$-addition to the carbon to form a geminal-diol intermediate $\left(\mathrm{CH}_{3} \mathrm{CH}(\mathrm{OH})_{2}\right.$, Rxn 6), oxidation via $0^{*}$-addition to the carbon to form the ethoxy intermediate of the geminal diol (ethoxy-diol, $\mathrm{CH}_{3} \mathrm{CH}(\mathrm{OH}) \mathrm{O}$, Rxn 5), and further $\mathrm{C}-\mathrm{H}$ activation of the $\alpha$-carbon to form hydroxyethylidene $\left(\mathrm{CH}_{3} \mathrm{COH}, \mathrm{Rxn} 7\right)$. The results from DFT indicate that none of these routes has a lower barrier than the barrier for the successive activation of the $\mathrm{O}-\mathrm{H}$ bond to form acetaldehyde. For example, the metal-catalyzed $\mathrm{C}-\mathrm{H}$ activation to form hydroxyethylidene has a barrier of 101 $\mathrm{kJ} / \mathrm{mol}$ (Rxn 7a), compared to the metal-catalyzed O-H activation to form acetaldehyde which has a barrier of $90 \mathrm{~kJ} / \mathrm{mol}(\mathrm{Rxn} 4 \mathrm{a})$. If $\mathrm{O}^{*}$ is present on the surface, it can act as a base to abstract the hydrogen of the $\mathrm{O}-\mathrm{H}$ bond, forming acetaldehyde with a barrier of $107 \mathrm{~kJ} / \mathrm{mol}$ (Rxn $4 \mathrm{~b}$ ). However, $\mathrm{O}^{*}$ does not aid in the activation of the $\mathrm{C}-\mathrm{H}$ bond which leads to hydroxyethylidene (Rxn 7b, 148 $\mathrm{kJ} / \mathrm{mol}$ ), which is consistent among all $\mathrm{C}-\mathrm{H}$ bond activations as was reported above. The barrier to oxidize the hydroxylethyl intermediate via $0^{*}$-addition has a barrier of $98 \mathrm{~kJ} / \mathrm{mol}$ (Rxn 5). In systems operating at high $\mathrm{pH}$, it is unlikely that the hydroxyethylidene intermediate will form on the surface. If it does, however, a surface bound hydroxide species will activate the $\mathrm{O}-\mathrm{H}$ bond, forming acetaldehyde with no barrier. As opposed to the route to from hydroxyethylidene via $\mathrm{OH}^{*}$ abstraction (56 kJ/mol, Rxn 7c) or the route to form a geminal diol through $\mathrm{OH}^{*}$-addition $(87 \mathrm{~kJ} / \mathrm{mol}$, Rxn 6). In summary, under the conditions studied (bare-surface, with $\mathrm{O}^{*}$ or $\mathrm{OH}^{*}$ present), there are no mechanisms that could proceed without passing through acetaldehyde, indicating that its presence is not the result of a side-reaction, but rather the first step in a sequential reaction.

From these results, it appears that different alcohol dehydrogenation mechanisms can occur depending upon the $\mathrm{pH}$, the oxygen pressure and the temperature as they set the chemical potential and as such the surface coverage of $\mathrm{OH}^{*}$ and $\mathrm{O}^{*}$. At neutral $\mathrm{pH}$ and low surface coverages of $\mathrm{O}^{*}$, the dehydrogenation appears to proceed via the metal which sequentially activates the $\alpha-\mathrm{C}-\mathrm{H}$ and $\mathrm{O}-\mathrm{H}$ bonds of the alcohol to form the aldehyde. However, if $\mathrm{O}^{*}$ is prevalent on the surface as a result of $\mathrm{O}_{2}$ 
or $\mathrm{OOH}^{*}$ dissociation, the dehydrogenation proceeds via the $\mathrm{O}^{*}$-assisted activation of the $\mathrm{O}-\mathrm{H}$ bond of the alcohol to form an alkoxide intermediate. At high $\mathrm{pH}$, the alkoxide intermediate is formed via $\mathrm{OH}$ assisted activation of the alcohol, either on the surface or in solution. In the last two cases, the C-H bond of the alkoxide is activated by hydride elimination onto the metal surface to form acetaldehyde.

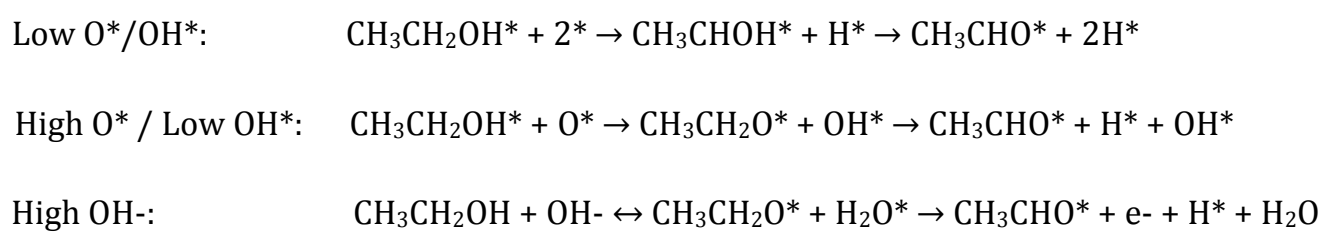

\section{Acetaldehyde Oxidation at High $\mathrm{pH}$}

The acetaldehyde that forms can desorb from the surface or react via the paths presented in Figure 2.4. The desorption of acetaldehyde should occur quite readily as it is only weakly held to the surface with a binding energy of $20 \mathrm{~kJ} / \mathrm{mol}$. Once in solution, it can rapidly undergo hydration via a nucleophilic attack of $\mathrm{OH}-$ on the $\mathrm{C}=\mathrm{O}$ bond to form the ethoxy-diol anion intermediate $\left(\mathrm{CH}_{3} \mathrm{CH}(\mathrm{OH}) \mathrm{O}-\right)^{32,34}$ as shown in the two-step process in Scheme 10. Figure 2.6 shows the detailed changes in the structure along with the changes in energies that occur along the reaction coordinate for the conversion of acetaldehyde to ethoxy-diol in basic water. In the reactant state, the hydroxyl anion is hydrogen bonded with three nearby water molecules, whereas the carbonyl group of the aldehyde is hydrogen bonded with only two. In the product, one of the water molecules shifts to hydrogen bond to the carbonyl group of the ethoxy-diol intermediate. These changes in the solvation shell result in a barrier of $45 \mathrm{~kJ} / \mathrm{mol}$ as previously reported. ${ }^{36}$ The ethoxy-diol intermediate can subsequently protonate in solution to form the geminal-diol hydrate. Once the geminal-diol intermediate has been formed in solution, it must be dehydrogenated to form the acetic acid product in an analogous manner to ethanol dehydrogenation to form acetaldehyde. Geminal-diols, however, have much lower pKa's ${ }^{116}$ (13-14) than ethanol (15.9), indicating that they would be more likely to deprotonate in solution. However, if they adsorb on the Pd surface intact, they can subsequently be deprotonated by adsorbed $\mathrm{OH}^{*}$ to form ethoxy-diol. This reaction appears to occur without an activation barrier (Rxn 8c, Figure 2.7). Either reaction (solution-phase deprotonation or adsorption followed by $\mathrm{OH}^{*}$-catalyzed deprotonation) results in a strongly adsorbed ethoxy-diol intermediate on 
the Pd surface. This aqueous-phase hydration to form the geminal-diol is believed to be equilibrated, which causes and equivalency of the two oxygens of the product acid. This explains the multiple incorporations of ${ }^{18} \mathrm{O}$ isotopes into glyceric and acetic acid when glycerol and ethanol oxidation is run in $\mathrm{H}_{2}{ }^{18} \mathrm{O}$. Rather than acetaldehyde desorbing and hydrating in the aqueous phase, an alternate route via the reaction between $\mathrm{OH}^{*}$ and the aldehyde on the $\mathrm{Pd}$ surface to form the ethoxy-diol intermediate was examined. The barrier for the nucleophilic attack of $\mathrm{OH}^{*}$ on the adsorbed acetaldehyde was calculated to be $28 \mathrm{~kJ} / \mathrm{mol}$ (Rxn 11a, Figure 2.7) which is lower than the solutionphase hydration. The ethoxy-diol intermediate subsequently reacts on the Pd surface to form the acetic acid product with a barrier of only $21 \mathrm{~kJ} / \mathrm{mol}$ (Rxn 12a). The mechanism involves an $\alpha$-hydride elimination onto the Pd surface and as such is identical to that for the $\alpha$-hydride elimination of the ethoxy intermediate discussed earlier (Rxn 2.5a).

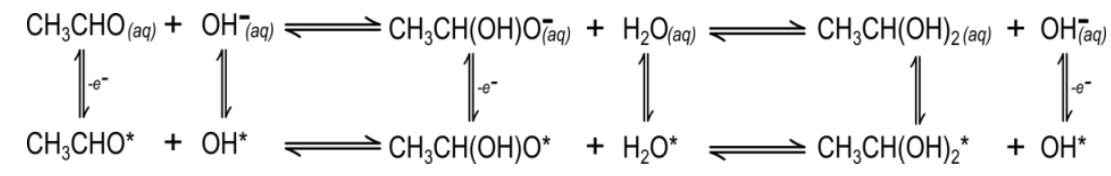

Acetaldehyde can also directly dehydrogenate to form the acetyl intermediate $\left(\mathrm{CH}_{3} \mathrm{CO}^{*}\right.$, Rxn 10, Figure 2.7) as is suggested in the literature. $33,34,96,98$ The activation of the $\mathrm{C}-\mathrm{H}$ bond to form acetyl preferentially proceeds via a metal-atom insertion mechanism and results in a barrier of only 29 $\mathrm{kJ} / \mathrm{mol}(\mathrm{Rxn} 10 \mathrm{a})$. The barriers for $\mathrm{O}^{*}$-assisted $(114 \mathrm{~kJ} / \mathrm{mol})$ and $\mathrm{OH}^{*}$-assisted $(50 \mathrm{~kJ} / \mathrm{mol})$ activation of the C-H bond are considerably higher than that over the metal. Once the acetyl is formed, it can react with $\mathrm{OH}^{*}$ on the surface to form acetic acid with a barrier of $17 \mathrm{~kJ} / \mathrm{mol}$ (Rxn 15). Both oxidation pathways, through ethoxy-diol and acetyl intermediates, depend on the local $\mathrm{OH}^{*}$ coverage. 


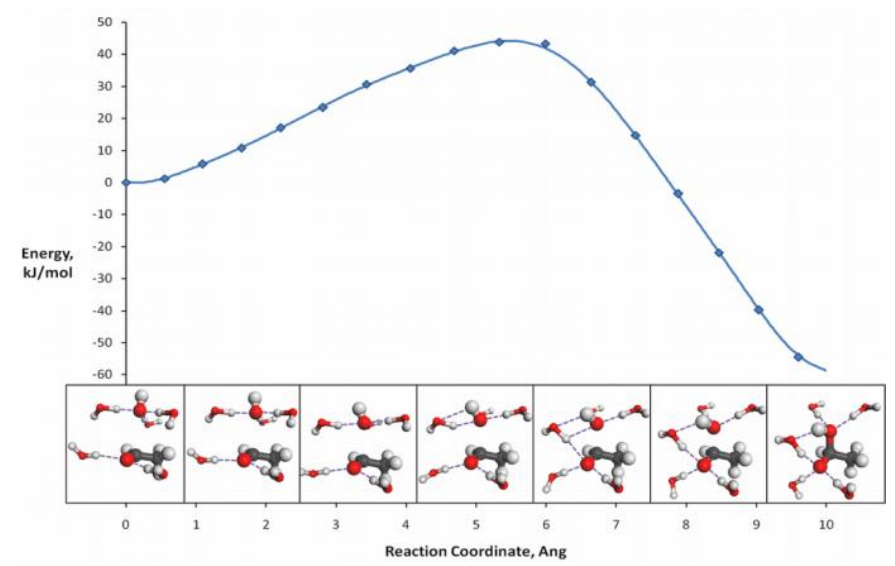

Figure 2.6. Base-catalyzed oxidation of acetaldehyde in the aqueous phase. The change in energy along the reaction coordinate shows a barrier of $45 \mathrm{~kJ} / \mathrm{mol}$ due to the restructuring of the water network.

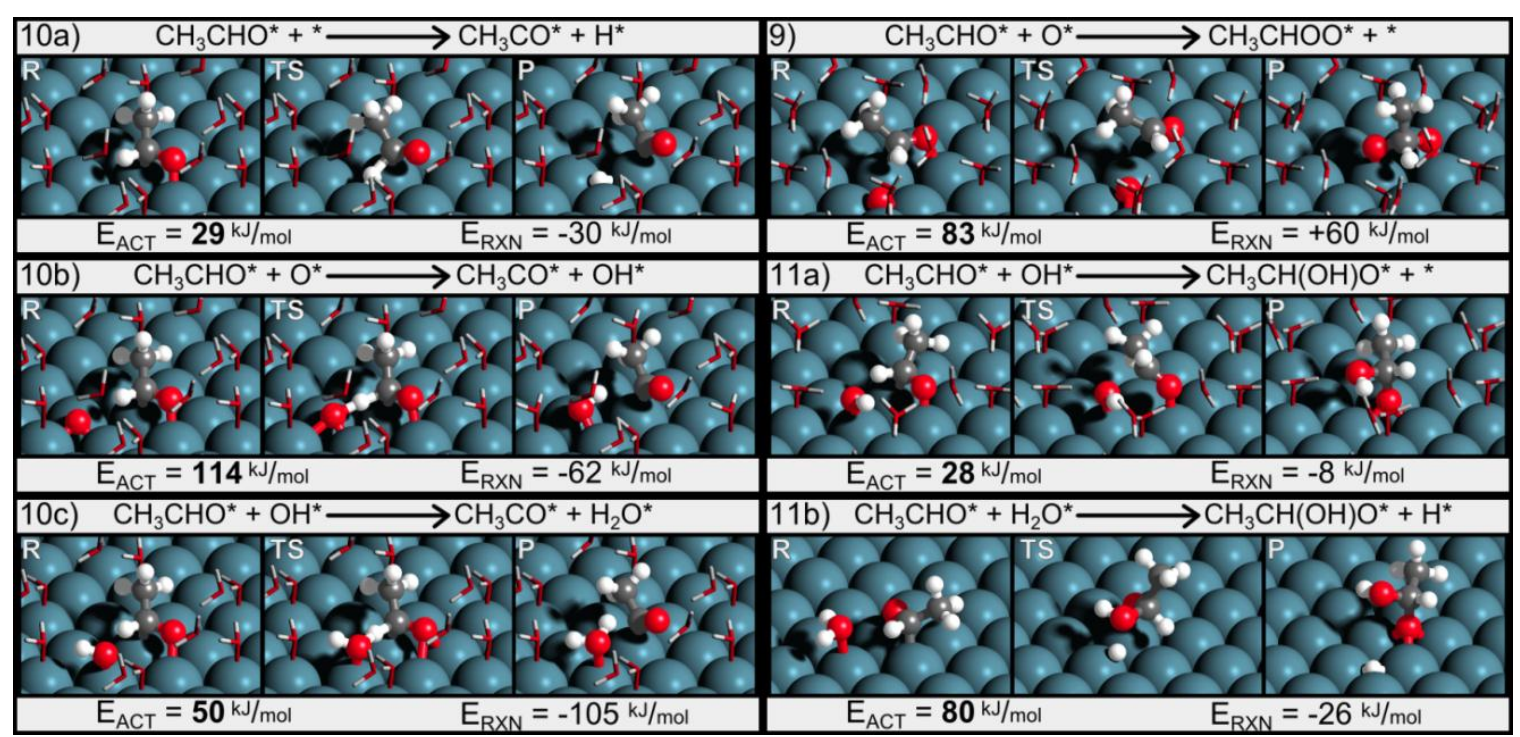

Figure 2.7. Oxidation reactions of acetaldehyde over $\operatorname{Pd}(111)$ in the presence an aqueous media.

DFT-calculated reactant, transition state and product states are shown for both acetaldehyde $\mathrm{C}-\mathrm{H}$ activation to form acetyl as well as $\mathrm{O}^{*}$ and $\mathrm{OH}^{*}$ addition steps. An additional step in which acetaldehyde reacts directly with water is also shown (not modeled in solvent). While the solvent was modeled using four layers, only the layer of solvent nearest to the surface is shown in each of the figures here. 
If acetaldehyde desorbs, it can still react with water in solution to form the geminal-diol hydrate, although the rate of reaction is slower in neutral $\mathrm{pH}$. In this case, it is still believed to form the ethoxy-diol intermediate (and a proton) as shown in Scheme 11.

$$
\mathrm{CH}_{3} \mathrm{CHO}+2 \mathrm{H}_{2} \mathrm{O} \rightarrow \mathrm{CH}_{3} \mathrm{CH}(\mathrm{OH}) \mathrm{O}^{-}+\mathrm{H}_{3} \mathrm{O}^{+} \rightarrow \mathrm{CH}_{3} \mathrm{CH}(\mathrm{OH})_{2}+\mathrm{H}_{2} \mathrm{O}
$$

Similarly, on the catalyst surface under neutral conditions, $\mathrm{OH}^{*}$-addition steps can still occur through direct reaction with the water solvent on the catalyst surface as shown in Scheme 12. However, this concerted mechanism of activating water and oxidizing the aldehyde results in a very high activation barrier $(80 \mathrm{~kJ} / \mathrm{mol})$ as shown in Table 2.5 or Figure 2.7 .

$$
\begin{aligned}
& \mathrm{CH}_{3} \mathrm{CHO}^{*}+\mathrm{H}_{2} \mathrm{O}^{*} \rightarrow \mathrm{CH}_{3} \mathrm{CH}(\mathrm{OH}) \mathrm{O}^{*}+\mathrm{H}^{*} \\
& \mathrm{CH}_{3} \mathrm{CO}^{*}+\mathrm{H}_{2} \mathrm{O}^{*} \rightarrow \mathrm{CH}_{3} \mathrm{COOH}^{*}+\mathrm{H}^{*}
\end{aligned}
$$

Under these conditions, it becomes very difficult to predict whether there will be a greater concentration of $\mathrm{O}^{*}$ or $\mathrm{OH}^{*}$ on the surface (both of which can be created as a result of ORR), so it is also important to consider $\mathrm{O}^{*}$-addition oxidation steps along with those for $\mathrm{OH}^{*}$ addition. The oxidation of acetaldehyde via the addition of $\mathrm{O}^{*}$ to form dioxyethylidene $\left(\mathrm{CH}_{3} \mathrm{CHOO}^{*}\right)$ has a barrier of $83 \mathrm{~kJ} / \mathrm{mol}$. This intermediate can subsequently undergo C-H activation to form the observed acetate product with a barrier of $7 \mathrm{~kJ} / \mathrm{mol}$ via $\alpha$-hydride elimination. If the acetyl intermediate $\left(\mathrm{CH}_{3} \mathrm{CO}{ }^{*}\right)$ is formed, the $\mathrm{O}^{*}$-addition step to form acetate has a barrier of $67 \mathrm{~kJ} / \mathrm{mol}$. 
Table 2.5. Complete Summary of Modeled Oxidation Reactions

\begin{tabular}{|c|c|c|c|c|}
\hline \multirow[b]{2}{*}{ Reaction } & \multicolumn{2}{|c|}{$P d(111)$} & \multicolumn{2}{|c|}{ Pd(111) Aqueous ${ }^{a}$} \\
\hline & $\boldsymbol{E}_{A C T}$ & $E_{R X N}$ & $E_{A C T}$ & $E_{R X N}$ \\
\hline $\mathrm{CH}_{3} \mathrm{CH}_{2} \mathrm{OH}^{*}+* \rightarrow \mathrm{CH}_{3} \mathrm{CH}_{2} \mathrm{O}^{*}+\mathrm{H}^{*}$ & 106 & 17 & 131 & 58 \\
\hline $\mathrm{CH}_{3} \mathrm{CH}_{2} \mathrm{OH}^{*}+\mathrm{O}^{*} \rightarrow \mathrm{CH}_{3} \mathrm{CH}_{2} \mathrm{O}^{*}+\mathrm{OH}^{*}$ & 40 & 22 & 80 & 25 \\
\hline $\mathrm{CH}_{3} \mathrm{CH}_{2} \mathrm{OH}^{*}+\mathrm{OH}^{*} \rightarrow \mathrm{CH}_{3} \mathrm{CH}_{2} \mathrm{O}^{*}+\mathrm{H}_{2} \mathrm{O}^{*}$ & $\mathbf{0}$ & -25 & 29 & -21 \\
\hline $\mathrm{CH}_{3} \mathrm{CH}_{2} \mathrm{OH}^{*}+* \rightarrow \mathrm{CH}_{3} \mathrm{CHOH}^{*}+\mathrm{H}^{*}$ & 50 & -31 & 84 & -3 \\
\hline $\mathrm{CH}_{3} \mathrm{CH}_{2} \mathrm{OH}^{*}+\mathrm{O}^{*} \rightarrow \mathrm{CH}_{3} \mathrm{CHOH}^{*}+\mathrm{OH}^{*}$ & 122 & -26 & 126 & -35 \\
\hline $\mathrm{CH}_{3} \mathrm{CH}_{2} \mathrm{OH}^{*}+\mathrm{OH}^{*} \rightarrow \mathrm{CH}_{3} \mathrm{CHOH}^{*}+\mathrm{H}_{2} \mathrm{O}^{*}$ & 105 & -73 & 64 & -70 \\
\hline $\mathrm{CH}_{3} \mathrm{CH}_{2} \mathrm{O}^{*}+* \rightarrow \mathrm{CH}_{3} \mathrm{CHO}^{*}+\mathrm{H}^{*}$ & 53 & -47 & 51 & -65 \\
\hline $\mathrm{CH}_{3} \mathrm{CH}_{2} \mathrm{O}^{*}+\mathrm{O}^{*} \rightarrow \mathrm{CH}_{3} \mathrm{CHO}^{*}+\mathrm{OH}^{*}$ & 73 & -41 & 95 & -97 \\
\hline $\mathrm{CH}_{3} \mathrm{CH}_{2} \mathrm{O}^{*}+\mathrm{OH}^{*} \rightarrow \mathrm{CH}_{3} \mathrm{CHO}^{*}+\mathrm{H}_{2} \mathrm{O}^{*}$ & 75 & -88 & 60 & -126 \\
\hline $\mathrm{CH}_{3} \mathrm{CHOH}^{*}+* \rightarrow \mathrm{CH}_{3} \mathrm{CHO}^{*}+\mathrm{H}^{*}$ & 69 & 1 & 90 & -4 \\
\hline $\mathrm{CH}_{3} \mathrm{CHOH}^{*}+\mathrm{O}^{*} \rightarrow \mathrm{CH}_{3} \mathrm{CHO}^{*}+\mathrm{OH}^{*}$ & 20 & 7 & 107 & -36 \\
\hline $\mathrm{CH}_{3} \mathrm{CHOH}^{*}+\mathrm{OH}^{*} \rightarrow \mathrm{CH}_{3} \mathrm{CHO}^{*}+\mathrm{H}_{2} \mathrm{O}^{*}$ & $\mathbf{0}$ & -40 & $\mathbf{0}$ & -76 \\
\hline $\mathrm{CH}_{3} \mathrm{CHOH}^{*}+\mathrm{O}^{*} \rightarrow \mathrm{CH}_{3} \mathrm{CH}(\mathrm{OH}) \mathrm{O}^{*}+*$ & 91 & -18 & 98 & -60 \\
\hline $\mathrm{CH}_{3} \mathrm{CHOH}^{*}+\mathrm{OH}^{*} \rightarrow \mathrm{CH}_{3} \mathrm{CH}(\mathrm{OH})_{2}{ }^{*}+*$ & 74 & -37 & 87 & -63 \\
\hline $\mathrm{CH}_{3} \mathrm{CHOH}^{*}+* \rightarrow \mathrm{CH}_{3} \mathrm{COH}^{*}+\mathrm{H}^{*}$ & 106 & -25 & 101 & 40 \\
\hline $\mathrm{CH}_{3} \mathrm{CHOH}^{*}+\mathrm{O}^{*} \rightarrow \mathrm{CH}_{3} \mathrm{COH}^{*}+\mathrm{OH}^{*}$ & 121 & -19 & 148 & -12 \\
\hline $\mathrm{CH}_{3} \mathrm{CHOH}^{*}+\mathrm{OH}^{*} \rightarrow \mathrm{CH}_{3} \mathrm{COH}^{*}+\mathrm{H}_{2} \mathrm{O}^{*}$ & 66 & -66 & 56 & -69 \\
\hline $\mathrm{CH}_{3} \mathrm{CH}(\mathrm{OH})_{2}{ }^{*}+\mathrm{CH}_{3} \mathrm{CH}(\mathrm{OH}) \mathrm{O}^{*}+\mathrm{H}^{*}$ & 78 & 23 & 97 & 48 \\
\hline $\mathrm{CH}_{3} \mathrm{CH}(\mathrm{OH})_{2}{ }^{*}+\mathrm{O}^{*} \rightarrow \mathrm{CH}_{3} \mathrm{CH}(\mathrm{OH}) \mathrm{O}^{*}+\mathrm{OH}^{*}$ & 37 & 29 & 35 & 2 \\
\hline $\mathrm{CH}_{3} \mathrm{CH}(\mathrm{OH})_{2}{ }^{*}+\mathrm{OH}^{*} \rightarrow \mathrm{CH}_{3} \mathrm{CH}(\mathrm{OH}) \mathrm{O}^{*}+\mathrm{H}_{2} \mathrm{O}^{*}$ & $\mathbf{0}$ & -18 & $\mathbf{0}$ & -44 \\
\hline $\mathrm{CH}_{3} \mathrm{CH}(\mathrm{OH})_{2}{ }^{*}+* \mathrm{CH}_{3} \mathrm{C}(\mathrm{OH})_{2}{ }^{*}+\mathrm{H}^{*}$ & 78 & -35 & -- & -- \\
\hline $\mathrm{CH}_{3} \mathrm{CH}(\mathrm{OH})_{2}{ }^{*}+\mathrm{O}^{*} \rightarrow \mathrm{CH}_{3} \mathrm{C}(\mathrm{OH})_{2}{ }^{*}+\mathrm{OH}^{*}$ & 00 & -29 & -- & -- \\
\hline $\mathrm{CH}_{3} \mathrm{CH}(\mathrm{OH})_{2}{ }^{*}+\mathrm{OH}^{*} \rightarrow \mathrm{CH}_{3} \mathrm{C}(\mathrm{OH})_{2} *+\mathrm{H}_{2} \mathrm{O}^{*}$ & 94 & -76 & -- & -- \\
\hline $\mathrm{CH}_{3} \mathrm{CHO}^{*}+\mathrm{O}^{*} \rightarrow \mathrm{CH}_{3} \mathrm{CHOO}^{*}+*$ & 41 & 14 & 83 & 60 \\
\hline $\mathrm{CH}_{3} \mathrm{CHO}^{*}+\mathrm{OH}^{*} \rightarrow \mathrm{CH}_{3} \mathrm{CH}(\mathrm{OH}) \mathrm{O}^{*}+*$ & 24 & -15 & 28 & 57 \\
\hline $\mathrm{CH}_{3} \mathrm{CHO}^{*}+\mathrm{H}_{2} \mathrm{O}^{*} \rightarrow \mathrm{CH}_{3} \mathrm{CH}(\mathrm{OH}) \mathrm{O}^{*}+\mathrm{H}^{*}$ & 80 & 26 & -- & -- \\
\hline $\mathrm{CH}_{3} \mathrm{CHO}^{*}+* \rightarrow \mathrm{CH}_{3} \mathrm{CO}^{*}+\mathrm{H}^{*}$ & 22 & -70 & 29 & -30 \\
\hline $\mathrm{CH}_{3} \mathrm{CHO}^{*}+\mathrm{O}^{*} \rightarrow \mathrm{CH}_{3} \mathrm{CO}^{*}+\mathrm{OH}^{*}$ & 80 & -65 & 114 & -62 \\
\hline $\mathrm{CH}_{3} \mathrm{CHO}^{*}+\mathrm{OH}^{*} \rightarrow \mathrm{CH}_{3} \mathrm{CO}^{*}+\mathrm{H}_{2} \mathrm{O}^{*}$ & 39 & -111 & 50 & -105 \\
\hline $\mathrm{CH}_{3} \mathrm{CH}(\mathrm{OH}) \mathrm{O}^{*}+* \rightarrow \mathrm{CH}_{3} \mathrm{COOH}^{*}+\mathrm{H}^{*}$ & 11 & -106 & 21 & -146 \\
\hline $\mathrm{CH}_{3} \mathrm{CH}(\mathrm{OH}) \mathrm{O}^{*}+\mathrm{O}^{*} \rightarrow \mathrm{CH}_{3} \mathrm{COOH}^{*}+\mathrm{OH}^{*}$ & 54 & -100 & 90 & -184 \\
\hline $\mathrm{CH}_{3} \mathrm{CH}(\mathrm{OH}) \mathrm{O}^{*}+\mathrm{OH}^{*} \rightarrow \mathrm{CH}_{3} \mathrm{COOH}^{*}+\mathrm{H}_{2} \mathrm{O}^{*}$ & 38 & -147 & 86 & -207 \\
\hline $\mathrm{CH}_{3} \mathrm{COH}^{*}+* \rightarrow \mathrm{CH}_{3} \mathrm{CO}^{*}+\mathrm{H}^{*}$ & 62 & -44 & 26 & -54 \\
\hline $\mathrm{CH}_{3} \mathrm{COH}^{*}+\mathrm{O}^{*} \rightarrow \mathrm{CH}_{3} \mathrm{CO}^{*}+\mathrm{OH}^{*}$ & 24 & -39 & 79 & -86 \\
\hline $\mathrm{CH}_{3} \mathrm{COH}^{*}+\mathrm{OH}^{*} \rightarrow \mathrm{CH}_{3} \mathrm{CO}^{*}+\mathrm{H}_{2} \mathrm{O}^{*}$ & $\mathbf{0}$ & -171 & 17 & -112 \\
\hline $\mathrm{CH}_{3} \mathrm{COH}^{*}+\mathrm{O}^{*} \rightarrow \mathrm{CH}_{3} \mathrm{COOH}^{*}+*$ & 105 & -90 & 142 & -144 \\
\hline $\mathrm{CH}_{3} \mathrm{COH}^{*}+\mathrm{OH}^{*} \rightarrow \mathrm{CH}_{3} \mathrm{C}(\mathrm{OH})_{2}{ }_{+}^{*}$ & 72 & -48 & -- & -- \\
\hline $\mathrm{CH}_{3} \mathrm{C}(\mathrm{OH})_{2}{ }^{*}+* \rightarrow \mathrm{CH}_{3} \mathrm{COOH}^{*}+\mathrm{H}^{*}$ & 37 & -47 & -- & -- \\
\hline $\mathrm{CH}_{3} \mathrm{C}(\mathrm{OH})_{2} *+\mathrm{O}^{*} \rightarrow \mathrm{CH}_{3} \mathrm{COOH}^{*}+\mathrm{OH}^{*}$ & 8 & -42 & -- & -- \\
\hline $\mathrm{CH}_{3} \mathrm{C}(\mathrm{OH})_{2}{ }^{*}+\mathrm{OH}^{*} \rightarrow \mathrm{CH}_{3} \mathrm{COOH}^{*}+\mathrm{H}_{2} \mathrm{O}^{*}$ & $\mathbf{0}$ & -89 & -- & -- \\
\hline $\mathrm{CH}_{3} \mathrm{CO}^{*}+\mathrm{O}^{*} \rightarrow \mathrm{CH}_{3} \mathrm{COO}^{*}+*$ & 67 & -95 & 74 & -104 \\
\hline $\mathrm{CH}_{3} \mathrm{CO}^{*}+\mathrm{OH}^{*} \rightarrow \mathrm{CH}_{3} \mathrm{COOH}^{*}+*$ & 30 & -51 & 17 & -111 \\
\hline $\mathrm{CH}_{3} \mathrm{CO}^{*}+\mathrm{H}_{2} \mathrm{O}^{*} \rightarrow \mathrm{CH}_{3} \mathrm{COOH}^{*}+\mathrm{H}^{*}$ & 104 & -9 & -- & -- \\
\hline $\mathrm{CH}_{3} \mathrm{CHOO}^{*}+* \rightarrow \mathrm{CH}_{3} \mathrm{COO}^{*}+\mathrm{H}^{*}$ & 25 & -179 & 7 & -194 \\
\hline $\mathrm{CH}_{3} \mathrm{CHOO}^{*}+\mathrm{O}^{*} \rightarrow \mathrm{CH}_{3} \mathrm{COO}^{*}+\mathrm{OH}^{*}$ & 28 & -174 & 105 & -226 \\
\hline $\mathrm{CH}_{3} \mathrm{CHOO}^{*}+\mathrm{OH}^{*} \rightarrow \mathrm{CH}_{3} \mathrm{COO}^{*}+\mathrm{H}_{2} \mathrm{O}^{*}$ & 24 & -220 & 54 & -249 \\
\hline
\end{tabular}




\section{Effect of $\mathrm{O}^{*}$ and $\mathrm{OH}^{*}$ on $\mathrm{O}-\mathrm{H}$ and $\mathrm{C}-\mathrm{H}$ Bond Activations}

Through the course of this study, five $\mathrm{O}-\mathrm{H}$ and seven $\mathrm{C}-\mathrm{H}$ activations were calculated over the model Pd(111) surface. Each of these reactions were studied on the bare metal surface, where they occur either through metal-atom insertion, similar to oxidative insertion reported in organometallic catalysis,117 or through hydride elimination. The activation barriers for this mechanism (in the absence of solvent) range from 11-106 kJ/mol and follow a loose Brønsted-EvansPolyani (BEP) relationship as shown in Figure 2.8.

The $\mathrm{O}-\mathrm{H}$ and $\mathrm{C}-\mathrm{H}$ activations were also examined in the presence of $\mathrm{O}^{*}$ and $\mathrm{OH}^{*}$ which can alter the mechanism in various ways. One altered mechanism is similar to $\sigma$-bond metathesis reported in organometallic catalysis. ${ }^{117}$ A four-center M-C-H-O complex is formed in the transition state, indicating contributions from both metal-atom insertion into the $\mathrm{C}-\mathrm{H}$ bond and hydrogen atom abstraction by the $0^{*}$ or $\mathrm{OH}^{*}$ ligand on the surface. During other activations, the metal does not act to stabilize the hydrogen; the abstraction occurs directly between the intermediate and the $\mathrm{O}^{*}$ or $\mathrm{OH}^{*}$.

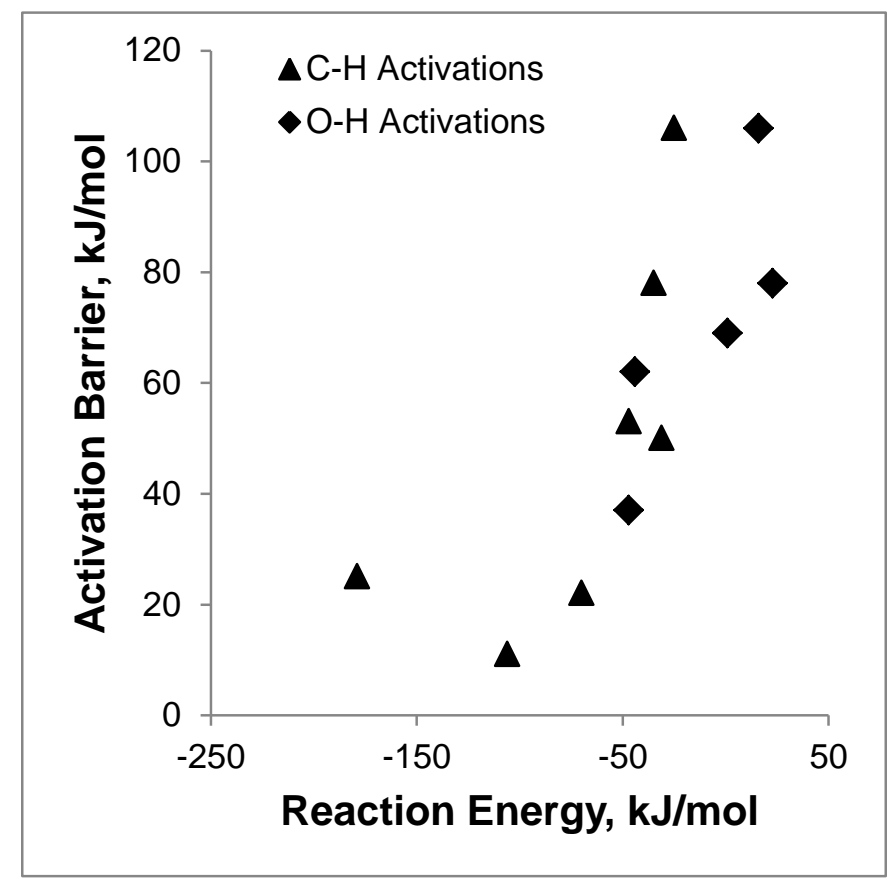

Figure 2.8. Brønsted-Evans-Polyani (BEP) correlation for the activation of $\mathrm{C}-\mathrm{H}$ and $\mathrm{O}-\mathrm{H}$ bonds, metal-catalyzed, over the Pd(111) surface. 
In all cases of $\mathrm{C}-\mathrm{H}$ activation, the activation barrier is higher for the reactions involving the Pd-O* sites than those over Pd-Pd sites (by an average of $31 \mathrm{~kJ} / \mathrm{mol}$ ). Examining the transition state for over the Pd-O* site pairs (examples of which are shown in Figures 2.5 and 2.7), the $0^{*}$ must shift from a very stable three-fold fcc site to a more active site, usually a bridge position; this comes with an energetic penalty up to $47 \mathrm{~kJ} / \mathrm{mol}$ (shown in Figure 2.9). The $\mathrm{C}-\mathrm{H}$ bonds of alcohols are not typically acidic and as such they are not readily assisted by proton transfer mechanisms to $0^{*}$ unless $\mathrm{O}^{*}$ is very basic, thus most of the activation barriers with $\mathrm{Pd}-\mathrm{O}^{*}$ sites increase. Only on $\mathrm{Au}^{36}$ and other coinage metals, ${ }^{31}$ do the $\mathrm{C}-\mathrm{H}$ activation energies decrease with $\mathrm{O}^{*}$-assisted mechanisms. In those cases, the noble nature of the metal causes the metal-atom insertion mechanism to have a very high barrier. Furthermore, it decreases the binding strength of $0^{*}$ thus making it more basic and allowing it to more easily shift to an active site. As a result, the oxygen is more basic and reactive on coinage metals than on Pd, allowing it to activate the $\mathrm{C}-\mathrm{H}$ bond despite the weak acidity of the bond.

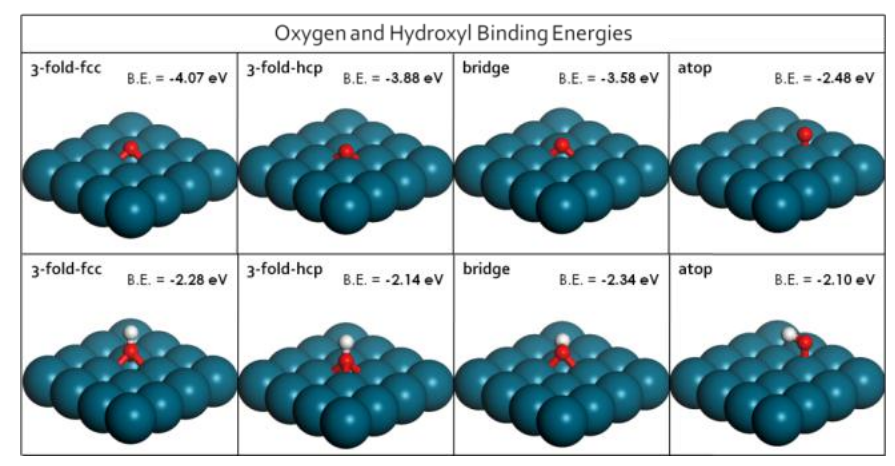

Figure 2.9. Binding energy of $\mathrm{O}^{*}$ and $\mathrm{OH}^{*}$ in various modes over a $\mathrm{Pd}(111)$ surface. Atomic $\mathrm{O}^{*}$ bound to the 3 -fold-fcc site has the strongest binding energy and shifting it to a bridge site requires 47 $\mathrm{kJ} / \mathrm{mol}$ whereas $\mathrm{OH}^{*}$ is more stable in the bridge site and can shift to an atop site with only a 23 $\mathrm{kJ} / \mathrm{mol}$ penalty. Four metal layers were modeled, only the top layer is shown.

The $\mathrm{O}-\mathrm{H}$ bonds, as opposed to the $\mathrm{C}-\mathrm{H}$ bonds, are much more acidic and as a result the average barrier for $\mathrm{O}-\mathrm{H}$ activation via $\mathrm{O}^{*}$-assisted proton abstraction is only $26 \mathrm{~kJ} / \mathrm{mol}$ whereas the average barrier for metal-atom insertion is $70 \mathrm{~kJ} / \mathrm{mol}$, showing a significant decrease in barrier despite the energetic penalty associated with promoting the $0^{*}$ to an active state. 
The presence of $\mathrm{O}^{*}$ on the surface thus lowers the activation barriers for $\mathrm{O}-\mathrm{H}$ activation but increases those for $\mathrm{C}-\mathrm{H}$ activation. This difference cannot be explained through the relative strengths of the $\mathrm{C}-\mathrm{H}$ and $\mathrm{O}-\mathrm{H}$ bonds being studied, as the $\mathrm{C}-\mathrm{H}$ bond of ethanol is $36 \mathrm{~kJ} / \mathrm{mol}$ weaker than the $\mathrm{O}-\mathrm{H}$ bond, whereas the $\mathrm{C}-\mathrm{H}$ activation barrier is $82 \mathrm{~kJ} / \mathrm{mol}$ higher than that for $\mathrm{O}-\mathrm{H}$ activation. The differences instead are related to the significant differences in acidity between the $\mathrm{O}-\mathrm{H}$ vs. C-H bonds as the abstraction reaction involves a proton transfer from the oxygenate molecule to the basic $0^{*}$ on the metal surface.

For $\mathrm{OH}^{*}$-assisted activations, there is no significant penalty for shifting the binding state of $\mathrm{OH}^{*}$ on the Pd surface as shown in Figure 6, in contrast to $0^{*}$. The average activation barrier for the activation of $\mathrm{C}-\mathrm{H}$ bonds on $\mathrm{Pd}-\mathrm{OH}^{*}$ sites is $61 \mathrm{~kJ} / \mathrm{mol}$, which is just $6 \mathrm{~kJ} / \mathrm{mol}$ higher than the average on Pd-Pd sites. The small shift in activation barrier (compared to the large increase observed for $0^{*}$ assisted activations) is likely due to the smaller penalty for shifting $\mathrm{OH}^{*}$ to an active bridge or atop site. It's also important to note that for most cases, the metal-atom insertion mechanism is the favored route for $\mathrm{C}-\mathrm{H}$ activation. In contrast, all five $\mathrm{O}-\mathrm{H}$ bond activations show no barrier for the reaction to take place on $\mathrm{Pd}(111)$ in the absence of solvent. The basic properties of $\mathrm{OH}^{*}$ and the very small penalties associated with moving $\mathrm{OH}^{*}$ to an active site make it ideal for the activation of $\mathrm{O}-\mathrm{H}$ bonds on a Pd surface (as well as $\mathrm{Au}$ and $\mathrm{Pt}{ }^{36}$ ).

\section{Summary of Alcohol Oxidation over Pd Catalysts}

For aqueous phase alcohol oxidation, equilibrium is set between the ethanol and hydroxide in solution with adsorbed ethoxy as shown previously in Scheme 8. Therefore, as the pH of the system increases, the coverage of ethoxy increases on the Pd surface. This ethoxy intermediate subsequently undergoes hydride elimination on the Pd surface, resulting in the formation of acetaldehyde as well as adsorbed hydrogen (Scheme 10d). Acetaldehyde subsequently hydrates in solution to form a geminal-diol species. This hydration forms an ethoxy-diol intermediate, which can then adsorb on the metal surface. Through these processes, acetaldehyde is in equilibrium with the ethoxy-diol intermediate and the geminal diol hydrate as shown in Scheme 10. The ethoxy-diol 
intermediate irreversibly dehydrogenates on the Pd surface to form acetic acid. This mechanism, which consumes multiple hydroxyl groups per turnover, is quite similar to those proposed in studies of alcohol electro-oxidation in direct alcohol fuel cells.118,119 In systems operating at neutral or slightly acidic $\mathrm{pH}$, the coverage of ethoxy on the surface is much lower, which could alter the mechanism towards a metal atom insertion into the $\mathrm{C}-\mathrm{H}$ bond of ethanol, forming hydroxyethyl. Hydroxyethyl subsequently dehydrogenates in a second metal-atom insertion into the $\mathrm{O}-\mathrm{H}$ bond, forming acetaldehyde. Following this, the rate is significantly limited by the low coverage of $0^{*}$ and $\mathrm{OH}^{*}$ on the surface, but can proceed through the ethoxy-diol intermediate as at high $\mathrm{pH}$.

Oxygen Reduction Reaction

As $\mathrm{OH}^{*}$ appears to catalyze the $\mathrm{O}-\mathrm{H}$ bond activations as well as the oxygen-addition step of the aldehyde in systems operating at high $\mathrm{pH}$, oxygen (in the form of $\mathrm{O}_{2}$ or $\mathrm{O}^{*}$ ) does not appear to be necessary in the direct conversion of ethanol to acetic acid over Pd, which is consistent with previous results over $\mathrm{Au}$ and $\mathrm{Pt}^{36}$ However, unlike $\mathrm{Au}$, the oxidation over Pd can proceed (at lower rates) at neutral or slightly acidic $\mathrm{pH} .34,102^{3}$ Furthermore, this reaction, when carried out over Pd, generates atomic hydrogen intermediates on the surface, which may not occur when the reaction takes place over $\mathrm{Au}$. The oxidation sequence also transfers four electrons into the Pd catalyst, which must be removed (along with the hydrogen intermediates) in order to close the catalytic cycle and preserve activity. This occurs via the reduction of molecular oxygen. In general, the reduction reaction must dissociate $\mathrm{O}_{2}$ and add hydrogen atoms to the intermediates to form one of three products: water, the most studied and common product of ORR due to its application in fuel cells; hydroxide, replenishing the supply consumed by the oxidation; or hydrogen peroxide, an observed byproduct in fuel cells and alcohol oxidation over $\mathrm{Au}^{36,79}$ Each of these three end-products can remove electrons and adsorbed hydrogen from the catalyst, so it's important to consider the entire reaction network as a whole. Table 3 shows all of the elementary steps that are considered along with their reaction energies and activation barriers in the presence and absence of solvent on the $\operatorname{Pd}(111)$ surface. 
Table 2.6. Complete Summary of Modeled ORR Reactions

\begin{tabular}{lcccc}
\hline \multicolumn{1}{c}{ Reaction } & \multicolumn{2}{c}{$P d(111)$} & \multicolumn{2}{c}{$P d(111)$ Aqueous $^{a}$} \\
& $\boldsymbol{E}_{\text {ACT }}$ & $E_{R X N}$ & $\boldsymbol{E}_{\text {ACT }}$ & $E_{R X N}$ \\
\hline $\mathrm{O}_{2}{ }^{*}+{ }^{*} \rightarrow \mathrm{O}^{*}$ & $\mathbf{6 5}$ & -161 & $\mathbf{5 4}$ & -171 \\
$\mathrm{O}_{2}{ }^{*}+\mathrm{H}^{*} \rightarrow \mathrm{OOH}^{*}+\mathrm{H}^{*}$ & $\mathbf{8 5}$ & 15 & $\mathbf{1 1 0}$ & -29 \\
$\mathrm{O}_{2}{ }^{*}+\mathrm{H}_{2} \mathrm{O}^{*} \rightarrow \mathrm{OOH}^{*}+\mathrm{OH}^{*}$ & $\mathbf{2 5}$ & 24 & $\mathbf{3 7}$ & 35 \\
\hline $\mathrm{OOH}^{*}+{ }^{*} \rightarrow \mathrm{O}^{*}+\mathrm{OH}^{*}$ & $\mathbf{4}$ & -171 & $\mathbf{4 4}$ & -176 \\
$\mathrm{OOH}^{*}+\mathrm{H}^{*} \rightarrow \mathrm{H}_{2} \mathrm{O}_{2}{ }^{*}$ & $\mathbf{7 0}$ & 3 & $\mathbf{7 6}$ & -9 \\
$\mathrm{OOH}^{*}+\mathrm{H}_{2} \mathrm{O}^{*} \rightarrow \mathrm{H}_{2} \mathrm{O}_{2}{ }^{*} \mathrm{OH}^{*}$ & $\mathbf{4 8}$ & 44 & $\mathbf{4 4}$ & 0 \\
\hline $\mathrm{H}_{2} \mathrm{O}_{2}{ }^{*} \rightarrow 2 \mathrm{OH}^{*}$ & $\mathbf{4}$ & -168 & $\mathbf{5}$ & -199 \\
\hline $\mathrm{O}^{*}+\mathrm{H}^{*} \rightarrow \mathrm{OH}^{*}$ & $\mathbf{1 0 4}$ & 5 & $\mathbf{9 9}$ & -32 \\
$\mathrm{O}^{*}+\mathrm{H}_{2} \mathrm{O}^{*} \rightarrow 2 \mathrm{OH}^{*}$ & $\mathbf{5 0}$ & 47 & $\mathbf{6 9}$ & 39 \\
\hline $\mathrm{OH}^{*}+\mathrm{H}^{*} \rightarrow \mathrm{H}_{2} \mathrm{O}^{*}+{ }^{*}$ & $\mathbf{6 6}$ & -41 & $\mathbf{7 7}$ & 71 \\
\hline
\end{tabular}

Energies are reported in kJ/mol. a Reactions with $\mathrm{H}_{2} \mathrm{O}^{*}$ in the reactants were modeled with 22 water molecules, otherwise 23 water molecule were modeled as the solvent.

Molecular oxygen binds to Pd with an energy of $75 \mathrm{~kJ} / \mathrm{mol}$ and can readily to dissociate to form two oxygen adatoms with a barrier of $54 \mathrm{~kJ} / \mathrm{mol}$ with solvent present and $65 \mathrm{~kJ} / \mathrm{mol}$ without solvent (Rxn 01), which is similar to that reported previously. ${ }^{103,120}$ While the $0^{*}$ can subsequently react with $\mathrm{H}^{*}$ to form $\mathrm{OH}^{*}$, the barrier is rather high at $110 \mathrm{~kJ} / \mathrm{mol}$. Alternatively, $\mathrm{O}^{*}$ can be reduced through the direct reaction with the water solvent: $0^{*}+\mathrm{H}_{2} \mathrm{O}^{*} \rightarrow 2 \mathrm{OH}^{*}$ (Rxn 06b), which has a barrier of $69 \mathrm{~kJ} / \mathrm{mol}$. Instead of dissociation, $\mathrm{O}_{2}$ can undergo an initial reduction to form a peroxide $\left(\mathrm{OOH}^{*}\right)$ intermediate. This reduction can occur via the reaction with $H^{*}\left(E_{A C T}=110 \mathrm{~kJ} / \mathrm{mol}, \mathrm{Rxn}\right.$ 03a) or through the reaction with $\mathrm{H}_{2} \mathrm{O}\left(37 \mathrm{~kJ} / \mathrm{mol}\right.$, Rxn 03b). Once formed, $\mathrm{OOH}^{*}$ easily dissociates in a strongly exothermic reaction to form $\mathrm{O}^{*}$ and $\mathrm{OH}^{*}$ with a barrier of $20 \mathrm{~kJ} / \mathrm{mol}$. The resulting $\mathrm{O}^{*}$ can (as before) be reduced through reaction with water from the solvent. These two processes leading to hydroxide, shown in Scheme 11, are both limited by the 0-0 cleavage step, with overall energy barriers of 54 and $55 \mathrm{~kJ} / \mathrm{mol}$, respectively. Once $\mathrm{OH}^{*}$ is formed, it can react with $\mathrm{H}^{*}$ on the surface to form water, with a barrier of $77 \mathrm{~kJ} / \mathrm{mol}$, consuming $\mathrm{H}^{*}$ which is produced in the oxidation reactions. However, as only two-three $\mathrm{H}^{*}$ are produced via the oxidation process discussed above, not all of the $\mathrm{OH}^{*}$ will be fully reduced to $\mathrm{H}_{2} \mathrm{O}$ thus regenerating some $\mathrm{OH}^{*}$ consumed during oxidation. 


$$
\begin{gathered}
\mathrm{O}_{2}{ }^{*}+2 \mathrm{H}_{2} \mathrm{O}^{*} \rightarrow 2 \mathrm{O}^{*}+2 \mathrm{H}_{2} \mathrm{O}^{*} \rightarrow 4 \mathrm{OH}^{*} \\
\mathrm{O}_{2}{ }^{*}+2 \mathrm{H}_{2} \mathrm{O}^{*} \rightarrow \mathrm{OH}^{*}+\mathrm{OOH}^{*}+\mathrm{H}_{2} \mathrm{O}^{*} \rightarrow 2 \mathrm{OH}^{*}+\mathrm{O}^{*}+\mathrm{H}_{2} \mathrm{O}^{*} \rightarrow 4 \mathrm{OH}^{*} \\
\mathrm{OH}^{*}+\mathrm{H}^{*} \rightarrow \mathrm{H}_{2} \mathrm{O}^{*}
\end{gathered}
$$

The formation of $\mathrm{H}_{2} \mathrm{O}_{2}$ was found to be unlikely over $\mathrm{Pd}$ at these conditions, as the further reduction barriers (shown in Table 3) are rather high compared to the dissociation barrier, this is in contrast to the recent work on $\mathrm{Au}^{36}$, but is consistent with earlier work which showed very little rates of peroxide production on $\mathrm{Pd}^{85}$ during glycerol oxidation.

\section{Conclusions}

Alcohol oxidation over Pd is catalytically promoted by the presence of base as hydroxide catalyzes deprotonation and increasing the $\mathrm{pH}$ raises the coverage of alkoxy intermediates on the surface through equilibrium. The alkoxy intermediate undergoes an irreversible hydride transfer on the catalyst surface to form an aldehyde. The oxidation takes place via a base-catalyzed nucleophilic addition to the aldehyde which forms an alkoxy intermediate of a geminal diol in solution or on the surface. The equilibrium between the alkoxy-diol intermediate that forms and the geminal diol species offers an explanation for the multiple incorporations of ${ }^{18} \mathrm{O}$ in the product acid that is found experimentally. Finally, the alkoxy-diol intermediate irreversibly dehydrogenates to form a carboxylic acid on the catalyst surface. This carboxylic acid is in equilibrium with the experimentallyobserved carboxylate-cation adduct.

In systems operating at neutral or slightly acidic $\mathrm{pH}$, hydroxide (in solution or on the surface) is present in very low concentration, forcing the mechanism to take a different route. The dehydrogenation initially proceeds via metal-atom insertion into the $\mathrm{C}-\mathrm{H}$ bond with a barrier of 84 $\mathrm{kJ} / \mathrm{mol}$, forming the hydroxyethyl intermediate which subsequently undergoes $\mathrm{O}-\mathrm{H}$ activation by the metal to form acetaldehyde. Acetaldehyde further dehydrogenates to form an acetyl intermediate which subsequently reacts with a surface $0^{*}$ to form acetate with a barrier of $74 \mathrm{~kJ} / \mathrm{mol}$. Alternatively, if the $0^{*}$ intermediate is first reduced to form $\mathrm{OH}^{*}$, the acetyl intermediate can react with $\mathrm{OH}^{*}$ to form acetic acid with an overall barrier of $69 \mathrm{~kJ} / \mathrm{mol}$, which is very similar to the barrier 
to form acetate. In either case, the barriers for this process are higher than those with hydroxide present, consistent with experimental findings which demonstrate first-order kinetics with the concentration of hydroxide.

The role of $\mathrm{O}_{2}$ in this system is to remove the electrons that form on the surface as a result of the oxidation of the alcohol through the reduction of oxygen by water. This regenerates hydroxide intermediates and removes the $\mathrm{H}^{*}$ produced during oxidation. The presence of an aqueous environment diminishes the dissociative-reduction of oxygen but favors the associative-reduction. The combination of the alkaline environment along with the Pd surface provides unique opportunities for mechanisms which involve direct interaction with the solvent or hydroxide species present in aqueous media, such as the reduction of $\mathrm{O}_{2}$ with $\mathrm{H}_{2} \mathrm{O}$ to form $\mathrm{OOH}$ intermediates.

The alcohol oxidation and $\mathrm{O}_{2}$ reduction mechanisms reported here for the catalytic oxidation of alcohols in basic media are quite similar to those involved in the electrocatalytic oxidation and reduction reactions that occur in alkaline fuel cells. In these aqueous phase reactions at high $\mathrm{pH}$, the combination of the solvent and ionic species creates a potential on the catalyst surface which is often neglected in heterogeneous catalysis. 


\section{3...Effect of $\mathrm{O}^{*}$ and $\mathrm{OH}^{*}$ on $\mathrm{C}-\mathrm{H}$ and $\mathrm{O}-\mathrm{H}$ Bond Activations}

\section{1 : The Study of Methane Activation over Clean and Oxygen-Covered Transition}

\section{Metal Surfaces}

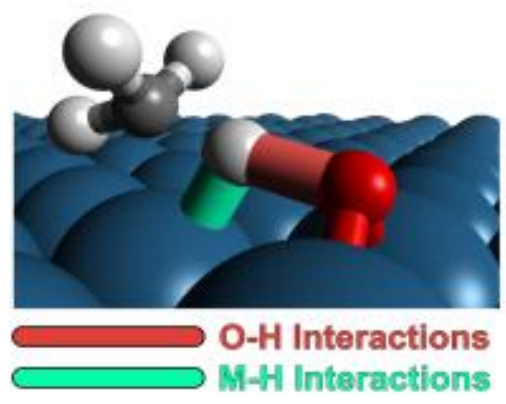

The partial oxidation of methane over supported metal catalysts is a potential route to syngas that may be used to produce hydrocarbons. The activation of methane as well as other hydrocarbons can often be assisted by the presence of oxygen as formation of adsorbed oxygen $\left(\mathrm{O}^{*}\right)$ can help to activate $\mathrm{C}-\mathrm{H}$ bonds. The reactivity of oxygen is strongly dependent on nature of the metal and the coverage of $0^{*}$ on the surface.

\section{2 : Evaluation of the Brønsted Basicity of $\mathrm{O}^{*}$ and $\mathrm{OH}^{*}$ on Transition Metal Surfaces}

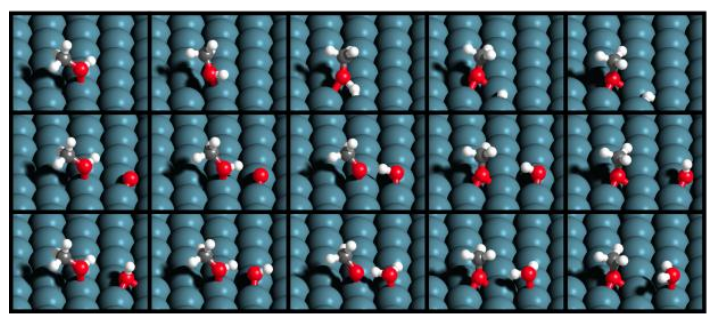

For a range of alkanes and alcohols, the activation of $\mathrm{C}-\mathrm{H}$ and $\mathrm{O}-\mathrm{H}$ bonds were examined across platinum-group and coinage metal surfaces. The results form a set of rules describing under what conditions $\mathrm{O}^{*}$ and $\mathrm{OH}^{*}$ can act as Brønsted base species. 


\section{1 - The Study of Methane Activation over Clean and Oxygen-Covered Transition Metal Surfaces}

[Adopted from: C. Buda, D. D. Hibbitts, and M. Neurock, to be submitted]

\section{Introduction}

The conversion of methane, the major component of natural gas, into syngas products could enable the production of hydrogen or longer-chain alkanes from abundant natural gas resources. Steam and dry reforming, using $\mathrm{H}_{2} \mathrm{O}$ and $\mathrm{CO}_{2}$ as source of $\mathrm{O}$, respectively, are the most widely used industrial processes that convert methane into synthesis gas. ${ }^{122,130,131}$ Recently, increased interest has been shown for the catalytic partial oxidation (CPOX) of methane with $\mathrm{O}_{2}$ for syngas production.

Reactions of $\mathrm{CH}_{4}$ with $\mathrm{O}_{2}, \mathrm{H}_{2} \mathrm{O}$ or $\mathrm{CO}_{2}$ have been extensively studied both experimentally and computationally over a large range of transition metals, including $\mathrm{Pt}, 26,28,125,126,128,132-137 \mathrm{Pd},{ }^{136,138-143}$ $\mathrm{Ni},{ }^{135,144-150} \mathrm{Rh},{ }^{26,28,125,134,140,143,151,152} \mathrm{Ru},{ }^{125,153-156}$ and Ir. ${ }^{125,157,158}$ These studies, while examining a large variety of reactions, consistently suggest that the initial activation of methane is the kinetically relevant step. ${ }^{125,126}$ During catalysis with organometallic complexes, the initial activation of methane is thought to proceed through an oxidative addition mechanism, in which the $\mathrm{C}-\mathrm{H}$ bond is broken concomitantly with C-M and H-M bond formation in the transition state. ${ }^{117,127,128}$ On a clean metal surface, the initial activation of methane is thought to proceed through a metal-atom-insertion reaction, very similar to the oxidative addition mechanism reported in the organometallic literature.

Chin, et al. has recently shown promising results for the partial oxidation of methane on supported Pt catalysts operated at a range of oxygen coverages. ${ }^{28}$ Those results, from a combination of kinetic, isotopic, and density functional theory (DFT) data indicate that the reaction can operate in four distinct kinetic regimes which depend upon the coverage of $0^{*}$ on the catalyst particle. The active site for the activation of methane changes between regimes with different $0^{*}$ coverage, from a site composed of two vacancies $\left({ }^{*}-\right.$ ) on the metal surface at low $0^{*}$ coverage, to a site in which one adsorbed $0^{*}$ is involved during methane activation $\left(0^{*-*}\right)$ at intermediate $0^{*}$ coverage, to a site in which methane is activated over a two adsorbed $0^{*}$ atoms $\left(0^{*}-0^{*}\right)$. These findings introduced two 
additional mechanisms for methane activation on transition metal surfaces: one similar to $\sigma$-bond metathesis of organometallic literature, ${ }^{117,127,128}$ in which an adsorbed $\mathrm{O}^{*}$ participates during the $\mathrm{C}-\mathrm{H}$ activation at an $\mathrm{O}^{*}-*$ site forming $\mathrm{OH}^{*}$ and $\mathrm{CH}_{3}{ }^{*}$ intermediates and one a $\mathrm{H}$-abstraction mechanism in which a methyl radical is formed above an $\mathrm{O}^{*}-\mathrm{O}^{*}$ site leading to $\mathrm{OH}^{*}$ and $\mathrm{CH}_{3} \mathrm{O}^{*}$ intermediates.

In this section we extend the theoretical portion of that prior work ${ }^{28}$ by examining the activation of methane at an $0^{*}-*$ site through a $\sigma$-bond metathesis like mechanism across a range of low-index surfaces of platinum group and coinage metals using first principles DFT calculations. In order to capture the effects of $0^{*}$ coverage, a series of these reactions were carried out for $0^{*}$ coverages ranging from $1 / 9$ to $6 / 9 \mathrm{ML}$ for selected metals. The results show that $0^{*}$ shifts from its stable 3 -fold site to a near-bridge site in the transition state of $\mathrm{C}-\mathrm{H}$ activation at an $\mathrm{O}^{*}-*$ site. The methane activation barrier primarily depends upon the energy required to promote $0 *$ to its active site and the strength of the $\mathrm{M}-\mathrm{C}$ and $\mathrm{O}-\mathrm{H}$ bonds being formed in the transition state. These factors are set by the nature of the metal, the binding energy of oxygen to the metal as well as the coverage of oxygen. In order to provide a more detailed understanding of the role of $0^{*}$ during this methane activation mechanism, an analysis of the elementary thermochemical process was performed on the transition states of the studied reactions.

\section{Computational Details}

Periodic, plane-wave DFT calculations were all carried out using the Vienna Ab-initio Simulation Package (VASP).1,3,4 The exchange and correlation terms were calculated using the Perdew-Wang $91^{13}$ (PW91) functional form of the generalized gradient approximation (GGA) with the Vosko, Wilk, and Nusair interpolation. Ultra-soft pseudopotentials (USPP) ${ }^{11,12}$ were used with an energy cutoff of $396 \mathrm{eV}$.

Slab calculations were carried out with a $3 \times 3$ unit cell of the closed packed surface $(111$ for fcc metals and 0001 for hcp metals). A $10 \AA$ vacuum region was added on the top of closed packed surface, separating the slabs and ensuring an area of low charge density in the z-direction. The slabs contained four layers and the bottom two layers were fixed to their bulk positions while the upper 
two layers were allowed to relax. Due to the non-magnetic nature of the metals studied, the majority of the calculations were carried out with closed shell electronic configurations, with the exception of $\mathrm{Ni}$ and Co which were carried out spin-polarized. The band occupancy was determined using a second order Methfessel-Paxton occupation scheme with a smearing of $0.20 \mathrm{eV}$. A 3x3x1 k-point mesh in the Brillouin zone was selected and the condition for convergence of SCF loop was set to 1e$4 \mathrm{eV}$. The position of all unconstrained atoms was relaxed until the forces on each atom were less than $0.05 \mathrm{eV} / \AA ̊$. For calculations of adsorbates in the vacuum, the molecules were fully optimized in a 10 Å cubic cell. The wavefunctions were all calculated spin-polarized, using lower value for smearing of $0.02 \mathrm{eV}$ and the same values for convergence of SCF loop and forces on each atom discussed above.

The adsorption energy was calculated according to Equation 3.1a and referenced the isolated adsorbate in the gas phase and the isolated bare metal surface The differential adsorption energies of oxygen, however, carried out at higher coverages (nO) were referenced the most stable configuration of oxygen at the next lower coverage $((n-1) 0)$, as well as $\mathrm{O}_{2}$ in the vacuum phase rather than atomic 0 , Equation $3.1 \mathrm{~b}$.

$$
\begin{aligned}
& E_{\mathrm{ADS}}=\mathrm{E}_{\mathrm{M}+n 0+a d s}-\mathrm{E}_{\mathrm{M}+n 0}-\mathrm{E}_{\mathrm{ads}} \\
& \mathrm{E}_{n 0}=\mathrm{E}_{\mathrm{M}+n 0}-\mathrm{E}_{\mathrm{M}+(n-1) \mathrm{O}}-1 / 2 \mathrm{E}_{02}
\end{aligned}
$$

where $\mathrm{E}_{\mathrm{ADS}}$ is the adsorption energy of the adsorbate, $\mathrm{E}_{\mathrm{M}+n 0+\text { ads }}$ is the energy of the adsorbate bound to the partially oxygen-covered metal surface, $\mathrm{E}_{\mathrm{M}+n \mathrm{n}}$ is the energy of oxygen configuration at $n / 9$ coverage, $\mathrm{E}_{\mathrm{ads}}$ is the energy of the adsorbate in the vacuum, $\mathrm{E}_{n 0}$ is the differential adsorption energy of the $n$ oxygen atoms, $\mathrm{E}_{\mathrm{M}+(n-1) 0}$ is the most stable energy of (n-1) partially oxygen-covered metal surface and $\mathrm{E}_{02}$ is the energy of $\mathrm{O}_{2}$ optimized individually in the vacuum phase.

The nudged elastic band (NEB) method was used to provide the initial transition state structures. Bands of eight to sixteen intermediate images were generated along the reaction path between the reactant and product states and optimized subject to the constraint of equal spacing between images. Each of the structures along the band was relaxed until the force normal to the reaction path was beneath $0.20 \mathrm{eV} / \AA ̊$. The resulting transition state structure was further refined using either the climbing image-nudged elastic band (CI-NEB) method until forces get bellow 0.05 
$\mathrm{eV} / \AA$, or the Dimer method with an inter-dimer distance of $0.005 \AA$ and converged until the forces perpendicular to the reaction mode were less than $0.05 \mathrm{eV} / \AA ̊$ for every relaxed atom. As before, the bottom two layers of the metal slab were held fixed during all TS searches. The overall activation barriers were calculated according to Equation 3.2a, in which the reference state was methane in the vacuum phase and the surface at the most stable oxygen configuration at that coverage. Also in the manuscript we present the intrinsic activation barrier, in which the reference state is the reactant state, which has methane physisorbed on the surface while the oxygen atoms are adsorbed in 3-fold sites, Equation 3.2b.

$$
\begin{aligned}
& E_{\mathrm{Act}, 0 \mathrm{v}}=E_{\mathrm{TS}}-E_{\mathrm{M}+n 0}-E_{\mathrm{CH} 4} \\
& E_{\text {Act,Int }}=E_{T S}-E_{\text {React }}
\end{aligned}
$$

where $E_{A c t, O v}$ is the overall activation barrier, $E_{T S}$ is the energy of that transition state, $E_{\mathrm{CH} 4}$ is the energy of methane in the vacuum phase, $\mathrm{E}_{\mathrm{Act}, \mathrm{Int}}$ is the intrinsic activation barrier and $\mathrm{E}_{\text {React }}$ is the energy of the reactant state. The main reason we provide both intrinsic and overall activation barriers is because the intrinsic energies are not always based on the most stable oxygen configuration and the differences in stability of different oxygen configurations makes it relatively difficult to compare methane activation barriers at the same oxygen coverage.

\section{Results and Discussions.}

\section{Methane Activation at Low $0^{*}$ Coverage}

The adsorption energy of atomic oxygen was found to vary significantly from one metal to another, with energies that range from $+0.46 \mathrm{eV}$ on $\mathrm{Au}(111)$ to $-2.70 \mathrm{eV}$ on $\mathrm{Ru}(0001)$ surfaces as shown in Table 3.1. In order for $0^{*}$ to participate in the reaction, it must first shift from its stable 3 fold site to a bridge site. ${ }^{6}$ The energy required to shift $0^{*}$ to the bridge site correlates to the overall adsorption energy, consequently, the value of the methane activation barrier will be closely associated with the strength of oxygen adsorption. As displayed in Figure 3.1, a linear dependence was observed between the methane activation energy calculated in the presence of one adsorbed 
oxygen atom and the oxygen adsorption energy. Here, the high activation barriers of methane calculated on some metal surfaces (e.g., Ru, Os) are the result of the strong adsorption of oxygen on those metal surfaces. On the opposite side of the spectrum, weakly adsorbed $0^{*}$ on Au and Ag may more easily migrate to a bridge position, where it behaves as a Brønsted base, contributing to the dissociation of methane.

Table 3.1. The 0 adsorption energies, methane activation barriers and bond distances associated with each TS geometry on $10^{*}(0.11 \mathrm{ML})$ on metal surfaces.

\begin{tabular}{ccccccccccc}
\hline & $R u$ & $O s$ & $R h$ & $I r$ & $N i$ & $P d$ & $P t$ & $C u$ & $A g$ & $A u$ \\
\cline { 2 - 10 } O Ads. $(\mathrm{eV})$ & -2.70 & -2.48 & -1.95 & -1.66 & -2.45 & -1.30 & -0.92 & -1.35 & -0.19 & +0.46 \\
$\mathrm{E}_{\text {Act, I }}(\mathrm{eV})$ & 1.55 & 1.60 & 1.30 & 1.31 & 1.60 & 1.38 & 1.26 & 1.32 & 1.03 & 1.12 \\
$\mathrm{E}_{\text {Act, } \mathrm{O}}(\mathrm{eV})$ & 1.52 & 1.58 & 1.26 & 1.34 & 1.58 & 1.33 & 1.25 & 1.28 & 0.97 & 1.09 \\
$\mathrm{M}-\mathrm{H}(\AA)$ & 1.97 & 2.18 & 2.01 & 2.15 & 1.92 & 2.10 & 1.99 & 1.90 & 2.32 & 2.26 \\
$\mathrm{M}-\mathrm{C}(\AA)$ & 2.36 & 2.39 & 2.29 & 2.37 & 2.09 & 2.28 & 2.35 & 2.26 & 2.57 & 2.60 \\
$\mathrm{C}-\mathrm{H}(\AA)$ & 1.40 & 1.34 & 1.36 & 1.31 & 1.44 & 1.36 & 1.30 & 1.38 & 1.40 & 1.35 \\
$\mathrm{O}-\mathrm{H}(\AA)$ & 1.23 & 1.31 & 1.35 & 1.34 & 1.28 & 1.34 & 1.42 & 1.26 & 1.23 & 1.30 \\
\hline
\end{tabular}

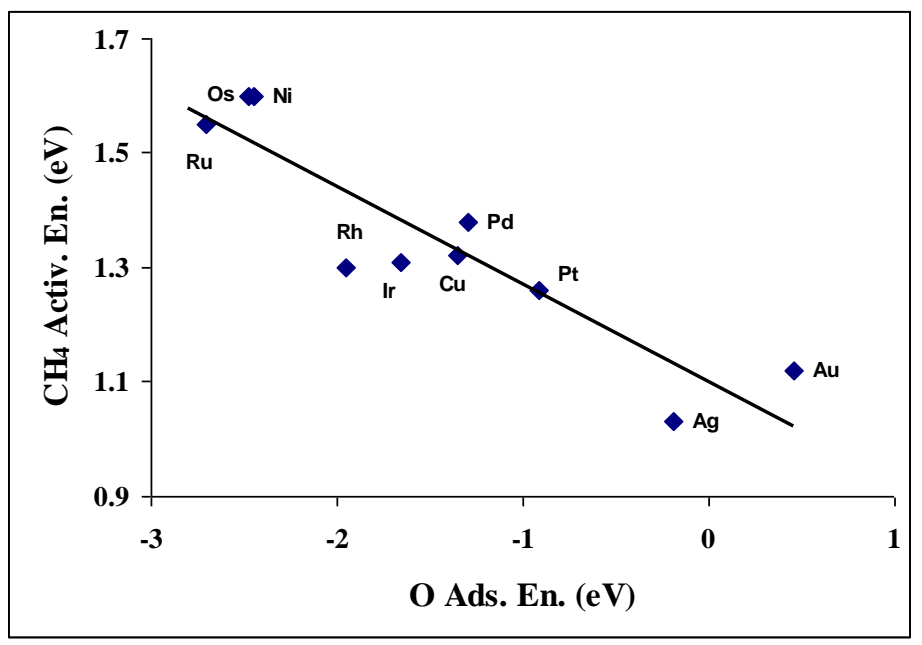

Figure 3.1. Activation energy of methane with a single oxygen bound to various transition metal surfaces.

In order to better understand the nature of $0^{*}$ and the metal in the transition state and their role in activating the $\mathrm{C}-\mathrm{H}$ bond, a series of single point calculations were performed that isolate the important thermochemical steps that comprise each transition state. This thermochemical cycle is shown in Figure 3.2 and begins with the desorption of methane, which is a low-energy process across all metals studied. This is followed by the dissociation of gas phase methane into to $\mathrm{H} \cdot$ and $\mathrm{CH}_{3}$. free 
radical fragments, which does not depend upon the metal catalyst. In order to activate the adsorbed oxygen to aid in the activation of the $\mathrm{C}-\mathrm{H}$ bond, it is shifted from its stable 3 -fold site to the active bridge site it holds in the TS (O-Shift). The gas phase $\mathrm{H}$ atom is then placed at its TS position (H-Ads) in order to calculate the $\mathrm{M}-\mathrm{H}$ and $\mathrm{O}-\mathrm{H}$ interactions simultaneously. Lastly, we add the $\mathrm{CH}_{3}$ fragment $\left(\mathrm{CH}_{3}-\mathrm{Ads}\right)$, thus recreating the TS structure and capturing both the $\mathrm{M}-\mathrm{CH}_{3}$ and $\mathrm{CH}_{3}-\mathrm{H}$ interactions at once. While the $\mathrm{O}$-Shift and $\mathrm{CH}_{3}$-Ads steps of the thermochemical cycle alter the transition state significantly, they are poor indicators of the activation barrier across different metals. On the other hand, as shown in Figure 3.3, the $\mathrm{H}$-adsorption step (which encompasses both $\mathrm{O}-\mathrm{H}$ and $\mathrm{M}-\mathrm{H}$ interactions) provides a very strong correlation to the activation barrier. In order to decouple the M$\mathrm{H}$ and $\mathrm{O}-\mathrm{H}$ interactions, we also ran a single point calculation of the $\mathrm{H}$ atom, in its $\mathrm{TS}$ geometry, without any $\mathrm{CH}_{3} *$ or $\mathrm{O}^{*}$ present. This allows us to determine, as we move across the periodic table, the relative influence of the metal and the $0^{*}$ in stabilizing the $\mathrm{H}$ atom in the transition state. The results, shown in the pie charts of Figure 3.3, clearly demonstrate that when oxygen is strongly adsorbed to the metal surface (e.g., $\mathrm{Ru}, \mathrm{Os}, \mathrm{Ni})$, the $\mathrm{O}-\mathrm{H}$ interactions are very weak $(<10 \%$ of the total $\mathrm{H}$-atom stabilization) and, as such, the $\mathrm{M}-\mathrm{H}$ interactions control the $\mathrm{C}-\mathrm{H}$ activation barrier. In contrast, on metals where oxygen is weakly adsorbed (e.g., Ag, $\mathrm{Au}$ ) the $\mathrm{O}-\mathrm{H}$ interactions represent the major contribution to the $\mathrm{H}$ stabilization and control the $\mathrm{C}-\mathrm{H}$ activation. 


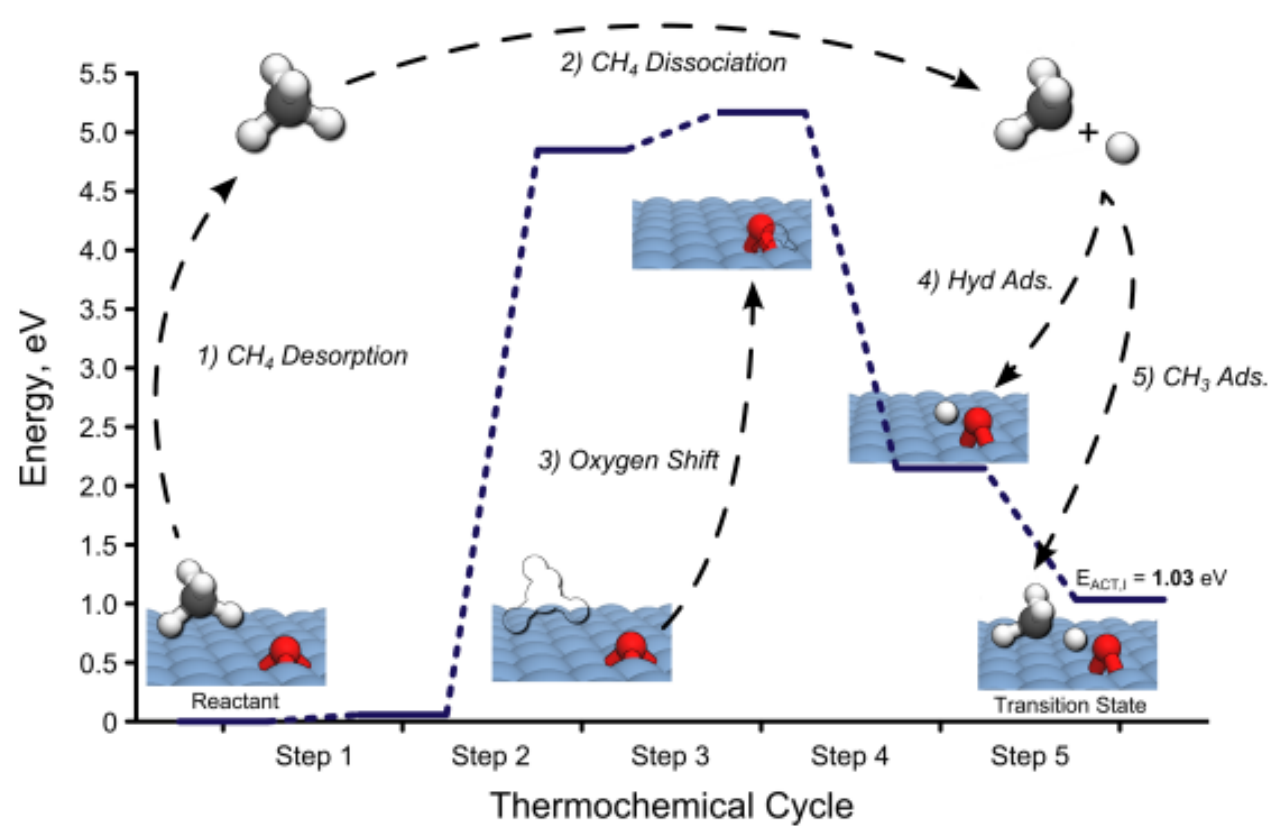

Figure 3.2. The thermochemical cycle for the transition state of Ag-10*, this type of cycle was used to determine the thermochemical steps that control the $\mathrm{C}-\mathrm{H}$ activation barrier.

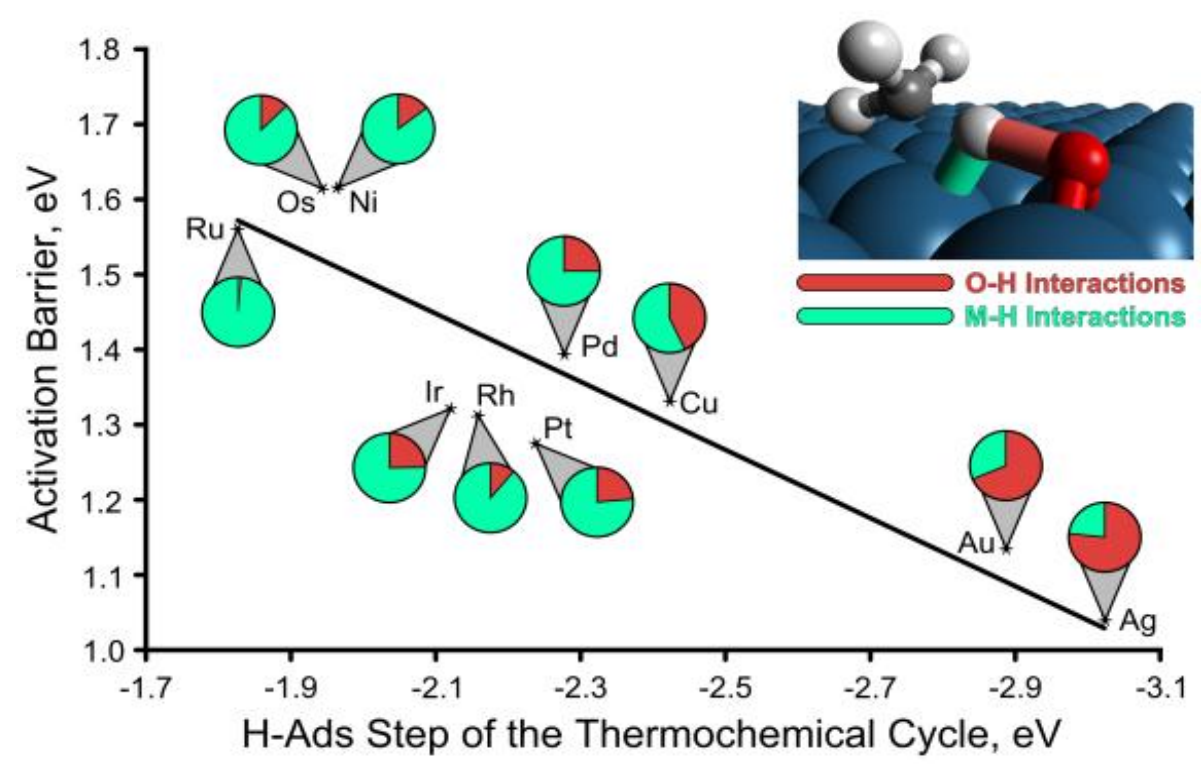

Figure 3.3. The activation barrier is strongly dependent upon the stabilization of hydrogen in the transition state by the metal and oxygen. As seen by the pie-chart insets, across coinage metals, the oxygen atom provides the bulk of stabilization. 
Although this work is focused on methane activation, it is important to note the universal importance of this finding. While it is known that this mechanism was a combination of metalinsertion and oxygen abstraction, here, through the use of thermochemical cycles, the extents of those two contributions are further elucidated across a large range of metals. Furthermore, this work demonstrates that the inert nature of bare coinage metals towards $\mathrm{C}-\mathrm{H}$ bond of methane is over compensated by an elevated activity of adsorbed atomic oxygen on these metals, which diminishes the activation barrier quite significantly (e.g., 2.45 to $1.03 \mathrm{eV}$ for $\mathrm{Ag}$ ). While the fundamental understanding of oxygen's ability to assist in methane activation is useful, it's important to note that for all of the group VIII metals studied, the activation barrier is higher than the activation over the *_* site on a clean metal surface. This indicates that at low coverages, methane continues to activate over bare-metal sites for group VIII metals. As previously mentioned, the reason for the increase in barrier over group VIII metals is associated with an energetic penalty required to promote the oxygen atom from its stable 3-fold to the bridge site in which it's active; this penalty ranges from $0.52-0.78 \mathrm{eV}$ across group VIII metals. For most metals, this is the majority of the difference in activation barriers between metal atom insertion at a ${ }^{*-*}$ site compared to $0^{*}$-assisted activation at an $0^{*}-*$ site. Our results for methane activation in vicinity of a single adsorbed oxygen atom, Table 3.1, comes in very close agreement with ones reported in other studies: Pd 1.37 eV, ${ }^{140} \mathrm{Rh} 1.10 \mathrm{eV}, \mathrm{Pd} 1.21 \mathrm{eV}, \mathrm{Cu} 1.31$ $\mathrm{eV}, \mathrm{Ag} 1.06 \mathrm{eV}, \mathrm{Au} 1.23 \mathrm{eV} \cdot{ }^{141}$

\section{The Mechanism of Methane Activation at Higher Oxygen Coverages.}

At higher coverages of oxygen, the situation becomes more complicated as a result of the different oxygen configurations that can result at a single coverage (even within a $3 \times 3$ unit cell). Here, it becomes important whether we use the intrinsic barrier, referenced to the reactant state that has the same oxygen configuration as the transition state, or whether we consider the overall activation barrier, which uses the most stable oxygen configuration and methane in the gas phase as the reference state. Both values provide important input in their own way, the intrinsic barrier can 
be used to discuss fundamental changes between transition states and how those changes are brought about, whereas the overall barrier is more useful for describing experimentally relevant activation barriers which are measured with respect to gas phase methane and identifying the most likely mechanisms for methane activation to occur.

As $0^{*}$ coverage increases, the $0^{*}-\mathrm{H}$ interaction in the transition state strengthens while the M-H interaction weakens. For most metals, the total stabilization remains nearly constant (or slightly decreases) with $0^{*}$ coverage, the result of this is a nearly constant overall activation energy as shown in Figure 3.4. The coinage metals appear to follow a different trend, as shown by Ag in Figure 3.4, as a result of the increased weak binding of $\mathrm{O}^{*}$ and its increased charge. For $\mathrm{Ag}$, the increase in the $\mathrm{O}-\mathrm{H}$ stabilization far outweighs the decrease in the M-H stabilization, resulting in a decrease in the overall activation barrier.

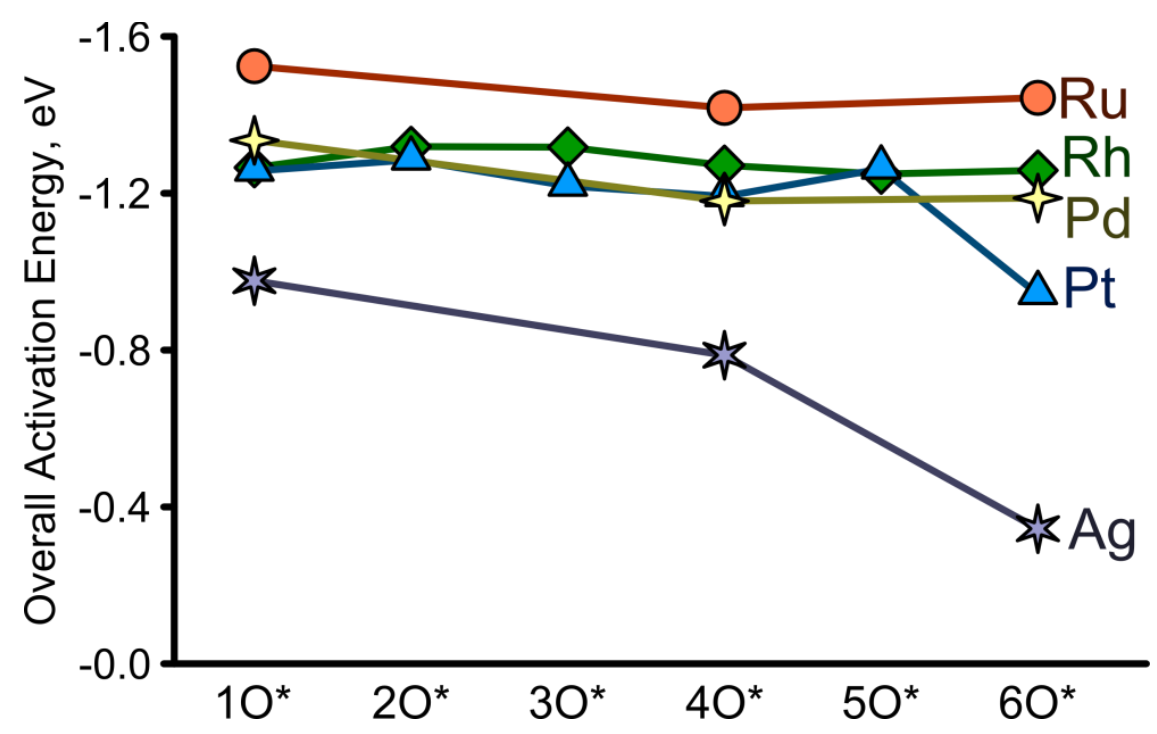

Figure 3.4. The activation energy variations with increasing the oxygen coverage.

High Oxygen Coverages on Pt.

The most stable configurations from $1 / 9$ to $3 / 9 \mathrm{ML}$ are very similar, therefore, it is not surprising that the activation barriers for Pt calculated at 2/9 ML: $1.29 \mathrm{eV}$ (Figure 3.5b) and 3/9 ML: $1.23 \mathrm{eV}$ (Figure 3.5c) are almost identical with the one calculated at 1/9 ML: 1.26 eV (Figure 5c - side 
view and Figure 3.5a - top view). Furthermore, this activation barrier is very similar with one calculated on 111 terraces of a 201-atom Pt nanoparticle $(1.23 \mathrm{eV}) .{ }^{28}$ The similarities between the activation barriers calculated at low oxygen coverages on $\operatorname{Pt}(111)$ surface is consistent with the nearly identical M-H, M-C, C-H and $\mathrm{O}-\mathrm{H}$ bond distances of the TS geometries shown in Table 3.2. These TS geometries illustrate a three centered H-Pt-C complex, as described elswere, ${ }^{28}$ where C-H bond is elongated to about $1.3 \AA$ by an oxidative insertion of one Pt atom into C-H bond of methane, which is associated with $\mathrm{H}$ abstraction process aided by $\mathrm{O}^{*}$ situated in adjacent bridge position. A detailed view of the stabilization that results from the successive adsorptions of $\mathrm{H}$ and $\mathrm{CH}_{3}$ is provided by thermochemical cycle calculations of TS geometries. Virtually identical O-H interaction energies $(-0.53,-0.63,-0.76 \mathrm{eV}), \mathrm{M}-\mathrm{H}$ interaction energies $(-1.70,-1.64,-1.50 \mathrm{eV})$, and $\mathrm{CH}_{3}-\mathrm{Ads}$ steps $(-1.85,-1.83,-1.85 \mathrm{eV})$ were observed, emphasizing once again the similarity between $1 / 9$ and $3 / 9$ ML.

At an oxygen coverage of $4 / 9 \mathrm{ML}$, two (or more) of the $0^{*}$ adsorbates will be adsorbed to the same metal atom, significantly decreasing their adsorption strength due to bond order conservation of the shared metal atom. For methane activation, three configurations were studied which have different relative stabilities and activation barriers. The most stable configuration of $0^{*}$ at $4 / 9 \mathrm{ML}$ is shown in Figure 3.5e. This configuration of $\mathrm{O}^{*}$ is similar to the 3/9 ML configuration (Figure 3.5c) and the reaction occurs at the same site, with $\mathrm{O}^{*}$ being 'pushed' away from the metal atom as $\mathrm{CH}_{4}$ interacts with it which causes the H-transfer to occur above the previously occupied 3-fold fcc site. For this 'push' mechanism (shown in Figures 3.5a,b,c,e,g), the metal atom of the M-O bond which is broken only has one $\mathrm{O}^{*}$ bound to it in the reactant state. For these reactions, the strength of the M-O bond which is being broken is largely unchanged (despite the overall coverage ranging from 1/9 $5 / 9 \mathrm{ML}$ ) and the $O$ Shift energy slightly increases from 3/9 - 5/9 ML (from $0.56 \mathrm{eV}$ to $0.62 \mathrm{eV}$ to 0.64 $\mathrm{eV}$ ) which causes the intrinsic activation barrier to increase from $1.23 \mathrm{eV}$ to $1.30 \mathrm{eV}$ to $1.38 \mathrm{eV}$. This 'push' mechanism is limited at higher coverages, because the active metal atom needs to have no adsorbed $0^{*}$ atoms in the transition state of the reaction, therefore there can only be one $0^{*}$ atom 
adsorbed to the active metal in the reactant state, so that $\mathrm{M}-\mathrm{O}$ bond remains relatively strong, even at high coverage.

However, another mechanism exists, shown in Figure 3.5d, in which the $0^{*}$ is not 'pushed' away from the active metal site, but instead is 'pulled' towards it during methane activation. In this case, an $0^{*}$ atom adsorbed in a nearby 3 -fold fcc site shifts towards the active metal atom, such that the H-transfer occurs over a 3 -fold hcp site in the transition state. In the reactant state of this reaction, the $\mathrm{M}-\mathrm{O}^{*}$ bond that will be broken is one of two $\mathrm{M}-\mathrm{O}$ bonds of that metal atom (which is not the active metal). This significantly weakens the M-O bond which is broken, resulting in a decrease in the $O$ Shift energy $(0.44 \mathrm{eV}$ for Figure $3.5 \mathrm{~d}$ compared to $0.62 \mathrm{eV}$ for Figure $3.5 \mathrm{e}$, both at $4 / 9 \mathrm{ML}$ coverage) which results in a decrease in the intrinsic activation barrier down to $1.12 \mathrm{eV}$ from $1.30 \mathrm{eV}$ for Figure 3.5e. Unfortunately, this configuration of oxygen is $0.07 \mathrm{eV}$ less stable than the configuration of oxygen shown in Figure 3.5e, which causes the overall activation barrier to be slightly higher $(1.19 \mathrm{eV})$ than the intrinsic activation barrier $(1.12 \mathrm{eV})$, but still lower than the overall activation barrier of the reaction shown in Figure 3.5e (1.27 eV). Figure 3.5f shows another 'pull' mechanism at 4/9 ML coverage with a different configuration of $0^{*}$, which is $0.37 \mathrm{eV}$ less stable than the most stable configuration. Once again, the $\mathrm{M}-\mathrm{O}$ bond being broken is weakened by metal atom sharing, which results in a small 0 Shift energy $(0.42 \mathrm{eV})$ and a small intrinsic activation barrier (1.11 $\mathrm{eV})$. However, in this case, the penalty to create this configuration is much larger, resulting in an increased overall activation barrier $(1.48 \mathrm{eV})$. This is a nice example that illustrates the importance of studying different oxygen configurations as the reactant structure in Figure 3.5e is the most stable, while that in Figure 3.5f has the lowest intrinsic barrier and that in Figure 3.5d has the lowest overall barrier. These calculations also demonstrate that the coverage of oxygen is not the critical factor in determining the overall activation barrier, instead is the local coverage of the metal atoms involved in the reaction.

At 5/9 ML, once again three oxygen configurations were studied. In this case, most stable configuration is shown in Figure 3.5g and is very similar to the 4/9 ML configuration shown in Figure 3.5e described above. The $O$ Shift energy is $0.64 \mathrm{eV}$, the intrinsic activation barrier is $1.38 \mathrm{eV}$ and the 
overall activation barrier is $1.35 \mathrm{eV}$. The configuration shown in Figure $3.5 \mathrm{i}$ is $0.27 \mathrm{eV}$ less stable than the previous case and in this reaction the metal atom which the active $0^{*}$ is bound to in the reactant state has three $0^{*}$ bound to it, which causes the M-O* bond which is broken to be significantly weaker. This results in very low $O$ Shift energy $(0.27 \mathrm{eV})$ and a very low intrinsic activation barrier $(1.03 \mathrm{eV})$ and an overall barrier of $1.26 \mathrm{eV}$.

At 6/9 ML, the most stable oxygen configuration has two $0^{*}$ bounded to each $\mathrm{Pt}$ atom. Unfortunately, this effectively prevents any metal atoms from being active for the desired $\sigma$-bond metathesis like mechanism which we are pursuing. Another configuration is possible, shown in Figure $3.5 \mathrm{j}$, which is $0.64 \mathrm{eV}$ less stable but creates a vacant metal site. This reaction is very similar to the 5/9 ML configuration shown in Figure 3.5i and has an intrinsic activation barrier of $1.01 \mathrm{eV}$.

Above 6/9 ML, Pt atoms bonded with two or more $0^{*}$ are lifted out of the surface upon interacting with methane, while those that are bound to $30^{*}$ are completely blocked from any interaction with the $\mathrm{C}-\mathrm{H}$ bond. Under these conditions, the $\mathrm{C}-\mathrm{H}$ bond is activated instead on an $\mathrm{O}^{*}-\mathrm{O}^{*}$ site pair as presented previously. ${ }^{28}$ Furthermore, the sequential adsorption of oxygen beyond 6/9 ML coverage on the ideal $\mathrm{Pt}(111)$ surface is very unfavorable and endothermic requiring at least $1 \mathrm{eV}$ as shown in Figure 3. As shown in Figure 9, methane $\mathrm{C}-\mathrm{H}$ activation barriers decrease slightly with increasing the oxygen coverage on $\operatorname{Pt}(111)$ surface, which is primarily due to the decrease in $O$-Shift energies, that result from the higher $0^{*}$ repulsive interactions that result at higher $0^{*}$ coverages. 

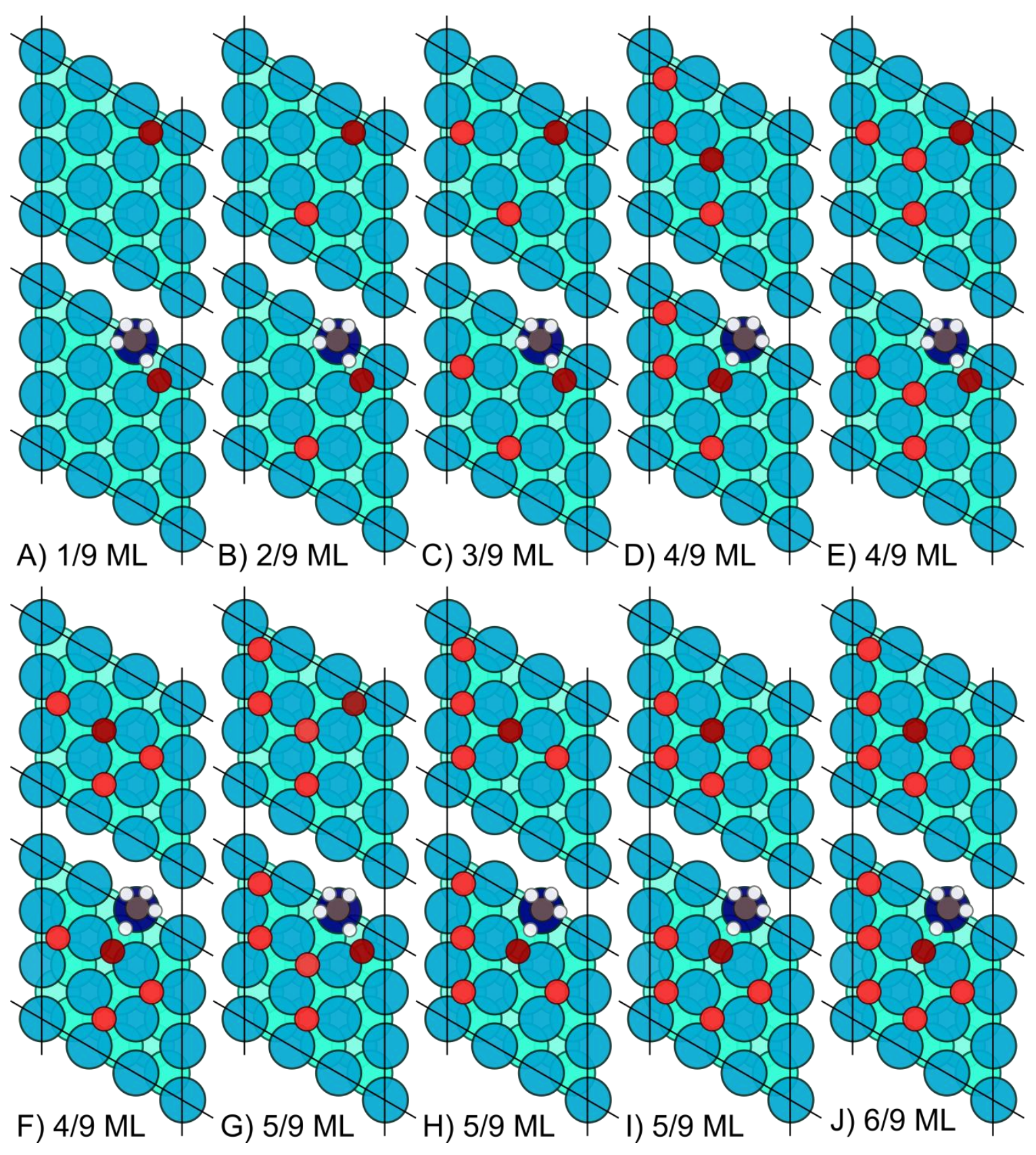

Figure 3.5. Oxygen configurations and methane activation transition states on $\operatorname{Pt}(111)$ at various $0^{*}$ coverages: a) 1/9; b) 2/9; c) 3/9 d-f) 4/9; g-i) 5/9; j) 6/9 ML. 
Table 3.2. The activation barriers and bond distances for each TS geometry with oxygen coverage on a Pt(111) surface, as illustrated in Figure 3.5.

\begin{tabular}{ccccccccccc}
\hline \multirow{2}{*}{$\operatorname{Pt}(111)$} & $\begin{array}{c}10^{*} \\
(a)\end{array}$ & $\begin{array}{c}20^{*} \\
(b)\end{array}$ & $\begin{array}{c}30^{*} \\
(\mathrm{c})\end{array}$ & $\begin{array}{c}40^{*} \\
(\mathrm{~d})\end{array}$ & $\begin{array}{c}40^{*} \\
(\mathrm{e})\end{array}$ & $\begin{array}{c}40^{*} \\
(f)\end{array}$ & $\begin{array}{c}50^{*} \\
(\mathrm{~h})\end{array}$ & $\begin{array}{c}50^{*} \\
(\mathrm{i})\end{array}$ & $\begin{array}{c}50^{*} \\
(j)\end{array}$ & $\begin{array}{c}60^{*} \\
(\mathrm{l})\end{array}$ \\
\hline $\mathrm{E}_{\mathrm{Act}, \mathrm{I}}(\mathrm{eV})$ & 1.26 & 1.29 & 1.23 & 1.12 & 1.30 & 1.11 & 1.38 & 1.04 & 1.03 & 1.01 \\
$\mathrm{E}_{\mathrm{Act}, \mathrm{O}}(\mathrm{eV})$ & 1.25 & 1.28 & 1.21 & 1.19 & 1.27 & 1.48 & 1.36 & 1.47 & 1.26 & 1.62 \\
& & & & & & & & & & \\
$\mathrm{M}-\mathrm{H}(\AA)$ & 1.99 & 2.00 & 1.99 & 2.07 & 2.03 & 2.07 & 1.99 & 2.02 & 2.07 & 2.13 \\
$\mathrm{M}-\mathrm{C}(\AA)$ & 2.35 & 2.40 & 2.39 & 2.37 & 2.38 & 2.39 & 2.39 & 2.37 & 2.39 & 2.41 \\
$\mathrm{C}-\mathrm{H}(\AA)$ & 1.30 & 1.30 & 1.28 & 1.28 & 1.29 & 1.29 & 1.28 & 1.29 & 1.30 & 1.30 \\
$\mathrm{O}-\mathrm{H}(\AA)$ & 1.42 & 1.41 & 1.43 & 1.43 & 1.42 & 1.40 & 1.46 & 1.43 & 1.39 & 1.37 \\
\hline
\end{tabular}

High Oxygen Coverages on Pd, Rh and Ru.

Similar to Pt, these metals all show a small decrease activation barrier with an increase in $0^{*}$ coverages. The activity is controlled by the availability of a vacant metal site and the ability to promote $0^{*}$ to the active bridge site, which is controlled by $0^{*}-0^{*}$ repulsions through metal atom sharing. Examining the $\mathrm{O}-\mathrm{H}$ and $\mathrm{M}-\mathrm{H}$ interactions for each of these metals moving from low to high $\mathrm{O}^{*}$ coverages, we observe that the $\mathrm{O}-\mathrm{H}$ interactions become stronger while $\mathrm{M}-\mathrm{H}$ interactions become weaker. These effects, displayed for Rh in Figure 3.6, nearly balance out, resulting in only very small changes in the activation barrier as shown in Figure 3.4. 


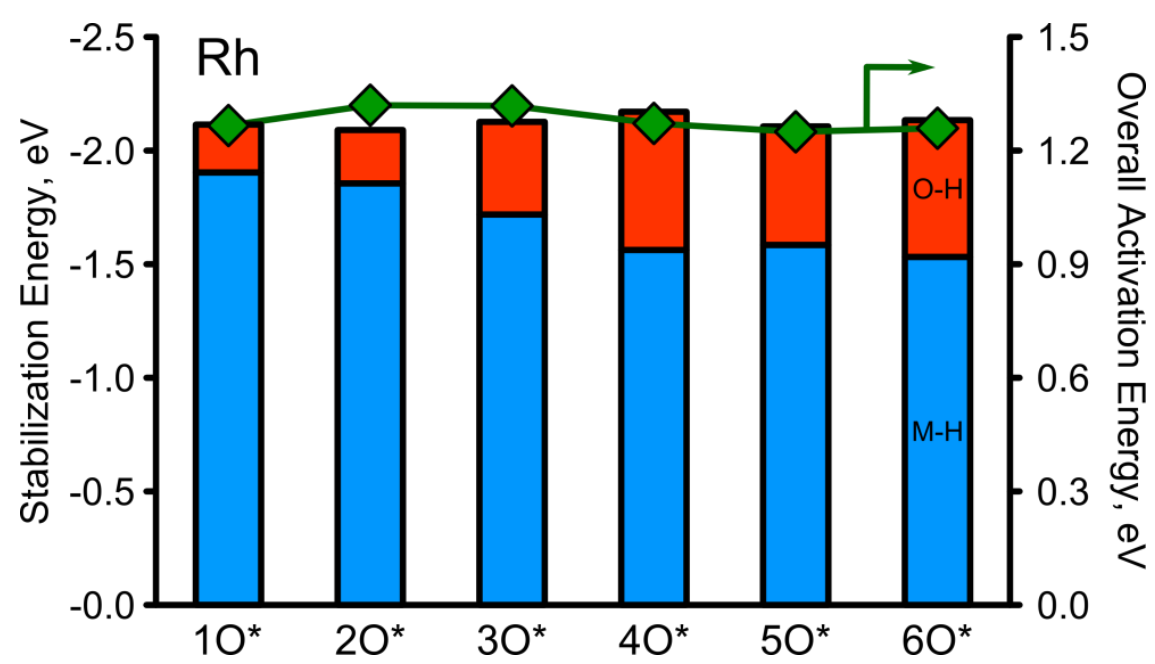

Figure 3.6. Overall activation energy of methane activation over $\mathrm{Rh}$ at $1 / 9$ - 6/9 ML coverage plotted alongside $\mathrm{O}-\mathrm{H}$ and $\mathrm{M}-\mathrm{H}$ stabilization energies. As you shift from low to high coverage, $\mathrm{SE}_{0-\mathrm{H}}$ increases, $\mathrm{SE}_{\mathrm{M}-\mathrm{H}}$ decreases, but their sum remains nearly constant, resulting in nearly constant overall activation energies.

High Oxygen Coverages on Ag.

At an oxygen coverage of $4 / 9 \mathrm{ML}$, the TS geometry, pictured in Figure $10 \mathrm{~b}$, is significantly different from the case at $1 / 9$ ML coverage. The $\mathrm{O}-\mathrm{H}$ distance of $1.02 \AA$ is considerably shorter $(1.23$ $\AA$ at $1 / 9 \mathrm{ML}$ ), which emphasizes the much stronger basicity of the active oxygen at higher $0^{*}$ coverages. This highly reactive oxygen results from the significant repulsion between neighboring $0^{*}$ atoms on Ag that further weaken the binding energy of the active $0^{*}\left(+0.78 \mathrm{eV}\right.$ for the $4^{\text {th }} 0^{*}$ compared to $-0.19 \mathrm{eV}$ for the $1^{\text {st }}$ ). As a result, the overall $\mathrm{C}-\mathrm{H}$ activation barrier for methane decreases from 1.03 for $1 / 9 \mathrm{ML} 0^{*}$ to $0.79 \mathrm{eV}$ at $4 / 9 \mathrm{ML} \mathrm{O*}$ as shown in Table 3. In the TS, the $0-\mathrm{H}$ interaction energy is $-3.70 \mathrm{eV}$, which is considerably larger than the value of $-3.01 \mathrm{eV}$ for $1 \mathrm{O}^{*}$. At $6 / 9 \mathrm{ML}$ coverage, Figure 3.7d, the overall activation barrier decreases to $0.45 \mathrm{eV}$ as the $0-\mathrm{H}$ interaction energy increases to $-4.97 \mathrm{eV}$. This particular TS geometry closely resembles one that is characteristic for oxides where the active site is across two oxygen atoms $\left(0^{*}-0^{*}\right)$ as the methyl fragment is very far from the metal surface in the transition state. 
Overall, as the coverage increases, the $\mathrm{O}-\mathrm{H}$ interaction increases while the $\mathrm{M}-\mathrm{H}$ interactions decrease, as is shown in Figure 3.8. The sum of those stabilizations also increases, which results in a decrease of the overall activation barrier, as shown in Figure 3.4.

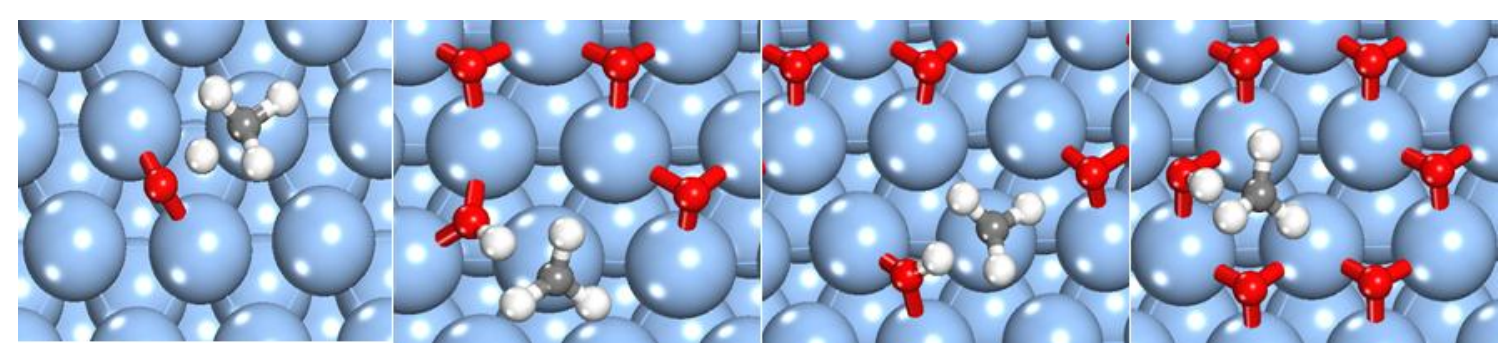

Figure 3.7. The TS geometries on $\mathrm{Ag}(111)$ at high oxygen coverage: a) 1/9; b), c) 4/9; d) 6/9 ML.

Table 3.3. The barriers and bond distances for each TS geometry with oxygen on a $\mathrm{Ag}(111)$ surface, as illustrated in Figure 3.7.

\begin{tabular}{ccccc}
\hline $\mathbf{A g}(\mathbf{1 1 1})$ & $\begin{array}{c}10^{*} \\
(\mathrm{a})\end{array}$ & $\begin{array}{c}40^{*} \\
(\mathrm{~b})\end{array}$ & $\begin{array}{c}40^{*} \\
(\mathrm{c})\end{array}$ & $\begin{array}{c}60^{*} \\
(\mathrm{~d})\end{array}$ \\
\hline $\mathrm{E}_{\text {Act, } \mathrm{I}}(\mathrm{eV})$ & 1.03 & 0.45 & 0.94 & 0.40 \\
$\mathrm{E}_{\text {Act,O }}(\mathrm{eV})$ & 0.97 & 0.79 & 0.88 & 0.35 \\
& & & & \\
$\mathrm{M}-\mathrm{H}(\AA)$ & 2.32 & 2.44 & 2.40 & 2.86 \\
$\mathrm{M}-\mathrm{C}(\AA)$ & 2.57 & 3.14 & 2.92 & 3.75 \\
$\mathrm{C}-\mathrm{H}(\AA)$ & 1.40 & 1.73 & 1.70 & 1.59 \\
$\mathrm{O}-\mathrm{H}(\AA)$ & 1.23 & 1.02 & 1.03 & 1.04
\end{tabular}

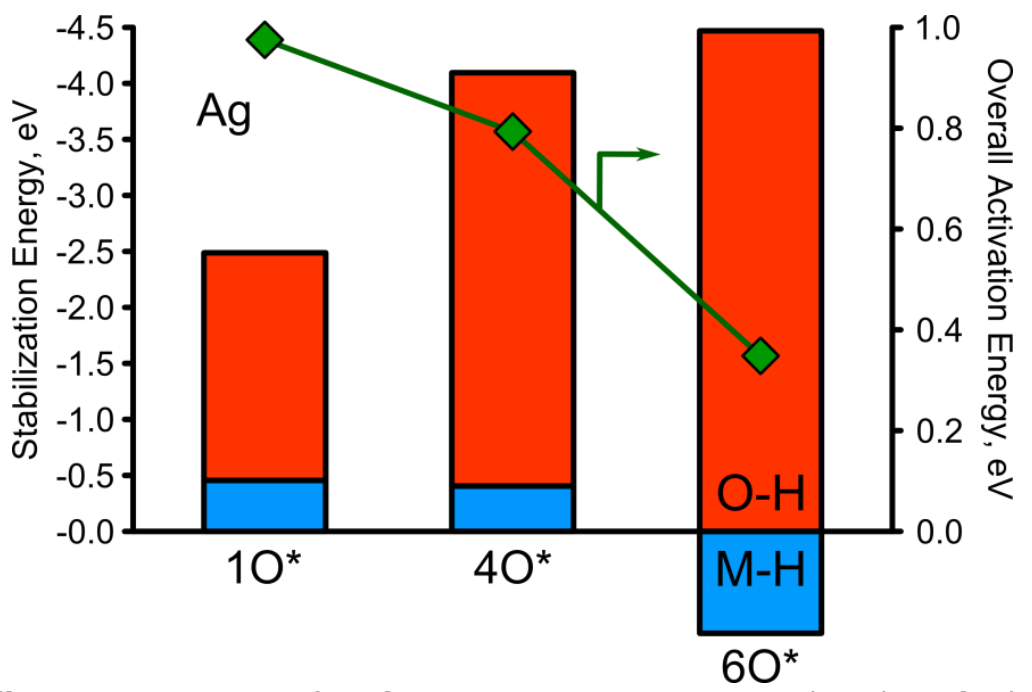

Figure 3.8. Overall activation energy of methane activation over Ag at 1/9, 4/9 and 6/9 ML coverage plotted alongside $\mathrm{O}-\mathrm{H}$ and $\mathrm{M}-\mathrm{H}$ stabilization energies. As you shift from low to high coverage, $\mathrm{SE}_{\mathrm{M}-\mathrm{H}}$ decreases, but $\mathrm{SE}_{\mathrm{O}-\mathrm{H}}$ dramatically increases, resulting in a decrease in the overall activation energies. 


\section{Conclusions}

In this work, we have analyzed the activation of methane through an $\mathrm{O}^{*}$-assisted $\mathrm{C}-\mathrm{H}$ activation at various coverages of $0^{*}$ on a selection of platinum group and coinage metals. At low coverage $\left(1 / 9 \mathrm{ML} 0^{*}\right)$, the activation of methane occurs across a single metal atom with shifting from a nearby 3 -fold site to a nearby bridge site. Once $0^{*}$ occupies this bridge site, it becomes significantly more basic, which polarizes the $\mathrm{C}-\mathrm{H}$ bond of methane and assists in the activation. This mechanism is a mixture of oxidative addition and hydrogen abstraction and creates a four-center M-C-H-O complex, similar to the $\sigma$-bond metathesis mechanism described in organometallic literature. ${ }^{117,127,128}$ Because $0^{*}$ is not stable in this bridge site, there is an energy associated with promoting the $0^{*}$ to its active site, which loosely correlates to the overall adsorption strength of $0^{*}$ on that metal surface. In the transition state, the $\mathrm{H}$ being transferred is stabilized by both the $\mathrm{O}^{*}$ and the nearby metal atom and the relative strengths of these interactions were found to vary based on the metal, with coinage metals having much stronger $\mathrm{O}-\mathrm{H}$ interactions than $\mathrm{M}-\mathrm{H}$ interactions. Overall, the $\mathrm{O}^{*}$-assisted methane activation energy is lower for coinage metals than for platinum group metals, due to the decreased oxygen binding energy and the increased basicity of $0^{*}$ on those surfaces.

At higher coverages, the binding energy of $0^{*}$ decreases which decreases the energy required to promote $0^{*}$ from its stable 3 -fold site into its active bridge site. This increases the basicity of $0^{*}$ on the metal surface, which increases the $\mathrm{O}-\mathrm{H}$ interactions in the transition state. Unfortunately, due to the electron withdrawing effects of high $0^{*}$ coverage, the reactivity of the metal atom decreases, compensating for the increased reactivity of $0^{*}$. For platinum group metals, these two effects nearly balance out, resulting in a slight decrease in the activation barrier from oxygen coverages of $1 / 9 \mathrm{ML}$ to $6 / 9 \mathrm{ML}$. On the other hand, for coinage metals, the increased reactivity of $0^{*}$ far outweighs the decreased reactivity of the metal, resulting in a large decrease in the activation barrier of methane at high $0^{*}$ coverage. Unfortunately, producing high coverages of $0^{*}$ on these coinage metals is difficult, due to the weak binding energy of $0^{*}$ on these surfaces. At coverages above 6/9 ML, the metal sites are effectively blocked by adsorbed oxygen, causing the reaction 
mechanism to shift from a $0^{*-*}$ site to an $\mathrm{O}^{*}-\mathrm{O}^{*}$ site which proceeds via an $\mathrm{H}$-abstraction mechanism as described elsewhere. ${ }^{28}$

This investigation of the activation of methane at various coverages on different transition metal surfaces provides a fundamental understanding of the $0^{*}$-assisted methane activation mechanism and how it varies with coverage and transition metal surface. It can also provide a practical guideline for experimental research, by describing the relative activity of various oxygen coverages, allowing researchers to focus their studies on the most favorable oxygen coverages. 


\section{2 - Evaluation of the Brønsted Basicity of $\mathrm{O}^{*}$ and $\mathrm{OH}^{*}$ on Transition Metal Surfaces}

As discussed previously, under certain conditions, $\mathrm{O}^{*}$ and/or $\mathrm{OH}^{*}$ on a metal surface can act as a Brønsted base, greatly reducing the activation barrier for $\mathrm{C}-\mathrm{H}$ and/or $\mathrm{O}-\mathrm{H}$ activation. As shown in previous chapters, this can impact the reaction mechanism and kinetics of a variety of metalcatalyzed reactions which involve $\mathrm{C}-\mathrm{H}$ or $\mathrm{O}-\mathrm{H}$ bond activation, such as the partial oxidation of methane to form syngas or selective oxidation of alcohols to organic acids. In order to investigate this further, a series of $\mathrm{C}-\mathrm{H}$ or $\mathrm{O}-\mathrm{H}$ activations were examined for a variety of alkanes and alcohols over coinage $(\mathrm{Cu}, \mathrm{Ag}$, and $\mathrm{Au})$ and platinum-group $(\mathrm{Ru}, \mathrm{Rh}, \mathrm{Pd}, \mathrm{Os}$, Ir, and $\mathrm{Pt})$ metals.

Methane activation, as discussed in the previous chapter, involves oxidative insertion of a metal atom into a $\mathrm{C}-\mathrm{H}$ bond of the weakly adsorbed methane. In the transition state, this forms a three-center C-M-H complex as shown in Figure 3.9 for methane activation on Pd. For the platinum group metals, methane dissociation has a barrier of 1.05-1.14 eV, referenced to methane in the gas phase, as shown in Figure 3.10. On coinage metals, on the other hand, the activation barriers for methane dissociation are much higher, due to their filled d-states, which lead to weak binding energies of the $\mathrm{CH}_{3}{ }^{*}$ and $\mathrm{H}^{*}$ product fragments. So, as shown in Figure 3.11, the activation barrier for methane dissociation correlates with the reaction energy in a Brønsted Evans Polanyi (BEP) type relationship. However, it's important to mention that this trend is only apparent due to the inclusion

of the coinage metals; if the platinum-group metals are plotted by themselves, the BEP relationship is much weaker, mostly due to the small changes in reaction energy between the platinum-group metals. 


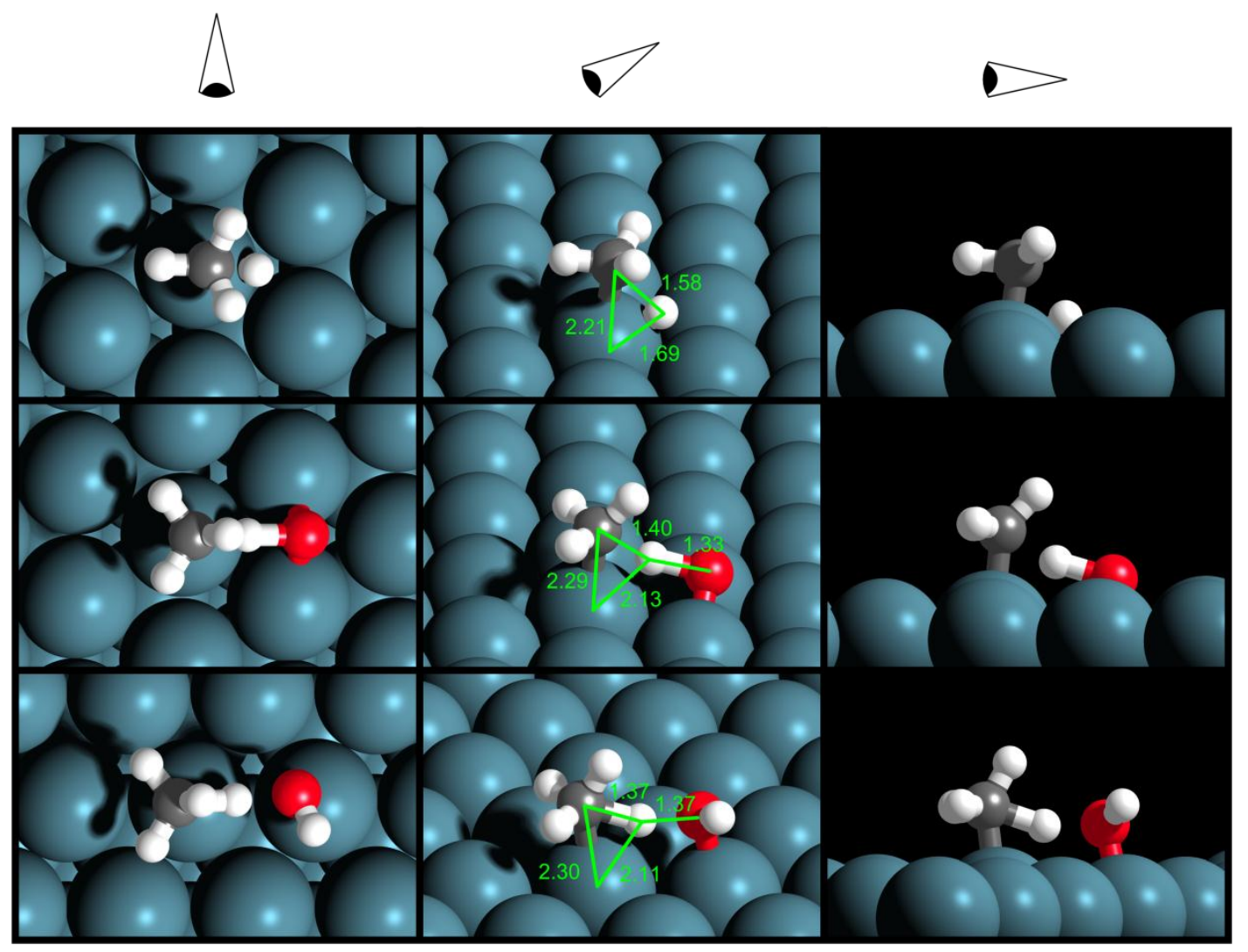

Figure 3.9. Transition state geometries for the activation of methane through direct, $0^{*}$-assisted and $\mathrm{OH}^{*}$-assisted C-H activations.

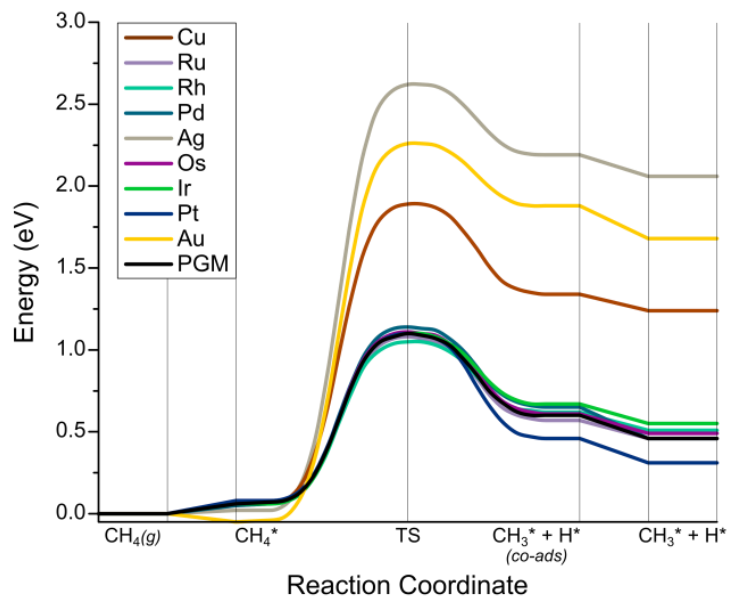

Figure 3.10. Reaction energetics for methane dissociation on closed-packed transition metal surfaces. 

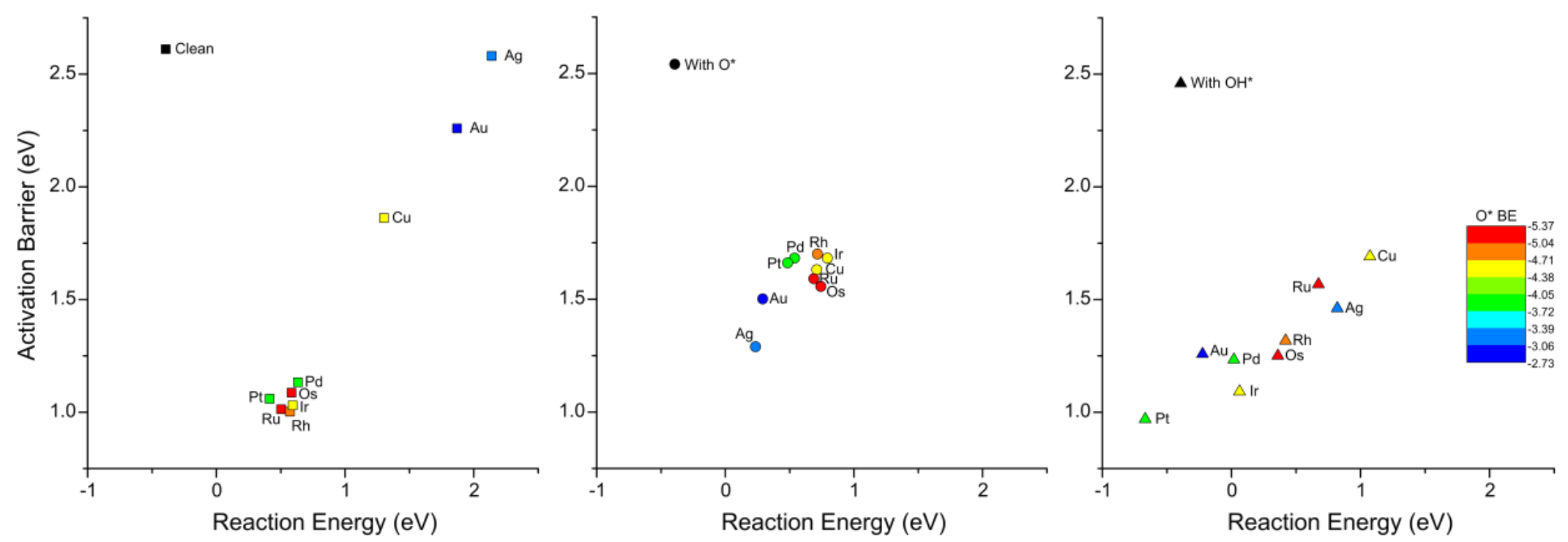

Figure 3.11. Activation barriers and reaction energies for the activation of methane on closed-packed metal surfaces. (Left) Methane activation on the clean metal surfaces. (Center) Methane activation over $\mathrm{M}^{*}-\mathrm{O}^{*}$ site pairs via an $\mathrm{O}^{*}$-assisted mechanism. (Right) Methane activation over $\mathrm{M}^{*}$-OH* site pairs via an $\mathrm{OH}^{*}$-assisted mechanism. 
With a single $0^{*}$ adsorbed to the surface, transition state now involves the activation over the $\mathrm{M}^{*}-\mathrm{O}^{*}$ site pair where the oxygen shifts from its stable 3-fold site to the more active bridge site in order to facilitate the $\mathrm{C}-\mathrm{H}$ bond activation. As shown in Figure 3.9 for Pd, the transition state now involves the four-center complex comprised of $\mathrm{M}-\mathrm{C}, \mathrm{M}-\mathrm{H}, \mathrm{O}-\mathrm{H}$, and $\mathrm{C}-\mathrm{H}$ interactions that typically result for $\sigma$-bond metathesis. Due to the energy penalty associated with shifting the $0^{*}$ from the 3 fold to the active 2 -fold bridge site and since the $\mathrm{C}-\mathrm{H}$ bond of methane is not acidic, the activation barriers for the platinum-group metals increase over those on the pure metal by $0.55-0.88 \mathrm{eV}$ (with an average of $0.68 \mathrm{eV}$ ). However, on coinage metals, the activation barrier decreases by $0.27,1.33$ and $0.75 \mathrm{eV}$ for $\mathrm{Cu}, \mathrm{Ag}$ and $\mathrm{Au}$. This is due to 1) the weak adsorption of $\mathrm{O}^{*}$ on coinage metals, 2) the increased charge transfer and basicity of $0^{*}$ on coinage metals, and 3) the inert nature of these metals for $\mathrm{C}-\mathrm{H}$ activation. Shown in Figure $3.11 \mathrm{~b}$ is the BEP relationship for $\mathrm{O}^{*}$-assisted methane dissociation. This plot also shows that the reaction energy for the PGMs has shifted to be more endothermic, while the reaction energies for the coinage metals have shifted to be less endothermic. The difference in the activation barriers between bare metal and $0^{*}$-assisted methane activation correlates well with the binding energy of $\mathrm{O}^{*}$, as shown in Figure 3.12. $\mathrm{Cu}$ is an interesting case, due to its relatively oxophilic nature, it demonstrates that the binding energy of $0^{*}$ alone does not account for the differences between coinage and platinum-group metals, as it has an oxygen binding energy stronger than $\mathrm{Pd}$ or $\mathrm{Pt}$, but $\mathrm{O}^{*}$ still decreases the methane activation barrier. 


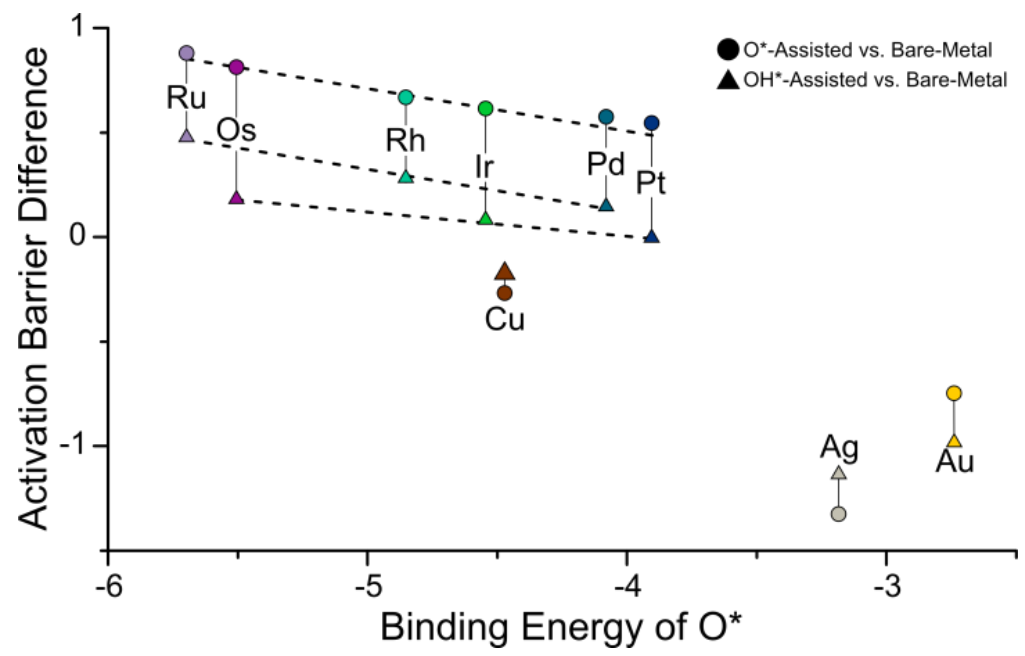

Figure 3.12. Difference between $0^{*}$-assisted $\left(M^{*}-0^{*}\right.$ site pairs) and bare-metal $\left(M^{*}-M^{*}\right.$ site pairs) methane activation barriers and the difference between $\mathrm{OH}^{*}$-assisted $\left(\mathrm{M}^{*}\right.$ - $\mathrm{OH}^{*}$ site pairs) and baremetal $\left(\mathrm{M}^{*}-\mathrm{M}^{*}\right)$ methane activation. The difference for the PGMs are all $>0.5 \mathrm{eV}$ for $\mathrm{O}^{*}$-assisted and correlate strongly with the binding energy of $0^{*}$. For the coinage metals, the differences are all $<0 \mathrm{eV}$ and a weaker correlation exists.

During $\mathrm{OH}^{*}$-assisted methane activation, $\mathrm{OH}^{*}$ sits in a near-atop site, leaning towards methane to form the transition state complex as shown in Figure 3.9 for Pd. Hydroxide, like 0*, can act as a Brønsted base to facilitate certain $\mathrm{C}-\mathrm{H}$ and $\mathrm{O}-\mathrm{H}$ activation reactions. However, unlike $\mathrm{O}^{*}, \mathrm{OH}^{*}$ sometimes preferentially binds to an atop site, where it can act as a Brønsted base. Even in situations in which it is most stable in the bridge or 3-fold site, the energy penalty to shift it to the active atop site is much smaller than the energy penalty to shift oxygen from the 3 -fold to the bridge site for all metals with the exception of $\mathrm{Cu}$ and Ag. For this reason, the barriers for $\mathrm{OH}^{*}$-assisted $\mathrm{R}-\mathrm{H}$ activation were smaller than the $\mathrm{O}^{*}$-assisted activation of $\mathrm{C}-\mathrm{H}$ and $\mathrm{O}-\mathrm{H}$ bonds during the study of alcohol oxidation presented earlier. Similarly, for methane activation, the $\mathrm{OH}^{*}$-assisted barriers are smaller than the $\mathrm{O}^{*}$-assisted barriers for the PGMs and $\mathrm{Au}$, as shown in Figure 3.11c. However, for $\mathrm{Cu}$ and $\mathrm{Ag}$, the $\mathrm{OH}^{*}$-assisted barriers are higher than the $\mathrm{O}^{*}$-assisted barriers by 0.09 and $0.19 \mathrm{eV}$, respectively. These increases are related to the relatively high energy required to shift $\mathrm{OH}^{*}$ from its stable 3 -fold site to the active atop site on $\mathrm{Cu}$ and $\mathrm{Ag}(0.63$ and $0.50 \mathrm{eV})$. Comparing the $\mathrm{OH}^{*}$-assisted barriers to 
the bare-metal barriers, once again the coinage metals see a decrease in barrier (Cu:-0.17 eV, Ag: $1.14 \mathrm{eV}, \mathrm{Au}:-0.99 \mathrm{eV}$ ) and the barrier on PGMs increase (Avg: $0.19 \mathrm{eV}$ ), with the exception of Pt which slightly decreases by $0.01 \mathrm{eV}$. As shown in Figure 13.12, the change in activation barrier depends upon the binding energy of oxygen and the period of the PGM, with period 5 metals showing a larger increase than period 6 metals. This discrepancy between period 5 and period 6 metals is due to the relative stability of $\mathrm{OH}^{*}$ in the atop position between those two rows. On period 5 metals, $\mathrm{OH}^{*}$ is most stable in the fcc position and the atop position is less stable with differences of $0.37,0.19$ and 0.09 for $\mathrm{Ru}, \mathrm{Rh}$ and Pd. However, on period 6 metals, the atop site is much more stable, while on Os $\mathrm{OH}^{*}$ still binds to the fcc site, the difference is much smaller than on $\mathrm{Ru}(0.05 \mathrm{eV})$ and for Ir and Pt, the atop site is more stable, with differences of -0.27 and $-0.33 \mathrm{eV}$. So, on period 5 metals, a penalty must be paid to shift the $\mathrm{OH}^{*}$ from the more stable 3 fold site to the atop position where it is active for this reaction, whereas on period 6 metals, $\mathrm{OH}^{*}$ is either in the atop site already (on Ir and Pt), or the penalty to shift it to that position is much smaller (on Os).

As chain length increases, the binding energy of the alkanes remains near zero, although this is under-predicted by DFT, due to the lack of dispersion forces. The binding energy of the alkyl group, on the other hand, varies with chain length as shown in Figure 3.13. Methyl $\left(\mathrm{CH}_{3}{ }^{*}\right)$ binds to an atop site on the metal surface, as shown in Figure 3.14 for Pd, and its binding energy varies from -0.67 to $-1.74 \mathrm{eV}$ with the binding energy on coinage metals significantly weaker (avg: $-0.89 \mathrm{eV}$ ) than on PGMs (avg: $-1.53 \mathrm{eV}$ ). Among the PGMs, the binding energy is strongest on Pt at $-1.74 \mathrm{eV}$, with the other PGMs falling in a tight cluster around $-1.5 \mathrm{eV}$. For ethyl $\left(\mathrm{CH}_{3} \mathrm{CH}_{2}{ }^{*}\right)$, shown adsorbed to Pd in Figure 3.14 , the binding energy is weaker on all metals, varying between -0.37 and $-1.40 \mathrm{eV}$. So, replacing a $-\mathrm{H}$ of methyl with $-\mathrm{CH}_{3}$ reduces the binding energy by $0.22-0.45 \mathrm{eV}$, a strong substituent effect which is the result of the increased stability of the ethyl radical in the vacuum compared to the methyl radical. These calculations however do not include dispersion effects which could alter these changes as the weak van der Waal interactions increase within increasing carbon length. If we wish to compare the binding energies without taking into effect the stability of the radical species in vacuum, we can define a 'molecular binding energy' based on a new reference state, namely the 
alkane in the vacuum phase as shown in Equation 3.3 for ethyl adsorption. Using this equation, any changes in the stability of the radical in vacuum will not be detected, only changes of the energy of the alkane itself.

$$
\mathrm{BE}^{\mathrm{mol}}=\mathrm{E}\left[\mathrm{CH}_{3} \mathrm{CH}_{2}{ }^{*}\right]-\mathrm{E}[\mathrm{Surf}]-\left(\mathrm{E}\left[\mathrm{CH}_{3} \mathrm{CH}_{3}\right]-1 / 2 \mathrm{E}\left[\mathrm{H}_{2}\right]\right)
$$

With this new reference state, the molecular binding energy of methyl varies from +1.68 to $+0.61 \mathrm{eV}$ (the differences between binding energies on different metals is the same regardless of the reference state selected.) For ethyl, the molecular binding energy varies from +1.76 to $+0.73 \mathrm{eV}$, displaying a much smaller substituent effect ( $0-0.23 \mathrm{eV}$ reduction), as expected as shown in Figure 3.16. These molecular binding energies are more consistent with changes in reaction energy between the activation of different alkanes, making them more useful descriptors of activity, while the previous binding energies are more useful for understanding the C-M bond strength of the adsorbed alkyl intermediates.
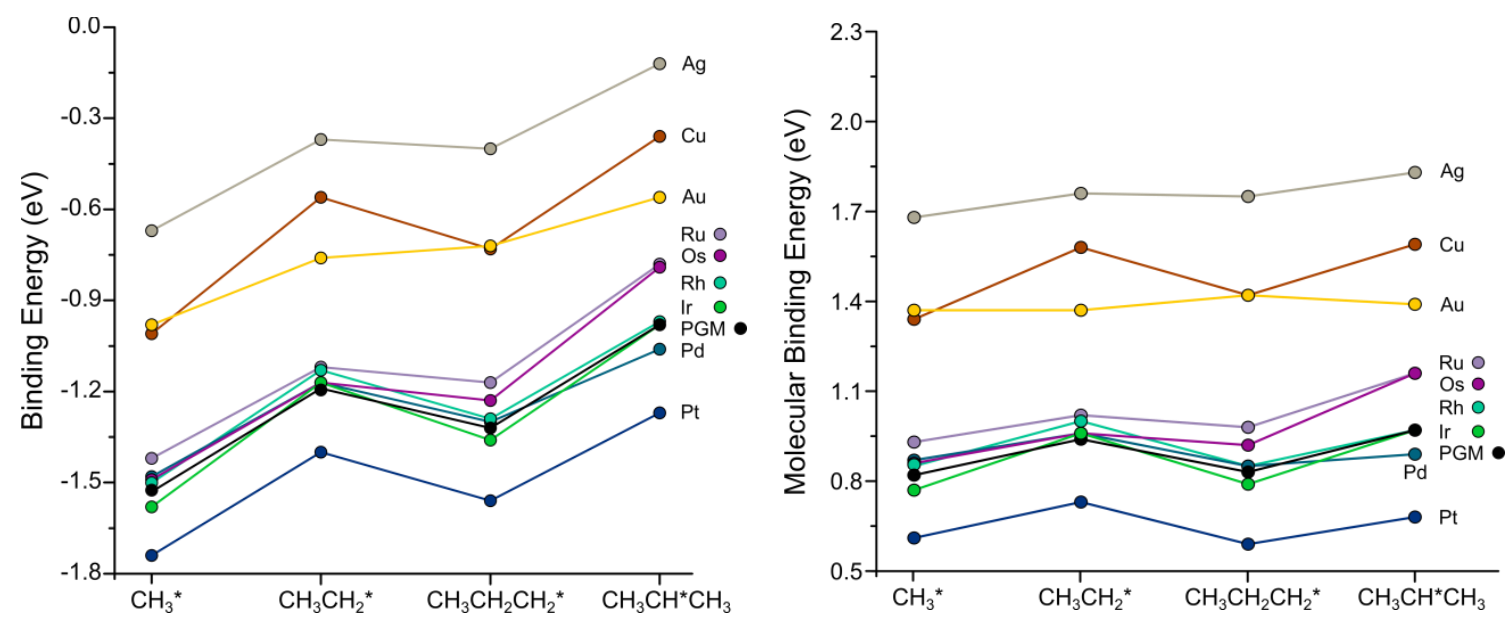

Figure 3.13. Binding energies referenced to radicals in vacuum (left) and molecular species (right) of alkyl species on different transition metal surfaces. 


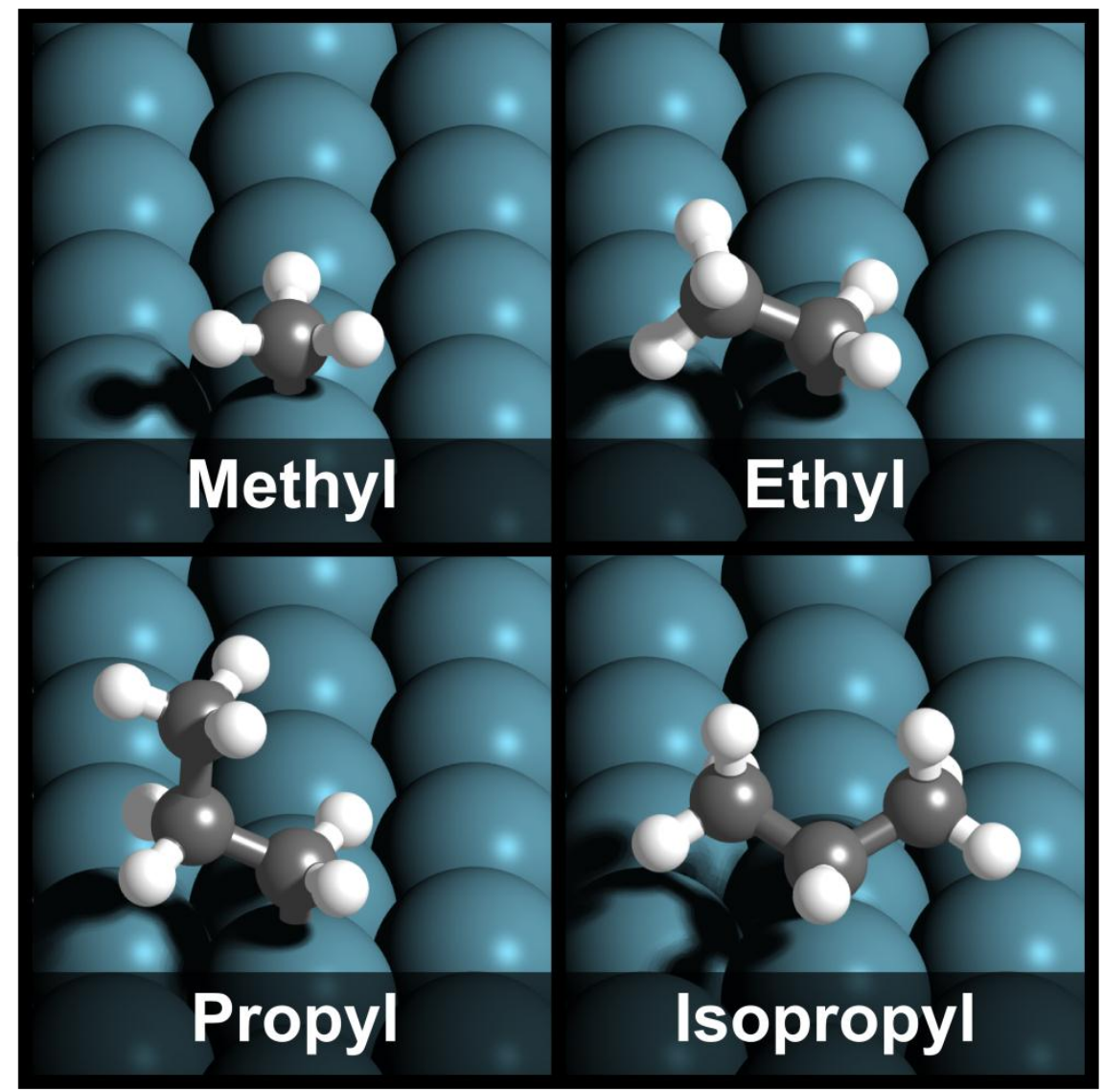

Figure 3.14. Binding modes of alkyl species in atop positions on Pd (111).

Propyl $\left(\mathrm{CH}_{3} \mathrm{CH}_{2} \mathrm{CH}_{2}{ }^{*}\right)$, shown adsorbed to Pd in Figure 3.14, has molecular binding energies between +1.75 and $+0.59 \mathrm{eV}$ across the metals that were examined. For most metals, propyl's molecular binding energy is slightly weaker than methyl (avg difference of $0.03 \mathrm{eV}$ ) with coinage metals showing the largest decrease in binding energy (avg difference of $0.07 \mathrm{eV}$ ). With the exception of $\mathrm{Au}$, the molecular binding energy of propyl is stronger than ethyl for all the metals considered (avg difference of $-0.10 \mathrm{eV})$. Finally, isopropyl $\left(\mathrm{CH}_{3} \mathrm{CH}^{*} \mathrm{CH}_{3}\right)$, shown adsorbed to Pd in Figure 3.14, has molecular binding energies similar to ethyl (weaker than methyl and propyl) with the exception of adsorption onto Ru and Os, the only hcp metals studied. For those surfaces, propyl bound 0.15 and $0.20 \mathrm{eV}$ weaker than ethyl, making them 0.24 and $0.30 \mathrm{eV}$ weaker than methyl for $\mathrm{Ru}$ and $\mathrm{Os}$, respectively, although it is unclear why. 
As stated, these molecular binding energies are useful for predicting changes in reactivity because differences between them are equal to differences between reaction energies for alkane activation. This is demonstrated in Figure 3.15, which shows the activation barriers and reaction energies for the activation of methane, ethane and propane (at its primary and secondary position). All three primary alkane activations have similar reaction energies (due to the similar molecular binding energies of the alkyl products) and as a result, the activation barriers of ethane and propane are quite similar to the activation of methane, shown earlier. However, the activation of propane at the secondary carbon have activation barriers that are $\sim 0.2 \mathrm{eV}$ higher than their primary counterparts for the platinum-group metals, despite much smaller shifts in reaction energy, indicating that this secondary $\mathrm{C}-\mathrm{H}$ bond activation is characteristically different from the primary $\mathrm{C}-\mathrm{H}$ bond activations studied.

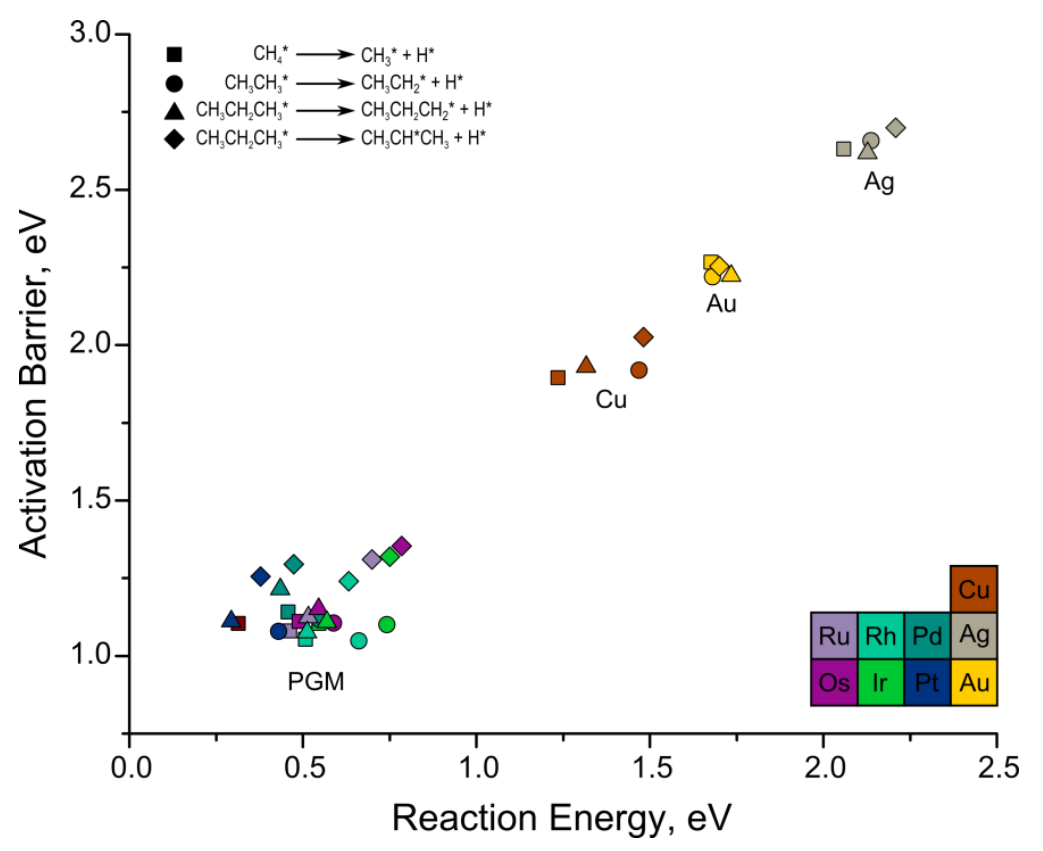

Figure 3.15. The reaction energy and activation barrier of the primary C-H activation of methane ( $\mathbf{})$,

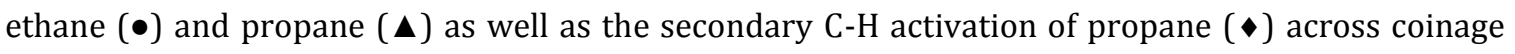
and platinum-group metals.

For the activation of ethane and propane through $\mathrm{O}^{*}$ - or $\mathrm{OH}^{*}$-assisted mechanisms, the results are similar to methane. For the coinage metals, the $\mathrm{O}^{*}$ - or $\mathrm{OH}^{*}$-assisted paths have lower 
barriers than direct metal insertion, as was the case with methane activation. For $\mathrm{Ag}$ and $\mathrm{Au}$, the decrease is dramatic $(>0.9 \mathrm{eV})$ while on $\mathrm{Cu}$, the decrease is more modest $(\sim 0.2 \mathrm{eV})$. For methane activation on $\mathrm{Au}$, the $\mathrm{OH}^{*}$-assisted mechanism was $0.2 \mathrm{eV}$ lower than the $\mathrm{O}^{*}$-assisted mechanism (and $1 \mathrm{eV}$ lower than metal-atom-insertion). However, for ethane and propane, the two coadsorbates give similar results near $1.25 \mathrm{eV}$. On $\mathrm{Ag}$ and $\mathrm{Cu}$, as before, $\mathrm{O}^{*}$-assisted pathways give lower barrier than $\mathrm{OH}^{*}$-assisted pathways. For the PGMs there are only minor differences between methane, ethane and propane activation as shown in Figure 3.16. Although it does appear that as chain length increases, on average, the activation becomes more difficult, regardless of the mechanism. Although slope of activation barrier compared to chain length is larger for the $0^{*}$ assisted mechanism on the more oxophilic metals, indicating that the steric effects of the substituents causes the $0^{*}$ to have to move further out of the surface, increasing the barrier (an increase proportional to the oxophilicity of the metal). The secondary activation of propane with $\mathrm{O}^{*}$ or $\mathrm{OH}^{*}$ co-adsorbates is still under investigation. 


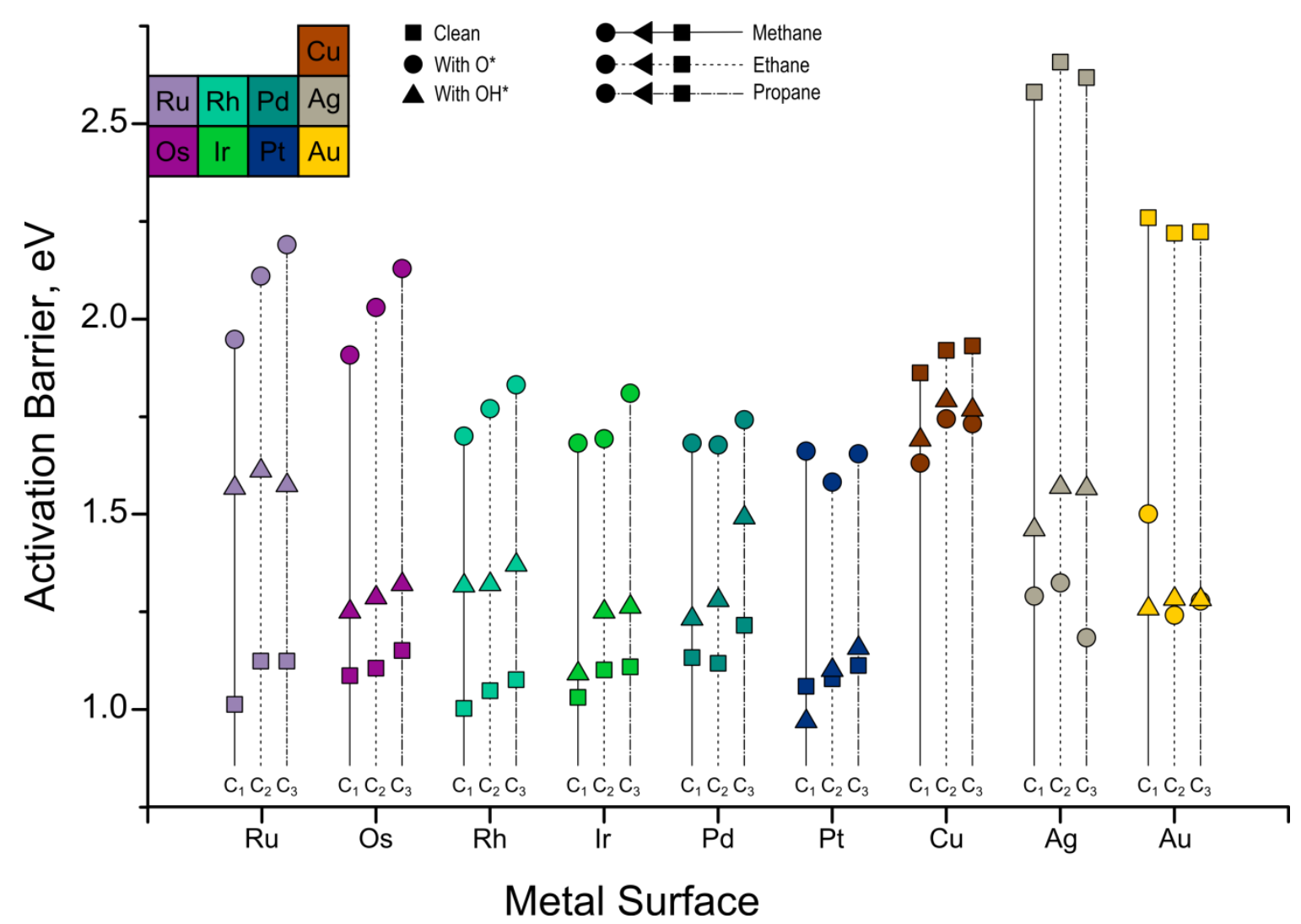

Figure 3.16. The activation of primary $\mathrm{C}-\mathrm{H}$ bonds of methane, ethane and propane via metal-atominsertion, $\mathrm{O}^{*}$-assisted and $\mathrm{OH}^{*}$-assisted routes for coinage and platinum-group metals.

In summary, the $\mathrm{C}-\mathrm{H}$ activation of alkanes typically involves oxidative insertion of a metal atom into the $\mathrm{C}-\mathrm{H}$ bond. Since the $\mathrm{H}$ is not acidic, a surface-bound species which can act as a Brønsted base, such as $\mathrm{O}^{*}$ or $\mathrm{OH}^{*}$, does not assist via $\mathrm{H}$-abstraction on platinum-group metal catalysts. On coinage metals, however, both $\mathrm{O}^{*}$ - and $\mathrm{OH}^{*}$-assisted pathways give lower barriers, this is due to the inert nature of the metal surface, the increased charge transfer to $0^{*}$ or $\mathrm{OH}^{*}$ when bound to these coinage metals, and the weak binding energies of $\mathrm{O}^{*}$ and $\mathrm{OH}^{*}$ which reduce the enthalpic penalties associated with shifting the adsorbates from their stable positions to their more active ones. As the chain length increases, the activation barriers (in general) increase as well and the effects of $0^{*}$ and $\mathrm{OH}^{*}$ are consistent. For the secondary $\mathrm{C}-\mathrm{H}$ activation of propane, the activation barriers are considerably higher when activated through metal atom insertion. 
As shown in Figure 3.9, during direct methane activation, the C-M bond in the transition state is $2.21 \AA$ for Pd (2.25 ̊̊averaged across all studied metals). Carrying out the reaction through $\mathrm{O}^{*}$ or $\mathrm{OH}^{*}$-assisted methane activation causes that $\mathrm{C}-\mathrm{M}$ bond to stretch in the transition state to permit interaction between the activated $\mathrm{H}$ and nearby $\mathrm{O}^{*}$ or $\mathrm{OH}^{*}$. For $\mathrm{O}^{*}$-assisted methane activation, the C-M bond length for Pd is $2.29 \AA$ (Figure 9) an increase of $0.08 \AA$, which is typical of PGMs (avg. increase of $0.08 \AA ̊$ ). However, for coinage metals, mainly Ag and Au, the increase in C-M bond length is much more dramatic (0.45 ̊). This trend is similar for $\mathrm{OH}^{*}$-assisted methane activation, in which the C-M bond lengths in the transition states on PGMs increase by an average of $0.09 \AA$ and on $\mathrm{Ag}$ and Au they increase by $0.25 \AA$. The elongation of the C-M bond can significantly increase the activation barrier because the methyl radical is very unstable in the gas phase.

However, for an adsorbed alkyl, a strong C-M bond exists (as shown in Figure 3.14) so the further C-H activation of that carbon (for instance, $\mathrm{CH}_{3}{ }^{*} \rightarrow \mathrm{CH}_{2}{ }^{*}+\mathrm{H}^{*}$ ) must then be structurally different from the initial methane activation due to the pre-existing C-M bond. The effect of these structural (and possibly electronic) differences was investigated by examining the further $\mathrm{C}-\mathrm{H}$ activation of methyl to methylene. Shown in Figure 3.17 are the transition state geometries for this reaction on the Pd surface which are very different from methane activation (much shorter C-M bond as expected, a shorter $\mathrm{M}-\mathrm{H}$ bond and a longer $\mathrm{C}-\mathrm{H}$ bond). As shown in Figure 3.18, the activation barrier of methyl is lower than the activation barrier of methane across the coinage metals, $\mathrm{Ag}, \mathrm{Au}$ and $\mathrm{Cu}$ by $0.11,0.19$ and $0.37 \mathrm{eV}$ (the difference grows larger as the barrier decreases). For the group 10 metals (Pd and Pt), the barriers are slightly lower by an average of $0.09 \mathrm{eV}$. However, the methyl activation barrier for the group 9 metals, Rh and Ir, are lower by an average of $0.47 \mathrm{eV}$ and the group 8 metals by an average of $0.67 \mathrm{eV}$. These large differences in activation barrier, favoring the activation of methyl, are due to the increased interaction of methylene on group 8 and 9 , compared to other metals. ${ }^{159}$ This is also demonstrated by the Brønsted-Evans-Polyani (BEP) plot, shown in Figure 3.19. Due to the linear nature of BEP, it can be inferred that the mechanism is consistent across the metals studied, with the differences in activation barrier arising from changes in the reaction energy (due to changes in product binding energies). 


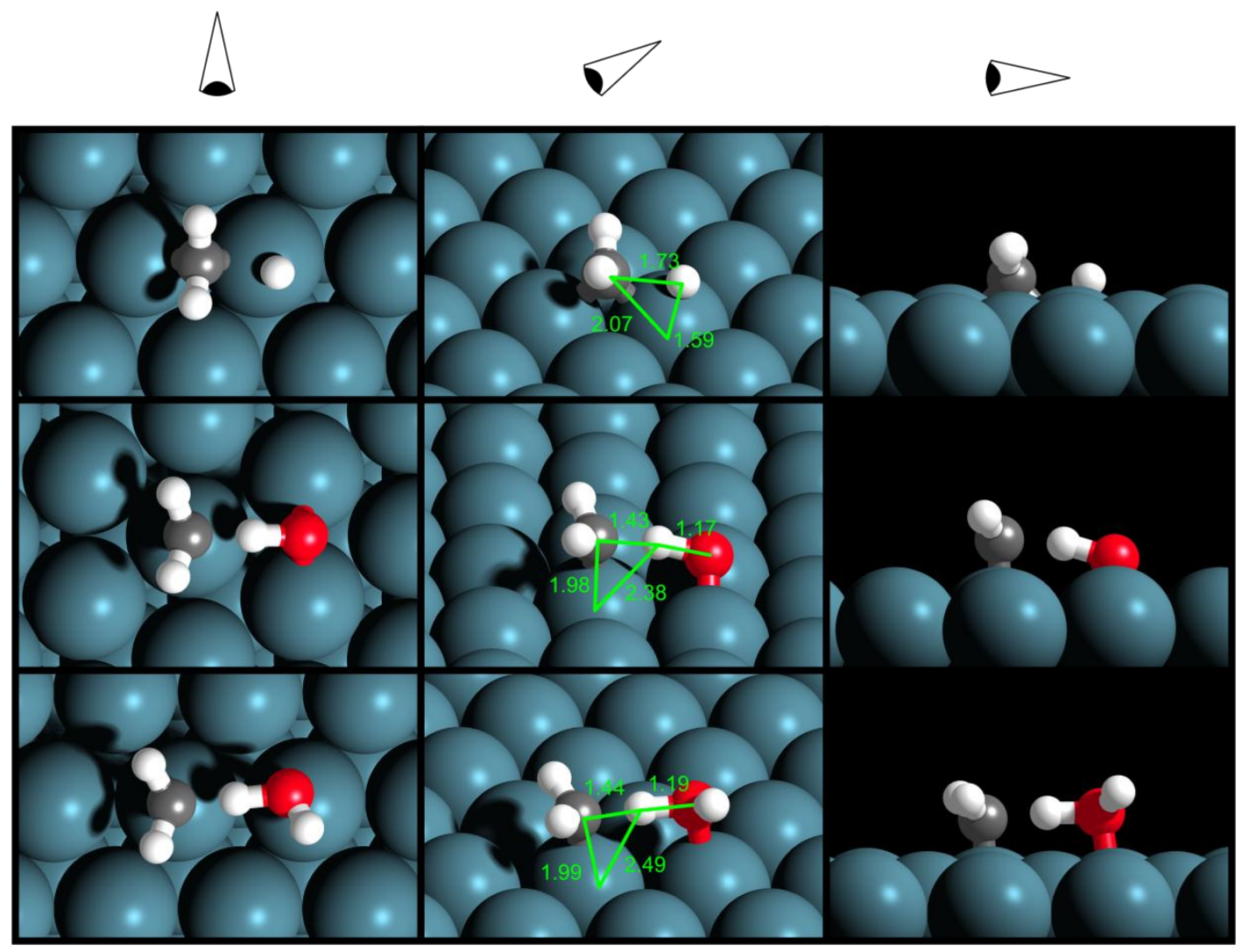

Figure 3.17. Transition state geometries for the $\mathrm{C}-\mathrm{H}$ activation of methyl through direct, $\mathrm{O}^{*}$-assisted and $\mathrm{OH}^{*}$-assisted reactions on $\mathrm{Pd}$. 


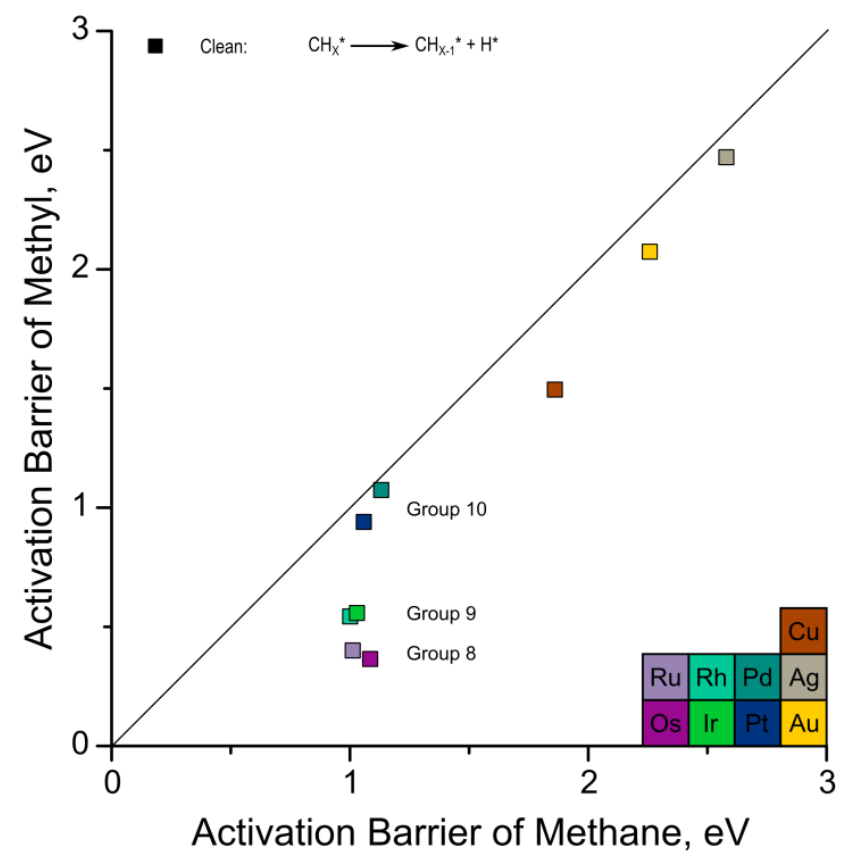

Figure 3.18. A comparison of the activation barriers of methane and methyl on platinum-group and coinage metals.

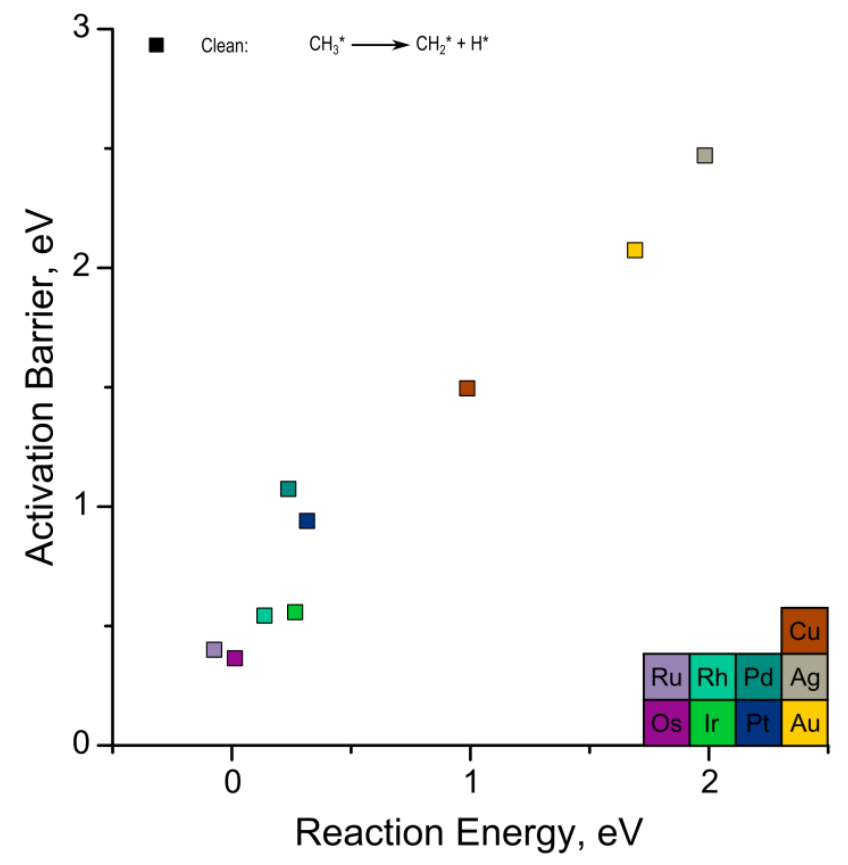

Figure 3.19. BEP plot for the $\mathrm{C}-\mathrm{H}$ activation of methyl to form methylene on platinum-group and coinage metals. 
As previously discussed, during $\mathrm{O}^{*}$ - or $\mathrm{OH}^{*}$-assisted methane activation, the $\mathrm{C}-\mathrm{M}$ bond is significantly elongated compared to the direct metal insertion. However, this is not the case during methyl activation due to the already present $\mathrm{C}-\mathrm{M}$ bond in the reaction state. Without that contribution, the $\mathrm{O}^{*}$ - and $\mathrm{OH}^{*}$-assisted activations of methyl are more dependent upon the energy to shift $\mathrm{O}^{*}$ or $\mathrm{OH}^{*}$ to their active sites and their Brønsted basicity in those active sites. For the coinage metals, the weak binding energy of $0^{*}$ allows for an easier promotion to their active site and the Brønsted basicity of $0^{*}$ on those surfaces enables results in a large decrease in activation barrier between the direct and $0^{*}$-assisted case $(\mathrm{Cu}:-0.33 \mathrm{eV}, \mathrm{Ag}:-1.38 \mathrm{eV}, \mathrm{Au}:-0.89 \mathrm{eV})$ as shown in Figure 3.20. Furthermore, the decreases are slightly larger for methyl activation than they were for methane activation (Figure 3.21). For PGMs, the barrier increases with $0^{*}$-assistance (as it did with methane) and this increase is once again proportional to the binding energy of $0^{*}$ as shown in Figure 3.20. In this case the increases are significantly larger than in the case of methane activation $(0.94 \mathrm{eV}$ compared to $0.68 \mathrm{eV}$ ) as shown in Figure 3.21. Part of the reason for $0^{*}$-assisted activation being particular poor for methyl (compared to methane) is that since the methyl is strongly bound in the reactant state, the $0^{*}$ must shift further into the bridge site in order to reach it, whereas in the case of methane activation, the $\mathrm{O}^{*}$ is closer to the fcc site in the transition state. For $\mathrm{OH}^{*}$-activation, the same effect is observed, the differences between $\mathrm{OH}^{*}$-assisted and direct $\mathrm{C}-\mathrm{H}$ activation for methane activation are always more favorable than for methyl activation on PGMs as shown in Figure 3.21. Overall, as shown in Figure 3.22, the activation barriers for the C-H activation of the bound methyl are lower (with few exceptions) than the activation barriers for the $\mathrm{C}-\mathrm{H}$ activation of methane, regardless of the mechanism. 


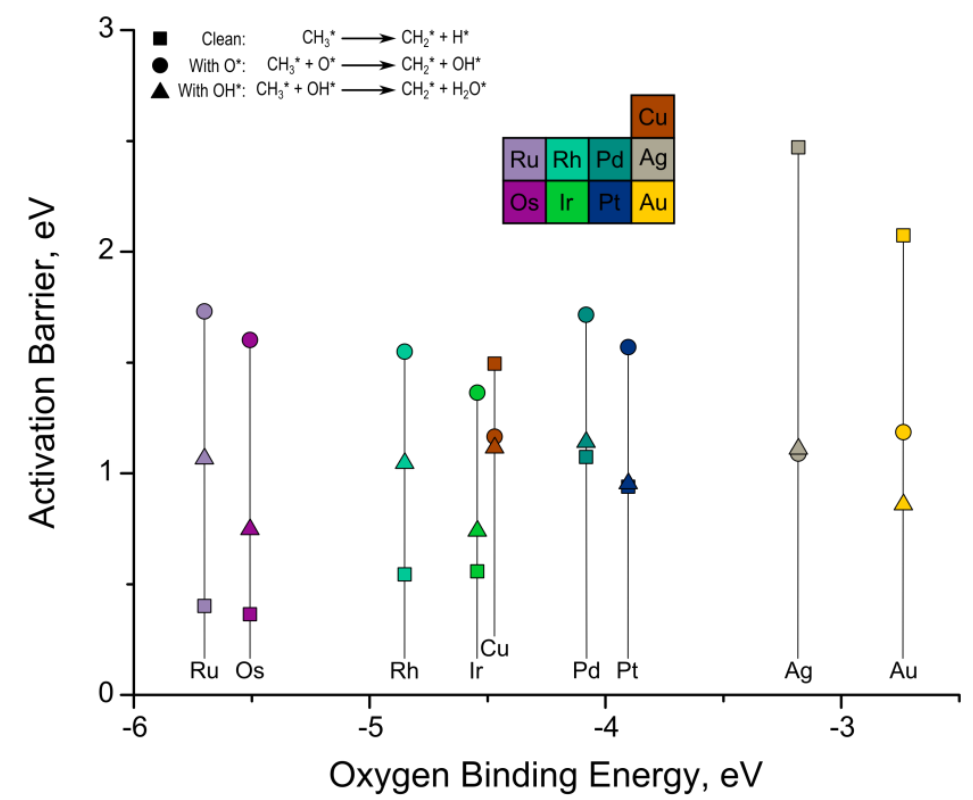

Figure 3.20. A comparison of the activation barriers for the $\mathrm{C}-\mathrm{H}$ activation of methyl through direct, $\mathrm{O}^{*}$-assisted and $\mathrm{OH}^{*}$-assisted reactions on platinum-group and coinage metals.

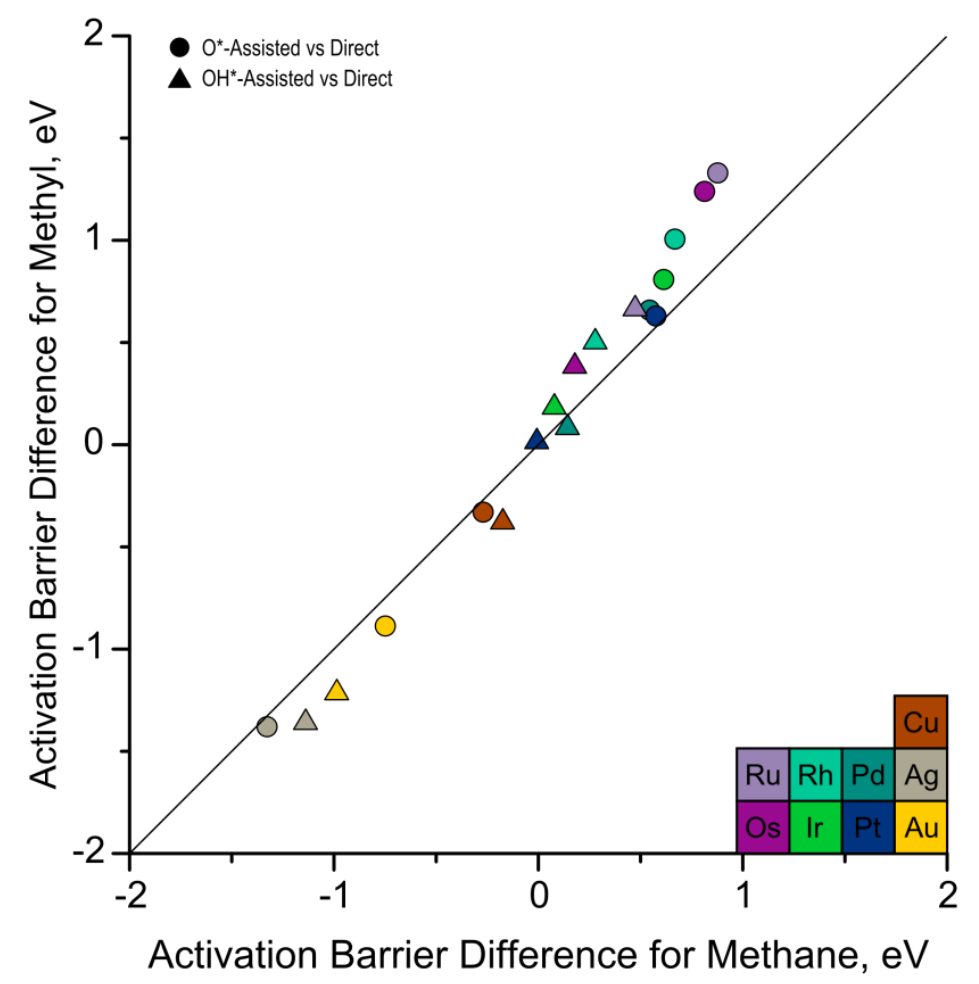

Figure 3.21. A comparison of the effect of $\mathrm{O}^{*}$ - and $\mathrm{OH}^{*}$-assistance on the $\mathrm{C}-\mathrm{H}$ activation barriers of methyl and methane. 


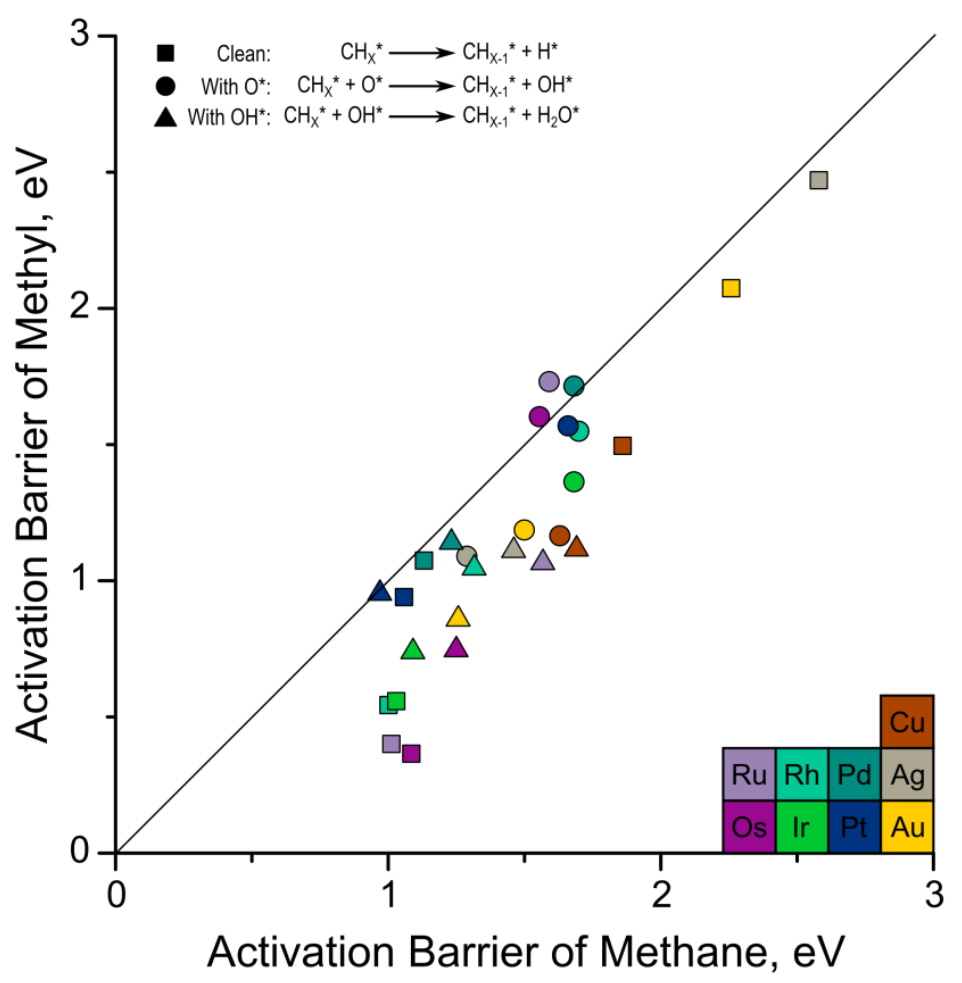

Figure 3.22. A comparison of the $\mathrm{C}-\mathrm{H}$ activation barriers of methane and methyl through direct, $\mathrm{O}^{*}$-assisted and $\mathrm{OH}^{*}$-assisted reactions on platinum-group and coinage metals.

We now consider the activation of acidic $\mathrm{O}-\mathrm{H}$ bonds such as the activation of the $\mathrm{O}-\mathrm{H}$ bond of adsorbed methanol $\left(\mathrm{CH}_{3} \mathrm{OH}^{*}\right)$ to form its methoxide intermediate $\left(\mathrm{CH}_{3} \mathrm{O}^{*}\right)$. Methanol, like other alcohols, ${ }^{36,37,160}$ adsorbs to metal surface via the donation of electrons from its oxygen into the metal as well as through van der Waal interactions. The oxygen atom typically sits in an atop position and at angle to surface. DFT-calculated binding energies range from -0.04 to $-0.27 \mathrm{eV}$ and typically underestimate the adsorption of methanol and other alcohols as doesn't include the weaker van der Waals interactions. Unlike methane, which activates over a single metal atom, the $\mathrm{O}-\mathrm{H}$ activation takes place across a 3 metal atoms, where the 0 of methanol first shifts from the atop site to a bridge position, and the $\mathrm{H}$ is abstracted by the metal atom across the 3 -fold site. Following $\mathrm{O}-\mathrm{H}$ scission, both the methoxide and hydrogen intermediates migrate to adjacent 3-fold sites. This reaction is pictured in Figure 3.23 on a Pd surface. Across the series of platinum-group and coinage metals, the 
direct $\mathrm{O}-\mathrm{H}$ activation of methanol follows a BEP relationship, as shown in Figure 3.24. The activation barriers on $\mathrm{Au}$ and $\mathrm{Ag}$ are high, similar to what was observed in alkane activation, and it appears that Ir and Pt have slightly lower activation barriers than their reaction energies would predict, possibly due to the fact that the product methoxide $\left(\mathrm{CH}_{3} \mathrm{O}^{*}\right)$ is more stable in the atop site on these surfaces (on all other surfaces it prefers to sit 3-fold). $\mathrm{Cu}$, which binds $\mathrm{O}^{*}$ stronger than Pt or Pd, despite being a coinage metal, has a reaction energy and activation barrier similar to platinum-group metals. Comparing the $\mathrm{C}-\mathrm{H}$ activation of methane with the $\mathrm{O}-\mathrm{H}$ activation of methanol (Figure 3.25) shows that for most metals, the activation barrier of methanol is lower than that of methane, due to the metal's increased affinity for oxygen over carbon. This is most dramatic for Ag and Cu coinage metals, but it's notably absent from Au. On the other hand, Ir, Rh and Pd show higher O-H activation barriers, indicating these metals have greater affinity for carbon than oxygen.
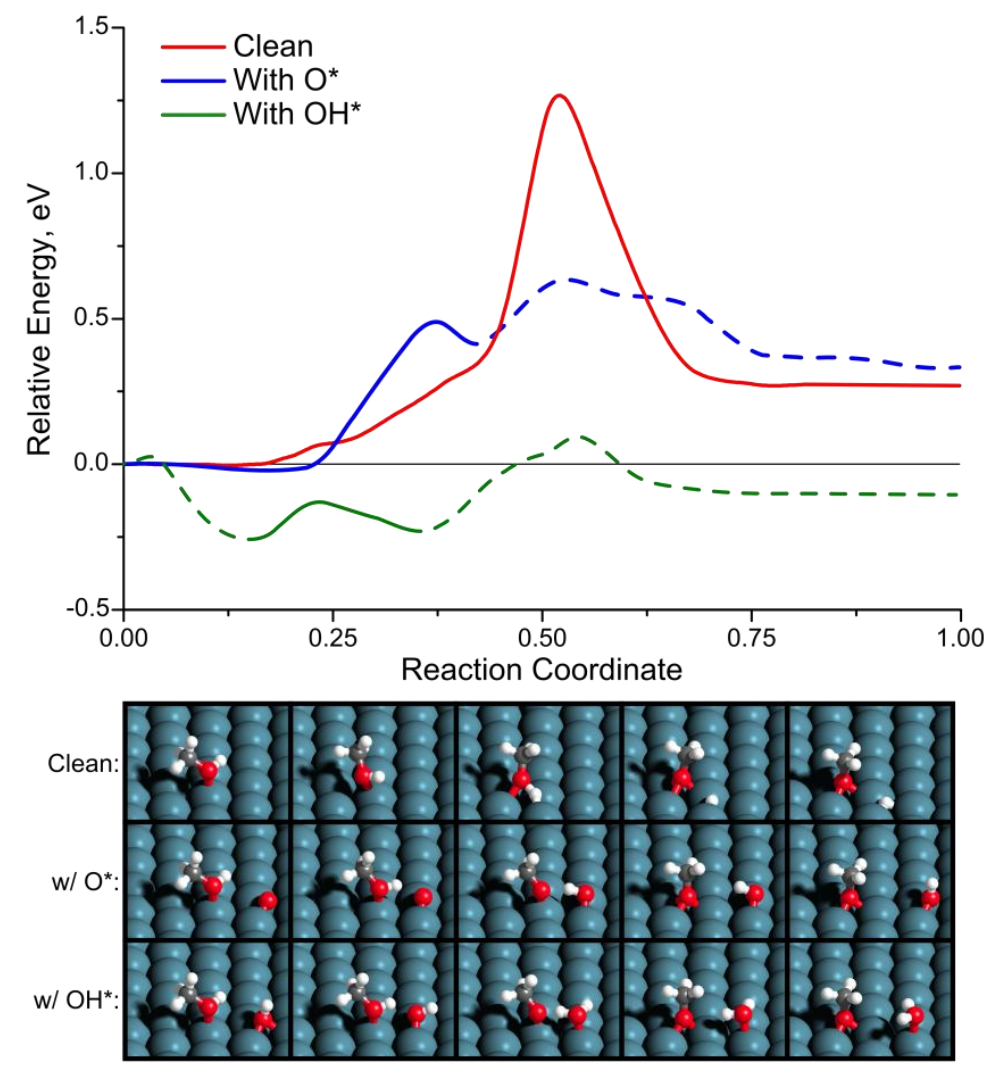

Figure 3.23. Reaction pathway for the activation of the $\mathrm{O}-\mathrm{H}$ bond of methanol, on a clean metal surface and through $\mathrm{O}^{*}$ - and $\mathrm{OH}^{*}$-abstraction mechanisms, shown in the pictures below. 


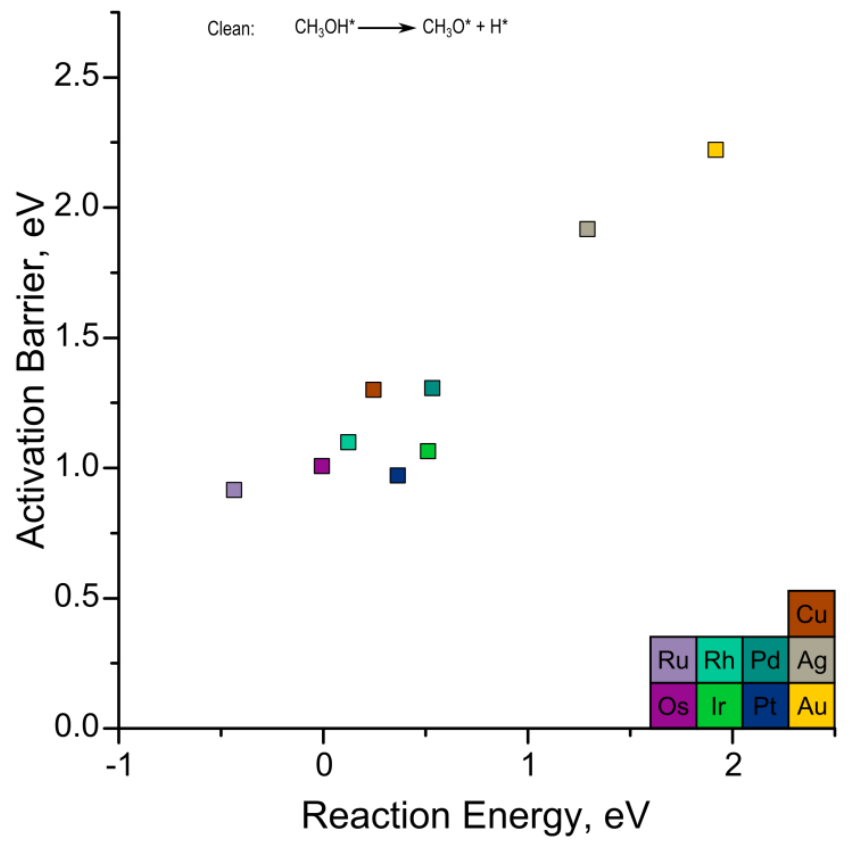

Figure 3.24. BEP relationship for the $\mathrm{O}-\mathrm{H}$ activation of methanol on bare surfaces of platinum-group and coinage metals.

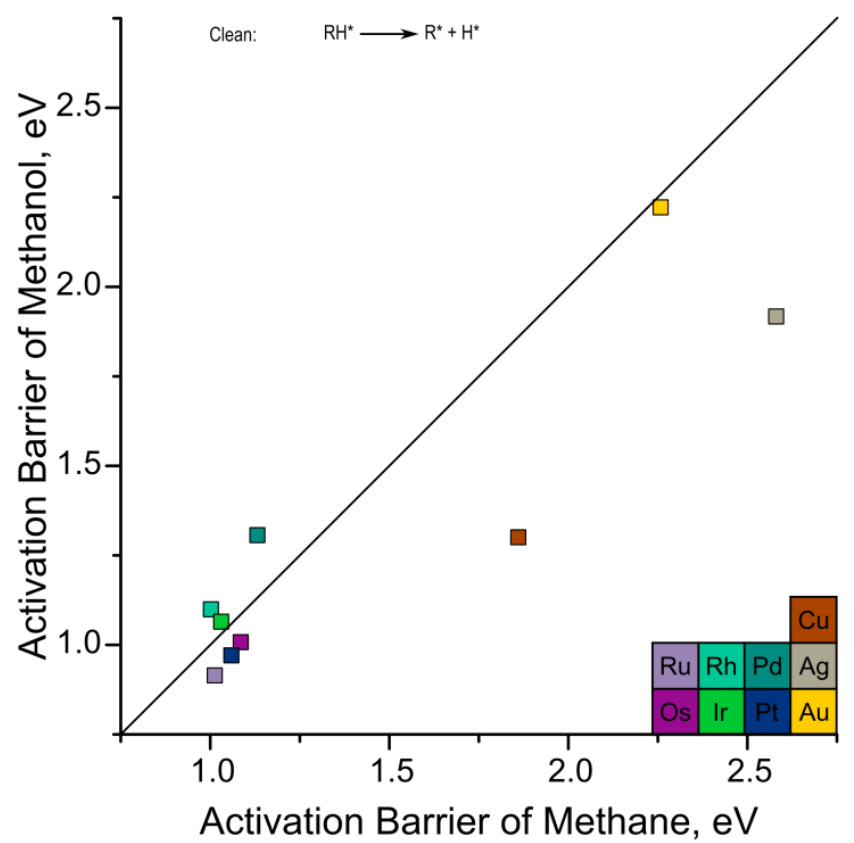

Figure 3.25. Comparison between the $\mathrm{C}-\mathrm{H}$ activation of methane and the $\mathrm{O}-\mathrm{H}$ activation of methanol on bare surfaces of platinum-group and coinage metals. 
In the presence of $\mathrm{O}^{*}$, the $\mathrm{O}-\mathrm{H}$ bond of the alcohol can be activated by proton-transfer mechanism where the $0^{*}$ first shifts from its stable 3 -fold binding mode to a bridging position as shown for the reaction on Pd in the inset of Figure 3.23. Once in the bridging position, the terminal proton on methanol transfers from the $\mathrm{O}-\mathrm{H}$ bond to $\mathrm{O}^{*}$, with a transition state at the first maximum shown on the reaction profile. The second and larger peak involves the breaking of the hydrogen bond that exists between the initial atop-bound methoxide and the bridge-bound hydroxyl intermediates as they diffuse into 3 -fold fcc positions. The relative energies of these states vary from metal-to-metal, but the overall mechanism is consistent for the studied metals, with the exception of Ir and Pt. On those metals, the product methoxide and hydroxide species prefer to bind atop, (whereas on the other metals they prefer to bind 3-fold). This alters the sequence of the reaction; after the H-transfer step, hydroxide shifts to the atop position, forming a strong hydrogen bond with methoxide (which remains atop).

When $\mathrm{OH}^{*}$ is present on $\mathrm{Pd}$, it first shifts from its fcc position to the bridging position adjacent to the alcohol, forming strong hydrogen bonds between the alcohol and hydroxide. The shift of $\mathrm{OH}^{*}$ from the fcc to the bridging position results in the first (very small) barrier shown in Figure 3.23. The first minimum in the reaction profile is the state in which the hydrogen bond has been formed which is $0.27 \mathrm{eV}$ more stable than the reactant state. Next, the hydroxide shifts from the bridge to atop position concomitant with a proton transfer directly between the methanol and hydroxide, with very little interaction with the metal surface; this proton transfer and $\mathrm{OH}^{*}$ shift is the second maximum shown in Figure 3.23. Following that transfer, the methoxide is bound to the atop position, hydrogen bonding with water in an adjacent atop site. The final (and larger) maximum along the reaction coordinate diagram corresponds to breaking the newly formed hydrogen bond as methoxide diffuses to the nearby fcc site. Once again, the reaction sequence on Ir and Pt is slightly different due to the fact that hydroxide and methoxide prefer to bind atop on those surfaces. In those cases, methanol binds in an atop position adjacent to hydroxide, forming a very strong hydrogen bond which gives methanol binding energies of $-0.56 \mathrm{eV}$ and $-0.39 \mathrm{eV}$ for Ir and Pt, respectively. Once 
bound, the proton transfer occurs near-spontaneously, with very small barriers of 0.03 and $0.02 \mathrm{eV}$, forming product states which are very similar in energy to the reactant states. This indicates that on Ir and $\mathrm{Pt}$, this reaction approaches equilibrium rapidly; which should favor the deprotonation of methanol (because it has a lower pKa than water).

As can be seen in Figure 3.23, there are multiple activated steps during the H-transfer reactions between $\mathrm{CH}_{3} \mathrm{OH}$ and $\mathrm{O}^{*}$ or $\mathrm{OH}^{*}$ on a metal surface. In order to simplify the analysis, we will focus on the H-transfer step itself, rather than any transition states that may form from the intermediates changing their binding modes. Thus, the $\mathrm{H}$-transfer activation barriers (referenced to desorbed methanol) for this reaction on Pd are 1.20, 0.07 and $-0.58 \mathrm{eV}$ through the three mechanisms described in Figure 3.23. Demonstrating that $\mathrm{O}^{*}$ - or $\mathrm{OH}^{*}$-assisted $\mathrm{O}-\mathrm{H}$ activation of methanol is much easier than activation over a bare metal surface $\left(1.13 \mathrm{eV}\right.$ less for $\mathrm{O}^{*}$-assisted and $1.78 \mathrm{eV}$ less for $\mathrm{OH}^{*}$ assisted). This is very different from the $\mathrm{C}-\mathrm{H}$ activation of methane as expected, due to the large difference in acidity between methane (pKa 56) and methanol (pKa 15.2).

On the coinage metals, the $0^{*}$-assisted reaction has barriers of $-0.40,-0.20$ and 0.18 for $\mathrm{Cu}$, $\mathrm{Ag}$ and $\mathrm{Au}$, respectively. These are significantly lower than the barriers for direct $\mathrm{C}-\mathrm{H}$ activation, which was true during the $\mathrm{C}-\mathrm{H}$ activation of methane as well. However, the decreases in activation barrier are much larger in the case of $0-\mathrm{H}$ activation $(-1.25,-2.07,-1.98 \mathrm{eV})$ than they were in the case of methane activation $(-0.27,-1.33,-0.75 \mathrm{eV})$. This is consistent with the view that $0^{*}$ is acting as a Brønsted base during these $\mathrm{O}-\mathrm{H}$ and $\mathrm{C}-\mathrm{H}$ activations, so it's effect is directly related to the acidity of the hydrogen being abstracted. For platinum-group metals, the $\mathrm{O}^{*}$-assisted reaction for the $\mathrm{C}-\mathrm{H}$ activation of methane was much more difficult than the direct activation, by an average of $0.68 \mathrm{eV}$. However, for this $\mathrm{O}-\mathrm{H}$ activation, the $\mathrm{O}^{*}$-assisted reaction is easier than the direct activation by an average of $0.72 \mathrm{eV}$. Once again this is due to the increased acidity of the $\mathrm{O}-\mathrm{H}$ bond of methanol compared to the $\mathrm{C}-\mathrm{H}$ bond of methane. The size of the difference on different metals, as before, scales with the binding energy of $0^{*}$, as shown in Figure 3.26, with weakly bound $0^{*}$ leading to lower barriers. 


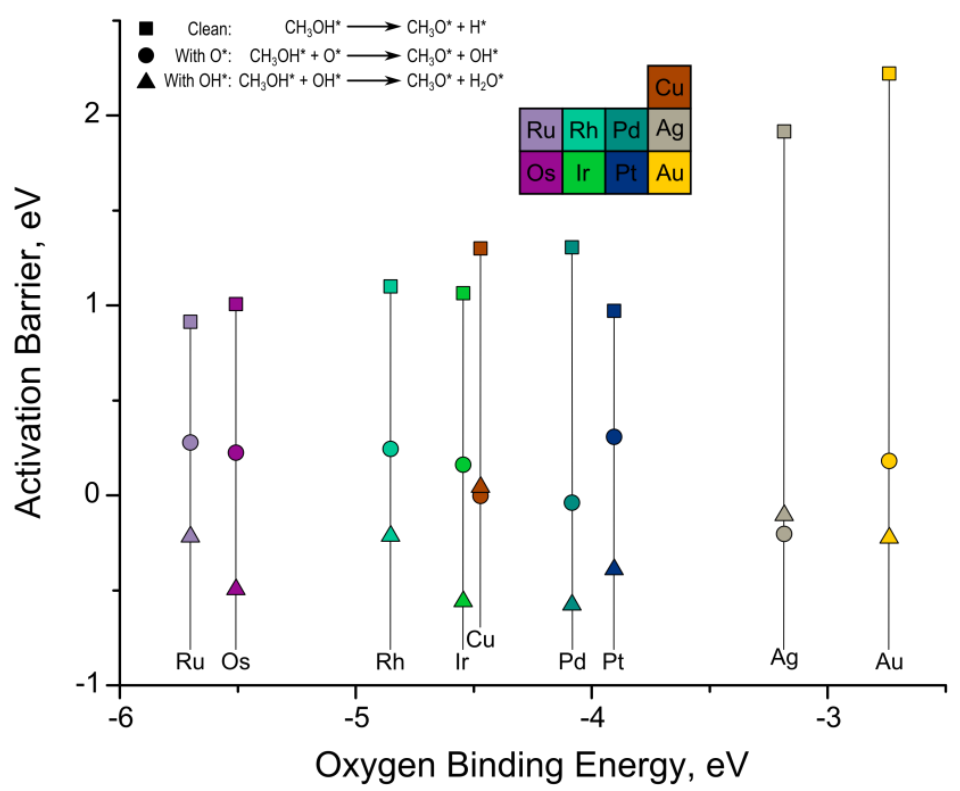

Figure 3.26. Activation barrier (referenced to methanol in the gas phase) for the $\mathrm{O}-\mathrm{H}$ activation of methanol through direct, $\mathrm{O}^{*}$-assisted and $\mathrm{OH}^{*}$-assisted mechanisms for platinum-group and coinage metals.

For $\mathrm{OH}^{*}$-assisted activation, the $\mathrm{H}$-transfer between methanol and hydroxide occurs with essentially no barrier once the hydroxide has diffused to the atop position, regardless of the metal surface. As such, the barriers shown in Figure 3.27 only represent the changes in methanol binding energy and the energy to diffuse the $\mathrm{OH}^{*}$ to the atop position. This indicates that for an $\mathrm{O}-\mathrm{H}$ activation, $\mathrm{OH}^{*}$, regardless of the metal surface, can easily act as a Brønsted base, abstracting the proton of methanol. The differences between the activation barriers for $\mathrm{OH}^{*}$-assisted $\mathrm{O}-\mathrm{H}$ activation do not represent changes in the basicity of $\mathrm{OH}^{*}$ on different metals, because the basicity of $\mathrm{OH}^{*}$ is not a controlling factor (it is always sufficiently basic). 


\section{Conclusions}

The ability of $\mathrm{O}^{*}$ or $\mathrm{OH}^{*}$ to act as a Brønsted base during the activation of $\mathrm{O}-\mathrm{H}$ and $\mathrm{C}-\mathrm{H}$ bonds depends upon:

1) The acidity of the $\mathrm{H}$ being transferred, with $\mathrm{O}-\mathrm{H}$ bonds being much more acidic than $\mathrm{C}-\mathrm{H}$ bonds.

2) The nature of $\mathrm{O}^{*}$ or $\mathrm{OH}^{*}$ on the metal surface, with $\mathrm{O}^{*}$ or $\mathrm{OH}^{*}$ being much more negatively charged when bound to coinage metals, enabling them to act more basic on these surfaces.

3) The binding energy and mode of $\mathrm{O}^{*}$ or $\mathrm{OH}^{*}$ on the metal surface, because the $\mathrm{O}^{*}$ or $\mathrm{OH}^{*}$ must shift to the bridging and atop positions, respectively, before it accepts the proton. The energy required to shift the species to its active site is typically proportional to the binding energy.

For the activation of alkanes, in which the $\mathrm{H}$ being transferred is not acidic, the direct metal catalyzed $\mathrm{C}-\mathrm{H}$ activation is the preferred mechanism on platinum-group metals. When $\mathrm{O}^{*}$ is present at low coverages, the reaction will likely continue over metal-metal sites, such that the adsorbed $0^{*}$ affects the rate by blocking active sites. However, at higher coverages, $0^{*}-0^{*}$ repulsion on the surface can enable the reaction to proceed through $0^{*}$-assisted alkane activation on certain platinum-group metals, as discussed in the previous section for the partial oxidation of methane. In these cases, $0^{*}-0^{*}$ repulsion effectively lowers the binding energy of $0^{*}$ on the surface, which directly decreases the barrier for $0^{*}$-assisted methane activation. On coinage metals, the inert nature of the metal surface, combined with the weak binding energy and high charge transfer to $0^{*}$ on these surfaces, results in the $0^{*}$-assisted barrier being significantly lower than the direct barrier, indicating that $0^{*}$ is very active on coinage metal surfaces.

For $\mathrm{O}-\mathrm{H}$ activation, the $\mathrm{O}^{*}$-assisted barrier is lower than direct metal atom insertion for all platinum-group and coinage metals. In this case, the barrier loosely correlates with the binding 
energy of $0^{*}$, because this relates to the difference in energy between $0^{*}$ in the 3 -fold vs. bridge (active) site.

Due to the increased mobility and basicity of $\mathrm{OH}^{*}$ on most transition metal surfaces, it is more active during $\mathrm{C}-\mathrm{H}$ or $\mathrm{O}-\mathrm{H}$ activation on the studied platinum-group or coinage metals with the exception of $\mathrm{Cu}$ and $\mathrm{Ag}$. On these surfaces, the energy to shift $\mathrm{OH}^{*}$ from the 3 -fold (stable) to the atop (active) position is 0.63 and $0.51 \mathrm{eV}$, respectively; whereas the energy to shift $0^{*}$ from its 3 -fold (stable) to the bridge (active) position is 0.37 and $0.29 \mathrm{eV}$. These are the only two metals in which it is easier to shift $\mathrm{O}^{*}$ to its active position compared to $\mathrm{OH}^{*}$. If $\mathrm{OH}^{*}$ can act basic in the bridge position, the transition state may have a lower barrier than the case in which $\mathrm{OH}^{*}$ is in the atop position. This was tested for Pd, but has not yet been tested for $\mathrm{Cu}$ and $\mathrm{Ag}$.

Other calculations in progress include alkane activation at the secondary position of propanol (to form isopropyl adsorbed to the surface) through $\mathrm{O}^{*}$ and $\mathrm{OH}^{*}$ assisted mechanisms; the initial C-H activation of methanol and other alcohols; the initial $\mathrm{O}-\mathrm{H}$ activation of ethanol, propanol and isopropanol; and the hydride elimination of methoxide and other alkoxides (which give aldehyde products). These calculations are to further investigate different types of $\mathrm{C}-\mathrm{H}$ and $\mathrm{O}-\mathrm{H}$ activations as well as chain length and substituent effects. 


\section{4...Hydrogenolysis of Polyols and Cyclic Ethers over Bimetallic Alloys}

\section{1 : Selective Hydrogenolysis of Polyols and Cyclic Ethers over Bifunctional Surface} Sites on Rh-Re Catalysts

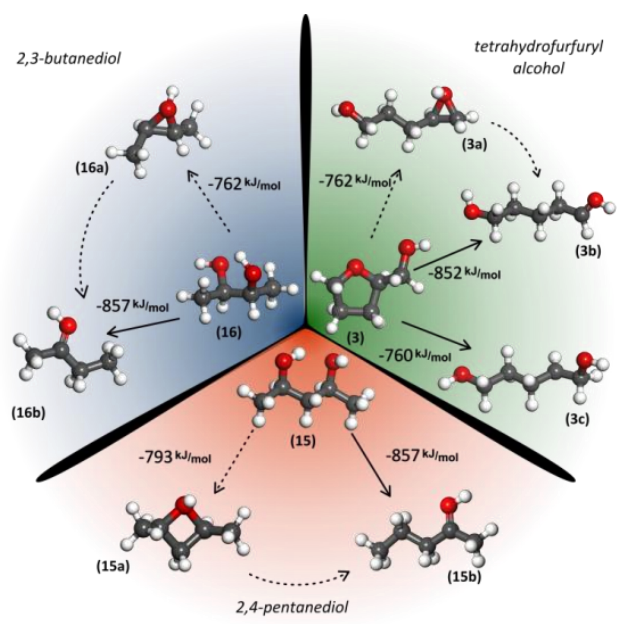

A combination of experimental and theoretical calculations at multiple institutions suggest, based on product selectivities, the presence of an acid site during selective hydrogenolysis on $\mathrm{ReO}_{\mathrm{x}}$-promoted $\mathrm{Rh}$. A simple model for the acid site was tested for its acidity and activity.

\section{2 : Acidity of Hydroxides on Alloys of Noble Metals and Oxophilic Oxide Promoters}

such as $\mathrm{Rh}-\mathrm{Re} \mathrm{O}_{\mathrm{x}}$

In a follow-up study, the acidity of a range of alloys was further investigated to explore other experimentallystudied catalysts (such as $\mathrm{Pt}-\mathrm{ReO}_{\mathrm{x}}$ ) and to find candidates for further experimental research (such as $\mathrm{Au}-\mathrm{ReO}_{\mathrm{x}}$ )

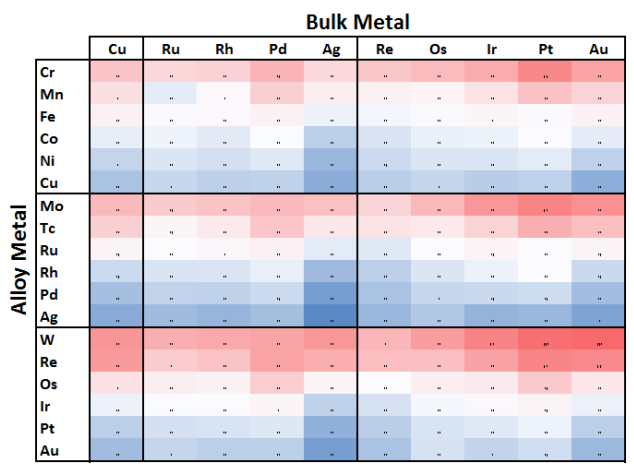




\section{1 - Selective Hydrogenolysis of Polyols and Cyclic Ethers over Bifunctional Surface}

\section{Sites on Rhodium-Rhenium Catalysts}

[ Adopted from: M. Chia, Y. J. Pagan-Torres, D. D. Hibbitts, Q. Tan, H. N. Pham, A. K. Datye, M. Neurock, R. J. Davis, J. A. Dumesic. Journal of the American Chemical Society. 2011. 133. 12675. ]

Overview

$\mathrm{A} \mathrm{ReO}_{\mathrm{x}}$-promoted $\mathrm{Rh} / \mathrm{C}$ catalyst is shown to be selective in the hydrogenolysis of secondary C-O bonds for a broad range of cyclic ethers and polyols, these being important classes of compounds in biomass-derived feedstocks. Experimentally-observed reactivity trends, $\mathrm{NH}_{3}$ temperatureprogrammed desorption (TPD) profiles, and results from theoretical calculations based on density functional theory (DFT) are consistent with the hypothesis of a bifunctional catalyst that facilitates selective hydrogenolysis of $\mathrm{C}-\mathrm{O}$ bonds by acid-catalyzed ring-opening and dehydration reactions coupled with metal-catalyzed hydrogenation. Results from DFT calculations suggest that hydroxyl groups on Re atoms associated with $\mathrm{Rh}$ are acidic, due to the strong binding of oxygen atoms to Re, and these groups are likely responsible for proton donation leading to the formation of carbenium ion transition states. Accordingly, the observed reactivity trends are consistent with the stability of the resulting carbenium ion structures that form upon ring-opening or dehydration. The presence of hydroxyl groups that reside $\alpha$-to the carbon in the C-O bond undergoing scission can form oxocarbenium ion intermediates that significantly stabilize the resulting transition states. The mechanistic insights from this work may be extended to provide a general description of a new class of bifunctional heterogeneous catalysts, based on the combination of a highly reducible metal with an oxophilic metal, for the selective C-O hydrogenolysis of biomass-derived feedstocks.

\section{Description of Theoretical Efforts}

If we examine the ring-opening of HMTHF, which was one of the main cyclic ethers studied by the Dumesic group experimentally, we observe that in the presence of the ReOx promoter, the selectivity shifts to the activation of the ring at the substituted carbon, which is in line with the well- 
known stability of carbenium ions (secondary 》 primary). However, the hydroxyl group present on HMTHF had a major impact on both the selectivity and activity of the reaction: when MTHF was run, the selectivity proceeded over the unsubstituted carbon at a much slower rate as shown in Table 4.1. For this to occur, it's clear that there must be a direct role of the $-\mathrm{OH}$ group of HMTHF in the transition state of the rate-limiting-step of this reaction. If this reaction is acid-catalyzed, the ratelimiting-step is most likely the formation of the carbenium ion so Dr. Neurock and I ran a series of calculations (in two different DFT codes) on the stabilities of various forms of carbenium intermediates that may exist upon the ring opening of HMTHF and other compounds studied by the Dumesic group as shown in Figure 4.1 (modified from the JACS publication). These calculations demonstrated that the formation energy of the secondary carbenium ion of MTHF was $-743 \mathrm{~kJ} / \mathrm{mol}$ (not shown), whereas the formation energy of the secondary carbenium ion of HMTHF was -760 $\mathrm{kJ} / \mathrm{mol}$, indicating that the presence of the hydroxyl does have an impact on the stability of the carbenium. Furthermore, if the hydroxyl moves to form a three-member oxirane ring, the formation energy further decreases to $-763 \mathrm{~kJ} / \mathrm{mol}$. Lastly, if the carbenium ion undergoes a hydride transfer from the C6 to the C5 position, a primary oxocarbenium ion is formed (which is a protonated aldehyde) with a formation energy of $-852 \mathrm{~kJ} / \mathrm{mol}$. This hydride transfer mechanism would not occur on MTHF, as it would result in a primary carbenium ion with a lower formation energy $(-731 \mathrm{~kJ} / \mathrm{mol})$. This also cannot occur at the unsubstituted ring-opening site of HMTHF, which leads to a primary carbenium ion with a formation energy of $-730 \mathrm{~kJ} / \mathrm{mol}$.

Table 4.1. Hydrogenolysis of HMTHF and MTHF over Rh-ReOx/C (1:0.5)

\begin{tabular}{|c|c|c|c|c|c|}
\hline \multicolumn{2}{|c|}{ Reactant } & \multirow{2}{*}{$\begin{array}{c}\text { Conversion } \\
(\%)\end{array}$} & \multicolumn{2}{|c|}{ Product Selectivity } & \multirow{2}{*}{$\begin{array}{l}\text { Specific Rate } \\
\left(\text { (umolg }^{-1} \text { min }^{-1}\right)\end{array}$} \\
\hline Structure & Name & & Compound & $(\%)$ & \\
\hline & HMTHF & 47.2 & $\begin{array}{c}1,5- \\
\text { pentanediol }\end{array}$ & 97.2 & 180 \\
\hline & & & 1-pentanediol & 2.8 & \\
\hline & MTHF & 1.4 & 2-pentanol & $>99.9$ & 7 \\
\hline
\end{tabular}




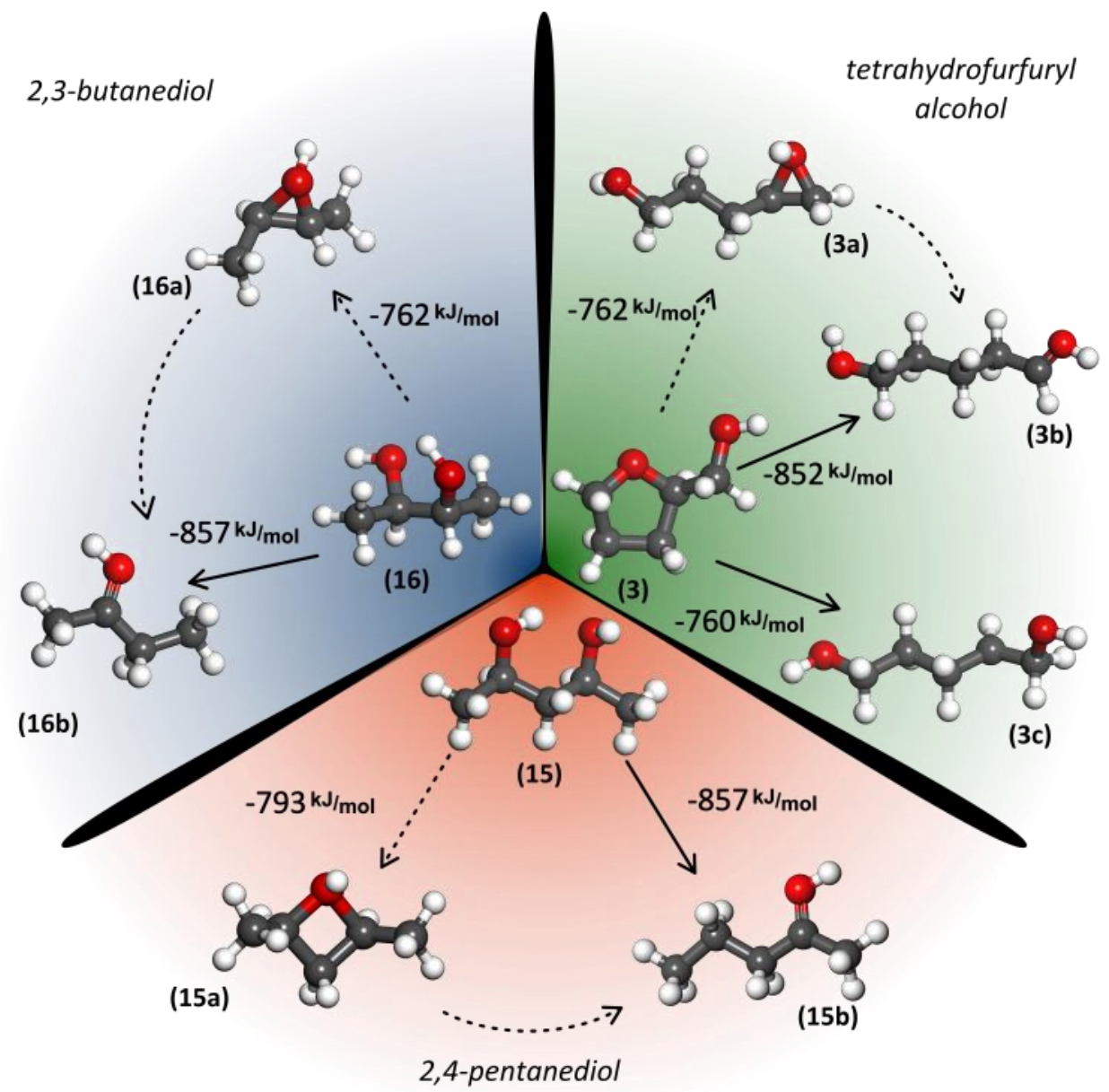

Figure 4.1. DFT-calculated carbenium and oxocarbenium ion formation or reaction energies for 2,3butanediol, 2,4-pentanediol, and MTHF.

It appears that the DFT-calculated carbenium and oxocarbenium stabilities predict the selectivity of HMTHF and other molecules studied. In fact, if the natural log of the rate, normalized by concentration, is plotted for the series of acid-catalyzed ring-opening and dehydration reactions reported by the Dumesic group, we see a correlation between the most stable form of the ionic intermediate as calculated by DFT as shown in Figure 4.2. 


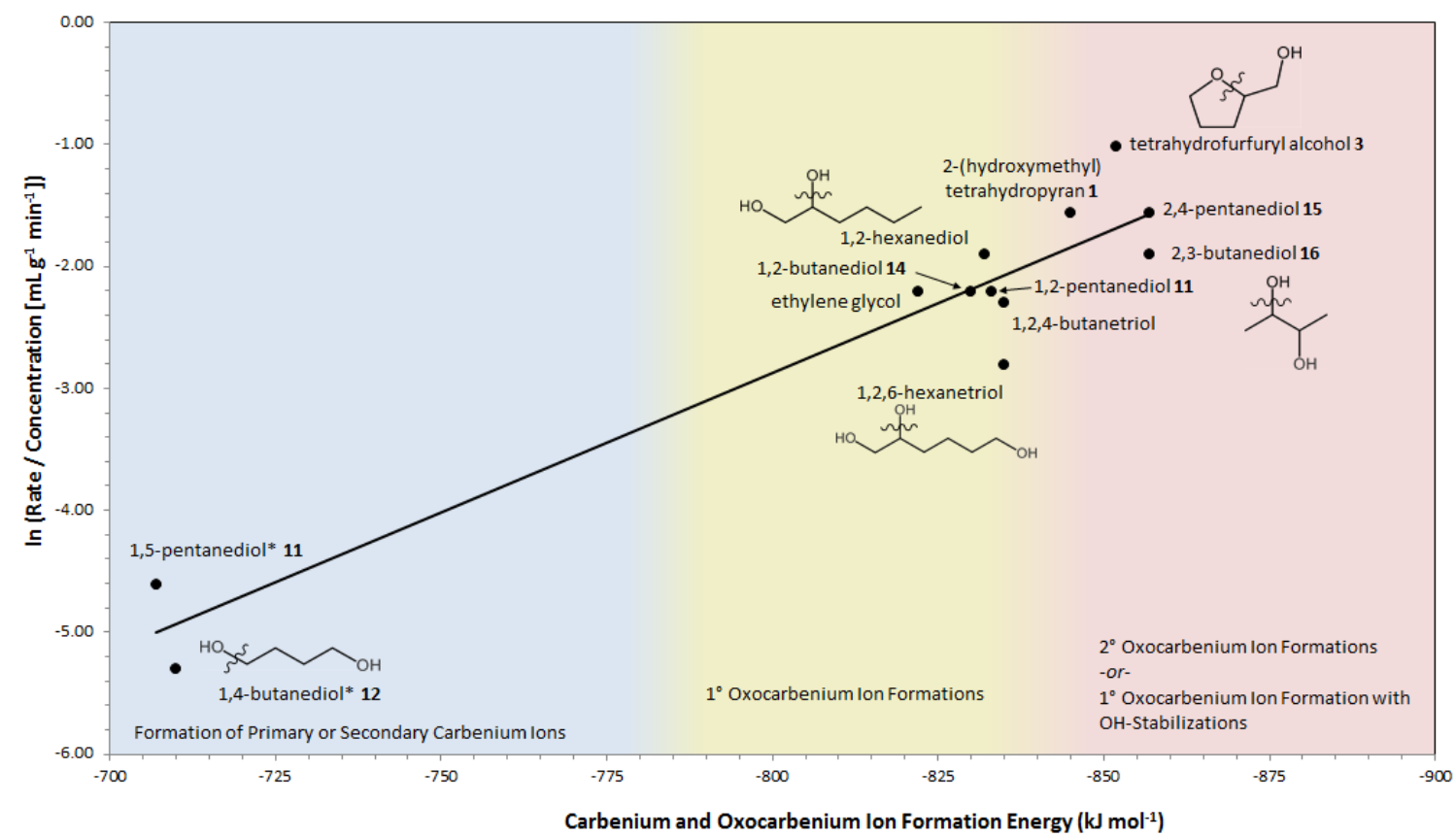

Figure 4.2. Comparison of the ratio between specific reaction rate $\left(\mu \mathrm{mol} \mathrm{g}^{-1} \mathrm{~min}^{-1}\right)$ and initial reactant concentration ( $\mu \mathrm{mol} \mathrm{mL}-1$ ) (on a logarithmic scale) and DFT-calculated carbenium and oxocarbenium ion energies.

In order to test the ability of hydroxide bound to an oxophilic metal to provide a Brønsted acid site, the deprotonation energy of a simple model, in which a single oxophilic metal is in the surface of a noble metal nanoparticle, was calculated. The results, shown in Figure 4.3, demonstrate that $\mathrm{OH}^{*}$ bound to $\mathrm{Re}$ or $\mathrm{Mo}$ in a Pt or $\mathrm{Rh}$ nanoparticle gives deportation energies $<12$, similar to heteropolyacids and zeolites, and significantly more acidic than $\mathrm{OH}^{*}$ on the pure Pt or Rh particles. These calculations also demonstrate that the acidity correlates with the binding energy of $0^{*}$, which indicates that as the $\mathrm{M}-\mathrm{O}$ bond increases in strength, the $\mathrm{O}-\mathrm{H}$ bond becomes weaker and more acidic, consistent with bond-order conservation principles. 


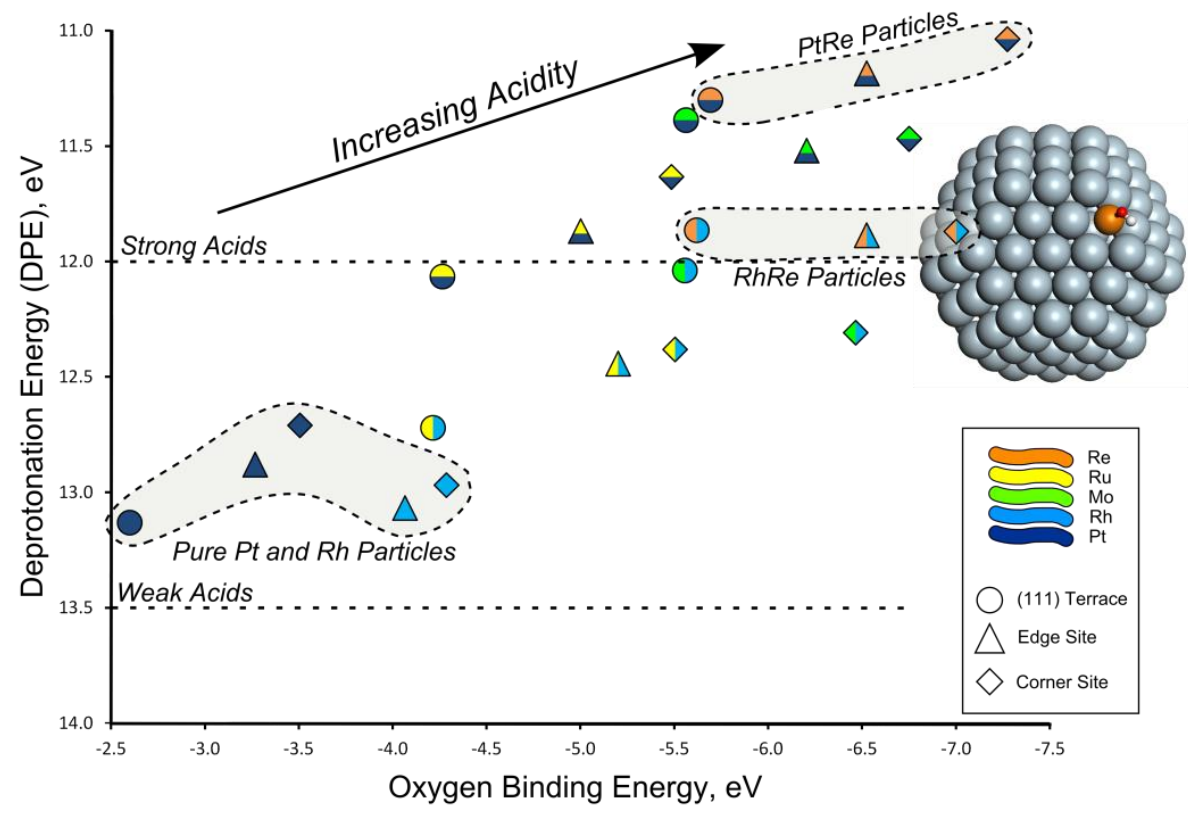

Figure 4.3. Acidity of hydroxide bound to nanoparticles of bimetallic alloys.

This work demonstrates a plausible active site and mechanism for the selective hydrogenolysis of these compounds. To combine these two approaches and confirm the predicted trends, Qiaohua Tan of the Neurock group ran ring-opening reactions of HMTHF and MTHF over a RhRe_201 nanoparticle and used different methods for stabilizing the carbenium ion as guided by Dr. Neurock and myself. His results indicate for MTHF (in which there is no $-\mathrm{OH}$ to stabilize the transition state), the activation barrier for the ring opening reaction is $118 \mathrm{~kJ} / \mathrm{mol}$. For HMTHF, there is some formation of a three-member oxirane structure (although it has not fully formed), which lowers the barrier to $110 \mathrm{~kJ} / \mathrm{mol}$. With a single water molecule present to hydrogen bond to the $-\mathrm{OH}$ as its stabilizing the carbenium ion, the barrier further decreases to $104 \mathrm{~kJ} / \mathrm{mol}$. However, the hydride-transfer mechanism which forms the very stable oxocarbenium ion has a much lower barrier $(84 \mathrm{~kJ} / \mathrm{mol}$ ) as shown in Figure 4.4. During the transition state (modeled with two water molecules on a $\operatorname{ReRh}(111)$ surface, both waters shift to stabilize the hydride transfer as well as the terminal $\mathrm{OH}$ group. 


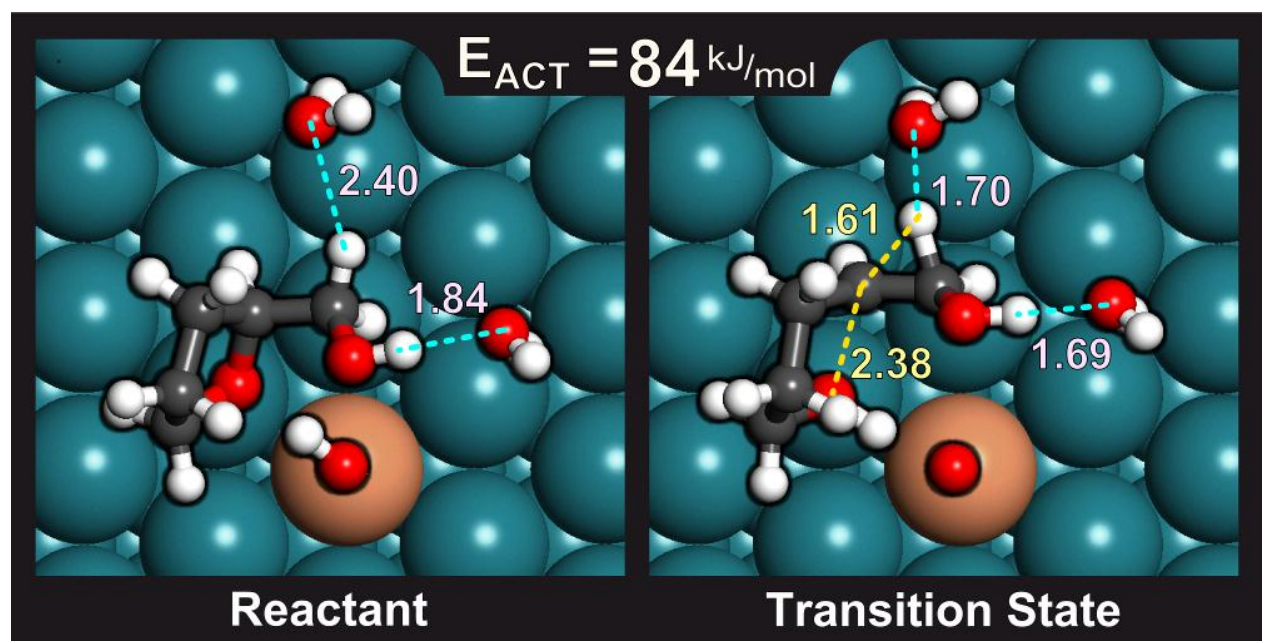

Figure 4.4. DFT-calculated reactant and transition state structures for the concerted protonation, hydride transfer and ring-opening of the water-stabilized HMTHF over a model Rh(111) surface with well dispersed Re-OH sites. 


\section{2 - Acidity of Hydroxides on Alloys of Noble Metals and Oxophilic Oxide Promoters}

such as $\mathrm{Rh}-\mathrm{ReOx}$

\section{Introduction}

Biomass-derived fuels and chemicals offer a sustainable alternative to petroleum. Feedstocks from biomass are typically sugar alcohols high in oxygen content, which is unsuitable for fuels and many chemicals. To remove oxygen, catalytic processes such as decarboxylation, decarbonylation, and hydrogenolysis can selectively produce value-added chemicals and increase the $\mathrm{H} / \mathrm{C}$ ratio for fuels production. ${ }^{86-88}$ Among these, hydrogenolysis has the distinct advantage of maintaining the chain length of the substrate.

Various biomass-derived feedstocks have been targeted by recent literature for hydrogenolysis, including glycerol, a polyol byproduct of biodiesel production. ${ }^{86}$ Glycerol hydrogenolysis has been shown to be active ${ }^{161}$ on Raney $\mathrm{Ni}$ and Cu catalysts ${ }^{162}$ as well as on supported metal catalysts, such as $\mathrm{Ru}{ }^{162-165}$, Pd 162,166, $\mathrm{Pt}$ 162,164,167, $\mathrm{Rh}$ 166,168, as well as PtRu and AuRu 164 alloys at temperatures of near $473 \mathrm{~K}$ under moderate pressures of hydrogen as a co-reactant (14100 bar). Under these conditions, the observed products include methane, ethylene glycol, and 1,2propanediol (1,2-PrDO), also known as propylene glycol, a medium-value commodity chemical often used as a non-toxic antifreeze. ${ }^{161}$ The selectivity patterns differ among the aforementioned catalysts: $\mathrm{Ru}$ is known for its ability to perform C-C hydrogenolysis, thus it generates mostly ethylene glycol at low rates of conversion, which further reacts to form methane. ${ }^{162,164}$ On the other hand, carbonsupported Pt, Pd and Rh has shown initial 1,2-PrDO selectivity near $80 \% 162,164,166,167$, although the rate is slower than $\mathrm{Ru}$ catalysts. For $\mathrm{Rh} / \mathrm{C}$ operating at a lower temperature (393 K), C-C hydrogenolysis is suppressed and the product distribution is $18 \% 1,2-\operatorname{PrDO}, 5 \% 1,3-P D O, 8 \% 1$ propanol (1-PrOH) and 69\% 1-propanol (1-PrOH). ${ }^{169}$ As shown in Figure 4.5, the product selectivities reported indicate that the initial hydrogenolysis of glycerol occurs at the primary alcohol group, the less-substituted carbon. Very little or no 1,3-PrDO is reported for any of the catalysts discussed thus far. 


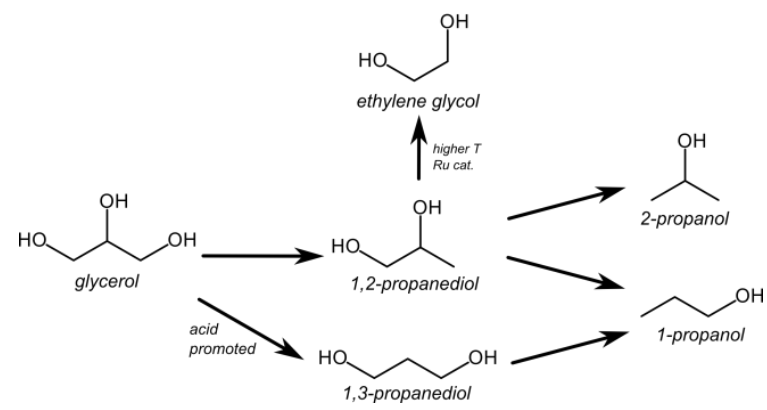

Figure 4.5. Reaction network of glycerol hydrogenolysis.

Cyclic ethers, like polyols, can also be produced from biorenewable resources. 87,170 Therefore, another form of $\mathrm{C}-\mathrm{O}$ activation, ring-opening hydrogenolysis, is important for the conversion of bio-mass derived feedstocks into value-added chemicals. Among ring-ethers, five- and six-member rings are the most feasible feedstocks produced from biomass, such as those shown in Figure 4.6. Recently, Chia, et al. studied $\mathrm{Rh} / \mathrm{C}$ catalyzed hydrogenolysis of 2(hydroxymethyl)tetrahydropyran (HMTHP) and 2-(hydroxymethyl)tetrahydrofuran (HMTHF, also known as tetrahydrofurfural alcohol, THFA) and found a mixture of ring opening at the substituted and unsubstituted carbon site: HMTHP was converted to 44\% 1,6-hexanediol (1,6-HxDO), 11\% 1,2hexanediol (1,2-HxDO) and 43\% alkanes; $H M T H F$ was converted to 59\% 1,6-pentanediol (1,6-PeDO), 21\% 1,2-hexanediol (1,2-PeDO) and 17\% 1- and 2-pentanols. ${ }^{169}$ However, work over $\mathrm{Rh} / \mathrm{SiO}_{2}$ has indicated that $\mathrm{C}-\mathrm{O}$ hydrogenolysis occurs more selectively at the unsubstituted carbon of the ringether, forming 1,2-PeDO from $H M T H F$ at $>60 \%$ selectivity. ${ }^{171}$ Without the alcohol group on methyl substituent, the ring-opening of $M T H P$ and $M T H F$ occurs exclusively at the less-substituted carbon on $\mathrm{Rh} / \mathrm{SiO}_{2}{ }^{172}$ and $\mathrm{Pt} / \mathrm{C}{ }^{173}$ to form 2-hexanol and 2-pentanol. Finally, the ring-opening hydrogenolysis of the unsubstituted ring-ether, $T H F$, formed 1-butanol ${ }^{171}$ at low temperatures on $\mathrm{Rh} / \mathrm{SiO}_{2}$ and at higher temperatures on supported Pt it forms a mixture of butanol, butane and propane. ${ }^{174}$ So, similarly to the case of polyols previously reported, it appears that ring-opening hydrogenolysis on supported metal catalysts favors activation at the less-substituted carbon, although the presence of alcohols substituents shifts that preference. 


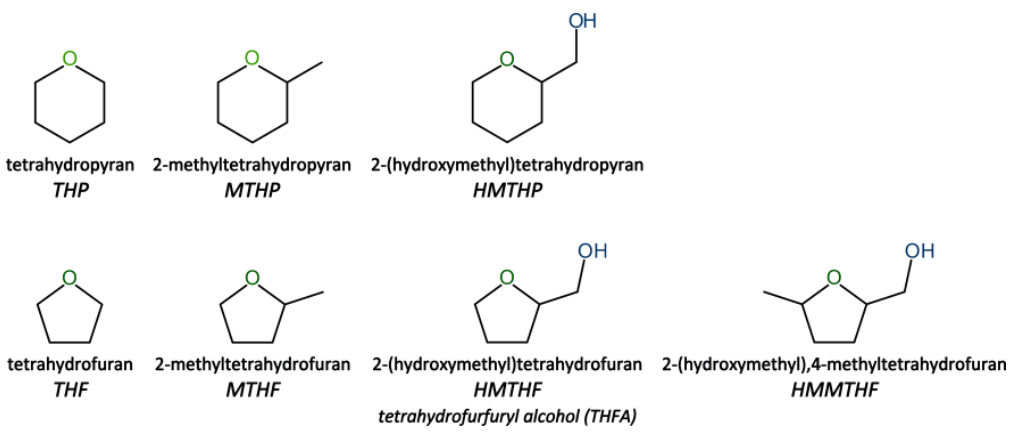

Figure 4.6. Commonly studied ring ethers for ring-opening hydrogenolysis.

In addition to these unpromoted cases, studies have been presented with supported noble metal catalysts such as $\mathrm{Rh}$, Pt and Ir promoted by acidic species such as amberlyst ${ }^{175-177}, \mathrm{H}_{2} \mathrm{SO}_{4}$ 172,178, $\mathrm{H}_{2} \mathrm{WO}_{4} 166,176, \mathrm{H}_{4} \mathrm{SiW}_{12} \mathrm{O}_{40}{ }^{179}$ and alloyed with partially reduced oxides such as $\mathrm{MoO}_{\mathrm{x}}$ $168,169,180,181, \mathrm{WO}_{\mathrm{x}} 168,180$, and most notably, $\mathrm{ReO}_{\mathrm{x}}{ }^{168,171,178,180-183}$ These promoted catalysts display distinctly different trends in selectivity, most notably for the substituted ring ethers, HMTHP and HMTHF, which now convert with high selectivity to the their $\alpha, \omega$-diols: $1,5-P e D O$ and 1,6HxDO. 169,171,180,181 For glycerol, these promoters result in an increase in selectivity to 1,3-PrDO $167-$ $169,178,183$, only observed in small quantities on the unpromoted catalysts. Both of these shifts indicate that the promoters are enhancing C-O hydrogenolysis at the more-substituted carbon. That, along with the fact that these promoters are acidic or partially reduced solid acids indicates that the selectivity-controlling step may involve the formation of a carbocation species from an acid site at the catalyst-solution interface. In addition to the shifts in selectivity, the activity was also greatly increased by the presence of these promoters, indicating that the selectivity-controlling step is also rate-limiting, also indicative of acid-catalyzed chemistry.

Beyond glycerol and the ring ethers previously discussed, Chia, et al. studied a large range polyols over $\mathrm{ReO}_{\mathrm{x}}$-promoted $\mathrm{Rh} / \mathrm{C}:$ 1,2,6-hexanetriol, 1,6-hexanediol, 1,2-hexanediol, 1,5pentanediol, 1,2-pentanediol, 2,4-pentanediol, 1,2,4-butanetriol, 1,4-butanediol, 1,2-butanediol, and 2,3-butanediol. ${ }^{169}$ When present, hydrogenolysis of secondary alcohols groups was selectively active and the species without secondary alcohol groups had much lower activity. Following this study, 
Koso, et al. presented many of the same polyols studied on $\mathrm{ReO}_{\mathrm{x}}$ and $\mathrm{MoO}_{\mathrm{x}}$-promoted $\mathrm{Rh} / \mathrm{SiO}_{2}$, similar results were observed. ${ }^{181}$

The nature of the acid site is unknown; however, when a $\mathrm{Rh} / \mathrm{C}$ catalyst is operated with $\mathrm{H}_{2} \mathrm{SO}_{4}$ or $\mathrm{HCl}$ present, the homogeneous acid promoters are much less active and selective than alloying with partially reduced oxides, indicating that it's likely a solid acid site. ${ }^{169}$ Ammonia TPD offers experimental evidence of acid sites on $\mathrm{ReO}_{\mathrm{x}}$-promoted $\mathrm{Rh} / \mathrm{C}$ and indicates that (for that system) the ratio of acid to metal sites is 0.28 with an $\mathrm{NH}_{3}$ adsorption energy of $-100 \mathrm{~kJ} / \mathrm{mol}$ to the acid site, indicating a moderate acid site. ${ }^{169}$ In addition to this data, EXAFS has been performed on a number of these alloys, including $\mathrm{Rh}-\mathrm{ReO}_{\mathrm{x}} 168,171,181,184, \mathrm{Rh}-\mathrm{MoO}_{\mathrm{x}} 181, \mathrm{Pt}-\mathrm{ReO}_{\mathrm{x}} 167,185$, and most recently, Ir- $\mathrm{ReO}_{\mathrm{x}}{ }^{178}$ The curve-fitting results from these studies can offer insights into the nature of the alloy and therefore the acid site. However, as these results are averaged across the entire system, it is difficult to determine whether the results are indicative of the alloy sites, or an average between alloy sites and segregated oxides on the $\mathrm{SiO}_{2}$ or $\mathrm{C}$ support. Furthermore, uncertainties in coordination number can be as high as 1 , further complicating the conclusions one can draw.

As previously reported, ${ }^{169}$ density functional theory (DFT) can provide a method to test the acidity of possible acid sites on wide range of alloy materials. In that work, the deprotonation energy (DPE) was used as a direct measure of acidity on hydroxylated Re in the surface of Rh and Pt nanoparticles (as well as other alloys). The results indicated a DPE $<12$, similar to values measured for heteropolyacids (HPAs) such as the aforementioned $\mathrm{H}_{4} \mathrm{SiW}_{12} \mathrm{O}_{40},{ }^{179,186}$ and much more acidic than hydroxide on a pure Rh or Pt nanoparticle $(\sim 13)$ due to the strength of the Re-O bond. In this work, we seek to extend that study; examining a wider range of alloy systems and acid sites and determining the impact of the $\mathrm{O}-\mathrm{H}$ bond strength and electron affinity of the conjugate base. Furthermore, we seek to determine how DPE compares with experimentally-relevant measurements such as $\mathrm{NH}_{3}$ adsorption strength. 


\section{Computational Methodology}

First-principle density functional theory (DFT) calculations were carried out using the Vienna ab initio simulation package (VASP). ${ }^{187-189}$ The planewaves were constructed with an energy cutoff of $396 \mathrm{eV}$ and Vanderbilt ultrasoft pseudopotentials with real space projection operators defining the features of the core region. The correlation and exchange energies were obtained using the Perdew-Wang 91 (PW91) form of the generalized gradient approximation (GGA). ${ }^{13}$

Vacuum-cell calculations (for binding energy calculations) were performed spin-polarized using an 18x18x18 Å unit cell. Calculations on the metal clusters were carried on non-spin-polarized in a cubic unit cell with a minimum of $12 \AA$ of vacuum separating clusters between periodic cells. A relaxation was performed until the maximum force upon any atom was less than $0.05 \mathrm{eV} / \AA \AA$; the forces were obtained using a fast Fourier transform (FFT) grid with a cutoff of twice the planewave cutoff; the wavefunctions were converged to within $10^{-6} \mathrm{eV}$. These calculations were performed using the $\gamma$-point version of VASP. The dipole moments of the cell were calculated and used to correct the energy, for charged calculations quadrupole corrections were also applied.

The deprotonation energy (DPE) was defined as the energy between the heterolytically cleaved state and bound state of the MOH species (Equation 4.1). The dehydrogenation energy (DHE) was defined as the energy between the homolytically cleaved state and the bound state of the MOH species (Equation 4.2). The electron affinity of the conjugate base (eAff) was the difference between the charged and neutral calculation of the MO site (Equation 4.3). Rearrangement of Equations 4.1-3 demonstrates the relationship between DPE, DHE and eAff (Equation 4.4). The binding energy of $\mathrm{NH}_{3}$ was calculated as the difference between the bound state and the MOH cluster plus the energy of $\mathrm{NH}_{3}$ in a vacuum cell (Equation 4.5). The binding energy of $\mathrm{O}^{*}$ and $\mathrm{OH}^{*}$ were the calculated as the difference between the bound state and the metal cluster plus the energy of the $\mathrm{O}$ or $\mathrm{OH}$ radical in a vacuum cell (Equations 4.6-7). The conventions set herein indicate that a lower DPE will be more acidic, a lower DHE will indicate a weaker $\mathrm{O}-\mathrm{H}$ bond, and lower (more negative) $\mathrm{NH}_{3}, \mathrm{O}^{*}$ and $\mathrm{OH}^{*}$ binding energies indicate stronger adsorption strengths. 


$$
\begin{aligned}
& \mathrm{DPE}=E\left[\mathrm{MO}^{-}\right]+E\left[\mathrm{H}^{+}\right]-E[\mathrm{MOH}] \\
& \mathrm{DHE}=E[\mathrm{MO}]+E[\mathrm{H}]-E[\mathrm{MOH}] \\
& \mathrm{eAff}=E\left[\mathrm{MO}^{-}\right]-E[\mathrm{MO}] \\
& \mathrm{DPE}=\mathrm{DHE}+\mathrm{eAff}+\left(E\left[\mathrm{H}^{+}\right]-E[\mathrm{H}]\right) \\
& \mathrm{NH}_{3} \mathrm{BE}=E\left[\mathrm{MOH}-\mathrm{NH}_{3}\right]-E[\mathrm{MOH}]-E\left[\mathrm{NH}_{3}\right] \\
& \mathrm{O} \mathrm{BE}=E[\mathrm{MO}]-E[\mathrm{M}]-E[\mathrm{O}] \\
& \mathrm{OH} \mathrm{BE}=E[\mathrm{MOH}]-E[\mathrm{M}]-E[\mathrm{OH}]
\end{aligned}
$$

\section{Results and Discussion}

Figure 4.7 shows the results of a survey of 180 bimetallic alloys involving the insertion of an alloy metal into the surface of a 'bulk' hydrogenation catalyst. The alloy metals studied include groups 6-11, periods 4-6 of the periodic table and the bulk metals studied were $\mathrm{Cu}, \mathrm{Ru}, \mathrm{Rh}, \mathrm{Pd}, \mathrm{Ag}, \mathrm{Re}$, Os, Ir, Pt and Au. The heatmap shows the DHE of each of these alloys, with red boxes indicating a weaker (more likely to be acidic) $\mathrm{O}-\mathrm{H}$ bond and blue boxes indicating a stronger bond. Its neighboring plot (Figure 4.7-Right) shows the $\mathrm{NH}_{3} \mathrm{BE}$, a commonly used experimental probe of Brønsted acidity, with stronger binding energies indicating a stronger acid.
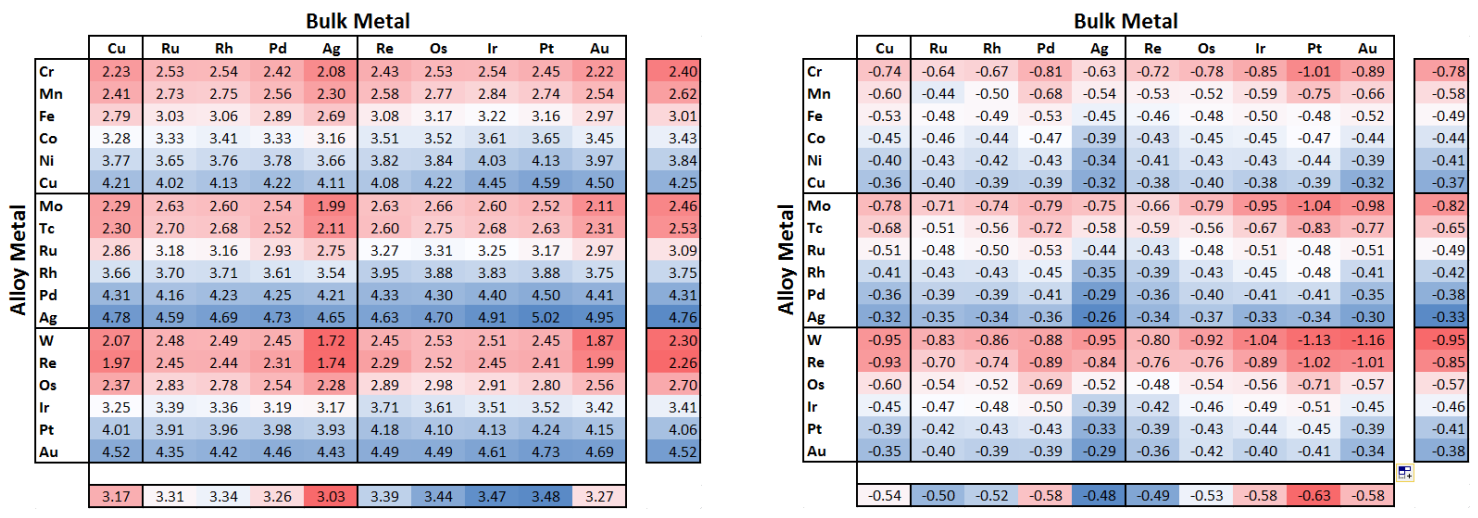

Figure 4.7. (Left) A heatmap of the dehydrogenation energies (DHEs) of hydroxide bound atop on a survey of bimetallic metal alloys. (Right) A similar heatmap showing the binding energy of $\mathrm{NH}_{3}$ to hydroxide bound atop the same set of alloys. 
The DHE of the hydroxide becomes weaker as you change the alloy metal from right-to-left on the periodic table; oxophilic metals such as $\mathrm{W}, \mathrm{Re}, \mathrm{Cr}, \mathrm{Mn}$ and Mo lead to the weakest $\mathrm{O}-\mathrm{H}$ bonds. This is consistent with previous results which indicate that as you increase the $\mathrm{M}_{1}-\mathrm{O}$ bond strength, the $\mathrm{O}-\mathrm{H}$ bond strength decreases through bond order conservation principles. ${ }^{20,21}$ As you change the alloy metal, the opposite is true, elements from the right side of the transition metal block give the desired weak $\mathrm{O}-\mathrm{H}$ bond strengths. This can also be related to bond order conservation, as the interaction between the alloy metal $\left(M_{1}\right)$ and the bulk metal $\left(M_{2}\right)$ weakens, due to the increased nobility of the bulk metal, the bond strength between the alloy metal and oxygen must increase, thus weakening the $\mathrm{O}-\mathrm{H}$ bond strength. These two trends combine to predict that alloys such as Re and W in a $\mathrm{Ag}$ surface give $\mathrm{O}-\mathrm{H}$ bond strengths of $\sim 1.7 \mathrm{eV}$, nearly $3 \mathrm{eV}$ weaker than the $\mathrm{O}-\mathrm{H}$ bond strength on pure $\mathrm{Ag}$ (or pure $\mathrm{Au}$ ).

The $\mathrm{NH}_{3} \mathrm{BE}$ shows a similar, yet distinct, trend. Once again, oxophilic metal promoters are desirable; however group 11 does not give the highest $\mathrm{NH}_{3}$ BEs, instead there is a drop-off between the $\mathrm{NH}_{3} \mathrm{BE}$ on group 10 metals and group 11, most likely due to the increased electron affinity of group 10 metals over group 11 metals. The results indicate that promoted Pt (not Ag) will give the best results, with promoted $\mathrm{Cu}, \mathrm{Rh}, \mathrm{Pd}$, $\mathrm{Ir}$ and $\mathrm{Au}$ yielding $\mathrm{NH}_{3} \mathrm{BEs}$ stronger than $-0.8 \mathrm{eV}$ with oxophilic promoters. These plots, based on relatively simple DFT calculations, immediately identify many commonly studied catalyst systems, such as Re-, Mo- and W- promoted Pt, Rh, and Ir, many of which are further investigated in this work. It also identifies a long list of bimetallic alloys which have yet to be studied experimentally such as Re-promoted $\mathrm{Au}$ or $\mathrm{Cu}$ catalysts. Each possibly alloy combination will have synthesis challenges, as the partial reduction of the oxophilic promoter through the formation of M-M bonds is thought to be critical to the active sites of these catalysts.

Table 4.2 summarizes the results from in-surface monoalloy sites like the one shown in Figure 4.8. For two alloys Pt-Re and Rh-Re, the results are shown from five metal sites on a cubooctahedral nanoparticle, where the metal atom can be in a (111) terrace, a (100) terrace, an edge between two (111) surfaces (edge11), an edge between a (111) and (100) surface (edge10), and a corner site between one (100) and two (111) surfaces; these sites are highlighted in Figure 4.7. For 
the other alloys, only the site with the lowest DPE (most acidic) is shown, however all sites were calculated and their values are included in Figures 4.9-13. As shown, the DPE of the alloys range from 11.04 for $\mathrm{ReO}_{\mathrm{x}}$-promoted Pt and 14.04 for monometallic Au. As shown in Equation 4.4, the DPE of a system can be rewritten into the sum of three components, the DHE, eAff and the difference between the energy of a proton and a hydrogen atom, which is constant. Table 4.2 shows that the eAff depends only upon the 'bulk' metal and does not vary appreciably with site or composition of the alloyed element. This is a reflection of the fact that our calculation for electron affinity is a bulk measurement. However, during catalytic processes, it is possible that the relevant measurement may be are more localized eAff. The other component, DHE, depends upon the site and alloy composition. Since eAff is constant for each 'bulk' metal, it is clear that there is a linear relationship between DHE and DPE, as shown in Figure 4.9, with slopes of 1 and a y-intercept dependent upon the eAff. A site with a low DHE is clearly desired, this indicates a weakly bound hydroxyl and a strongly bound oxygen atom at that site, toward the lower-right of Figure 4.10. 
Table 4.2. Selected results from surface monoalloy sites.

\begin{tabular}{|c|c|c|c|c|c|c|c|c|c|c|c|c|}
\hline \multirow[b]{2}{*}{ Bulk } & \multirow[b]{2}{*}{ Alloy } & \multirow[b]{2}{*}{ Site } & \multirow[b]{2}{*}{ CN } & \multirow[b]{2}{*}{$\begin{array}{c}\boldsymbol{O}^{*} \\
\boldsymbol{B E}\end{array}$} & \multirow[b]{2}{*}{$\begin{array}{c}O H^{*} \\
B E\end{array}$} & \multirow[b]{2}{*}{$\begin{array}{c}\mathrm{NH}_{3} \\
\mathrm{BE} \\
\end{array}$} & \multirow[b]{2}{*}{ DHE } & \multirow[b]{2}{*}{ eAff } & \multirow[b]{2}{*}{$D P E$} & \multicolumn{3}{|c|}{$\begin{array}{l}\mathrm{MOH}-\mathrm{NH}_{3} \\
\text { Geometry }\end{array}$} \\
\hline & & & & & & & & & & $\begin{array}{c}M-O \\
\AA \\
\end{array}$ & $\begin{array}{c}O-H \\
\AA\end{array}$ & $\begin{array}{c}\mathrm{H}-\mathrm{N} \\
\stackrel{\AA}{A} \\
\end{array}$ \\
\hline \multirow[t]{9}{*}{ Pt } & $\mathbf{P t}$ & corner & 6 & -3.51 & -2.67 & -0.39 & 3.77 & -4.71 & 12.71 & 1.92 & 1.02 & 1.67 \\
\hline & Mo & 111 terrace & 9 & -5.56 & -3.37 & -0.96 & 2.42 & -4.68 & 11.39 & 1.76 & 1.49 & 1.10 \\
\hline & $\mathbf{R u}$ & corner & 6 & -5.48 & -3.56 & -0.61 & 2.68 & -4.69 & 11.64 & 1.84 & 1.06 & 1.55 \\
\hline & $\mathbf{W}$ & 111 terrace & 9 & -5.98 & -3.73 & -1.07 & 2.36 & -4.68 & 11.33 & 1.75 & 1.50 & 1.09 \\
\hline & $\mathbf{R e}$ & 111 terrace & 9 & -5.67 & -3.41 & -0.89 & 2.35 & -4.69 & 11.30 & 1.76 & 1.50 & 1.09 \\
\hline & & 100 te & 8 & -5.81 & -3.69 & -0.90 & 2.49 & -4.67 & 11.47 & 1.78 & 1.52 & 1.09 \\
\hline & & edge11 & 7 & -6.53 & -4.15 & -0.96 & 2.23 & -4.69 & 11.19 & 1.77 & 1.44 & 1.11 \\
\hline & & edge10 & 7 & -6.65 & -4.31 & -1.11 & 2.27 & -4.68 & 11.24 & 1.76 & 1.50 & 1.09 \\
\hline & & corner & 6 & -7.27 & -4.75 & -1.04 & 2.08 & -4.69 & 11.04 & 1.76 & 1.45 & 1.11 \\
\hline \multirow[t]{9}{*}{$\mathbf{R h}$} & $\mathbf{R h}$ & corner & 6 & -4.29 & -3.07 & -0.33 & 3.39 & -4.07 & 12.97 & 1.90 & 1.02 & 1.72 \\
\hline & Mo & 111 terrace & 9 & -5.56 & -3.37 & -0.70 & 2.42 & -4.02 & 12.04 & 1.79 & 1.44 & 1.12 \\
\hline & $\mathbf{R u}$ & corner & 6 & -5.50 & -3.68 & -0.43 & 2.79 & -4.05 & 12.38 & 1.86 & 1.03 & 1.63 \\
\hline & $\mathbf{w}$ & 111 terrace & 9 & -5.97 & -3.69 & -0.82 & 2.32 & -4.03 & 11.94 & 1.77 & 1.47 & 1.11 \\
\hline & $\mathbf{R e}$ & 111 terrace & 9 & -5.62 & -3.26 & -0.54 & 2.24 & -4.02 & 11.87 & 1.85 & 1.13 & 1.40 \\
\hline & & 100 terrace & 8 & -5.76 & -3.62 & -0.50 & 2.46 & -4.02 & 12.09 & 1.88 & 1.05 & 1.61 \\
\hline & & edge11 & 7 & -6.33 & -4.00 & -0.71 & 2.27 & -4.04 & 11.87 & 1.78 & 1.54 & 1.09 \\
\hline & & edge10 & 7 & -6.53 & -4.20 & -0.67 & 2.28 & -4.03 & 11.89 & 1.83 & 1.12 & 1.42 \\
\hline & & corner & 6 & -7.00 & -4.67 & -0.68 & 2.28 & -4.05 & 11.87 & 1.81 & 1.11 & 1.40 \\
\hline \multirow[t]{5}{*}{ Ir } & Ir & corner & 6 & -5.09 & -3.44 & -0.55 & 2.95 & -4.48 & 12.12 & 1.88 & 1.04 & 1.60 \\
\hline & Mo & 111 terrace & 9 & -5.43 & -3.31 & -0.92 & 2.48 & -4.46 & 11.66 & 1.77 & 1.42 & 1.12 \\
\hline & $\mathbf{R u}$ & corner & 6 & -5.38 & -3.61 & -0.57 & 2.84 & -4.48 & 12.01 & 1.84 & 1.06 & 1.52 \\
\hline & $\mathbf{W}$ & 111 terrace & 9 & -5.90 & -3.67 & -1.06 & 2.38 & -4.47 & 11.55 & 1.75 & 1.49 & 1.10 \\
\hline & $\mathbf{R e}$ & 111 terrace & 9 & -5.46 & -3.11 & -0.97 & 2.25 & -4.46 & 11.44 & 1.74 & 1.54 & 1.08 \\
\hline \multirow[t]{4}{*}{$\mathbf{R u}$} & $\mathbf{R u}$ & corner & 6 & -5.45 & -3.69 & -0.43 & 2.85 & -3.85 & 12.65 & 1.88 & 1.01 & 1.79 \\
\hline & Mo & 111 terrace & 9 & -5.72 & -3.60 & -0.66 & 2.49 & -3.82 & 12.31 & 1.83 & 1.09 & 1.46 \\
\hline & W & 111 terrace & 9 & -6.19 & -3.92 & -0.79 & 2.33 & -3.82 & 12.15 & 1.77 & 1.46 & 1.11 \\
\hline & $\mathbf{R e}$ & 111 terrace & 9 & -5.72 & -3.30 & -0.75 & 2.19 & -3.82 & 12.02 & 1.76 & 1.49 & 1.10 \\
\hline \multirow[t]{5}{*}{$\mathbf{A u}$} & $\mathbf{A u}$ & corner & 6 & -2.07 & -2.08 & -0.25 & 4.61 & -4.27 & 13.99 & 2.02 & 1.00 & 1.83 \\
\hline & Mo & corner & 6 & -7.58 & -4.90 & -0.89 & 1.93 & -4.21 & 11.36 & 1.77 & 1.40 & 1.13 \\
\hline & $\mathbf{R u}$ & corner & 6 & -5.48 & -3.54 & -0.48 & 2.66 & -4.21 & 12.09 & 1.84 & 1.05 & 1.59 \\
\hline & W & edge10 & 7 & -7.40 & -4.50 & -1.08 & 1.70 & -4.22 & 11.12 & 1.74 & 1.48 & 1.11 \\
\hline & $\mathbf{R e}$ & corner & 6 & -7.71 & -4.78 & -0.99 & 1.68 & -4.21 & 11.11 & 1.74 & 1.47 & 1.10 \\
\hline
\end{tabular}




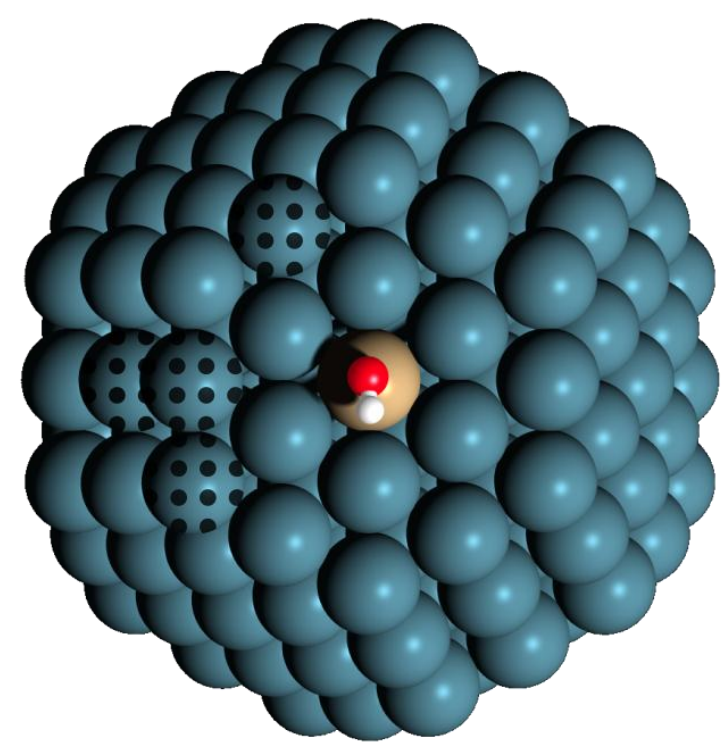

Figure 4.8. Hydroxylated (111) terrace surface monoalloy site. Dotted atoms represent the (100) terrace, edge11, edge10 and corner sites.

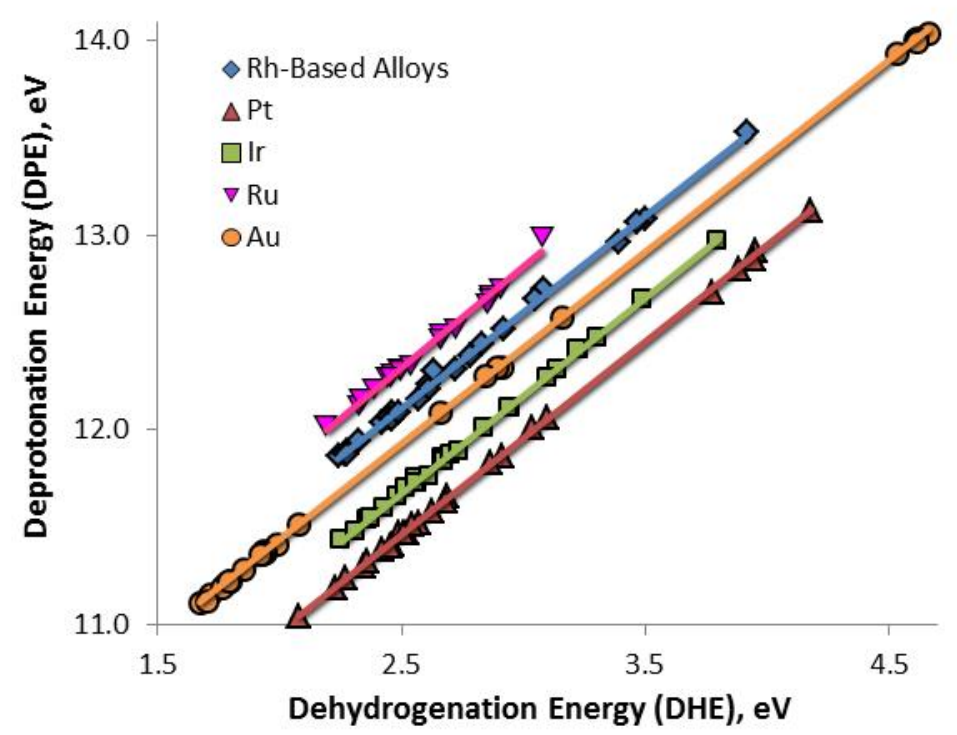

Figure 4.9. Relationship between DPE, DHE and the eAff of the bulk metal. DPE is linearly proportional to DHE with a slope of 1 and the y-intercept shifted by the eAff of the 'bulk' metal. 


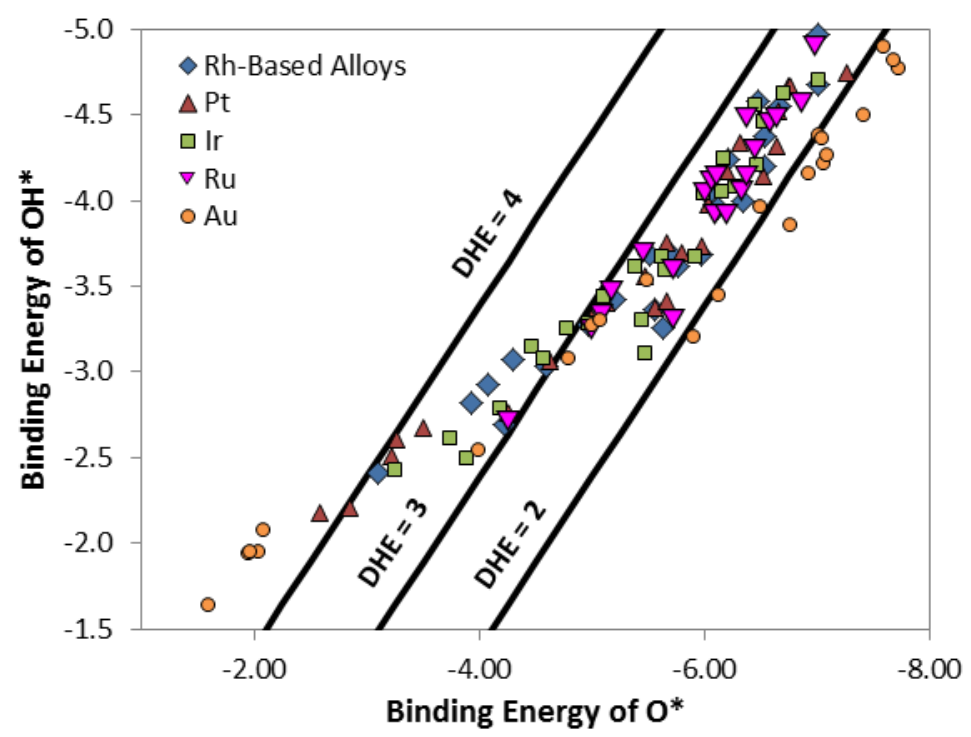

Figure 4.10. DHE shown as the relationship between the binding energy of $\mathrm{O}^{*}$ and $\mathrm{OH}^{*}$. As $\mathrm{O}^{*} \mathrm{BE}$ increases, so does $\mathrm{OH}^{*} \mathrm{BE}$, however, the slope is $<1$, indicating that stronger $0^{*}$ will have lower DHE, indicating weaker $\mathrm{O}-\mathrm{H}$ bonds.

As you decrease the coordination number of the metal atom, bond-order-conservation dictates that an increase in binding strength will be observed. For oxygen atoms, the increase in binding strength between edge $(\mathrm{CN}=7)$ and $(111)$ terrace $(\mathrm{CN}=9)$ sites ranges from 0.35 to $1.31 \mathrm{eV}$, with an average of $0.81 \mathrm{eV}$ across the systems studied. Corner $(\mathrm{CN}=6)$ sites show even stronger binding strength by an average of $1.29 \mathrm{eV}$ compared to terrace sites. For hydroxyl, similar increases in binding strength are observed; however, if the increase is equal in magnitude for both $\mathrm{O}^{*}$ and $\mathrm{OH}^{*}$ then there is no overall change in DHE. Comparing corner and (111) terrace sites, some systems undergo an increase in DHE while others undergo a decrease, ranging from $0.30 \mathrm{eV}$ stronger to 0.85 $\mathrm{eV}$ weaker, with an average of $0.13 \mathrm{eV}$.

Experimental results 169,180 have indicated that $\mathrm{ReO}_{\mathrm{x}}$-promoters are ideal when compared to $\mathrm{WO}_{\mathrm{x}}$ or $\mathrm{MoO}_{\mathrm{x}}$, our results here are consistent with those findings, with an average decrease in DPE (or DHE) of $1.69 \mathrm{eV}$, followed by $\mathrm{WO}_{\mathrm{x}}(1.56 \mathrm{eV})$ and $\mathrm{MoO}_{\mathrm{x}}(1.42 \mathrm{eV})$. However, experimental results also show that promoted $\mathrm{Rh}$ is significantly more active than promoted $\mathrm{Pt}$, followed by promoted 
Ir. ${ }^{167-169}$ These are inconsistent with our predictions of acidity, however, Figure 4 demonstrates that the increased acidity of Pt-based alloys as measured through DPE is merely a reflection of its greater electron affinity, as the strength of the $\mathrm{O}-\mathrm{H}$ bond on those systems is similar to promoted $\mathrm{Rh}$ and $\mathrm{Ir}$ alloys, and slightly stronger than promoted Au alloys. Since the increased electron affinity is a bulk measurement, it may not reflect catalytic behavior. Another cause for the discrepancy could be that the rate-limiting step in these systems is not related to the deprotonation of the solid acid; however, this is unlikely due to the observed trends in reactivity and selectivity, as described elsewhere. ${ }^{169}$ The third and most likely cause for this discrepancy is the due to the difficulty of quantifying the active sites of these catalysts. To date, only one study of these oxide-promoted metals has distinguished between the number of metal and acid sites in the system, and determined the strength of those acid sites, through ammonia TPD measurements on Re-promoted Rh systems. ${ }^{169}$ If these were performed on promoted Ir and Pt systems, it may reveal that these bimetallic acids produce dramatically fewer acid sites, resulting in decreased activity compared to promoted-Rh. Furthermore, it could provide an important comparison between their experimentally observed ammonia adsorption energy and DFT-calculated values reported herein.

In addition to the experimentally-used promoters of $\mathrm{ReOH}, \mathrm{MoOH}$ and $\mathrm{WOH}, \mathrm{RuOH}$ was also modeled. As stated previously, hydrogenolysis of polyols over supported Ru has been shown to be highly active, although it is unselective due to its affinity to break C-C bonds. ${ }^{162-164}$ While this behavior is undesired for selective processes meant to produce value-added chemicals, other processes, such as reforming or catalytic hydrocracking would benefit from this ability of Ru. For that purpose, an alloy which could utilize the hydrogenation abilities of Rh or Pt, coupled with the hydrocracking abilities of $\mathrm{Ru}$, could be improved if some of those Ru sites could remain partially oxidized with acidic character, similar to the other promoters studied. However, RuOH sites did not have as large an effect as the other promoters, only decreasing the DPE by an average of $0.65 \mathrm{eV}$ for Ir, Pt and Rh alloys. This results in DPE values of 11.62-12.72 (average: 12.19) which is not believed to be acidic enough to catalyze these reactions. Therefore, using $\mathrm{RuO}_{\mathrm{x}}$ as a promoter is unlikely to result in increased activity due to acid-catalyzed chemistry. Another approach would be to promote 
metallic Ru catalysts with $\mathrm{ReOx} / \mathrm{MoOx} /$ WOx. This would utilize the ability of metallic Ru sites to break C-C bonds, C-O bonds and hydrogenate fragments while providing oxidic sites which have demonstrated high activity at C-O hydrogenolysis through acid mechanisms.

In examining selectivity of glycerol hydrogenolysis reported in literature, it has been shown that ReOx-promoted Ir shows the highest selectivity to 1,3-PDO ( $>60 \%$ at low conversion) of the alloys studied in this work. ${ }^{183}$ This is compared to $\mathrm{ReO}_{\mathrm{x}}$-promoted Pt with a 1,3-PDO selectivity of 25$35 \% .{ }^{167}$ While this shift could be explained due to changes in acid strength since Pt alloys are predicted to be stronger than Ir alloys, which may open up additional routes, reducing selectivity, it is also possible that metal sites in the alloy are carrying out hydrogenolysis chemistry in addition to the solid acid alloy sites. This would significantly lower the selectivity over a metal such as Pt, which has shown activity for glycerol hydrogenolysis while unpromoted which leads predominantly to 1,2 $P D O$ and propanols while very little 1,3-PDO is observed. ${ }^{162,164,167}$ On Ir catalysts, however, glycerol hydrogenolysis has been shown to be not active ${ }^{178}$, meaning that during hydrogenolysis of $\mathrm{ReO}_{\mathrm{x}^{-}}$ promoted Ir, it is likely that only the acid sites are active, leading to higher selectivities.

Continuing with that trend, promoted Au catalysts may provide even greater selectivity. Au, due to the it's inert nature, will much more weakly interact with the alloyed species, which will cause that alloyed metal to interact more strongly with the oxygen of the hydroxide species, increasing the acidity. In fact, promoted-Au alloys show the weakest O-H bonds (lowest DHE) of any studied alloy. The eAff of Au systems is in between that of Rh and Ir, which leads to DPE values of 11.11-11.41 for the alloys with strong promoters ( $\mathrm{ReOH}, \mathrm{MoOH}$ and WOH). However, the weak interaction of Au with the alloying metals makes it unclear whether the synthesis of such alloys is feasible, furthermore, supported Au catalysts are typically synthesized through colloidal deposition whereas these other alloys are prepared via wetness impregnation. Furthermore, due to the noble nature of $\mathrm{Au}$, it is unclear whether it can carry out hydrogenation of the intermediates to complete the catalytic cycle.

The binding energy of ammonia ranges from $-1.11 \mathrm{eV}(107 \mathrm{~kJ} / \mathrm{mol})$ for PtReOH to $-0.23 \mathrm{eV}$ for monometallic AuOH. Figure 4.11 shows the correlation between ammonia binding energy and DPE and demonstrates that alloys of all four bulk metals follow a similar trend. As the DPE of the 
hydroxide decreases (become more acidic), the binding energy of ammonia increases. This increase is slow at first, but once the acid has become sufficiently strong, ammonia deprotonates the acid site, forming a strongly bound acid-base pair between ammonium and the charged MO conjugate base. Once this deprotonation has occurred, further increases in acid strength dramatically increase the binding energy between the acid-base pair. This results in a nonlinear relationship between $\mathrm{NH}_{3}-\mathrm{BE}$ and DPE and fits display a logarithmic relationship with a vertical and horizontal asymptotes which depend upon the bulk metal. The vertical asymptotes display a qualitative relationship to the average eAff of the bulk-metal alloys (eAff $\mathrm{Pt}>\mathrm{Ir}>\mathrm{Au}>\mathrm{Rh}>\mathrm{Ru}$ ). Of course, since DPE takes into account the eAff, the shift in this vertical asymptote may be coincidental. Shown as ' $\mathrm{X}$ ' in Figure 4.10 are the literature-reported values for phosphotungstic acid $\left(\mathrm{H}_{3} \mathrm{PW}_{12} \mathrm{O}_{40}, \mathrm{HPW}\right)$ and phosphomolybdic acid $\left(\mathrm{H}_{3} \mathrm{PMo}_{12} \mathrm{O}_{40}\right.$, HPMo), HPAs reported by Janik, et al. These values near the trends for the Pt- and Irbased alloys. Unfortunately, it appears that altering the bulk-metal has a significant impact on the relationship between $\mathrm{NH}_{3}$ adsorption and acidity. This indicates that $\mathrm{NH}_{3} \mathrm{BE}$ is not a 1:1 descriptor of acid strength for these materials since a single binding energy can be described by a range of DPE values as large as $1 \mathrm{eV}$, depending on the bulk metal being studied. Similarly, a single DPE value, can give a wide range of $\mathrm{NH}_{3} \mathrm{BEs}$. This indicates that, based on this model of the acid site, $\mathrm{NH}_{3} \mathrm{BE}$ gives only a qualitative indication of the DPE. 


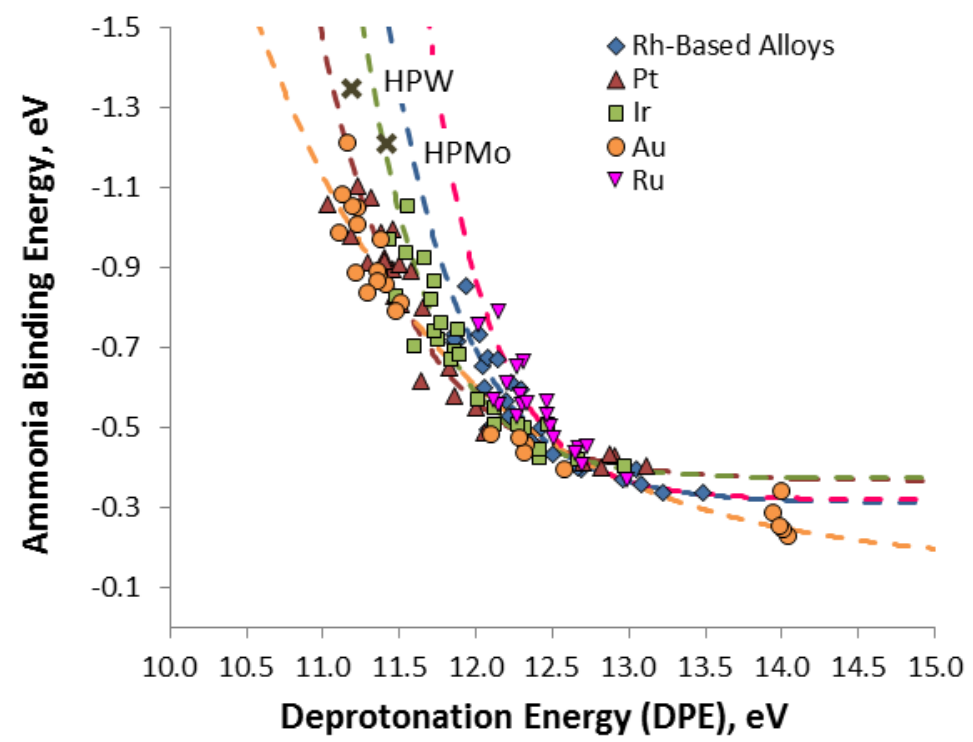

Figure 4.11. Relationship between DPE and ammonia binding energy.

In examining the geometry of the $\mathrm{MO}-\mathrm{H}-\mathrm{NH}_{3}$ complex during $\mathrm{NH}_{3}$ adsorption, a relationship between the $\mathrm{O}-\mathrm{H}$ and $\mathrm{H}-\mathrm{N}$ bond distances is observed. Figure 4.12 displays this correlation, which is similar to previously reported work on HPAs ${ }^{190}$. According to bond order conservation, it is expected that as the $\mathrm{H}-\mathrm{N}$ bond order increases, the $\mathrm{O}-\mathrm{H}$ bond order must decrease, extending the bond length. ${ }^{20}$ Furthermore, UBI-QEP relates bond order to bond length according to Equation 4.7, in which $r_{0}$ represents the equilibrium distance of the two-body system. Rearrangement produces Equation 4.8, which was used to generate the fit shown in Figure 4.12. Fitting all four parameters of Equation 4.8 gives the results shown in Table 4.3. However, the predicted $r_{0}$ values are inconsistent with the bond lengths predicted from $\mathrm{MOH}$ and $\mathrm{NH}^{+}$calculations (also shown in Table 4.3). Using these values as $r_{0}$, an additional two-parameter fit was performed. A similar analysis can be performed on the M-O and $\mathrm{O}-\mathrm{H}$ three-body system detailed in the supplemental text. Also included in Figure 4.12 is data from Janik, et al. ${ }^{190}$, which shows that although that data is generated across a wide range of adsorbates, deprotonated $\mathrm{MOH}$ and HPA systems have similar bond lengths; $r_{0, \mathrm{H}-\mathrm{Ads}}$ remains the same. However, that data shows scatter on the other end of the correlation due to changes in the equilibrium $\mathrm{O}-\mathrm{H}$ bond lengths $\left(r_{0, \mathrm{OH}}\right)$ between MOH and HPA systems. 


$$
\begin{aligned}
& X=x_{\mathrm{OH}}+x_{\mathrm{NH}}=1 \\
& x(r)=\exp \left\{-\left(r-r_{0}\right) / b\right\} \\
& r_{\mathrm{OH}}=-b_{\mathrm{OH}} * \ln \left[1-\exp \left(-\left(r_{\mathrm{NH}}-r_{0, \mathrm{NH}}\right) / b_{\mathrm{NH}}\right)\right]+r_{0, \mathrm{OH}}
\end{aligned}
$$

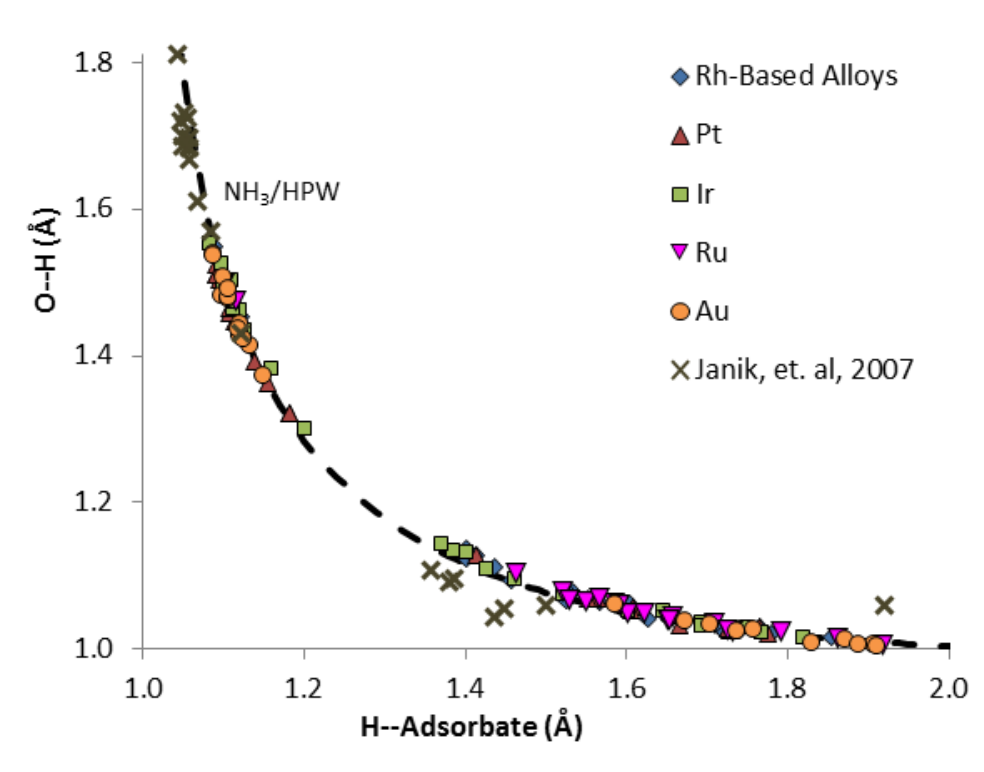

Figure 4.12. Proton-ammonia and proton-oxygen bond lengths of ammonia bound to a variety of

\begin{tabular}{|c|c|c|c|c|c|}
\hline Fitting Scheme & Residual & $r_{0, \mathrm{NH}}$ & $r_{0, \mathrm{OH}}$ & $b_{\mathrm{NH}}$ & $b_{\mathrm{OH}}$ \\
\hline Two-Parameter (2P)a & 0.079 & 1.029 & 0.977 & 0.332 & 0.319 \\
\hline Four-Parameter (4P) & 0.025 & 0.986 & 0.960 & 0.378 & 0.395 \\
\hline \multirow[t]{2}{*}{ MOH Bond Data $\left(r_{0,0 \mathrm{H}}\right)$} & Range & Avg & St Dev & \multicolumn{2}{|c|}{$\mathrm{NH}_{3}--\mathrm{H}^{+}(\AA)$} \\
\hline & 0.971-0.983 & 0.977 & 0.0028 & $r_{0, \mathrm{NH}}:$ & 1.029 \\
\hline
\end{tabular}
MOH surface alloys as well as a variety of adsorbates bound to HPA systems from Janik, et al. ${ }^{190}$

Table 4.3. Regression Data for Figure 4.11.

Figure 4.12 also shows a distinct gap in $\mathrm{O}-\mathrm{H}$ bond lengths between $\sim 1.15$ and 1.3 which demonstrates that at a certain acidity, the proton will shift from being bound to the MO site to forming an ammonium ion above the surface. Unlike previous studies over HPAs, in which this always occurred for $\mathrm{NH}_{3}$ adsorption, the wide range of acidity of these $\mathrm{MOH}$ systems allow us to show at what range of DPE will $\mathrm{NH}_{3}$ adsorption cause deprotonation of the acid site. Figure 4.13 shows the $\mathrm{N}-\mathrm{H}$ bond distance against the DPE. As shown, the transition to an ammonium ion can 
occur across a range of DPE, from 11.6 - 12.1 both ammonia and ammonium are observed, beneath that, only ammonium and above that, only ammonia.

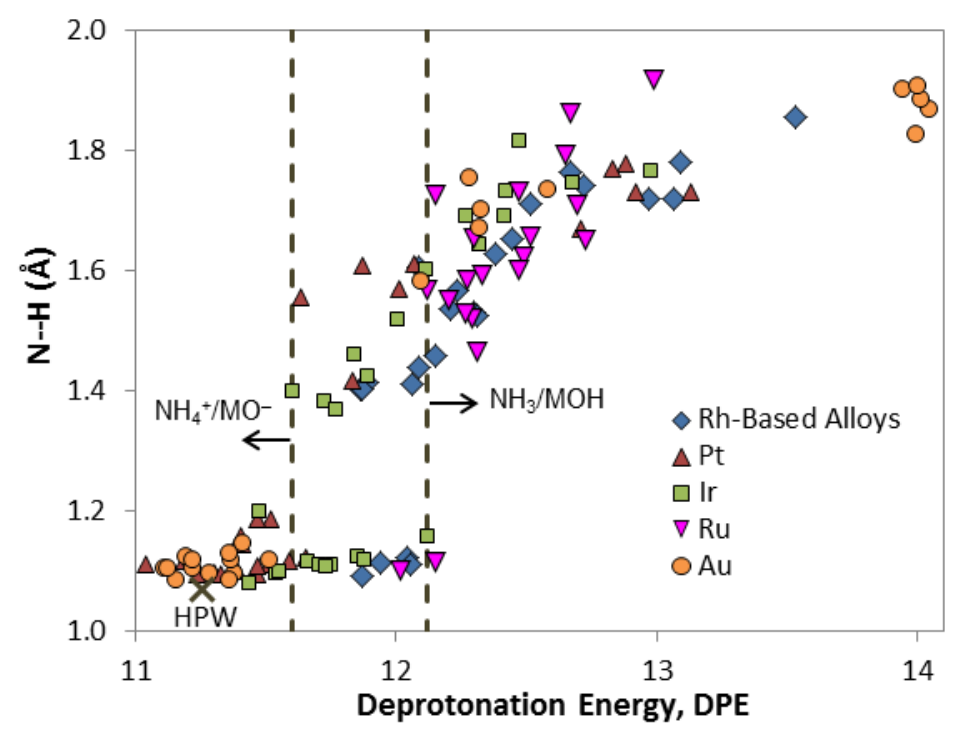

Figure 4.13. $\mathrm{N}-\mathrm{H}$ bond lengths $\leq 1.2$ indicate ammonium ions have been formed. At DPE $>\sim 12.1$, ammonia only chemi- and physi-sorbs to the $\mathrm{MOH}$ cluster. Beneath 11.6, the MOH clusters deprotonate, forming strongly bound ammonium cations. Between DPE of 12.1 and 11.6, both ammonia and ammonium species are observed, depending on the alloy and MOH site.

\section{Conclusions}

Calculations of DHE and $\mathrm{NH}_{3}$ BE for a wide range of metal alloy surfaces indicate that hydroxides bound to oxophilic metals, alloyed into platinum-group and coinage metals are acidic. Hydroxide bound to $\mathrm{W}, \mathrm{Re}, \mathrm{Mo}, \mathrm{Cr}$ and $\mathrm{Mn}$ interact strongly with $\mathrm{NH}_{3}$, indicating acidity. While $\mathrm{W}, \mathrm{Re}$ and Mo promoters have been experimentally investigated, the others have not and may provide these unique active sites which show high activity and selectivity for hydrogenolysis applications. Possible catalysts to alloy with these promoters include $\mathrm{Pt}, \mathrm{Ir}, \mathrm{Rh}, \mathrm{Cu}, \mathrm{Pd}$ and $\mathrm{Au}$, of which $\mathrm{Cu}, \mathrm{Pd}$ and Au have not been previously studied experimentally.

Extensive follow-up calculations of $\mathrm{W}-$, Re-, Mo- and $\mathrm{Ru}-$ promoted $\mathrm{Pt}, \mathrm{Rh}, \mathrm{Ir}, \mathrm{Au}$ and $\mathrm{Ru}$ catalyst nanoparticles permitted the explicit calculation of DPE, a direct measure of acid strength. 
These results indicate that alloying with Re provides the largest decrease in hydroxide acidity (compared to the pure bulk metal nanoparticle), followed by W and Mo. These resulted in the most acidic DPEs when promoting $\mathrm{Pt}$ and $\mathrm{Au}$ nanoparticles and while the promoter was in an uncoordinated corner or bridge position on the nanoparticle. $\mathrm{Ru}$, which shows increased rates of $\mathrm{C}-\mathrm{C}$ activation, useful during glycerol reforming, did not produce very strong acid sites when acting as a promoter or a promotee. Further study of promoted Au catalysts, which are predicted to have such acid sites, may lead to decreased hydrogenolysis activity, due to the difficulty of performing the subsequent hydrogenation on a $\mathrm{Au}$ catalyst. However, this weakness may enable promoted $\mathrm{Au}$ catalysts to selectively dehydrate polyols, forming unsaturated enols, ketones and/or aldehydes, which can provide further evidence for Brønsted-acid based dehydration with this novel class of catalysts.

The relationship between DPE and $\mathrm{NH}_{3} \mathrm{BE}$ was also investigated. It was found that $\mathrm{NH} 3 \mathrm{BE}$ increases with decreasing DPE, as expected. However the relationship is nonlinear, with two distinct regimes observed (with and without deprotonation of the acid site). For non-acidic hydroxides, the interaction is weak, but present, much like a hydrogen bond, which increases in strength slowly as the DPE decreases. As the DPE decreases, the interaction grows in an exponential-like form, until the acid deprotonates, forming a strongly interacting $\mathrm{NH}_{4}+$ and MO- acid-base pair. Further increases in acid strength continue to increase the $\mathrm{NH}_{3}$ binding energy at a faster pace, falling along the exponential-like curve. Unfortunately, point at which the curve starts to 'bend' depends upon the bulk metal being studied, complicating the relationship between $\mathrm{NH}_{3} \mathrm{BE}$ and DPE. In the future, more work is needed to understand the relationship between particle size and the electron affinity of the catalyst and how this impacts acid site properties such as $\mathrm{NH}_{3} \mathrm{BE}$. 


\section{Summary and Recommendations for Future Work}

The aim of this dissertation was to provide a thorough understanding of the chemical nature of adsorbed oxygen and hydroxide on transition metal catalysts, and how those adsorbates can influence chemistry. These adsorbates are present during catalysis of alcohol oxidation, oxygen reduction, methane activation, and hydrogenolysis, to name a few applications described in this work. Furthermore, many of these reactions take place in aqueous phase, which can interact with these adsorbates (and others) as well as enable solution-phase reactions, compensate the formation of charged species, and create electrostatic potentials at the catalyst-solution interface.

Taking into consideration the impacts of these co-adsorbates and solvent complicates the standard model which theoretical catalysis researchers have adhered to: a low-coverage metal surface with no condensed phase. However, the inclusion of these effects increases the accuracy and chemical relevance of theoretical calculations. Furthermore, establishing a set of rules for the behavior of these species can improve the understanding of a wide range of catalytic systems.

Atomically adsorbed oxygen can come from a number of sources during catalysis, most notably the dissociation of $\mathrm{O}_{2}$, but it can also come from $\mathrm{CO}_{2}$ or $\mathrm{H}_{2} \mathrm{O}$ (such as during 'dry' or 'steam' reforming of methane). The reactivity of $0^{*}$ on a transition metal surface depends primarily upon the strength of the interaction between the adsorbate and the metal it's bound to (the binding energy). The more strongly bound the $0^{*}$, the less likely it is to interact with the water solvent or react with co-adsorbates. This simple and intuitive result is complicated by the fact that the binding energy of 0* on commonly-studied catalyst materials varies widely, decreasing from right-to-left across the transition metal block of the periodic table. Another complicating factor is that the binding energy of $0^{*}$ rapidly decreases with increasing surface coverage, and the surface coverage of $0^{*}$ is primarily dependent upon the binding energy of $0^{*}$. So, as you increase the oxophilicity of the catalyst surface, more $0^{*}$ adsorbs, which causes the binding energy of the next $0^{*}$ to decrease until the adsorption is too endothermic or you've formed an oxide material. This indicates that on an equilibrated metal surface (which does not proceed to an oxide), the coverage of oxygen will increase until the oxygens are bound weakly (thus making them more reactive, while at the same time blocking active metal 
sites). This creates a 'moving target' of sorts, in which the coverage of oxygen can significantly impact the reaction mechanism, not just through site-blocking, but also through surface repulsion between O* co-adsorbates.

The reactivity described can come in a variety of roles although two were studied in which oxygen acts as a Brønsted base. In one role, it accepts a $\mathrm{H}$ atom to form $\mathrm{OH}^{*}$, assisting in the breaking of a $\mathrm{C}-\mathrm{H}$ or $\mathrm{O}-\mathrm{H}$ bond. In another role, it acts as a nucleophile, adding to the unsaturated carbon of an aldehyde en-route to an acid product. The first role, as a $\mathrm{H}$-acceptor, depends greatly upon the acidity of the $\mathrm{H}$, with $\mathrm{O}-\mathrm{H}$ bonds of alcohols or acids being activated with much lower barriers. Another example is the $\alpha$-hydrogen of an aldehyde, which is far more acidic than typical C-H bonds due to the resonance stabilization of the enolate conjugate base which need to be further studied. The C-H bonds of alkanes, on the other hand, are not acidic, and their activation is much easier through metal atom insertion across all platinum-group metals. However, $0^{*}$ on coinage metals, well known for their inertness, is quite active and can assist in the activation of these completely non-acidic $\mathrm{C}-\mathrm{H}$ bonds at low coverage. For platinum-group metals, high coverage is required before the binding energy of $\mathrm{O}^{*}$ is weak enough to begin to see lower barriers for the activation of $\mathrm{C}-\mathrm{H}$ bonds of alkanes. A third type of $\mathrm{C}-\mathrm{H}$ bond activation is currently under review, a $\beta$-hydride elimination reaction of an adsorbed alkoxide to produce an aldehyde. This reaction, important during alcohol oxidation, is very different from metal-atom-insertion type reactions typically seen for $\mathrm{C}-\mathrm{H}$ activation, instead the hydrogen elimination may be a proton coupled electron transfer, which is a phenomena often studied in organometallic catalysis, in which a $\mathrm{H}$ is induced to leave as a proton with a concomitant electron transfer that occurs through a different path or linkage. Once again, it will be important to determine the role of co-adsorbed $0^{*}$ on this process.

Adsorbed $\mathrm{OH}^{*}$ can be from the addition of base to the solution during aqueous phase catalysis. However, it can also come from the activation of water, due to an applied electrochemical potential or due to the presence of an oxophilic metal (possibly in an alloy). Co-adsorbed $\mathrm{OH}^{*}$, like $\mathrm{O}^{*}$, can act as a nucleophile or Brønsted base depending on the acidity of the $\mathrm{H}$ being abstracted. However, $\mathrm{OH}^{*}$ is less strongly adsorbed and more flexible on the catalyst surface. The preferred 
binding mode of $\mathrm{OH}^{*}$ can be atop, bridge, fcc or hcp depending upon the metal being studied and the differences in energy between these binding modes is much smaller than differences in energies of binding modes of $0^{*}$, which enables greater mobility and flexibility of $\mathrm{OH}^{*}$ on a metal surface. This greatly increases its reactivity during the abstraction of acidic protons and makes its performance less sensitive to the transition metal that it's bound to. As coverage increases, the binding energy of each additional $\mathrm{OH}^{*}$ species does not decrease, as in the case of $\mathrm{O}^{*}$, instead the $\mathrm{OH}^{*}$ occupy atop or bridge binding modes to minimize metal atom sharing and maximize the formation of hydrogen bonding networks across the catalyst surface. The presence of a water solvent does not disrupt this hydrogen bonding network, instead it integrates with it and forms a stable $\mathrm{OH} / \mathrm{H}_{2} \mathrm{O}$ interface at the catalyst-solution interface, depending upon the potential of that interface.

Another interesting feature of adsorbed $\mathrm{OH}^{*}$ occurs when you mix an oxophilic and noble transition metal. If the oxophilic metal can be partially reduced to form a metal-metal bonds with the noble transition metal, forming a bimetallic metal alloy, hydroxide species bound to that metal will form a very strong O-M bond, due to the isolation of the oxophilic metal surrounded (at least partially) by noble metal atoms. This strong $\mathrm{O}-\mathrm{M}$ bond reduces the $\mathrm{O}-\mathrm{H}$ bond due to bond order conservation principles, which results in the $\mathrm{H}$ of the $\mathrm{OH}^{*}$ adsorbate becoming acidic because of the weak $\mathrm{O}-\mathrm{H}$ bond and the ability of the metal catalyst to accept and delocalize the negative charge. These active sights are thought to be responsible for highly selective hydrogenolysis reactions of polyols and cyclic ethers and have also been shown active during fructose dehydration reactions. This area, which enables you to combine the reactivity of a noble metal catalyst (for hydrogenation or perhaps water gas shift) with the presence of a stable solid acid site. This is the reverse strategy of embedding sub-nanometer noble metal clusters into zeolite frameworks and is an area which offers many challenges and possibilities of future work.

Thus, $\mathrm{OH}^{*}$ bound to mono- and bi-metallic transition metal catalysts can act as a base or an acid, depending on the nature of the catalyst. Possible future work may be to extend the survey hydroxide bound to bimetallic alloys which calculated the dehydrogenation energy and ammonia binding energy (as probes for Brønsted acidity) to include the hydrogenation energy and methanol 
binding energy (as probes of Brønsted basicity) to establish a continuous set of data, describing the acidity and basicity of $\mathrm{OH}^{*}$ across a wide range of transition metal surfaces and their alloys.

Finally, an area of great interest to me that I have not had the time to fully explore is the strength and impact, if any, of the induced chemical potential on the surface of a catalyst in a nonelectrocatalytic environment. During aqueous phase catalysis, the adsorption / desorption of charged species from solution can alter the surface charge of the metal catalyst, thus altering the potential. Furthermore, any electron consuming or producing reactions (such as reduction or oxidation) will further alter the surface charge of the catalyst. These processes will result in a non-zero net charge which will result in an electrochemical potential, which could strongly alter adsorption and reaction thermodynamics and kinetics. My current belief is that the electrochemical potential, in a manner analogous to the coverage of an intermediate, allows oxidation/reduction catalysts to be self-tuned, allowing some of them to operate over wide ranges of $\mathrm{pH}$ due to changes in the induced (rather than applied) electrochemical potential. 


\section{References}

(1) Kresse, G.; Hafner, J. Ab initio molecular dynamics for liquid metals. Physical Review B 1993, 47, 558-561.

(2) Kresse, G.; Hafner, J. Ab initio molecular-dynamics simulation of the liquid-metal-amorphoussemiconductor transition in germanium. Physical Review B 1994, 49, 14251-14269.

(3) Kresse, G.; Furthmüller, J. Efficiency of ab-initio total energy calculations for metals and semiconductors using a plane-wave basis set. Computational Materials Science 1996, 6, 15-50.

(4) Kresse, G.; Furthmüller, J. Efficient iterative schemes for ab initio total-energy calculations using a plane-wave basis set. Physical Review B 1996, 54, 11169-11186.

(5) Blöchl, P. Projector augmented-wave method. Physical Review B 1994, 50, 17953-17979.

(6) Kresse, G.; Joubert, D. From ultrasoft pseudopotentials to the projector augmented-wave method. Physical Review B 1999, 59, 11-19.

(7) Perdew, J.; Burke, K.; Ernzerhof, M. Generalized Gradient Approximation Made Simple. Physical review letters 1996, 77, 3865-3868.

(8) Zhang, Y.; Yang, W. Comment on "Generalized Gradient Approximation Made Simple ." Physical Review Letters 1998, 80, 890.

(9) Hammer, B.; Hansen, L.; Nørskov, J. K. Improved adsorption energetics within densityfunctional theory using revised Perdew-Burke-Ernzerhof functionals. Physical Review B 1999, 59, 7413-7421.

(10) Monkhorst, H.; Pack, J. Special points for Brillouin-zone integrations. Physical Review B 1976, 13, 5188-5192.

(11) Vanderbilt, D. Soft self-consistent pseudopotentials in a generalized eigenvalue formalism. Physical Review B 1990, 41, 7892-7895.

(12) Kresse, G.; Hafner, J. Norm-conserving and ultrasoft pseudopotentials for first-row and transition elements. Journal of Physics: Condensed Matter 1994, 6, 8245-8257.

(13) Perdew, J. P.; Chevary, J. A.; Vosko, S. H.; Jackson, K. A.; Pederson, M. R.; Singh, D. J.; Fiolhais, C. Atoms, molecules, solids, and surfaces: Applications of the generalized gradient approximation for exchange and correlation. Physical Review B 1992, 46, 6671-6686.

(14) Lu, W. C.; Wang, C. Z.; Schmidt, M. W.; Bytautas, L.; Ho, K. M.; Ruedenberg, K. Molecule intrinsic minimal basis sets. I. Exact resolution of ab initio optimized molecular orbitals in terms of deformed atomic minimal-basis orbitals. Journal of Chemical Physics 2004, 120, 2629-37.

(15) Lu, W.; Wang, C.; Chan, T.; Ruedenberg, K.; Ho, K. Representation of electronic structures in crystals in terms of highly localized quasiatomic minimal basis orbitals. Physical Review $B$ 2004, 70, 1-4. 
(16) Chan, T.-L.; Yao, Y.; Wang, C.; Lu, W.; Li, J.; Qian, X.; Yip, S.; Ho, K. Highly localized quasiatomic minimal basis orbitals for Mo from ab initio calculations. Physical Review B 2007, 76, 1-10.

(17) Qian, X.; Li, J.; Qi, L.; Wang, C.-Z.; Chan, T.-L.; Yao, Y.-X.; Ho, K.-M.; Yip, S. Quasiatomic orbitals for ab initio tight-binding analysis. Physical Review B 2008, 78, 245112.

(18) Löwdin, P.-O. On the Non-Orthogonality Problem Connected with the Use of Atomic Wave Functions in the Theory of Molecules and Crystals. Journal of Chemical Physics 1950, 18, 365.

(19) Löwdin, P.-O. On the Nonorthogonality Problem. Advances in Quantum Chemistry 1970, 5, 185-199.

(20) Shustorovich, E.; Sellers, H. The UBI-QEP method: a practical theoretical approach to understanding chemistry on transition metal surfaces. Surface Science Reports 1998, 31, 1119.

(21) Shustorovich, E. M.; Zeigarnik, a. V. The UBI-QEP method: Basic formalism and applications to chemisorption phenomena on transition metal surfaces. Chemisorption energetics. Russian Journal of Physical Chemistry 2006, 80, 4-30.

(22) Haruta, M. Size-and support-dependency in the catalysis of gold. Catalysis Today 1997, 861, 153-166.

(23) Schubert, M. CO Oxidation over Supported Gold Catalysts - "Inert" and "Active" Support Materials and Their Role for the Oxygen Supply during Reaction. Journal of Catalysis 2001, 197, 113-122.

(24) Kim, T. S.; Stiehl, J. D.; Reeves, C. T.; Meyer, R. J.; Mullins, C. B. Cryogenic CO oxidation on $\mathrm{TiO}(2)$-supported gold nanoclusters precovered with atomic oxygen. Journal of the American Chemical Society 2003, 125, 2018-9.

(25) Mhadeshwar, a B.; Vlachos, D. G. Hierarchical multiscale mechanism development for methane partial oxidation and reforming and for thermal decomposition of oxygenates on Rh. Journal of Physical Chemistry B 2005, 109, 16819-35.

(26) Mhadeshwar, A.; Vlachos, D. A catalytic reaction mechanism for methane partial oxidation at short contact times, reforming, and combustion, and for oxygenate decomposition and oxidation on. Industrial \& Engineering Chemistry Research 2007, 2, 5310-5324.

(27) García-Diéguez, M.; Chin, Y.-H. (Cathy); Iglesia, E. Catalytic reactions of dioxygen with ethane and methane on platinum clusters: Mechanistic connections, site requirements, and consequences of chemisorbed oxygen. Journal of Catalysis 2012, 285, 260-272.

(28) Chin, Y.-H. C.; Buda, C.; Neurock, M.; Iglesia, E. Reactivity of chemisorbed oxygen atoms and their catalytic consequences during CH4-O2 catalysis on supported Pt clusters. Journal of the American Chemical Society 2011, 133, 15958-78.

(29) (Cathy) Chin, Y.-H.; Buda, C.; Neurock, M.; Iglesia, E. Selectivity of chemisorbed oxygen in C-H bond activation and $\mathrm{CO}$ oxidation and kinetic consequences for $\mathrm{CH} 4-\mathrm{O} 2$ catalysis on $\mathrm{Pt}$ and $\mathrm{Rh}$ clusters. Journal of Catalysis 2011, 283, 10-24. 
(30) Bradford, M. C. J.; Vannice, M. A. CO 2 Reforming of CH 4 over Supported Pt Catalysts. 1998, 171, 69-75.

(31) Buda, C.; Hibbitts, D. D.; Neurock, M. Role of Adsorbed Oxygen during Methane Activation over Transition Metal Surfaces 2012.

(32) Besson, M.; Gallezot, P. Selective oxidation of alcohols and aldehydes on metal catalysts. Catalysis Today 2000, 57, 127-141.

(33) Mallat, T.; Baiker, A. Oxidation of alcohols with molecular oxygen on solid catalysts. Chemical reviews 2004, 104, 3037-3058.

(34) Gangwal, V. R.; van der Schaaf, J.; Kuster, B. F. M.; Schouten, J. C. Influence of pH on noble metal catalysed alcohol oxidation: reaction kinetics and modelling. Journal of Catalysis 2005, $229,389-403$.

(35) Markusse, A.; Kuster, B.; Schouten, J. Platinum catalysed aqueous alcohol oxidation: experimental studies and reaction model discrimination. Journal of Molecular Catalysis A: Chemical 2000, 158, 215-222.

(36) Zope, B. N.; Hibbitts, D. D.; Neurock, M.; Davis, R. J. Reactivity of the gold/water interface during selective oxidation catalysis. Science 2010, 330, 74-8.

(37) Hibbitts, D. D.; Neurock, M. Influence of Oxygen and Alkalinity during Selective Oxidation of Ethanol over Pd Catalysts 2012.

(38) Markovic, N.; Gasteiger, H.; Ross, P. N.; Berkeley, L.; Division, M. S. Kinetics of Oxygen Reduction on Pt(hkl) Electrodes: Implications for the Crystallite Size Effect with Supported Pt Electrocatalysts. Journal of The Electrochemical Society 1997, 144, 1591.

(39) Janik, M. J.; Taylor, C. D.; Neurock, M. First-Principles Analysis of the Initial Electroreduction Steps of Oxygen over Pt(111). Journal of The Electrochemical Society 2009, 156, B126.

(40) Markovic, N. M.; Schmidt, T. J.; Grgur, B. N.; Gasteiger, H. A.; Behm, R. J.; Ross, P. N. Effect of Temperature on Surface Processes at the Pt (111)-Liquid Interface: Hydrogen Adsorption , Oxide Formation, and CO Oxidation. Journal of Physical Chemistry B 1999, 103, 8568-8577.

(41) Jacob, T. The Mechanism of Forming $\mathrm{H} 2 \mathrm{O}$ from $\mathrm{H} 2$ and $\mathrm{O} 2$ over a Pt Catalyst via Direct Oxygen Reduction. Fuel Cells 2006, 6, 159-181.

(42) Wang, J. X.; Zhang, J.; Adzic, R. R. WHAT MATTERS AFTER FIRST ELECTRON TRANSFER IN OXYGEN REDUCTION: A KINETIC STUDY OF Pt (111) AND Pt/C THIN LAYER CATALYSTS ON ROTATING DISK ELECTRODES. Prepr. Pap.-Am. Chem. Soc., Div. Fuel Chem 2004, 49, 664.

(43) Mulliken, R. S. Electronic Population Analysis on LCAO-MO Molecular Wave Functions. I. Journal of Chemical Physics 1955, 23, 1833-1840.

(44) Henkelman, G.; Jónsson, H. Improved tangent estimate in the nudged elastic band method for finding minimum energy paths and saddle points. Journal of Chemical Physics 2000, 113, 9978. 
(45) Henkelman, G.; Jónsson, H. A dimer method for finding saddle points on high dimensional potential surfaces using only first derivatives. Journal of Chemical Physics 1999, 111, 7010.

(46) Torres, D.; Neyman, K. M.; Illas, F. Oxygen atoms on the (111) surface of coinage metals: On the chemical state of the adsorbate. Chemical Physics Letters 2006, 429, 86-90.

(47) Min, B. K.; Friend, C. M. Heterogeneous Gold-Based Catalysis for Green Chemistry: LowTemperature CO Oxidation and Propene Oxidation. Chemical Reviews 2007, 107, 2709-2724.

(48) Liu, X.; Madix, R. J.; Friend, C. M. Unraveling molecular transformations on surfaces: a critical comparison of oxidation reactions on coinage metals. Chemical Society reviews 2008, 37, 2243-61.

(49) Madix, R.; Friend, C.; Liu, X. Anticipating catalytic oxidation reactions on gold at high pressure (including liquid phase) from ultrahigh vacuum studies. Journal of Catalysis 2008, 258, 410 413.

(50) Xu, B.; Zhou, L.; Madix, R. J.; Friend, C. M. Highly selective acylation of dimethylamine mediated by oxygen atoms on metallic gold surfaces. Angewandte Chemie 2010, 49, 394-8.

(51) Baker, T. a.; Kaxiras, E.; Friend, C. M. Insights from Theory on the Relationship Between Surface Reactivity and Gold Atom Release. Topics in Catalysis 2010, 53, 365-377.

(52) Madix, R. J.; Friend, C. M. Gold’s enigmatic surface. Nature 2011, 479, 482.

(53) Michaelides, a.; Hu, P. A density functional theory study of hydroxyl and the intermediate in the water formation reaction on Pt. Journal of Chemical Physics 2001, 114, 513.

(54) Sheldon, R.; Dakka, J. Heterogeneous catalytic oxidations in the manufacture of fine chemicals. Catalysis Today 1994, 19, 215-245.

(55) Corma, A.; Garcia, H. Supported gold nanoparticles as catalysts for organic reactions. Chemical Society reviews 2008, 37, 2096-126.

(56) Gallezot, P. Selective oxidation with air on metal catalysts. Catalysis Today 1997, 37, 405-418.

(57) Hammer, B.; Nørskov, J. K. Why gold is the noblest of all the metals. Nature 1995, 376, 238.

(58) van den Tillaart, J. A. A.; Kuster, B. F. M.; Marin, G. B. Oxidative dehydrogenation of aqueous ethanol on a carbon supported platinum catalyst. Applied Catalysis A: General 1994, 120, 127 145.

(59) Bond, G. C.; Thompson, D. T. Gold-catalysed oxidation of carbon monoxide. Gold Bulletin 2000, $33,41-50$.

(60) Abad, A.; Corma, A.; García, H. Catalyst parameters determining activity and selectivity of supported gold nanoparticles for the aerobic oxidation of alcohols: the molecular reaction mechanism. Chemistry - A European Journal 2008, 14, 212-22.

(61) Fristrup, P.; Johansen, L. B.; Christensen, C. H. Mechanistic Investigation of the Gold-catalyzed Aerobic Oxidation of Alcohols. Catalysis Letters 2007, 120, 184-190. 
(62) Conte, M.; Miyamura, H.; Kobayashi, S.; Chechik, V. Spin trapping of Au-H intermediate in the alcohol oxidation by supported and unsupported gold catalysts. Journal of the American Chemical Society 2009, 131, 7189-96.

(63) Haruta, M.; Yamada, N.; Iijima, S.; Kobayashi, T. Gold catalysts prepared by coprecipitation for low-temperature oxidation of hydrogen and of carbon monoxide. Journal of Catalysis 1989, $115,301$.

(64) Bond, G. C.; Louis, C.; Thompson, D. T. Catalysis by Gold, Vol. 6 of Catalytic Science Series; Imperial: London, 2006.

(65) Carrettin, S.; McMorn, P.; Johnston, P.; Griffin, K.; Hutchings, G. J. Selective oxidation of glycerol to glyceric acid using a gold catalyst in aqueous sodium hydroxide. Chemical Communications 2002, 696-7.

(66) Prati, L.; Rossi, M. Gold on Carbon as a New Catalyst for Selective Liquid Phase Oxidation of Diols. Journal of Catalysis 1998, 176, 552-560.

(67) Sanchez, a.; Abbet, S.; Heiz, U.; Schneider, W.-D.; Häkkinen, H.; Barnett, R. N.; Landman, U. When Gold Is Not Noble: Nanoscale Gold Catalysts. Journal of Physical Chemistry A 1999, 103, 9573-9578.

(68) Fu, Q.; Saltsburg, H.; Flytzani-Stephanopoulos, M. Active nonmetallic Au and Pt species on ceria-based water-gas shift catalysts. Science 2003, 301, 935-8.

(69) Guzman, J.; Gates, B. C. Catalysis by supported gold: correlation between catalytic activity for CO oxidation and oxidation states of gold. Journal of the American Chemical Society 2004, 126, 2672-3.

(70) Haruta, M.; Daté, M. Advances in the catalysis of Au nanoparticles. Applied Catalysis A: General 2001, 222, 427-437.

(71) Valden, M.; Lai, X.; Goodman, D. Onset of catalytic activity of gold clusters on titania with the appearance of nonmetallic properties. Science 1998, 281, 1647-50.

(72) Lopez, N.; Nørskov, J. K. Catalytic CO oxidation by a gold nanoparticle: a density functional study. Journal of the American Chemical Society 2002, 124, 11262-3.

(73) Haruta, M.; Tsubota, S.; Kobayashi, T.; Kageyama, H.; Genet, M. J.; Delmon, B. LowTemperature Oxidation of CO over Gold Supported on TiO2, Alpha-FeCO3, and C0304. Journal of Catalysis 1993, 144, 175.

(74) Ojifinni, R. a; Froemming, N. S.; Gong, J.; Pan, M.; Kim, T. S.; White, J. M.; Henkelman, G.; Mullins, C. B. Water-enhanced low-temperature $\mathrm{CO}$ oxidation and isotope effects on atomic oxygen-covered $\mathrm{Au}(111)$. Journal of the American Chemical Society 2008, 130, 6801-12.

(75) Kung, M. C.; Davis, R. J.; Kung, H. H. Understanding Au-Catalyzed Low-Temperature CO Oxidation. Journal of Physical Chemistry C 2007, 111, 11767-11775.

(76) Daté, M.; Okumura, M.; Tsubota, S.; Haruta, M. Vital role of moisture in the catalytic activity of supported gold nanoparticles. Angewandte Chemie 2004, 43, 2129-32. 
(77) Ketchie, W.; Fang, Y.; Wong, M.; Murayama, M.; Davis, R. Influence of gold particle size on the aqueous-phase oxidation of carbon monoxide and glycerol. Journal of Catalysis 2007, 250, 94101.

(78) Sanchez-Castillo, M. a; Couto, C.; Kim, W. B.; Dumesic, J. a Gold-nanotube membranes for the oxidation of CO at gas-water interfaces. Angewandte Chemie 2004, 43, 1140-2.

(79) Ketchie, W. C.; Murayama, M.; Davis, R. J. Promotional effect of hydroxyl on the aqueous phase oxidation of carbon monoxide and glycerol over supported Au catalysts. Topics in Catalysis 2007, 44, 307-317.

(80) Janssens, T. V. W.; Clausen, B. S.; Hvolbæk, B.; Falsig, H.; Christensen, C. H.; Bligaard, T.; Nørskov, J. K. Insights into the reactivity of supported Au nanoparticles: combining theory and experiments. Topics in Catalysis 2007, 44, 15-26.

(81) Deng, X.; Min, B. K.; Guloy, A.; Friend, C. M. Enhancement of O2 dissociation on Au111 by adsorbed oxygen: implications for oxidation catalysis. Journal of the American Chemical Society 2005, 127, 9267-70.

(82) Nolan, P. D.; Lutz, B. R.; Tanaka, P. L.; Davis, J. E.; Mullins, C. B. Molecularly chemisorbed intermediates to oxygen adsorption on Pt(111): A molecular beam and electron energy-loss spectroscopy study. Journal of Chemical Physics 1999, 111, 3696.

(83) Clayden, J.; Greeves, N.; Warren, S.; Wothers, P. Organic Chemistry; Oxford University Press: USA, 2000.

(84) Gewirth, A. A.; Thorum, M. S. Electroreduction of dioxygen for fuel-cell applications: materials and challenges. Inorganic chemistry 2010, 49, 3557-66.

(85) Ketchie, W. C.; Murayama, M.; Davis, R. J. Selective oxidation of glycerol over carbonsupported AuPd catalysts. Journal of catalysis 2007, 250, 264-273.

(86) Ragauskas, A. J.; Williams, C. K.; Davison, B. H.; Britovsek, G.; Cairney, J.; Eckert, C. a; Frederick, W. J.; Hallett, J. P.; Leak, D. J.; Liotta, C. L.; Mielenz, J. R.; Murphy, R.; Templer, R.; Tschaplinski, T. The path forward for biofuels and biomaterials. Science 2006, 311, 484-489.

(87) Chheda, J. N.; Huber, G. W.; Dumesic, J. A. Liquid-phase catalytic processing of biomassderived oxygenated hydrocarbons to fuels and chemicals. Angewandte Chemie 2007, 46, 7164-83.

(88) Huber, G. W.; Iborra, S.; Corma, A. Synthesis of transportation fuels from biomass: chemistry, catalysts, and engineering. Chemical Reviews 2006, 106, 4044-98.

(89) Zheng, Y.; Chen, X.; Shen, Y. Commodity chemicals derived from glycerol, an important biorefinery feedstock. Chemical Reviews 2008, 108, 5253-77.

(90) Román-Leshkov, Y.; Chheda, J. N.; Dumesic, J. a Phase modifiers promote efficient production of hydroxymethylfurfural from fructose. Science 2006, 312, 1933-7. 
(91) Davis, S. E.; Houk, L. R.; Tamargo, E. C.; Datye, A. K.; Davis, R. J. Oxidation of 5hydroxymethylfurfural over supported Pt, Pd and Au catalysts. Catalysis Today 2011, 160, 5560.

(92) Grunwaldt, J.-D.; Caravati, M.; Baiker, A. Oxidic or Metallic Palladium: Which Is the Active Phase in Pd-Catalyzed Aerobic Alcohol Oxidation? Journal of Physical Chemistry B 2006, 110, 25586-25589.

(93) Haider, P.; Grunwaldt, J.-D.; Seidel, R.; Baiker, A. Gold supported on $\mathrm{Cu}-\mathrm{Mg}$-Al and $\mathrm{Cu}-\mathrm{Ce}$ mixed oxides: An in situ XANES study on the state of Au during aerobic alcohol oxidation. Journal of Catalysis 2007, 250, 313-323.

(94) Demirel-Gulen, S.; Lucas, M.; Claus, P. Liquid phase oxidation of glycerol over carbon supported gold catalysts. Catalysis Today 2005, 102, 166-172.

(95) Alonso, C.; Gonzalez-Velsasco, J. Oxidation Electrocatalytic of Glycerol on Gold in Alkaline Medium. Z. Phys. Chemie 1990, 4, 799-822.

(96) Bianchini, C.; Shen, P. K. Palladium-based electrocatalysts for alcohol oxidation in half cells and in direct alcohol fuel cells. Chemical Reviews 2009, 109, 4183-4206.

(97) Cui, G.; Song, S.; Shen, P. K.; Kowal, A.; Bianchini, C. First-principles considerations on catalytic activity of Pd toward ethanol oxidation. Journal of Physical Chemistry C 2009, 113, 1563915642 .

(98) Liang, Z. X.; Zhao, T. S.; Xu, J. B.; Zhu, L. D. Mechanism study of the ethanol oxidation reaction on palladium in alkaline media. Electrochimica Acta 2009, 54, 2203-2208.

(99) Kluytmans, J. H. J.; Markusse, A. P.; Kuster, B. F. M.; Marin, G. B.; Schouten, J. C. Engineering aspects of the aqueous noble metal catalysed alcohol oxidation. Catalysis Today 2000, 57, 143-155.

(100) Yeager, E. Electrocatalysts for 02 reduction. Electrochimica Acta 1984, 29, 1527-1537.

(101) Adžić, R. R.; Wang, J. X. Configuration and Site of 02 Adsorption on the Pt(111) Electrode Surface. Journal of Physical Chemistry B 1998, 102, 8988-8993.

(102) Garcia, R.; Besson, M.; Gallezot, P. Chemoselective catalytic oxidation of glycerol with air on platinum metals. Applied Catalysis A: General 1995, 127, 165-176.

(103) Tang, W.; Henkelman, G. Charge redistribution in core-shell nanoparticles to promote oxygen reduction. Journal of Chemical Physics 2009, 130, 194504.

(104) Simões, F. C.; dos Anjos, D. M.; Vigier, F.; Léger, J.-M.; Hahn, F.; Coutanceau, C.; Gonzalez, E. R.; Tremiliosi-Filho, G.; de Andrade, A. R.; Olivi, P.; Kokoh, K. B. Electroactivity of tin modified platinum electrodes for ethanol electrooxidation. Journal of Power Sources 2007, 167, 1-10.

(105) Dijkgraaf, P. J. M.; Duisters, H. A. M.; Kuster, B. F. M.; van der Wiele, K. Deactivation of platinum catalysts by oxygen: 2 . Nature of the catalyst deactivation. Journal of Catalysis 1988, 112, 337344. 
(106) Markusse, A.; Kuster, B.; Schouten, J. Catalyst deactivation and reactivation during aqueous alcohol oxidation in a redox-cycle reactor. Studies in Surface Science and Catalysis 1999, 126, 273-280.

(107) Rottenburg, M.; Baertschi, P. No Title. Helvetica Chimica Acta 1956, 39, 1973-1975.

(108) Vinke, P.; de Wit, D.; de Goede, A. T. J. W.; van Bekkum, H. Noble Metal Catlayzed Oxidation of Carbohydrates and Carbohydrate Derivatives. Studies in Surface Science and Catalysis 1992, 72, 1-20.

(109) DiCosimo, R.; Whitesides, G. M. Oxidation of 2-propanol to acetone by dioxygen on a platinized electrode under open-circuit conditions. Journal of Physical Chemistry 1989, 93, 768-775.

(110) van Dam, H. E.; Wisse, L. J.; van Bekkum, H. Platinum / Carbon Oxidation Catalysts VIII. Selecting a Metal for Liquid-Phase Alcohol Oxidations. Applied Catalysis 1990, 61, 187-197.

(111) Hayashi, M.; Yamada, K.; Nakayama, S.-zo; Hayashi, H.; Yamazaki, S. Environmentally benign oxidation using a palladium catalyst system. Green Chemistry 2000, 2, 257-260.

(112) Keresszegi, C.; Burgi, T.; Mallat, T.; Baiker, A. On the Role of Oxygen in the Liquid-Phase Aerobic Oxidation of Alcohols on Palladium. Journal of Catalysis 2002, 211, 244-251.

(113) Vassilev, P.; van Santen, R. a; Koper, M. T. M. Ab initio studies of a water layer at transition metal surfaces. Journal of Chemical Physics 2005, 122, 54701.

(114) Filhol, J.-S.; Neurock, M. Elucidation of the Electrochemical Activation of Water over Pd by First Principles. Angewandte Chemie 2006, 118, 416-420.

(115) Taylor, C. D.; Janik, M. J.; Neurock, M.; Kelly, R. G. Ab initio simulations of the electrochemical activation of water. Molecular Simulation 2007, 33, 429-436.

(116) Kortum, G.; Vogel, W.; Andussow, K. Dissociation Constants of Organic Acids in Aqueous Solution; Butterworth: New York, NY, 1961.

(117) Cundari, T. R.; Grimes, T. V.; Gunnoe, T. B. Activation of carbon-hydrogen bonds via 1,2addition across $\mathrm{M}-\mathrm{X}(\mathrm{X}=\mathrm{OH}$ or $\mathrm{NH}(2))$ bonds of $\mathrm{d}(6)$ transition metals as a potential key step in hydrocarbon functionalization: a computational study. Journal of the American Chemical Society 2007, 129, 13172-82.

(118) Coutanceau, C.; Demarconnay, L.; Lamy, C.; Léger, J.-M. Development of electrocatalysts for solid alkaline fuel cell (SAFC). Journal of Power Sources 2006, 156, 14-19.

(119) Bambagioni, V.; Bianchini, C.; Filippi, J.; Oberhauser, W.; Marchionni, A.; Vizza, F.; Psaro, R.; Sordelli, L.; Foresti, M. L.; Innocenti, M. Ethanol Oxidation on Electrocatalysts Obtained by Spontaneous Deposition of Palladium onto Nickel-Zinc Materials. ChemSusChem 2009, 2, 99112.

(120) Ham, H. C.; Hwang, G. S.; Han, J.; Nam, S. W.; Lim, T. H. On the Role of Pd Ensembles in Selective H2O2 Formation on PdAu Alloys. Journal of Physical Chemistry C 2009, 113, 1294312945. 
(121) EIA Summary: U.S. Crude Oil, Natural Gas, and Natural Gas Liquids Proved Reserves; 2009.

(122) Vora, B.; Chen, J. Q.; Bozzano, A.; Glover, B.; Barger, P. Various routes to methane utilizationSAPO-34 catalysis offers the best option. Catalysis Today 2009, 141, 77-83.

(123) Luntz, a. C.; Winters, H. F. Dissociation of methane and ethane on Pt(110): Evidence for a direct mechanism under thermal conditions. Journal of Chemical Physics 1994, 101, 10980.

(124) Seets, D. Mechanism of the dissociative chemisorption of methane over $\operatorname{Ir}(110)$ : trappingmediated or direct? Chemical Physics Letters 1997, 266, 431-436.

(125) Wei, J.; Iglesia, E. Mechanism and Site Requirements for Activation and Chemical Conversion of Methane on Supported Pt Clusters and Turnover Rate Comparisons among Noble Metals. Journal of Physical Chemistry B 2004, 108, 4094-4103.

(126) Michaelides, a.; Hu, P. Insight into Microscopic Reaction Pathways in Heterogeneous Catalysis. Journal of the American Chemical Society 2000, 122, 9866-9867.

(127) Ess, D. H.; Gunnoe, T. B.; Cundari, T. R.; Goddard, W. a.; Periana, R. a. Ligand Lone-Pair Influence on Hydrocarbon $\mathrm{C}-\mathrm{H}$ Activation: A Computational Perspective $\triangle$. Organometallics 2010, 29, 6801-6815.

(128) Labinger, J. A.; Bercaw, J. E. Understanding and exploiting C-H bond activation. Nature 2002, 417, 507-514.

(129) Trevor, D. J.; Cox, D. M.; Kaldor, a. Methane activation on unsupported platinum clusters. Journal of the American Chemical Society 1990, 112, 3742-3749.

(130) Lercher, J. A.; Bitter, J. H.; Steghuis, A. G.; van Ommen, J. G.; Seshan, K. Methane Utilisation via Synthesis Gas Generation - Catalytic Chemistry and Technology. In Catalytic Science Series; 1999; p. 103.

(131) Gradassi, M. J.; Green, N. W. Economics of natural gas conversion processes. Fuel Processing Technology 1995, 42, 65-83.

(132) Bitsch-Larsen, a.; Horn, R.; Schmidt, L. D. Catalytic partial oxidation of methane on rhodium and platinum: Spatial profiles at elevated pressure. Applied Catalysis A: General 2008, 348, 165-172.

(133) Martins, R. L.; Baldanza, M. a. S.; Souza, M. M. V. M.; Schmal, M. The effect of support on methane activation over Pt catalysts in the presence of MoO3. Applied Catalysis A: General 2007, 318, 207-212.

(134) Pantu, P.; Gavalas, G. R. Methane partial oxidation on Pt/CeO2 and Pt/Al2O3 catalysts. Applied Catalysis A: General 2002, 223, 253-260.

(135) Horn, R.; Williams, K.; Degenstein, N.; Bitschlarsen, a; Dallenogare, D.; Tupy, S.; Schmidt, L. Methane catalytic partial oxidation on autothermal Rh and Pt foam catalysts: Oxidation and reforming zones, transport effects, and approach to thermodynamic equilibrium. Journal of Catalysis 2007, 249, 380-393. 
(136) Nave, S.; Jackson, B. Methane dissociation on $\mathrm{Ni}(111)$ and $\mathrm{Pt}(111)$ : energetic and dynamical studies. Journal of Chemical Physics 2009, 130, 054701.

(137) Li, H.-Y.; Guo, Y.-L.; Guo, Y.; Lu, G.-Z.; Hu, P. C-H bond activation over metal oxides: a new insight into the dissociation kinetics from density functional theory. Journal of Chemical Physics 2008, 128, 051101.

(138) Klier, K.; Hess, J. S.; Herman, R. G. Structure sensitivity of methane dissociation on palladium single crystal surfaces. Journal of Chemical Physics 1997, 107, 4033.

(139) Wu, M.-C.; Goodman, D. W. High-resolution electron energy-loss measurements of sticking coefficients of methane decomposition on Ru(0001). Surface Science 1994, 306, L529-L533.

(140) Lv, C.-Q.; Ling, K.-C.; Wang, G.-C. Methane combustion on Pd-based model catalysts: Structure sensitive or insensitive? Journal of Chemical Physics 2009, 131, 144704.

(141) Fratesi, G.; Gava, P.; Gironcoli, S. D. Direct Methane-to-Methanol Conversion: Insight from First-Principles Calculations. Journal of Physical Chemistry C 2007, 111, 17015-17019.

(142) Liu, Z.-P.; Hu, P. General rules for predicting where a catalytic reaction should occur on metal surfaces: a density functional theory study of C-H and C-O bond breaking/making on flat, stepped, and kinked metal surfaces. Journal of the American Chemical Society 2003, 125, 1958-67.

(143) Mayernick, A. D.; Janik, M. J. Methane oxidation on Pd-Ceria: A DFT study of the mechanism over PdxCe1-xO2, Pd, and PdO. Journal of Catalysis 2011, 278, 16-25.

(144) Beebe, T. P.; Goodman, D. W.; Kay, B. D.; Yates, J. T. Kinetics of the activated dissociative adsorption of methane on the low index planes of nickel single crystal surfaces. The Journal of Chemical Physics 1987, 87, 2305.

(145) Bradford, M. C. J.; Albert, M. V. Catalytic reforming of methane with carbon dioxide over nickel catalysts II. Reaction kinetics. Applied Catalysis A: General 1996, 142, 97-122.

(146) Wang, S.-G.; Cao, D.-B.; Li, Y.-W.; Wang, J.; Jiao, H. CO2 reforming of CH4 on Ni(111): a density functional theory calculation. The journal of physical chemistry. B 2006, 110, 9976-83.

(147) Abild-Pedersen, F.; Lytken, O.; Engbæk, J.; Nielsen, G.; Chorkendorff, I.; Nørskov, J. K. Methane activation on Ni(111): Effects of poisons and step defects. Surface Science 2005, 590, 127-137.

(148) Yang, H.; Whitten, J. L. Dissociative chemisorption of CH4 on Ni(111). The Journal of Chemical Physics 1992, 96, 5529.

(149) Kratzer, P.; Hammer, B.; Nørskov, J. K. A theoretical study of CH4 dissociation on pure and gold-alloyed Ni(111) surfaces. The Journal of Chemical Physics 1996, 105, 5595.

(150) Michaelides, A.; Hu, P. Methyl chemisorption on Ni (111) and C-H-M multicentre bonding: a density functional theory study. Surface Science 1999, 437, 362-376. 
(151) Dallenogare, D.; Degenstein, N.; Horn, R.; Canu, P.; Schmidt, L. Modeling spatially resolved profiles of methane partial oxidation on a $\mathrm{Rh}$ foam catalyst with detailed chemistry. Journal of Catalysis 2008, 258, 131-142.

(152) Hofstad, K. H.; Hoebink, J. H. B. J.; Holmen, A.; Marin, G. B. Partial oxidation of methane to synthesis gas over rhodium catalysts. Catalysis Today 1998, 40, 157-170.

(153) Bradford, M. C. J.; Vannice, M. A. CO 2 Reforming of CH 4 over Supported Ru Catalysts. 1999, 75, 69-75.

(154) Ciobica, I. M.; Frechard, F.; van Santen, R. A.; Kleyn, A. W.; Hafner, J. A DFT Study of Transition States for C-H Activation on the Ru (0001) Surface. Journal of Physical Chemistry B 2000, 104, 3364-3369.

(155) Ashcroft, A. T.; Cheetham, A. K.; Foord, J. S.; Green, M. L. H.; Grey, C. P.; Murrell, A. J.; Vernon, P. D. F. Selective oxidation of methane to synthesis gas using transition metal catalysts. Nature 1990, 344, 319-321.

(156) Lanza, R.; Canu, P.; Järås, S. G. Microemulsion-prepared ruthenium catalyst for syngas production via methane partial oxidation. Applied Catalysis A: General 2008, 337, 10-18.

(157) Erdohelyi, A.; Fodor, K.; Solymosi, F. Reaction of CH4 with $\mathrm{CO} 2$ and $\mathrm{H} 2 \mathrm{O}$ over supported Ir catalyst. In Studies in Surface Science and Catalysis; 1997; Vol. 107, p. 525.

(158) Wei, J.; Iglesia, E. Structural and mechanistic requirements for methane activation and chemical conversion on supported iridium clusters. Angewandte Chemie 2004, 43, 3685-8.

(159) Plaisance, C.; Neurock, M. Examining the Factors Controlling Transition Metal Surface Chemistry in terms of Local Bonding Interactions and Metal Bond Conjugation, 2012.

(160) Xu, B.; Haubrich, J.; Baker, T. A.; Kaxiras, E.; Friend, C. M. Theoretical Study of O-Assisted Selective Coupling of Methanol on Au (111). Journal of Physical Chemistry C 2011, 3703-3708.

(161) Zhou, C.-H. C.; Beltramini, J. N.; Fan, Y.-X.; Lu, G. Q. M. Chemoselective catalytic conversion of glycerol as a biorenewable source to valuable commodity chemicals. Chemical Society reviews 2008, 37, 527-49.

(162) Dasari, M. a.; Kiatsimkul, P.-P.; Sutterlin, W. R.; Suppes, G. J. Low-pressure hydrogenolysis of glycerol to propylene glycol. Applied Catalysis A: General 2005, 281, 225-231.

(163) Brandner, a.; Lehnert, K.; Bienholz, a.; Lucas, M.; Claus, P. Production of Biomass-Derived Chemicals and Energy: Chemocatalytic Conversions of Glycerol. Topics in Catalysis 2009, 52, 278-287.

(164) Maris, E.; Ketchie, W.; Murayama, M.; Davis, R. Glycerol hydrogenolysis on carbon-supported PtRu and AuRu bimetallic catalysts. Journal of Catalysis 2007, 251, 281-294.

(165) Ma, L.; He, D. Hydrogenolysis of Glycerol to Propanediols Over Highly Active Ru-Re Bimetallic Catalysts. Topics in Catalysis 2009, 52, 834-844. 
(166) Chaminand, J.; aurent Djakovitch, L.; Gallezot, P.; Marion, P.; Pinel, C.; Rosier, C. Glycerol hydrogenolysis on heterogeneous catalysts. Green Chem. 2004, 6, 359-361.

(167) Daniel, O. M.; DeLaRiva, A.; Kunkes, E. L.; Datye, A. K.; Dumesic, J. a.; Davis, R. J. X-ray Absorption Spectroscopy of Bimetallic Pt-Re Catalysts for Hydrogenolysis of Glycerol to Propanediols. ChemCatChem 2010, 2, 1107-1114.

(168) Shinmi, Y.; Koso, S.; Kubota, T.; Nakagawa, Y.; Tomishige, K. Modification of Rh/SiO2 catalyst for the hydrogenolysis of glycerol in water. Applied Catalysis B: Environmental 2010, 94, 318 326.

(169) Chia, M.; Pagán-Torres, Y. J.; Hibbitts, D.; Tan, Q.; Pham, H. N.; Datye, A. K.; Neurock, M.; Davis, R. J.; Dumesic, J. a Selective hydrogenolysis of polyols and cyclic ethers over bifunctional surface sites on rhodium-rhenium catalysts. Journal of the American Chemical Society 2011, $133,12675-89$.

(170) Lichtenthaler, F. W. No Title. Accounts of chemical research 2002, 35, 728.

(171) Koso, S.; Furikado, I.; Shimao, A.; Miyazawa, T.; Kunimori, K.; Tomishige, K. Chemoselective hydrogenolysis of tetrahydrofurfuryl alcohol to 1,5-pentanediol. Chemical Communications 2009, 2035-7.

(172) Koso, S.; Nakagawa, Y.; Tomishige, K. Mechanism of the hydrogenolysis of ethers over silicasupported rhodium catalyst modified with rhenium oxide. Journal of Catalysis 2011, 280, 221229.

(173) Gennari, U.; Kramer, R.; Gruber, H. L. No Title. Applied Catalysis 1984, 11, 341-351.

(174) Kreuzer, K.; Kramer, R. Support effects in the hydrogenolysis of tetrahydrofuran on platinum catalysts. Journal of Catalysis 1997, 167, 391-399.

(175) Miyazawa, T.; Kusunoki, Y.; Kunimori, K.; Tomishige, K. Glycerol conversion in the aqueous solution under hydrogen over $\mathrm{Ru} / \mathrm{C}+$ an ion-exchange resin and its reaction mechanism. Journal of Catalysis 2006, 240, 213-221.

(176) Kusunoki, Y.; Miyazawa, T.; Kunimori, K.; Tomishige, K. Highly active metal-acid bifunctional catalyst system for hydrogenolysis of glycerol under mild reaction conditions. Catalysis Communications 2005, 6, 645-649.

(177) Furikado, I.; Miyazawa, T.; Koso, S.; Shimao, A.; Kunimori, K.; Tomishige, K. Catalytic performance of $\mathrm{Rh} / \mathrm{SiO} 2$ in glycerol reaction under hydrogen. Green Chemistry 2007, 9, 582.

(178) Amada, Y.; Shinmi, Y.; Koso, S.; Kubota, T.; Nakagawa, Y.; Tomishige, K. Reaction mechanism of the glycerol hydrogenolysis to 1,3-propanediol over Ir-ReOx/SiO2 catalyst. Applied Catalysis B: Environmental 2011, 105, 117-127.

(179) Huang, L.; Zhu, Y.; Zheng, H.; Ding, G.; Li, Y. Direct Conversion of Glycerol into 1,3-Propanediol over Cu-H4SiW12040/SiO2 in Vapor Phase. Catalysis Letters 2009, 131, 312-320. 
(180) Koso, S.; Ueda, N.; Shinmi, Y.; Okumura, K.; Kizuka, T.; Tomishige, K. Promoting effect of Mo on the hydrogenolysis of tetrahydrofurfuryl alcohol to 1,5-pentanediol over Rh/SiO2. Journal of Catalysis 2009, 267, 89-92.

(181) Koso, S.; Watanabe, H.; Okumura, K.; Nakagawa, Y.; Tomishige, K. Comparative study of Rh$\mathrm{MoOx}$ and $\mathrm{Rh}-\mathrm{ReOx}$ supported on $\mathrm{SiO} 2$ for the hydrogenolysis of ethers and polyols. Applied Catalysis B: Environmental 2012, 111-112, 27-37.

(182) Shimao, A.; Koso, S.; Ueda, N.; Shinmi, Y.; Furikado, I.; Tomishige, K. Promoting Effect of Re Addition to Rh/SiO2 on Glycerol Hydrogenolysis. Chemistry Letters 2009, 38, 540-541.

(183) Nakagawa, Y.; Shinmi, Y.; Koso, S.; Tomishige, K. Direct hydrogenolysis of glycerol into 1,3propanediol over rhenium-modified iridium catalyst. Journal of Catalysis 2010, 272, 191-194.

(184) Koso, S.; Watanabe, H.; Okumura, K.; Nakagawa, Y.; Tomishige, K. Stable Low-Valence ReOx Cluster Attached on Rh Metal Particles Formed by Hydrogen Reduction and its Formation Mechanism. Journal of Physical Chemistry C 2012.

(185) Kunkes, E.; Simonetti, D.; Dumesic, J.; Pyrz, W.; Murillo, L.; Chen, J.; Buttrey, D. The role of rhenium in the conversion of glycerol to synthesis gas over carbon supported platinumrhenium catalysts. Journal of Catalysis 2008, 260, 164-177.

(186) Janik, M. J.; Macht, J.; Iglesia, E.; Neurock, M. Correlating Acid Properties and Catalytic Function: A First-Principles Analysis of Alcohol Dehydration Pathways on Polyoxometalates. Journal of Physical Chemistry C 2009, 113, 1872-1885.

(187) Kresse, G.; Furthmuller, J. No Title. Computational Materials Science 1996, 6, 15-50.

(188) Methfessel, M.; Paxton, A. High-precision sampling for Brillouin-zone integration in metals. Physical Review B 1989, 40, 3616-3621.

(189) Blochl, P. E.; Jepsen, O.; Andersen, O. K. No Title. Physical Review B 1994, 49, 16223-16233.

(190) Janik, M. J.; Davis, R. J.; Neurock, M. The relationship between adsorption and solid acidity of heteropolyacids. Catalysis today 2005, 105, 134-143. 